\title{
Architects of Buddhist Leisure
}
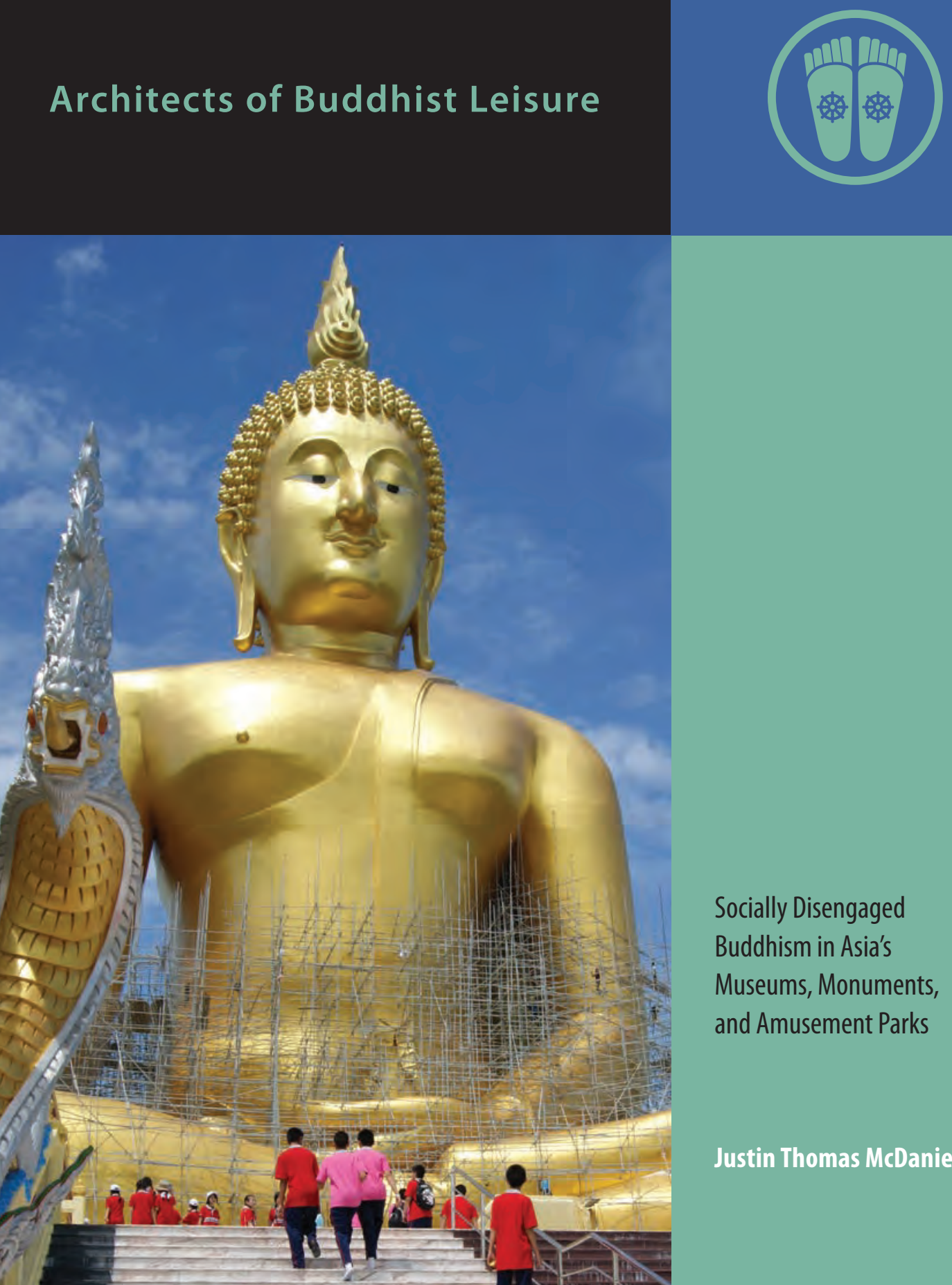

Socially Disengaged Buddhism in Asia's Museums, Monuments, and Amusement Parks

Justin Thomas McDaniel 


\section{Architects of Buddhist Leisure}


Contemporary Buddhism

MARK M. ROWE, SERIES EDITOR

Architects of Buddhist Leisure: Socially Disengaged Buddhism in Asia's Museums, Monuments, and Amusement Parks

Justin Thomas McDaniel 


\section{Architects of Buddhist Leisure}

Socially Disengaged Buddhism in Asia's Museums, Monuments, and Amusement Parks

Justin Thomas McDaniel 
(C) 2017 University of Hawai'i Press

All rights reserved

Printed in the United States of America

\section{Library of Congress Cataloging-in-Publication Data}

Names: McDaniel, Justin, author.

Title: Architects of Buddhist leisure : socially disengaged Buddhism in Asia's museums, monuments, and amusement parks / Justin Thomas McDaniel.

Other titles: Contemporary Buddhism.

Description: Honolulu : University of Hawai'i Press, [2017] | Series:

Contemporary Buddhism | Includes bibliographical references and index.

Identifiers: LCCN 2016034121 | ISBN 9780824865986 (hardcover ; alk. paper)

Subjects: LCSH: Architecture and recreation-Asia.| Buddhist architecture-

Asia. | Tange, Kenzo, 1913-2005. | Lek Wiriyaphan. | Fazhao, Shi.

Classification: LCC NA2543.R43 M39 2017 | DDC 725/.76095-dc23

LC record available at https://lccn.loc.gov/2016034121

University of Hawai' i Press books are printed on acid-free paper and meet the guidelines for permanence and durability of the Council on Library Resources.

III An electronic version of this book is freely available, thanks to the support of libraries working with Knowledge Unlatched. KU is a collaborative initiative designed to make high-quality books open access for the public good. The open-access ISBN for this book is 978-0-8248-7440-7. More information about the initiative and links to the open-access version can be found at www.knowledgeunlatched.org.

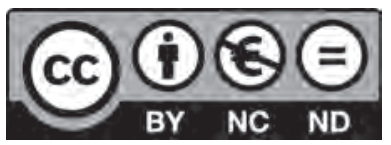

The open-access version of this book is licensed under Creative Commons Attribution-NonCommercial-NoDerivatives 4.0 International (CC BYNC-ND 4.0), which means that the work may be freely downloaded and shared for non-commercial purposes, provided credit is given to the author. Derivative works and commercial uses require permission from the publisher. For details, see https://creativecommons.org/licenses/by-nc-nd/4.0/.

Cover art: (front) Giant Seated Buddha at Wat Muang, Ang Thong, Thailand. 
For Christine, Henry, and J ane

Even in the time when as yet

I had no certain knowledge of her

She sprang from the nest, a young crow,

Whose first flight circled the forest.

I know now how then she showed me

Her mind, reaching out to the horizon,

She close above the tree tops.

I saw her eyes straining at the new distance

And as the woods fell from her flying

Likewise they fell from me as I followed ... .

From William Carlos Williams's The Wanderer (1914) 



\section{Contents}

ix Series Editor's Preface

xi Acknowledgments

1 INTRODUCTION

30 CHAPTER ONE

Monuments and Metabolism: Kenzo Tange and the Attempts to Bring New Architecture to Buddhism's Oldest Site

82 CHAPTER TWO

Ecumenical Parks and Cosmological Gardens: Braphai and Lek Wiriyaphan and Buddhist Spectacle Culture

131 CHAPTER THREE

Buddhist Museums and Curio Cabinets: Shi Fa Zhao and Ecumenism without an Agenda

162 CONCLUSIONS AND COMPARISONS

177 Notes

205 Bibliography

215 Index 



\section{Series Editor's Preface}

IT IS A DISTINCT PLeASURE to be able to introduce the first book in the new Contemporary Buddhism series from University of Hawai'i Press. Following in the groundbreaking steps of George Tanabe's Topics in Contemporary Buddhism, this series will continue to deliver the finest narratives and analyses of doctrine, institutions, personalities, ritual, gender, politics, economics, performance, and art in any cultural area of the Buddhist world today.

The study of contemporary Buddhism has emerged as a vital and distinct field in Buddhist studies. Primarily ethnographic and sociological to date, the field is now expanding to include insights from political, material, and leisure studies. J ustin McDaniel's pioneering exploration of Buddhist leisure activity at monuments, parks, and museums, which he evocatively calls "socially disengaged Buddhism," represents a significant step in opening up new understandings of how Buddhism is actually encountered in the worldrecreationally as much as ritually. This study is global and translocal in scope, yet intimate and personal in tone. In a fascinating shift from his earlier work on ritual, procedures, and pedagogy, McDaniel wants us to consider the "joys of Buddhists - the sensuous, entertaining, and beautiful aspects of Buddhist life" that can often be overlooked in attempts to get at "actual Buddhism." This affective and aesthetic turn toward what he calls the "total experience of contemporary Buddhism" delineates an exciting new strand of Buddhist studies, one that firmly embeds Buddhist leisure within the realm of Buddhist learning and thus continues the necessary work of breaking down arbitrary distinctions between the secular and the religious. 



\section{Acknowledgments}

MY DAUGHTER JANE IS USUALLY QUITE RESERVED, slow to warm up to new people. However, one day, at the Gilsangsa Monastery in Seoul, South Korea, she grabbed a young monk's arm and just started laughing. She was six years old, and she had come with me on a little research trip to a quiet residential neighborhood to see this monastery that had been home to one of modern Korea's most popular monks, Venerable Beopjeong Sunim (1932- 2010). I went to this temple not just because it was a renowned J ogye meditation center, but also because it was promoted by my friends in Seoul as a place for relaxation, good food, and a farmer's market. I thought my daughter would enjoy being out of the bustle of hypermodern high-rise Seoul for an afternoon.

Going to monasteries for leisure is not strange throughout the Buddhist world, as this book will show. However, Gilsangsa is relatively unusual because, according to the monastery's official history, up until 1997, it was a high-end brothel of sorts. The Seongbuk-dong neighborhood in which the monastery sits is quite wealthy, with a number of quiet and stately homes. In the center of this neighborhood was a restaurant and private men's club named Daewongak. It was owned by the daughter of a wealthy family, Young Han Kim (1916-1999), who had fallen on hard times. She became gisaeng (traditional female entertainer) to make ends meet and developed a following of wealthy businessmen and politicians. Near the end of her life, she decided to donate her home, restaurant, and entertainment center to Venerable Beopjeong (worth almost one hundred million US dollars), who had convinced her to focus on meditation instead of her somewhat questionable business. Today, visiting lay meditators, nuns, and monks mix here in a place that hosts charity events and children's games. There are even toys left in different places on the monastic grounds free for children to pick up and use. This new monastery has become so successful that they opened a branch in Paris. J ane and I had so much fun that we returned the next day with my friend Beopjin, a J ogye monk himself, and a specialist in early Buddhist texts, and brought along my son and wife. Jane, who loved being the tour guide, grabbed Venerable Beopjin's hand and led him around, laughing, dancing, and trying to pronounce 
Korean words. I had never seen her so gregarious and confident. Finally, a monastery that she felt was designed for someone just her size! I think this was the moment this book came together in my head. I had been traveling and visiting large Buddhist statues, amusement parks, monuments, and museums throughout Asia for a few years, but J ane's laughter in that monastery led me away from simply documenting the sociohistorical contexts and architectural design of these places and placed my focus squarely on leisure distraction and the casual affective encounters that these places foster.

While J ane was the spark for this book, she was only one of the many people who inspired and informed me along the way through e-mails, casual encounters, personal tours, and astute criticisms and questions. I received advice and inspiration in various countries from Chiaki Abe, Chris Baker, Pavin Chachavalpongpun, Kate Crosby, Charnvit Kasetsiri, Tatsuki Kataoka, Charles Keyes, J acques Leider, Tamara Loos, Mario Ivan Lopez, Sayuri Maeda, Nathan McGovern, Anake Nawigamune, Arnico Panday, Pasuk Phongpaichit, Prista Ratanapruk, Anil Sakya (Phra Sugandha), J effrey Samuels, Juliane Schober, Pram Sounsamut, Barend J an Terwiel, and the late Pattana Kitiarsa.

I received materials in the mail or answers to very difficult questions from Barbara and Leonard Andaya, Ian Baird, David Barnes, Benjamin Baumann, Julius Bautista, J ames Benn, Ted Bestor, Bodhi Bodhiprasiddhinand, William Bodiford, Venerable Boepjin, Bénédicte Brac de la Perrière, Beth Carter, Jack Meng-Tat Chia, Claudio Cicuzza, Shayne Clarke, Steven Collins, Cliff Cosgrove, Simon Creak, Erik Davis, Michael Feener, Louis Gabaude, David Geary, Volker Grabowsky, Gregory Green, Masami Harada, Nan Hebert, Julia Hintlian, James Hoesterey, Ee Tiang Hwee, Akiko Iijima, Irving Chan J ohnson, Susanne Kerekes, Ah-Young Kim, Sooja Kim, Orion Klautau, François Lagirarde, Amy Le, Kaviya Manavid, Jovan Maud, Lori Meeks, Miki Morita, Sally Ness, Oona Paredes, Aelita Parker, Deven Patel, Aaron Proffitt, Craig Reynolds, Gok Aik Sai, J effrey Samuels, Terenjit Sevea, Eviatar Shulman, Nicholas Sihlé, Jakkai Siributr, Pushkar Sohoni, David Spafford, Riri Tu Sri, Frederick Stange, Kanae Sunanda, Masami Tahara, Kazuhito Tanabe and his family, Anucha Thirakanont, Ruth Toulson, Ilya Vinitsky, Erick White, Thongchai Winichakul, Bella Wu, and Venerable Shi Fa Zhao. They all took time away from their own work to help me with specific problems with my research. Many guided me to particular sites, helped with translations, or just asked me the right questions at the right time. It is this type of collegial support that makes the field of Buddhist studies and my professional and personal life so rich.

My friendships with the Sister Alice, Prapod Assavavirulhakarn, the Biggs Family, Erik Braun, Anthea Butler, J osé Cabezón, Linda and Frank Chance, Suchitra Chongstitvatana, Paul Cobb, the Cortez Family, the Davis Family, the Dawursk Family, the Debrabander Family, Mir and Jamal 
Elias, Filemon Gemil, the Genuardi Family, Michael Keogh, the Leibman Family, Thongchai Likhitpornsawan, Angela Locatelli, Carla Locatelli, Ann Matter, James McHugh, the Miller Family, Greg Miller, Jin and Michael Montesano, Manjita and Projit Mukharji, the Palagi Family, the Powell Family, Annette Yoshiko Reed, Thomas Roach, Ruangsasitorn Sangwarosakul, Suwanna Satha-Anand, Arthid Sheravanichkul, the Shipper Family, the Simon Family, Mitesh Thakar, the Walton Family, the Weitzman Family, the Woodward Family, Matthew Wheeler, the late Avery deBoye Wright, and all of my friends from Samut Sakorn Burana in Mahachai, have sustained me through the process of research and writing. I often say the wrong thing, forget birthdays, talk too much, and don't listen well, but they keep humoring me and putting up with me. I can't imagine my life without them.

Rough drafts, chapters, and particularly troublesome sections were kindly read by Thomas Borchert, J ohn Holt, and Richard J affe. Their harsh criticisms and insightful comments greatly improved this book. They cannot be blamed for when I chose to take comfort in my own mistakes. Pattaratorn Chirapravati, Christoph Cueppers, Yoko Hayami, Masao Imamura, Yohei Shimizu, Hwang Soonil, Kazuko Tanabe, Woon Wee Teng, and Toshiya Unebe were particularly supportive at every stage of this process, reading closely, recommending sources, and identifying problems. It is especially encouraging when scholars of such experience and integrity take an active interest in your work. I owe them a great deal. Anne Blackburn, Anne Hansen, Peter Skilling, and Steven Collins have consistently been supportive and critical mentors. As always, Luang Pho Sombun is my preceptor and Donald Swearer is my achan.

I received generous research funding from Kyoto University, Nagoya University, Chulalongkorn University, Otani University, Ryukoku University, Dongguk University, the National University of Singapore, the Asian Civilizations Museum, the National Endowment of the Humanities, the Guggenheim Foundation, the Mellon Foundation, the Henry Luce Foundation, and the University of Pennsylvania. My colleagues at the University of Pennsylvania have made the publishing process go smoothly with their advice and friendship. I am so fortunate to teach alongside wonderful colleagues.

I value the comments of the external readers. The editorial group at University of Hawai'i Press, particularly Emma Ching, Stephanie Chun, Patricia Crosby, and Mark Rowe as well as Michael Bohrer-Clancy at Westchester Publishing Serivces, were supportive at every stage of the publishing process. Finally, it is the time spent with my complicated and wonderful family - the Fitzmaurices, Seips, Reddingtons, O’Dwyers, Coppingers, Brignolas, and Galvins - that gladly took me away from my work and gave me the renewed energy to write with fresh eyes. My brother Garvan, my sister-in-law Monica, and my in-laws Wendy and Thomas have been constant supports. My dear 
parents, Adelene and Thomas, gave me the best gift any parents could ever give a child - the gift of no expectations. They have expressed their warmth and love at every stage of my life and have never asked why I chose to engage in this very unexpected field of study. Jane challenges me intellectually and overwhelms me emotionally. My son Henry is more a phenomenon than a person. I am just continually stunned by his words, thoughts, and actions. His meals and music feed me. Christine and I have been together for a quarter century. She is my memory. She is my weather. I follow her like a sailor follows the stars. 


\section{Introduction}

FROM THE HEAD OF THE BODHISATTVA GUANYIN yOu can see the shore. The series of inlets and tiny islands along it was covered with trees and dotted with homes before the tsunami flattened many of them. Guanyin was fine though. She is quite tall and a good distance from the ocean. This statue, the sixth tallest in the world, stands awkwardly on the top of a small hill outside of Sendai, along the coast in the Tohoku region of northern J apan. There she stood for twenty years before the tsunami, and she will probably stand silently for many more as roads are repaired, shops reopened, and schools rebuilt. She might be the last of her kind though. She was constructed in the early 1990s, before J apan's debt soared, before the 1995 Kobe earthquake and the 2011 tsunami, before the disaster at Fukushima, and before the oftrepeated "crisis of confidence" among the consumers of Japan.

Guanyin is not alone though; she is one of many very big bodhisattva and buddha statues in Asia. Indeed, of the top thirty tallest statues in the world, twenty-six are either buddhas or bodhisattvas. Of the top ten, only one, the Statue of Peter the Great in Russia (no. 8) is not Asian and seven of the top ten are Buddhist. The Statue of Liberty is number 39 on the list. The Sendai Daikannon (The Great Guanyin/ Guanyin/Avalokiteśvara in Sendai, Japan) statue is 330 feet tall, more than twice the height of her sister in New York City. The Spring Temple Vairocana Buddha statue in Leshan, China, the tallest statue in the world, is 420 feet. From the small window in Guanyin's head, I could easily see the shore and far beyond into the great expanse of a violent sea, but I spent most of my time looking down.

I arrived in Sendai about two months after the tsunami had caused massive destruction and loss of life in J apan. Although it was irrational, moving at 130 miles an hour, I remember considering holding my breath as the train raced past the Dainichi Nuclear Power Plant at Fukushima on the way north, and past the third-tallest statue in the world, the Ushiku Daibutsu (Big 
Buddha of Ushiku). Like most people in the world, I was at a loss what to do or say about the disaster. With my less than two years of J apanese-language study at that point, even if I'd known what to say, it would have come out awkwardly and probably grammatically incorrect. It felt strange conducting research on new Buddhist museums, parks, and monuments, especially at that time and place. I thought I should have been more experienced emotionally, since I'd been on a research trip in Thailand soon after the 2004 tsunami there. However, back then I was safely ensconced in a manuscript archive with familiar colleagues speaking a familiar language, not traveling in an unfamiliar region in a barely familiar country to a very large statue surrounded by a public park, wedding center, and golf course.

Inside the huge statue, at a loss for words, trying to rationalize my way through impossible situations and improbable places, I looked down away from the shore and through the hollow central core of the statue. The nine suspended floors were connected by small bridges and stairways. Each floor held shrines to twelve smaller statues, most of them other buddhas and bodhisattvas, including thirty-three smaller statues of Guanyin/Kannon, all in

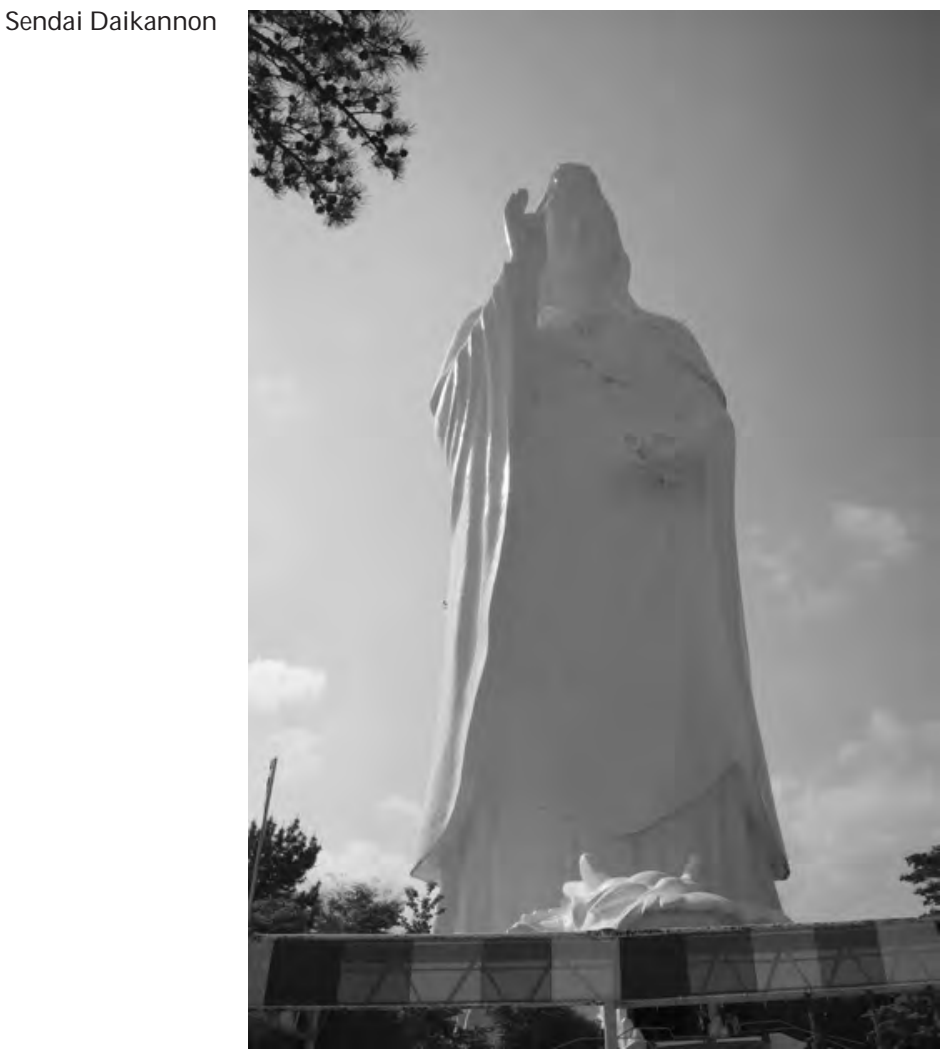


different poses. As I walked down the steps I was able to circumambulate these 108 statues all the way to the ground floor, which houses a museum of lifesize statues of bodhisattvas and protector deities representing the twelve signs of the Chinese zodiac, the Buddhas of the Pure Lands, and more statues of Guanyin, among many others. That day, I, along with three Japanese history experts (Satoshi Sonehara, Orion Klautau, and William Bodiford), were the only visitors to this giant statue besides an amorous young couple who looked as if they were trying to find a quiet place to be alone. ${ }^{1}$ The entire museum, including three gift shops, a ticket counter, a wedding center, a pet cemetery, and a park, was being run by a single staff person. At first I thought it was the aftermath of the tsunami that was keeping the crowds away from this massive site. However, I soon realized that the weeds growing in the cracks, the abandoned golf course, the gated-up parkinglot, the shuttered entertainment center, the broken lights and the empty fountain, and the frayed flags were the result of long-term neglect. The entrance sign had fallen down. If the waves of the tsunami had actually reached the statue, there wouldn't have been much on the ground to wash away.

A small, three-room temple stood behind the statue. Inside, a staff person and two monks seemed surprised to see us. They had little to do with the statue and did not even have literature or brochures about its history. They reluctantly answered my questions, saying that the statue does get a good crowd of visitors once a month when there is a flea market on its grounds and the occasional school group arrives, but they did not seem to pay attention much to its operation. They had not conducted any special chanting session or memorial service for the tsunami and often did not have an audience for their regular morning chanting. I was surprised that Orion Klautau, who had lived in J apan for many years, most of them in Sendai, had never been to the statue. Professor Sonehara had been to the statue only once before, and he had lived in Sendai for thirty years. He said it certainly was big and could be seen from almost every place in the city, but for him, it just interrupted the views of the mountains, and frankly, I think he thought it was strange I wanted to visit it. He had a much more enjoyable time taking me to Matsushima to see the Zuiganji monastery and the regional history museum nearby. For him, as it seemed for most people in Sendai, the Daikannon was like an old console television in the living room, certainly big and once beautiful, that you now wish someone would just take away.

The Sendai Daikannon was the brainchild of Yorozu Sugawara, who, until his passing, was the CEO of the Futaba Sōgō Development Company in the Daikanmitsuji Precinct of Sendai. He had amassed a fortune in nonresidential buildings for lease and many other ventures. However, after the decline of the Japanese economy in the late 1990s, the company is now no longer viable, and without Sugawara's vision and his company's funds, there 
is not enough support to properly maintain the statue or museum. While the Daikannon of Sendai might be declining into insignificance because of particular local economic reasons, it is not an isolated case. Many large Buddhist public museums, parks, and monuments, such as the Laykyun Setkyar Buddha (Monywa, Burma), the Awaji Kannon in Southern J apan, or the Sanctuary of Truth near Pattaya, Thailand, could be considered-in terms of the numbers of visitors, general upkeep and staff support, and amount of scholarly and artistic interest-failures. The Awaji Kannon, for example, is the twelfth-tallest statue in the world. Despite the expense of building a museum inside a statue this large, the museum is now abandoned. When I visited the site in February 2013, on a breezy winter day, it stood locked up. Several of the windows of the museum at its base were broken, the gate stood in disrepair with weeds growing around its base. The park around it and the "America" restaurant next door were also in disrepair. Behind the 295 foot tall statue stood an approximately twenty-foot replica of the Statue of Liberty, which was also closed to the public. $^{2}$ The town of Awaji, replete with seaside shops, a replica of the London Bridge, and a children's park, had seen better days. Not even Guanyin could save this town, it seems, from declining domestic tourism.

Not all giant buddha images are dying. Some, like the Buddhist enlightenment park in Bodh Gaya (North India), the Kamakura Daibutsu (near Yokohama, Japan), the Fairy Stream Amusement Park and Buddhist Temple (Ho Chi Minh City, Vietnam), and the Phra Putthamingmongkol Akenakkiri (Phuket, Thailand), receive tens of thousands of visitors every year. The Tian Tan Buddha (Lantau Island, Hong Kong) has a fun cable car that takes thousands of visitors every month to its base. The cable car station is home to a large shopping mall, and advertisements for the Tian Tan Buddha are often coupled with advertisements for Hong Kong Disneyland amusement park nearby. ${ }^{3}$

The success or failure of different Buddhist leisure and tourist sites (and I am defining success and failure simply in a site's ability to consistently attract visitors, fees, and donations, and be kept up and open on a regular basis) is difficult to generalize and depends largely on a combination of many economic, political, and labor/managerial factors, as well as specific local issues. However, that being said, as we will see in this book, the sites that are thriving usually offer not only delight and spectacle that attracts visitors, Buddhist and non-Buddhist, local and foreign, but also opportunities to listen to sermons and perform basic rituals. They also are usually in areas that offer other shopping, dining, and entertainment options for local and international tourists so that they can attract people looking for a variety of activities for families (especially those with young children). The more geographically isolated places often must have bigger spectacle displays to attract people from greater distances. These largely non-monastic spaces need to offer some type 
of ritual opportunity because this attracts local visitors to come to the site repeatedly after the effect of the spectacle has worn off. A person performing a ritual will come to a site again and again, whereas a person seeking only to witness the spectacle, and perhaps shop, will come only once or twice. However, some sites that offer both entertainment and ritual fail despite the efforts of architects to make their sites ecumenical, international, and accessible. Macro- and microeconomic conditions and political strife that can affect a site are often out of the designer's and owner's control. Moreover, a site's location (which includes the availability of affordable transportation and minimal national visa/immigration restrictions) and affordability are what actually determine how many people can visit and will want to come back. ${ }^{4}$ In other words, if you build it, they will come (that is, if the train station is nearby, the entrance fee is cheap, and the food is good).

That being said, I am less concerned with the "success" or "failure" of these sites. I am concerned with what these sites tell us about the study of religion. Despite the factors of location and affordability, there are three major arguments about these Buddhist leisure sites that I assert are important for the study of contemporary religion more broadly: First, the sites described in this book all show the importance of public religious culture and, more specifically, they demonstrate religious leisure from a Buddhist cultural perspective. The secular versus the religious, which is in many ways a false binary, are categories broken down at these sites. The sites are open to all people, regardless of their religious faith, practice, or lack thereof. One does not need any deep knowledge of Buddhist texts, chants, history, and no test of faith is required. People can often participate in activities that may be called explicitly religious such as chanting, prostrating, offering gifts, or meditating, or they can relax, chat leisurely, laugh, or gawk in amazement. As at secular parks, monuments, and amusement sites, visitors can have lunch, buy gifts, talk on their cell phones, or flirt. Visitors can learn something about Buddhist teachings or history, but this is not required. There is no particular way of performing or participating in Buddhist leisure. Certainly, specific cultural preferences in cuisine, jokes, dress, design, and color schemes do exist, but these do not have much connection to particular Buddhist teachings. There isn't really a particular Buddhist way to play, laugh, or nap, of course. In later chapters I also mention, in passing, for example, concomitant sponsored leisure sites with Catholic or Hindu themes, which operate in largely the same way and encourage similar leisure pursuits.

That being said, there are particular characteristics that define Buddhist public and leisure sites, and those lead us to the second argument: these sites reflect a growing Buddhist ecumenism that is partially the result of global communication and construction technologies, and partially of the Buddhist value of learning through affective encounters without an agenda. 
Many of these sites, success or failure aside, were designed by (primarily) men who have had global visions and aspirations. What makes this global Buddhism peculiar in comparison with many other global religious movements is that it does not actively seek converts, allegiance, or centralized power. There is no effort to "save" people or consciously prepare for an apocalypse or a day of judgment. Despite the growing Buddhist ecumenism throughout Asia, there have been no efforts to create a Vatican-like Buddhist capital, Buddhist homeland or caliphate, or global sect or institution, and no concerted efforts to influence global politics or economics. These sites are often individually ecumenical in purpose, but they execute this vision largely independently from each other. There is not a global Buddhist network of Buddhist ecumenical sites or a small cadre of men focused on creating a Buddhist empire. Metaphorically, these sites can be likened to a train network without a central hub or terminal stations - all are welcome, all mix without end. In Buddhist metaphorical terms they are similar to Indra's net, not a mandala. I later look closely at what it means to promote ecumenism without a specific telos in mind, on the one hand, or a coordinated effort among men with money on the other.

This leads to the third and final argument: the best laid plans often fail. Despite the vision of people like Kenzo Tange, Lek Wiriyaphan, Shi Fa Zhao, and others discussed below, building spectacular ecumenical leisure sites often runs into problems along the way. Methodologically, I approach the study of religion through the lens of material culture in the lineage of Alfred Gell, Cynthia Bogel, Eugene Wang, and David Morgan. Therefore, I take the materiality and the agency of material seriously. Parks, monuments, and museums, like temples, are complex adaptive systems changed and influenced by visitors, budgets, materials, and local and global economic conditions. They often respond to the cacophony of opinions on Internet travel sites, blogs, and local and newspaper reviews. No matter what the architect intends, buildings develop lives of their own. Therefore, although I look closely at three architects in this book (and many other comparative examples), I do not believe that they are lone visionaries who can simply execute their art in a vacuum. They have to adapt, often without admitting the compromise to themselves, to local conditions and the agency of particular materials. Their ecumenical dreams are interrupted by local and very specific realities. They compromise along the way and settle at local optima. Let me explain these arguments one by one.

\section{Buddhist Public Leisure Culture and the Importance of Spectacle}

Over the last two hundred years, the great rise in Buddhist public culture has in many ways mirrored the rise in public culture throughout the world. Pub- 
lic sites discussed in this book break down the often false binary between the secular and the religious. Secular architects have been called on by Buddhist monks, nuns, and lay devotees to design new types of Buddhist spaces outside traditional monastic ritual and educational complexes in places like Sendai and Saigon; there has been a growth in Buddhist museums, parks, memorials, and shops selling Buddhist products; and, of course, most recently there has been a rise in publicly accessible websites built by Buddhist organizations of various types. ${ }^{5}$ Regardless of religious, ethnic, or sectarian identity, people can visit these places physically or virtually, are not required to make statements of allegiance or faith, and generally are not required to contribute money (besides the occasional small entrance fee in some cases) or give gifts in exchange for their visit. Buddhist public culture has become part of public culture more broadly in Asia. This public (or open-to-the-public) leisure culture is often centered around the spectacle, as we will see.

In the recent history of Buddhism, public Buddhist sites flourished in Japan more than in any other place. Of course the giant buddha images (daibutsu) such as the ones in the Todaiji in Nara or the thirteenth-century Kamakura Daibutsu have long been iconic sites in J apan, like the giant Buddhas of Bamiyan or the walking Buddha of Sukhothai were and are to Afghanistan and Thailand, respectively. ${ }^{6}$ However, the late nineteenth and twentieth centuries in Japan saw a flurry of building daibutsu not seen before, thanks to new concrete building techniques and the rise of a new wealthy laity not formally connected to particular monasteries or noble bloodlines. ${ }^{7}$ For example, in 1922 a twenty-foot-tall statue of Amida Buddha, called the Yobiko Daibutsu, was erected in Saga Prefecture. The taller Ōfuna Kannon was built in 1960 to the south of Tokyo. Its designer, Kōun Takamura, built it originally as a temporary structure for an amusement park. It was based on the earlier Ueno Daibutsu in Tokyo. In 1928, the Beppu Daibutsu, which no longer survives, was built near the city of Usuki by a wealthy businessman, who later became a Jōdo priest, named Eizaburō Okamoto. A tourist resort was built around the statue. One large temporary daibutsu was even built in San Francisco in 1915 by a Japanese group at the Panama-Pacific International Exposition. It was modeled on the earlier Nōfuku Daibutsu in Kobe and "functioned as a showplace for J apanese products displayed at the fair." ${ }^{8}$

These statues were part of a class of sites called misemono or "spectacle attractions" that attract people to festivals. ${ }^{9}$ Although these misemono sites often include giant buddha images, recently a giant "Tetsujin 28-go" robot was built in Kobe and a giant mechanical robot called Gundam built in front of Diver City Plaza shopping complex and amusement park in Tokyo. Both are over fifty feet tall and based on the popular mecha (or meka, short for mechanical) genre of anime/ manga characters popular with children and adults in Japan. ${ }^{10}$ They were built as temporary installments to promote the 
commercial and entertainment complexes. Daibutsu have served similar purposes. While Takamura's was one of the first postwar examples, there have been many since, including the Sendai and Awaji images. ${ }^{11}$

I am not necessarily suggesting a direct relationship, but the early twentieth century also saw the rise of public parks, amusement parks, and government promotion of health, exercise, leisure, sports, and family time in J apan. The first amusement park was built in Osaka in 1912 (directly inspired by Coney Island in New York). A government report emphasized the importance of public parks in 1907, and government study in 1923 drew connections between leisure time and health and even proposed reducing workers' hours. Tourist hotels also started to open in great numbers, new tourist magazines were launched between 1890 and 1930, and the J apanese Tourist Board (Nihon Kōtsū Kōsha) opened in 1912. The Japanese government went on, in the postwar period, to help fund leisure spaces in Indonesia and Thailand, among other places. Related to this, government restrictions on Buddhist temples' income and the reduction of their landholdings in the Meiji period led many abbots to start carnivals and annual family fun days at temples in order to increase temple funds. These carnivals were connected to kaichō (the opening of temple sanctuaries and the exposure of certain precious statues and relics), which attracted crowds.

While these large public J apanese Buddhist sites might have been the most prevalent in the contemporary era, below we will see that Buddhists in other regions have also, because of rising economic resources and the involvement of a wider swath of lay supporters and visionaries, invested in creating a Buddhist built environment outside traditional monastic compounds. They've stretched the idea of what a monastery can be and shown how little actual ordained nuns and monks are involved in the building of these nonmonastic Buddhist leisure sites.

Too much distinction can be made between Buddhist monastic and non-monastic sites, though. These leisure sites offer a space in between the secular and the religious. In most of mainland Southeast Asia, many, if not most, men and some women take part in temporary ordination and feel comfortable in both lay and monastic settings. They may spend only a short time in the monastery and return to lay life. Most monasteries in the region have active lay councils that help support the monastery administratively and financially. Most of the men, and some of the women, on these councils were ordained in the past or plan to be ordained in the future. In Sri Lanka, monasteries are often run by a mixture of ordained and lay people from the same extended family. Japan over the past 150 years has seen the rise of married Buddhist priests and a blurring of lines between monkhood, priesthood, and lay in Buddhist life. Numerous priests in J apan now run liturgical services and funerary rites at monasteries on weekends, but dress in lay clothes and 
have nonreligious jobs during the week. In Singapore and Hong Kong, the daily running of many monasteries and shrines is undertaken by dedicated lay people. Furthermore, for many monks and nuns, daily activity might not be centered on keeping their monastic rules, conducting rituals, or providing pedagogical and liturgical services, but on managing monastic finances, repairing plumbing or electrical appliances, or creating Buddhist websites. Although some daibutsu and other large public Buddhist misemono were built at monasteries under the supervision of Buddhist priests like Wajo Kōsō of the Kōsanji monastery outside Hiroshima, many were built without any defined connection to a monastery or priest. For example, some misemono, such as the Naritasan Shinjōji Peace Pagoda (tahōtō), built in 1984, were sponsored and designed by lay committees but are built on monastery property. Some priests, like Kōsō, are also public figures. He was a JōdoShinshū priest, but also a successful steel manufacturer, art collector, and world traveler. ${ }^{12}$

In many places in Asia, the distinction between religious sites, royal sites, and "beautiful" sites is blurry. For example, similar to misemono, meisho in J apan are "famous places" and are often connected to sites mentioned in classical J apanese poetry and drama. Meisho include places like Mount Fuji, but also Buddhist monastic buildings like the Golden Pavilion in Kyoto, Shinto (jinja) shrines like the Kasuga Shrine in Nara, picturesque lakes and waterfalls like Takachiho in Miyazaki, important government or imperial places, and so on. Religious and nonreligious sites are similar. They are famous for their beauty, historical or literary significance, or Buddhist, Shinto, or Imperial sacredness, or, most often, a combination of all these things. In Thailand, I have been on weekend trips with many of my Thai coworkers and colleagues, piling into large tour buses replete with karaoke machines, DVD/ VCD players, and even disco balls. On these trips, we visit a combination of monasteries, waterfalls, historic sites, shopping malls, new museums, and ancient palaces. Buddhist monasteries are as much tourist sites to Thai Buddhists as they are to foreign non-Buddhists; while Thai Buddhists will participate in some ritual activity at these monasteries on their tours, they will be tourists as well. They will enjoy big group meals, listen to music, joke around, and post photographs on Facebook. Local people visit these sites, like foreign tourists do, not just for religious or ritual reasons, but also for leisure activities and family vacations.

Religious and nonreligious spaces are not often separated into special categories in tourist books throughout the world. However, in theacademic discipline of religious studies, religious and nonreligious "beautiful places" like the National Cathedral and the Lincoln Memorial in Washington, DC, or Saint Basil's and the Bolshoi in Moscow are not often subjects of comparison, even though an average tourist might visit both in the same day. They end up 
sharing space in the same photo album of a tourist, but not in the pages of a scholarly study. In religious studies, we often compare a religious site to another religious site and consider "religion" as the natural category they both share. However, if we compare beautiful site to beautiful site or misemono to misemono or meisho to meisho, what new possibilities can emerge? ${ }^{13}$ Leisure is not antithetical to the study of religion. In fact, focusing on leisure shows the flaws in attempting to excise the religious from the secular and vice versa.

This is not a new phenomenon; festival, beauty, and leisure have been part of Buddhist life in and around monasteries, as it was around Catholic churches in Europe or Hindu temples in India for centuries. Famous studies by Victor Turner and Michele Salzman have shown how festival and leisure activities often sprang up along pilgrimage routes and near temple and church enclosures. ${ }^{14}$ What has changed is that contemporary architects are being commissioned to design particular places specifically for Buddhist leisure activity and that this aspect of Buddhist public culture is being explicitly promoted, even by monks.

What do I mean by public? Work coming out of postmodern literary studies, sociology, subaltern studies, political science, and economics is so vast, it is difficult to summarize. Much of the recent work on public culture and "counterpublics" has been a response to Jürgen Habermas's seminal work, The Structural Transformation of the Public Sphere. ${ }^{15}$ His work, and much of the critical response to it, focused on the role of the citizen, self-cultivation, mass media, democratic debate, the rise of the middle class, and state efforts to undermine the efforts of private individuals to have public voices in western Europe in the eighteenth and nineteenth centuries. These studies are characterized by a study of political and social conflict. Although Habermas tended to idealize the rational and participatory communication that transcends class and economic conflict in public places, the problem for many critics is that there is no ideal nonpolitical space and no genuinely impersonal and apolitical dialog. People, in a sense, do not act passively and apolitically naturally, but have been conditioned to do so by long-term coercion and the internalization of power acting on them. Moreover, critics in the lineage of Bakhtin argue, in my opinion quite correctly, that it is difficult to trace patterned and rational discourse in public space and that "the sort of dialogue that is really meaningful to 'ordinary' people in their daily lives-is in fact fluid, permeable and always contested. Thus, far from speaking about abstract formal unities or abstract and formal rules of argumentation, people implicitly think and talk about the complexities and multiplicities that they face in real living social contexts."16 In other words, in no particular order they talk about how their children are doing in school, what they plan to eat for lunch, their cell phone bills, what temples they have visited in the past, soccer, and where they got those shoes. These important topics are occasionally inter- 
woven with arguments and reflections of the major political, ethical, and social questions of the day.

These responses to Habermas's work would be a welcome addition to the study of Buddhist public culture, especially in the context of the growing literature on Buddhism and the state. ${ }^{17}$ However, here I want to concentrate not on the political activity, class delineations, and surveillance and oppression that can occur within public places in Buddhist Asia, but on individuals' efforts to design new public places and the way they teach Buddhist history, ethics, and rituals. I focus more on individual architects' efforts to create these places and on how Buddhism is presented as a subject rather than provide ethnographies of what happens after they are created. I have visited every site discussed in these pages, some of them multiple times, and observed much and interviewed dozens of people, both formally and informally. However, here I stick to the architects and designers themselves. Based on my readings, interviews, and observations, although these sites have the potential to be places of public political activity and state surveillance, so far they generally have not. Instead they are places of leisure, relatively passive observance, tourism, low-level commerce, and casual repose. As will be seen, particularly in my discussion of hell parks and sculpture gardens, many Buddhist leisure places thrive on the aesthetics of spectacle, the grotesque, the comic, and the absurd. While small groups of visitors will inevitably discuss politics among themselves, there have been for the most part no significant instances of public debate, rebellion, or oppression at the places I will discuss. Certainly a huge abandoned buddha falling apart or even an amusement park mixing Buddhist values of humility and nonattachment with conspicuous consumption in Vietnam, Thailand, or J apan would bea poignant backdrop for a protest on the very value of religion in contemporary society, but so far local politics has largely left these Buddhist public sites alone. This could change anytime of course.

I am less concerned with these theoretical debates on the idea of public culture and the politics of public places. Most studies of public culture have, for good reason, excluded the study of religious public places; most have been of public parks, train stations, waterfronts, hotel lobbies, movie theatres, city squares, stadiums, and even parking lots. ${ }^{18}$ This might be because these are largely Western studies, and religious spaces in the J ewish and Christian West are largely private or semiprivate spaces with official member or parishioner lists, formal social activities and rituals, clearly designated ecclesia, and the like. Some synagogues and churches have strict gender restrictions and even entrance fees that can be paid only by formally approved members. On occasion, even weekly, churches and synagogues can host sports tournaments, raffles, pancake breakfasts, fish fries, academic competitions, dances, language classes, and reading and study clubs. However, that is usually not their designated primary mission. 
In most contemporary Buddhist cultures, most religious places are semiprivate as well, but often do not require active participation, official membership, or regular dues or donations. By "semiprivate" I mean that they are open to the Buddhist and non-Buddhist public (i.e., most monasteries do not have restrictions on who can visit), but there are standards of dress and decorum; a clearly defined ecclesia of nuns, novices, and monks; a designated ritual and educational space; and formal and semiformal ritual and liturgical activities.

People know when they are in a monastic space, and physical deportment changes for most visitors. For example, many years ago I was in a large monastery in Chiang Mai (Northern Thailand) waiting to meet with the abbot in order to gain permission to read manuscripts in their library. As I waited, a group of tourists entered the monastery's main sermon hall (wihan) where I was sitting and waiting. In the main hall, about fifty novice monks were kneeling on the floor listening to the abbot. Most of the tourists respectfully bowed their heads, folded their hands across their bodies, removed their hats and shoes, and looked nervous. Meanwhile Thai staff and visitors chatted openly, took photographs, joked around a bit, and generally paid no attention to the abbot at the front of the room or to the novices. I overheard one tourist whisper to the person next to them, "How can they be so rude while the abbot gives a sermon? Don't they respect his teachings?" What the tourist did not realize was that the abbot was not giving a sermon, he was telling the novices to be on time the next day for their class photograph. They were being told to fold their robes properly, be on time, and not fool around. Every year the monastic school had a photograph taken and they needed to make it look nice. He was simply conducting one of the many duties of a busy abbot. However, since he was not speaking in a language understandable to the tourists, they assumed that conduct in a "sacred" place or "house of worship" should be of a certain type (reserved, reverent, and respectful). Their bodies went automatically into the default mode of their own religious upbringing. The architecture of the room, combined with their expectations, worked on their bodies in clearly observable ways. I am sure I have acted in similarly uninformed ways when visiting orthodox churches in Russia or mosques in Turkey with my family as a tourist: hat off, hands folded, voice hushed, head down.

Visitors to monasteries across Asia are often surprised by the lack of decorum in many places and the amount of social and familial activity. Of course, many monasteries in Asia often find themselves used as public spaces where children play and run around, groups play cards and board games, people gossip and drink tea, and the like. Many host annual festivals, temporary amusement games, flea markets, and even beauty and singing contests. These activities are often not the main objective of the monastery, 
and social activities are often on clearly defined days of the year or in the midafternoon. Midafternoon is the time when many monks have done their morning duties and the grounds of the monastery are empty because monks are at other monasteries conducting funerals or other rituals, meditating or studying in their rooms, or occasionally napping. Most people who visit the monastery in the early morning, evening, or on weekends see the monastery as a place for ritual, liturgy, meditation, study, the production of religious material, and the ordination and training of monastics or professional religieux. But other times, people can also go to a monastery, and often do, to relax and chat with friends.

Most studies of Buddhist culture and history are rooted in the institution of the monastery. This is logical. Most Buddhist teachings, art, music, and architecture emerge from monastic life. In this study, I am considering Buddhist "public" spaces as largely synonymous with non-monastic and nonsectarian spaces. "Public" should not be considered synonymous with large, accessible, or famous. For example, Wat Dhammakaya in Thailand and Dharma Drum Mountain in Taiwan are two of the best-known and largest monasteries in the world. ${ }^{19}$ They have an impressive presence on the World Wide Web in multiple languages and have satellite centers in a variety of countries. The same can be said of Hsi Lai Temple on Hacienda Heights in Southern California, Fo Guang Shan French Center in the suburbs of Paris, or the Chi Lin Nunnery Kowloon (Hong Kong), which variously run vegetarian restaurants, book stores, and museums. ${ }^{20}$ However, these are all specific sectarian monasteries with nuns and monks in residence. They are open to lay visitors of all religions and classes, but actively promote their own sectarian rituals and approaches, and were begun and still remain as monasteries that specifically train monastics. Increasingly these monasteries are playing a larger and larger role in the public sphere, especially through mass meditation sessions involving thousands of people on certain weekends, which are broadcast on the web or through their own television stations. They also hold large ceremonies chanting for the protection of their respective nations or promoting certain social and political issues such as nuclear antiproliferation, the sexual morality of teenagers, nonviolence, or vegetarianism. Many of their monks and nuns have Facebook pages or personal websites to promote their monastery's agendas. I will not be exploring this type of Buddhist activity in this study, but it certainly is an important part of public culture.

The spaces I focus on below are run largely by the laity, with no connection to a single monastery, or are connected only loosely to the formal space and activity of a monastery and its concomitant ordained hierarchy. They do not ordain or train monks or nuns. These are places that are used not merely on occasion for non-monastic, non-ritual, non-liturgical, and noneducational activity, but are designated as such. In most cases they are privately owned, 
but open to visitors from all walks of life. Oftentimes one finds very few monks or nuns in these spaces, and those that are there are not in roles of teachers or administrators and do not offer formal sermons, accept formal gifts, or conduct specific rituals. These places in general are not affiliated with a specific lineage, sect, or school of Buddhism (although most visitors might come from a certain sect) and the designers and directors of these places do not overtly promote a particular approach to Buddhist learning and practice. In one example, though, I look closely at one location in Singapore that can be seen as having both a ritual (although not monastic) and public role. I will also briefly mention avant-garde Buddhist monastic architecture in Ehime and on Awaji Shima (Japan), and in Ang Thong and Chiang Rai (Thailand), which represent both public and monastic places. These examples, I hope, demonstrate the complexity and religious-secular ambiguity of these places in contemporary Buddhist Asia.

Therefore, I do not aim to study the public culture of contemporary Buddhism in general terms, but look at specific places and specific architects that, using Michael Warner's expression, "create a public." ${ }^{21} \mathrm{He}$ sees a public, like a public for a novel or a film, as categorized by choice-“a public organizes itself independently of state institutions, laws, formal frameworks of citizenship, or preexisting institutions such as the church."22 A public is self-organized and self-creating and often ephemeral and discontinuous. ${ }^{23}$ While this may be an idealized way of understanding a public and may not work as well for actual physically (albeit loosely) bounded places like parks, monuments, shops, and museums such as those I am researching, Warner poses a good question for those interested in religious studies to think about: "Imagine how powerless people would feel if their commonality and participation were simply defined by pre-given frameworks, by institutions and laws, as in other social contexts through kinship. What would the world look like if all ways of being public were more like applying for a driver's license or subscribing to a professional group-if, that is, formally organized mediations replaced the self-organized public as the image of belonging and common activity?"24

To better refine what counts as "public," and in an effort to look at the ways that places can create publics in contemporary Buddhist culture, I focus on leisure - what I like to call socially disengaged Buddhism. Scholars of Buddhist studies have always been very good at presenting research on obligation-paths (Pali: magga), sects (nikāya), ways (yāna), precepts and ascetic rules (i.e., things that fall under the categories of vinaya), morals, and the like. The role of the laity, especially studies of what lay families do in or outside their homes at their leisure, and writings or art of lay Buddhist artists and scholars have been much less important to scholars, including myself. ${ }^{25}$ Our primary subject-monasteries and monks and the art they create 
and books they write - are places defined by discipline and obligation. We have not been so good at studying leisure, the non-teleological and nonformal. In Western films, books, and art depicting and describing Buddhists, practitioners have been long associated with sobriety, discipline, shaven heads, and neatly folded robes. It is almost as if 1960s hippie self-importance and general humorlessness was projected on to monks and nuns. The picture of Buddhists I was given and reimagined growing up in the 1970s and 1980s was an impossible mixture of superhuman mental warriors and childlike innocents meditating in a distant forest. They were what I wanted them to be and what I wanted to be when I was a teenager-serious, supercool, and dressed in Zen jet-black.

Now in my early forties, I suppose I appreciate the less serious side of Buddhist life, and so have turned to the study of leisure. My back hurts, my feet are sore. When speaking of leisure, I am not referring to very active debates in sociology and economics on the activities of the so-called leisure class or the vast literature on games and contests. ${ }^{26}$ Instead I simply am referring to the non-obligated parts of life in J ohan Huizinga's sense of the term. Huizinga was concerned with, among other things, leisure as licere, or that which is permitted or unbound. ${ }^{27}$ Although the field of religious studies has not concerned itself much with leisure, when it has, it has usually been with leisure as otium (retreat, meditation, spiritual exercises, contemplation, even monastic labora, like gardening and manuscript copying), as Petrarch did in his famous On Religious Leisure (De otio religioso) - not idleness (Latin: accidia), but an active reflection on theological conundrums and ultimate truths. ${ }^{28}$ Some religious studies scholars have profitably learned from the approaches of Bakhtin or Turner and have seen religious festivals, plays, or pilgrimages as alternative or liminal places for testing and then reaffirming the value and power of moral rules and social norms. ${ }^{29}$ Leisure as otium is functionalist and goal oriented. However, in these new Buddhist places, activity is not necessarily directed or designed to be overtly purposive. Now, one could say that anyone who visits a Buddhist museum, monument, or park is purposefully "making-merit" or has an ulterior motive based on a vague sense of spiritual advancement. The same people might also want to impress members of their social circle with their wholesome activity or financial ability to travel and take time off from work. Others want to collect amulets, try new food, or take photographs. Perhaps there is no such thing as purposeless or non-teleological action. I certainly grant that true freedom and choice might be illusions. Every choice we make is somewhat controlled by our socioeconomic context and cultural and genetic background, and influenced constantly by the choices of others. However, unlike directly giving gifts to members of the sangha, chanting, performing rituals, participating in group meditation, or taking on precepts in a monastic setting, the goals in these Buddhist public and leisure 
places is not often articulated or prescribed by the architects themselves or the lay or ordained managers. It is not presented as a series of systematic assignments on signs, pamphlets, or mission statements. There are many social, economic, soteriological, and ritual reasons for entering a monastery, studying a Buddhist treatise, or performing a ritual, but there are few easily definable reasons or articulated goals for going to a museum or amusement park, besides a vague sense of intellectual enrichment, physical relaxation, or the desire to just pass time.

Buddhist visitors are not just lounging around passively in the places I describe in the following chapters. They are engaging in what Lauren Rabinovitz calls "energized relaxation," which is activity without having larger economic, social, religious, or intellectual goals. ${ }^{30}$ These places are not necessary. Visiting them does not directly improve one's chances at a job promotion, earn credit toward a degree, contribute knowledge needed to pass monastic or secular examinations, provide a place for a life-cycle ritual like tonsure, ordination, marriage, or cremation, or even provide karmic merit to improve one's present and future life.

While at these sites a person can engage in short-term distractions or short-term acts of accumulation. An act of accumulation can include the purchase of a piece of religious paraphernalia or memorabilia, as well as the incremental and accretive learning of ethical or historical facts about Buddhism, without an expressed goal. Parents often need inexpensive places to take children, and if the children can have an opportunity to learn a little history or something about their religious heritage then these places can serve as both distractions and educational venues. Children do not resist visiting these places, as seen from my experience, because these places are safe and visually stunning and parents can allow children to run around. Parents with teenage children go to these places to keep children away from narcotics and other less-savory pastimes. What Rabinovitz and Miriam Hansen see as one of the most important factors of success for amusement parks and movie theaters can be profitably applied to Buddhist leisure places: "[They] provide a space apart and a space in between . . . a site for the imaginative negotiation of the gaps between family, school, and workplace."31 These are not places of didactic sermons, forced spirituality, or ethical directives. They are fun.

For the last fifteen years I have been writing on the ways Buddhists learn how to be Buddhist. However, I have largely been studying obligationsthe rules, ritual procedures, ethical narratives, and pedagogical methods of Buddhists. In many ways, I have missed studying the joys of Buddhists-the sensuous, entertaining, and beautiful aspects of Buddhist life. I want to pay a bit more attention to the aesthetic and affective aspects of Buddhist cultures and not portray them as simply the frivolous "pretty things" that Buddhists place between them and actual Buddhism. I want to move out of the monas- 
tery and away from monk-centric teaching to see how the casual visitor experiences Buddhist history, art, and ideals at their leisure. I am interested in the way this type of "on-the-way" experience happens in non-monastic or semimonastic spaces. This experience isn't necessarily embedded in ritual, supported by texts, or part of a monastic training regimen, but is part of the total experience of contemporary Buddhism — a part that has been sorely neglected by scholars of religion.

Different Buddhisms are being summarized, universalized, and displayed in these leisure places. Looking closely at a few of these places and their designers will open a venue for discussing the very idea of Buddhist leisure. What I have been most surprised by in this research is that much of Buddhist public space has been designed and promoted by non-monastics and architects and visionaries with little formal training in Buddhist history, texts, or monastic discipline. Moreover, these often very large and public places are sites in which formal training cannot be done and that produce very little if any literature contributing to Buddhist education and scholarship. They host few if any regular sermons and rituals. What does it say about Buddhist experience if a large part of it is not based in texts, history, and philosophy, but in the leisurely experience of art and material culture?

\section{Buddhist Global Ecumenism and Affective Encounters}

I am arguing that public leisure culture is an essential part of the study of Buddhism and that by focusing on it we can get away from often false distinctions between the secular and the religious in the study of human cultural expression and meaning-making. However, this argument could be made about the study of any religious tradition. For example, as this book was going to press in March 2015, I had a chance to visit the Garuda Wisnu Kencana Cultural Park in Bali. Although started in 1997, it is still incomplete. The artist, I Nyoman Nuarta, has completed the head and torso of the Hindu god, Viṣnu (over sixty feet tall alone), and most of the beak and head of his mythical winged mount Garuda. When the two parts are combined the statue should be over 380 feet tall and 190 feet wide, making it nearly the largest in the world. The statue, as it now stands, is surrounded by ice cream shops and a Balinese theatre featuring dances and plays like the Balinese Kris Dance, the Kecak Parade, and the Barong Ngelawang. There is also a photo studio where families can dress as Balinese royalty and, as the sign says, "capture their moment in Balinese or casual style." The park attracts Muslim, Christian, and Hindu families alike, and the PT Alam Sutera Realty group that is funding the project clearly wants the site to be as much a leisure and shopping experience as a place to celebrate Balinese ecumenical culture. They emphasize that they want to "continuously align the harmony between 
Muslim and Christian tourists pose for pictures in front of the incomplete statue of Vișnu at the Garuda Wisnu Kencana Cultural Park in Bali

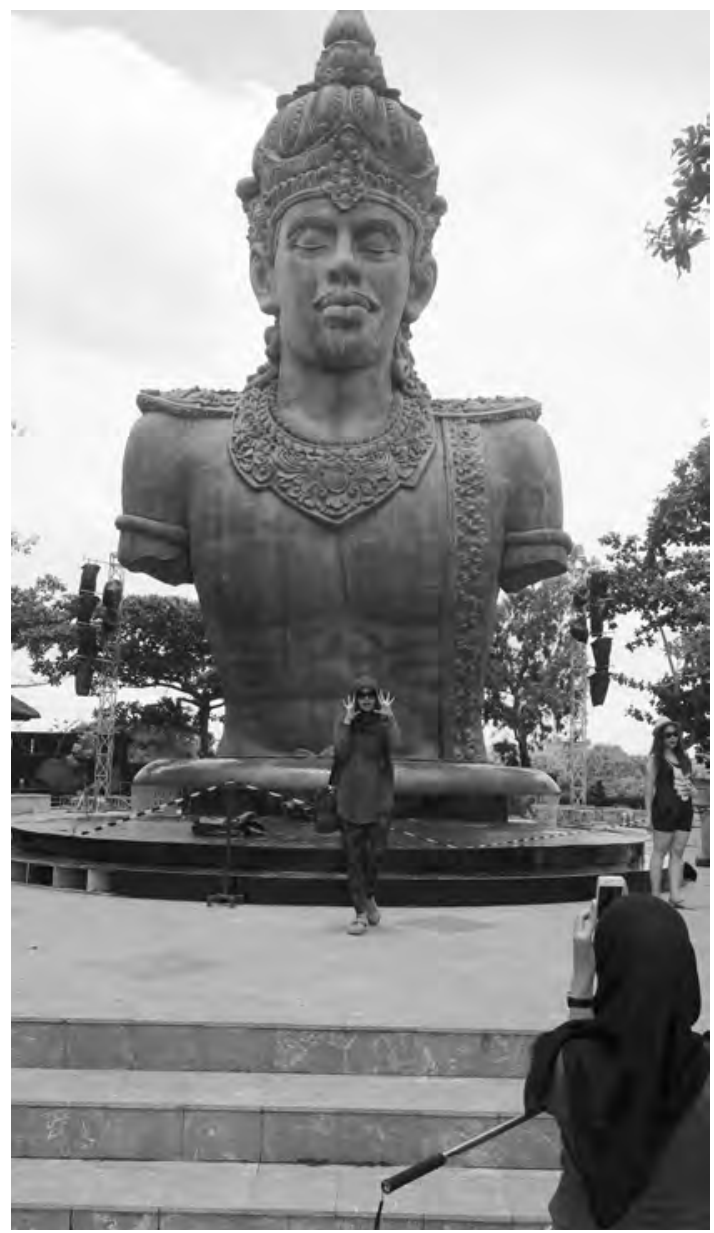

human, environment and God the Almighty." The shopping mall is under construction and the large assembly grounds are not yet finished. However, the dramatic views over the south Bali coastline make this an ideal spot for Vișnu to enjoy the view. This type of site, and other non-Buddhist ones, is certainly comparable in scale, aim, and management to the Buddhist sites. Therefore, I would hope this book speaks to those interested in Catholic or Islamic leisure, for example. However, this does not mean there is nothing particular about Buddhist public leisure culture.

Let's address the second argument of this book by looking at a field in which Buddhists have traditionally been very bad: Buddhists have traditionally been particularly unskilled in the art of empire-making. Sure, there have been emperors, queens, shoguns, and kings who have patronized particular Buddhist schools and materially and intellectually supported particular 
Buddhist teachers and institutions throughout history. However, there have never been serious attempts to create a pan-Buddhist empire. There has never been an agreed-upon capital city or singular holy land for Buddhists. There is no Buddhist pope. There is no central Buddhist ecclesia or ulama. There is no Buddhist notion of being "part of the tribe" and no ethnicity or nationality that makes someone "more" Buddhist. Buddhists have traditionally not agreed upon one canon of religious texts, let alone a single Buddhist scripture that speaks to all. There has never been one classical Buddhist language that all Buddhists use. Whereas a serious student of J ewish or Islamic studies would not be taken seriously without knowing Hebrew or Arabic, respectively, there have been well-known Buddhist scholars who do not know Sanskrit or Pali, on the one hand, or Classical Chinese, Tibetan, or Korean, on the other. There have been plenty of Buddhist travelers and pilgrims, but you are not necessarily a better Buddhist if you have been to Lumbini, Borobodur, Kyoto, Lhasa, Bagan, or Wutai Shan. Being a Nepali Buddhist who knows Sanskrit makes a person no more an authentic voice for Buddhists than does being a Japanese person who can read Classical Chinese. Buddhists have made almost no effort in history to create a unified pan-Buddhist movement or institution or centralized authority. There is no pan-Buddhist law or set of commandments. There is no agreed-upon color for monastic robes. Even the J apanese imperial military vision on the eve of World War II-the Greater East Asia Co-Prosperity Sphere - was both a failure and decidedly not Buddhist. It is striking to think that the one symbol of pan-Buddhist interaction is the "Silk Road"-not a single place, but a contested conduit.

That being said, Buddhists have been very good at building ecumenical spaces. From the libraries at Dun Huang to the "universities" of Nilanda and Taxila to the great monuments and temples at Angkor or Nara, spectacular Buddhist sites have attracted trans-regional students and pilgrims. Most of these students and pilgrims have not gone back to their homelands and actively attempted to create a pan-Buddhist movement. Similarly, the sites talked about in this book were designed by people with visions of global or, at least, pan-Asian Buddhism, but they have not attempted to start formal institutions, programs, sects, or campaigns. They remain, like large museums or cultural centers, places of pan-Buddhist ecumenical display, not strategy.

What do I mean by Buddhist ecumenism? Ecumenism is a Christian term, from the Greek oikoumene, for "the entire inhabited world," and often spelled as oecumenicall in early English usages. It has been used to refer to movements in both the Eastern Orthodox and Roman Catholic Churches to create a universal church without sectarian divisions. ${ }^{32}$ Despite its specific Christian origins, it can be profitably applied to Buddhism. Whereas there have been specific ecumenical councils in Christian history to develop strategies and guiding principles to create a universal church without denominations 
(although never successful), there has been no such concerted effort in Buddhism. Even early Mahayana notions of the ekayāna (one vehicle) were merely rhetorical arguments and philosophical positions without institutional support or sustained strategies. However, despite the lack of a pan-Buddhist ecumenical or nondenominational movement, non-monastic Buddhist leisure sites often promote, through accumulation, assembly, and display, a notion that all Buddhist schools and culture are equal and can and should coexist.

These sites are not on a mission to create a new movement or sect with converts and specific ethical, political, and economic policies. They are also rarely, if ever, concerned with the "authentic." They often display collections of objects and decidedly nonconfrontational (and perhaps a little wishywashy) Buddhist ideas from all over Asia, mixing together newer and older pieces and ethical teachings from various teachers and sects without necessarily favoring a particular vision. Some sites, such as the Ryūkoku Buddhist Museum in Kyoto, have a particular (Jōdo Shinshū) affiliation and certainly display more Jodo Shinshu objects and ideas than from other Buddhist schools, but they emphasize their pan-Buddhist intentions. While a site like Shi Fa Zhao's Nagapushpa Museum in Singapore will mention the age of an "authentic" piece of art from second-century India or ninth-century China, they will place it next to and on equal footing with a new resin buddha image from Thailand. These sites create an ecumenical "atmosphere," a giant curio cabinet of Buddhist cultures similar to other global display gardens (zoos, world music collections, Epcot-like amusement parks, and natural history, folklore, ethnology, and anthropology museums and the like). As an anonymous reader of a draft of this book pointed out, these sites "draw together ideas and objects from around the globe and virtual space to construct meaningful spaces that are articulated as 'Buddhist'"--but, I argue, they don't try to subsequently attempt to create a new type of Buddhism. The sum is often no more than the parts.

Why? What is the point of creating ecumenical Buddhist sites without a desire to create a new movement, new teaching, seek converts, or influence local or international politics? As we will see, the designers and managers of these sites rarely make profits enough to justify the efforts. Some of the sites regularly lose money. They are not training nuns or monks or building large numbers of members. The reasons are much more subtle. First, these sites are not necessarily a product of new technologies. There have been efforts throughout Buddhist history to create ecumenical and pan-Asian Buddhist sites where Buddhists from different linguistic, sectarian, and cultural locales could meet and learn from each other peacefully. However, new travel and communication technologies have greatly increased the ability to build these sites. A Buddhist of relatively modest means can save up to travel to Singapore, Lumbini, Kyoto, Macau, or Bangkok. Wealthy patrons can sponsor nuns 
and monks to travel, and families often visit these sites on vacations. Facebook and similar social media tools display photographs and videos of people who have visited these ecumenical sites on their pilgrimages or vacations. Even Buddhists who can't afford these trips are increasingly connected to the Internet and can visit these sites, many of which have extensive web presences. These sites receive gifts from Buddhists all over the world and purchase Buddhist images, texts, and ritual items on online auctions.

When I first visited a Thai monastery in Bangkok in 1993, there were no computers and, of course, no Internet. Today, many urban monasteries throughout Asia have dedicated computer rooms with Internet access. Highranking urban monks often produce websites, CDs, and the like, to teach their own students as well as students who have access to the Internet globally. Buddhism is packaged as an export product. A new transnational Buddhist class is emerging. New phrases, new rhetoric, have been developed to serve new audiences. These audiences are not only non-Buddhist or new-Buddhist Westerners, but also other Buddhists in Asia. High-ranking nuns and monks have begun traveling extensively and now can be seen in universities in India and J apan, at Buddhist tourist sites in Sri Lanka, China, Indonesia, and Taiwan, and at international ecumenical Buddhist meetings in Korea, Nepal, and Australia. There are new Buddhist Universities with an ecumenical focus, like the World Buddhist University in Bangkok (started in Australia) and the International Buddhist College (IBC) located in Songkhla (Southern Thailand), with its parent organization, Than Hsiang Temple, Penang, Malaysia, led by Venerable Wei Wu. The default language at these universities, tourist sites, and conferences is English. Joint Buddhist publications and websites that encourage J apanese Buddhist students to speak to Tibetan Buddhists and to Thai Buddhists are being developed. A wealthy class of international Buddhist patrons from Bangkok, Singapore, Hong Kong, and other places is subsidizing publications, conferences, and temple construction throughout Asia. New electronic Buddhist text editions in multiple scripts with English translations are being launched. There are Buddhist blogs and podcasts.

I assert that these ecumenical sites celebrate broader Buddhist cultural values of abundance and accretion. Monastic and non-monastic sites throughout the Buddhist world are characterized by accumulated objects. Even the famously "empty" Soto Zen temples of J apan, as Gregory Levine has shown, have large collections of gifts, artworks, ritual items, and documents on display. ${ }^{33}$ As I have previously argued, individual objects and buildings are certainly appreciated for their beauty, but they are seen as more significant when they become parts of larger collections and develop what I call concomitant associative power. The places I describe in this book are visually stunning spectacles, and each individual statue, plaque, painting, or architectural feature shares space with many other objects, just as the giant 
Sendai Guanyin (Daikannon) was filled with many smaller Guanyin. The architects and visionaries that designed them created not only functional spaces for ritual, religious instruction, ecclesiastical meetings, or meditation, but also highly stylized atmospheres filled with seemingly unnecessary, but beautiful, objects. They and their teams of artisans, especially the designers of museums I discuss in chapter 3, could be referred to as ensembliers more than architects. These ensembliers or decorators or couturiers were often masters of the superfluous and arbitrary, so that their spaces sanction luxury and enjoyment. ${ }^{34}$ The overwhelming number of assembled natural and constructed sensual objects work to inhibit systematic learning. This does not mean they are simply a decadent jumble, though. As Daniel Miller notes, some objects are important for the simple fact that they are not isolated and seen individually. They are important because we "do not 'see' them. The less we are aware of them, the more powerfully they can determine our expectations by setting the scene and ensuring normative behavior, without being open to challenge. They determine what takes place to the extent that we are unconscious of their capacity to do so."35 They help form a festive atmosphere where one can be anonymous and absorb sensory delight. There is no test of merit or knowledge, no time spent debating with nuns or monks, and no designated time to enter or leave.

Similarly, Michael Taussig asserts that when an object becomes expected and ordinary, it creates a space for non-contemplative practical memory. ${ }^{36}$ It becomes "distraction." Distraction is a type of "apperceptive mode." The object is no longer studied individually, it is noticed only when it is absent. With so many statues, murals, flowers, and burning incense sticks in many Buddhist leisure spaces, a visitor is not encouraged to focus on an objective, but to get lost in a maze among a menagerie of distractions and diversions. These distractions are an important but neglected aspect in the study of Buddhist architecture. "As for architecture," Taussig continues, "it is especially instructive because it has served as the prototype over millennia not for perception by the contemplative individual but instead by the distracted collectivity." Architecture is perceived by "touch, or better still, we might want to say, by proprioception, and this to the degree that this tactility, constituting habit, exerts a decisive impact on optical reception."37

E. H. Gombrich, one of the most innovative art historians of the twentieth century, whimsically describes a similar idea in the way everyday objects are perceived and how difficult it is to see them individually. On his ninetieth birthday, he wrote a two-paragraph article called "A Note Further to the Drawing of Bicycles," in which he discusses the fact that most people, regardless of their mental capacity, can't accurately draw everyday objects like bicycles. He writes, 
We can all recognise a bicycle, and we can recognise it without difficulty. ... After all, it has all the elements we remember: two wheels of equal size, one behind the other, handlebars in front, and pedals between the wheels linked to a chain. Where the attempt [in a specific test case he is referring to, but which he is using to make a general argument] went wrong was only in recalling the way the elements are fitted together-much as a child who can tell the features of face and body usually fails to join them correctly. It takes many hours in the lifeclass to learn to do this, though we generally can notice any mistakes or distortions. ${ }^{38}$

Architecture, and the objects arranged in its well-designed roomsthat is, experienced, lived in, played in, worshipped in-becomes normal or taken-for-granted. We often do not notice it and are unable to reconstruct a drawing of even the most iconic places. Can you draw, for example, Sydney's opera house from memory? Can you accurately draw the house you grew up in? Can you accurately draw the objects on your dresser at home without looking at them? Habitual knowledge acquired over time at leisure sites and by the objects arranged in them constitutes a great part of the experience of growing up Buddhist, but it is a knowledge and an experience that happens along the way, and reconstructing how it happened is difficult for most people. However, experience is happening apperceptively. Once you learn to ride a bicycle you never forget, but you often forget how to draw one.

Many of the sites I discuss are heavily ornamented. The ornament of these sights, whether the arabesque floral edges and intricately carved nymphs in Lek Wiriyaphan's Sanctuary of Truth in Thailand; the ghoulish statues at the Suối Tiên Amusement Park in Saigon; or the golden inlaid floors, wrathful bodhisattvas, and sculpted dragons of Shi Fa Zhao's multilevel museum, garden, ritual space, and teahouse in Singapore, works on the visitor and in total possesses an affective potential. Even the deliberate lack of decorative elements in Kenzo Tange's Lumbini Park design attempts to create a feeling of freedom from the chaos of highly ornamental Nepali Buddhist aesthetics. Trees and ponds become ornaments. These places are designed to delight. As J onathan Hay argues, visual effects, "pleasurable things," create this affective potential. They can, non-didactically, evoke feelings of happiness, prosperity, and even make people laugh —and, I would add, allow a person to suspend temporality and escape from the world of obligation. ${ }^{39}$

Buddhists often enter spaces of discipline and obligation in the form of monasteries, but they also enter spaces that are both Buddhist and that create feelings of pleasure and personal freedom. Gregory Seigworth and Melissa Gregg write that to study affect is to study "accumulative beside-ness." 
It is to study the accumulation of encounters - a "supple incrementalism." The senses accumulate images, feelings, scents, and sounds constantly. This accumulation is at once "intimate and impersonal." It is the slow accretion of knowledge in the form of nondiscursive impressions. It is not the systematic learning of facts, dates, titles, terms, narrative sequences, ethical standards, and logical progressions, but the body's "capacity to affect and be affected."40 The Buddhist images, decorative items, visually complex walls or lush gardens at these sites, whether beautiful or grotesque, become, like ritual and music, repetitious affective encounters. They do not teach through narrative, but through immediacy. They keep a person in the moment of aesthetic enjoyment. They are "presentational rather than representational; they operate in the here and now." 41 I am particularly influenced by Eve Sedgwick's phenomenological approach. She argues that attending to texture (touch) and affect (feeling) in our approach to everyday experience "is to enter a conceptual realm that is not shaped by lack nor by commonsensical dualities of subject versus object or of means versus ends." 42 As we will see by looking at the work of these artists and architects, they were not particularly controlled by one political, intellectual, or overarching aesthetic conceptual framework. Even when they did have explicit objectives, they could not control the affective encounters that were created by the spaces they initiated. I assert that the affective encounters at Buddhist ecumenical leisure places are a neglected part of Buddhist daily life that have been excised from scholarly studies because they fall on the wrong side of the secular-religious divide. These affective encounters are a type of Buddhist learning, but they are more accessible and common than ethical arguments, philosophical treatises, and doctrinal formulations.

\section{Local Optima}

The third argument this book makes is, perhaps ironically, against the very idea of studying the lives of architects. One could assume that a study of individual buildings and the architects is a purely agent-based study. Biographies, whether of objects, places, or people, do have the tendency to promote theidea that there is such a thing as an independent entity and in turn make that person, place, or thing an ideal exemplar. Whether we study the five khandhas of Buddhist psychology or basic neurophysiology, we find ample evidence that there is no such thing as an independent agent. Every person, place, or thing is composite-made of many parts and dependent on things outside of control-oxygen, gravity, genetic heritage, farmers, teachers, and the kindness of strangers. Therefore, I want to avoid creating a series of exemplars or representatives, or reviving the "great man" approach to history, which posits that history is moved along by certain creative, tendentious, or trailblazing out- 
liers. Instead I want to emphasize that by looking at individual agents we actually learn more about complex adaptive systems. A study of complex adaptive systems sees agents as part of heterogeneous, dynamic, flexible, processoriented, and ever-changing synchronic and diachronic networks. ${ }^{43}$ The architects, buildings, and artworks I look at below are part of complex adaptive systems, not just complicated ones. As computational modeling specialists J ohn Miller and Scott Page state, "Complexity is a deep property of a system, whereas complication is not. A complex system dies when an element is removed, but complicated ones continue to live on, albeit slightly compromised. Removing a seat from a car makes it less complicated; removing a timing belt makes it less complex (and useless). Complicated worlds are reducible, whereas complex ones are not." 44 Much of this work on complex adaptive systems first came out of early developments of the interdependent Erdős Rényi networks and the Sznajd Model. These attempts to map highly complex social interactions and decision making have influenced everything from polymer studies and percolation theories to predicting voter patterns. Although I will leave the construction of these models for mapping the world to my colleagues in statistics, engineering, mathematics, and political science, I think it is important to understand that buildings, parks, museums, and the like are the products of thousands of small decisions by many different people and not well-planned and perfectly executed by lone geniuses. It is the complexity and many layers of redundancy that prevent "cascading failures" in these large systems.

The world's largest metal animal statue, which holds a Buddhist temple within its belly, is the brainchild of Braphai and Lek Wiriyaphan. Without their funding, vision, and, some might say, foolhardiness, it would have never been built, enjoyed, or mocked. They are necessary parts of a complex system that involved thousands of construction workers, artisans, tickettakers, security guards, custodians, accountants, and miners. If one tickettaker goes on vacation or stays home to tend her sick father, the statue does not collapse or close. She makes it complicated; Braphai and Lek make it complex.

Braphai and Lek or Kenzo Tange or Shi Fa Zhao or any other architect or artist in this book might be important parts of complex systems, but they are not lone visionaries standing on a cliff peering over a vast sea with their shoulders back and their faces to the wind. They are what I like to call "in-between" agents. They are locally known in circles of architectural students or Buddhist art enthusiasts. They are not world leaders, spiritual masters, or once-in-a-generation philosophers. In fact, many of them could be called failures. As we will see, while many sites I will discuss are extremely popular and, in some cases, profitable, many were ignored, never finished, or abandoned. Some are ridiculed for being the follies of egocentric blowhards or simply very expensive quackery. I think that if scholars focus only on ideal 
agents, cultural exemplars, profound texts, and timeless creations, then we are missing the middling agents, who despite funding, creativity, and diligence, do not quite make it into the pantheon of greatness. These in-between agents are much more representative than the "great men" of history and teach us more about what is probable, not simply what is possible.

There is a problem with looking at agents through the approach of computational models designed by sociologists and social engineers: they have a tendency to focus on outcomes. Their systems model biological and mechanical behavior to produce solutions to issues of inefficiency, heat loss, reduced profits, or material stress. As a humanist, I have never been concerned much with outcomes. I practice a woefully inefficient and unprofitable craft. I am not really concerned (although I understand why other, more social-scientifically and managerially minded scholars would be) with studying ideal exemplars who successfully achieve optimal outcomes-great books, paradigm-shifting buildings, revolutionary theories, and inspirational epitaphs. I instead look at how certain agents "get stuck at local optima." ${ }^{45}$ They settle on a series of small "goods" and abandon the optimal "perfects" that they initially wanted to reach in the end. We will see that several of the architects had their visions compromised by funding issues, local politicians, lack of materials, changing fashions, economic downturns, or the death of a spouse. Along the way, many agents have to develop alternative plans or, in computational-speak-"lowlevel adaptive algorithms" - and give up ideal outcomes or overarching models. ${ }^{46}$ Sometimes lives and material creations are simply the product of a series of local optima. Architects have to settle on a series of local optima, as do buildings. Buildings are never places fixed in time-beginning at the golden-shovel ceremony or ending at the ribbon-cutting. Each is ever-evolving, going through its own series of local optima long after its architect is nothing but a name on a blueprint in a city's deed office.

However, even if these architects did not achieve their optimal outcomes and ran into seemingly endless and frustrating construction and design hiccups, they do show us something. They show us that monks are not always the prime movers of Buddhist art, practices, and ideas. Instead we find architects like Tadao Ando, who worked on several innovative Christian churches, homes, secular "meditation" spaces, and commercial buildings throughout the world, and inspired work on revolutionary Buddhist monastic architects. ${ }^{47}$ The grand projects of Braphai and Lek or Suchat Kosonkitiwong have led to new ways of displaying art and history at monasteries. The lay designers of secular museums led to the very idea of having Buddhist museums both connected and disconnected to monasteries. Lay funders and businesspeople have influenced monks to build sculpture gardens or amusement parks in or near monasteries. The laity have often been and often are the drivers of Buddhism, but the few studies of lay Buddhism generally study "them" as 
large groups and parts of mass movements, not as purposive and complex agents in complex systems. Laity don't simply bow down, follow, fund, and feed monks, but offer alternative ways of thinking about Buddhism as an everchanging world religion.

\section{Incipits}

To provide evidence for the three arguments described above, I have separated the chapters into three types of public sites for Buddhist leisure activity: (1) monuments/memorials; (2) historical, educational, and amusement parks; and (3) museums. ${ }^{48}$ As an organizing principle, I will look closely at the designers of three specific places and use their creations as the primary foci. The first chapter looks at the life of Kenzo Tange and his design of the Lumbini master plan to honor the birthplace of the Buddha in Southern Nepal. His work is compared to some other architects and their efforts to design Buddhist monuments and alternative monastic spaces. The second chapter focuses on the lives of Braphai and Lek Wiriyaphan, who worked together to create three massive Buddhist historical and amusement parks in Thailand. Their work will be compared to other sculpture gardens, "hell" parks, and entertainment complexes throughout Asia. The third chapter is a study of Shi Fa Zhao's continuing efforts to build a multipurpose "temple" in Singapore. I particularly look at his design of an ecumenical Buddhist museum, as well as other new Buddhist museums in Asia. Although I concentrate on these exemplars, I also mention a number of other places that fall into these categories; it soon becomes obvious that each site can play multiple roles and that many of these types overlap. I have tried to keep this book short-it could be considered an opening salvo to encourage other studies on Buddhist leisure culture, but also to encourage the study of other Buddhist pleasures like games, music, dance, comedy, and romance.

Each chapter serves, then-partly inspired by Italo Calvino's wonderful novel, If on a Winter's Night a Traveler-as incipits, or a series of beginnings to future studies written by others I hope more capable than I. ${ }^{49}$ The study of architecture must always be in the form of incipit, I believe. Buildings, parks, and the material objects assembled in them are never simply the creation of the architect; they are changed by every new manager, repairperson, renovator, and visitor. Governments change, zoning laws are rewritten,

and access roads are moved. The biography of a building is ever lengthening and being effected by the wind, the sun, and its occupants' heavy feet. I often wonder if George Hewitt, who in 1883 designed the rowhouse I live in, in Philadelphia, would be horrified or amused by what has happened to his creation 130 years later. A wooden arch from Kerala spans the rear courtyard, the coal chute has been replaced by a tankless water heater, and my son painted his 
bedroom black. Gone are the rear "servant's" staircase, every old window casing, and, sadly, the original tiles in the downstairs bathroom. Iceboxes have been replaced by refrigerators and intimate discussions by television. Buildings have their own biographies. A person studying one of the buildings I describe below a century from now will undoubtedly be upset about my ideas and write a very different book, because in one hundred years the buildings in question will have changed radically or the spaces they occupy will have been replaced by something different entirely. It is my hope that in whatever form they end up, they will be used for as long as possible for leisure and even some, not so sacred, idleness.

\section{Coming down from Star Peak}

A little less than two years after I found myself looking down from inside the head of the giant statue of Guanyin/ Kannon in the northern J apanese city of Sendai, I was looking up at a giant glass star in southern J apan. On top of a mountain in the rural area between Kobe and Osaka, a large glass assembly hall built in the shape of a star towers over the mountaintop and the adjacent Buddhist Nichiren monastery of Myōken. The hall, known as Star Peak of Seirei, is supposedly the earthly residence of the Bodhisattva Myōken, who represents the polestar as well as the Shinto Kami (god) of the mountain. Myōken is supposed to protect J apan from disasters, and this new glass assembly hall was built soon after Kobe's massive earthquake in 1995. This transparent and gleaming hypermodern structure stands in stark contrast to the monastery and the heavily forested area. The gently falling snow and the heavy mist at the base of the mountain the morning I visited added considerably to its otherworldliness, as it seemed to float above the clouds and sparkle like a snowflake. However, this ethereal feeling was soon wiped away by the laughter of children. Michael Feener, an old friend and a very helpful guide for this particular visit to Japan, informed me that the children running around were part of a "Beaver Troop," which is a type of J apanese boys' and girls' scout group that practices camping, learning about nature, and having fun. They were having snacks and throwing snowballs. As I walked up to the Star Peak hall we also saw young couples snuggling closely, enjoying the crisp air, and buying gifts at the two local gift stores, one run by a woman who was an intense San Francisco and Yomiuri Giants (baseball) fan and had her little shop on the monastery's grounds decorated with Giants' posters. The hall had another gift store where a group of children and adults were making crafts for the quickly approaching national Girls' Day celebration (Hinamatsuri).

The towering glass walls afforded us stunning views of the mountains and valleys and distant Inland Sea. As we looked up from the base of 


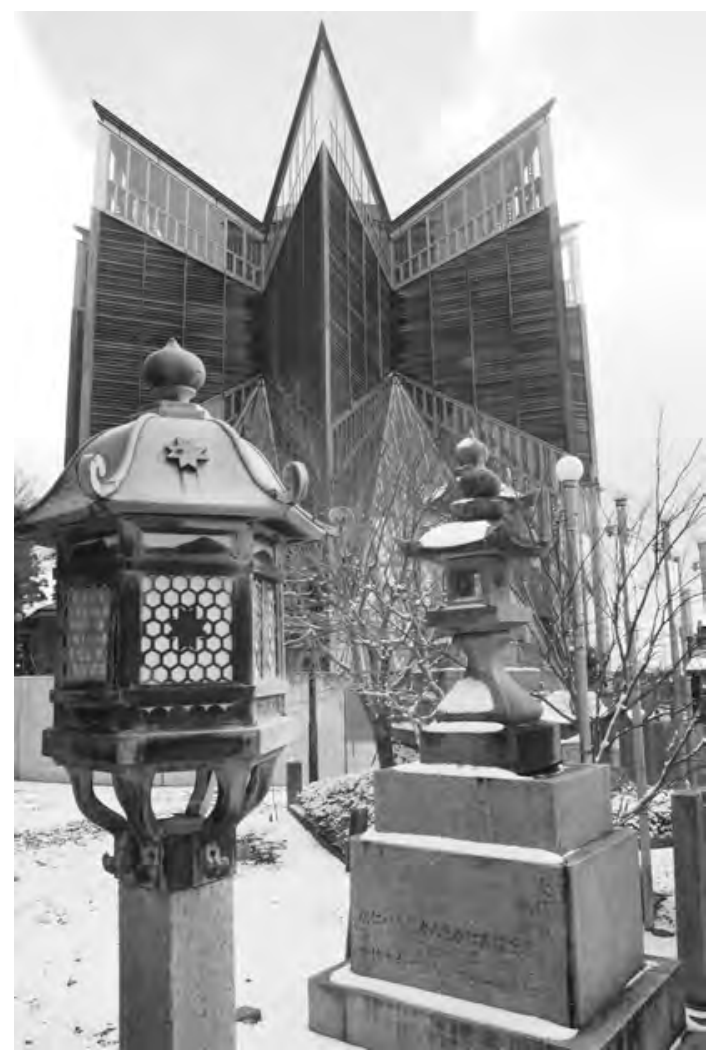

The hall known as Star Peak of Seirei, Mount Myōken

the hall we saw several new colorful sculptures of Jōgyō Bosatsu (Sanskrit: Viśișțacārita Bodhisattva), the bodhisattva representing "superior practice" in the Lotus Sutra and of whom Nichiren is thought to be a reincarnation..$^{50}$ These statues were suspended from thin wires and, against the backdrop of the glass building and the sky, they looked as if they were floating upward. They were perfectly paired with the earthy and delicious bowls of curry udon in the monastery's restaurant..$^{51}$ The whole complex is more like a mountain lodge for weekend getaways than an isolated monastery. Indeed, we saw only one monk at the entire complex while we were there, and leisure activities like Beaver Troop meetings, small meals, and romantic strolls seem to far outweigh monastic ones. The architect, Shin Takamatsu, who is one of J apan's leading architects specializing in large office buildings and new commercial complexes, has branched out and built three structures at Buddhist monasteries, which I describe in subsequent chapters. The Star Peak though, I believe, is his masterpiece and, unlike the Sendai Daikannon, is still glistening. Takamatsu is one of many contemporary architects who have designed Buddhist leisure places across Asia. To some of their work we now turn. 


\title{
1
}

\section{Monuments and Metabolism}

\author{
Kenzo Tange and the Attempts to Bring New \\ Architecture to Buddhism's Oldest Site
}

IN 2013 I HAD THE MOST ENJOYABLE research trip of my career. My ten-year-old son, Henry, and I made a trip to a park memorializing the history, religion, and culture of Vietnam. This museum and memorial to the greatness of the Vietnamese people is on the grounds of Vietnam's largest amusement park, the Suối Tiên Amusement Park, in the suburbs of Saigon (Ho Chi Minh City) in South Vietnam. The entrance fees are relatively manageable for a middle-class urban family in Saigon, and foreigners have to pay a slightly higher price. Suối Tiên (Fairy Stream) is not officially a Buddhist amusement park, but many of its rides, stage shows, and picnic areas are surrounded by large statues of Guanyin (Vietnamese: Quan Âm), Maitreya Buddha, or the historical Buddha. Other statues, including the tall man-made mountain overlooking the splash pool and log flume ride, depict Vietnam's former emperors. Other statues are of Âu Co, the mythological fairy from Vietnamese literary history, and Lạc Long Quân, the dragon she marries. A large palace with colorful reliefs depicts the origin of the Vietnamese people. A bronze plaque describes the history of Đinh Bộ Lĩnh defeating local warlords and forming an early South Vietnamese kingdom (Dai Co Viet) in Hoa Lu 968. ${ }^{1}$ These short history lessons are scattered throughout the park. A plaque placed on-site in March 2002 offers an account (supposedly written by Ho Chi Minh himself) that describes the earliest history of the area called Vietnam today. It recounts the largely imaginary Hồng Bàng family reign, starting with Kinh Dương Vương and his son Lạc Long Quân and his wife Âu Cơ (around 270 $\mathrm{BCE}$ ). These undocumented mythological accounts are presented alongside well-documented historical ones. All of them emphasize the eternal indepen- 


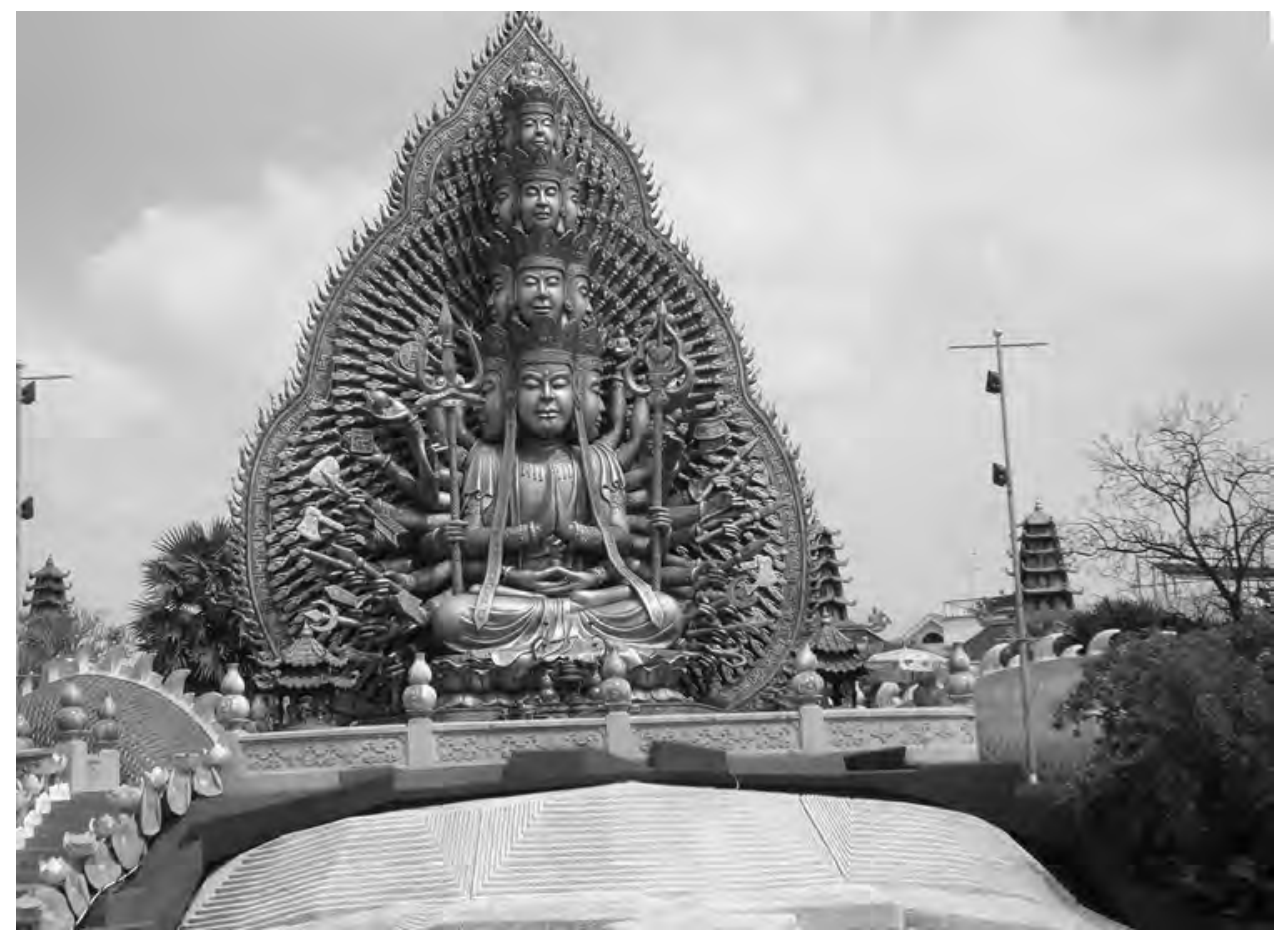

One of the many large buddha and bodhisattva images at Suối Tiên Amusement Park, Ho Chi Minh City

dence of Vietnam and its religious and cultural diversity. This particular origin story is celebrated annually at the park in a ceremony known as Giỗ Tổ, featuring historical parades and monks and nuns of many different Buddhist schools chanting in unison. Colorful statues of animals important in Vietnamese folklore, like unicorns, turtles, and phoenixes, also abound, as well as dolphin shows, a small zoo, a bat cave, crocodile farm, orchard, laser tag, race cars for children, a skating rink, a paintball fighting arena, a roller coaster, a "dreamy castle," and countless carnival games, snack stands, and ice cream carts. Local pop bands perform on a stage shaped like a mythological giant frog. A large buddha looks over the front entrance.

My son darted from the crocodile farm (with over two thousand crocodiles) to a show featuring macaques and baboons riding bicycles, playing soccer, and lifting weights. We decided not to take part in the fish foot massage, but instead explored the Mystery of Witch Forest (Vietnamese: Bí Mật Rừng Phù Thủy), which featured spooky music, animatronic skeletons, and an American Indian diorama next to an Egyptian mummy display. From there, we rode a roller coaster through the mouth of a Brahma head modeled after the Bayon at Angkor in Cambodia. I took his photograph beneath the 105 
foot thousand-eyed and thousand-armed Guanyin and bought a mango ice pop next to the giant rotating statue of the heroic Trung Sisters (Trưng Trắc and Trưng Nhị) on top of a giant elephant. The sisters are believed to haveled the liberation of Vietnam from the Chinese in the first century CE. There was an American-style Halloween display, a gold and silver mountain, swan boats, a laser war zone, and my favorite - the Snow Castle, a large refrigerated room in which a snow machine had created a sledding hill. We put on boots and long jackets provided by the staff and sledded on rubber, all while it was ninetythree degrees outside. After emerging, we came upon the center of the park, home to over eight hundred screaming children at the Biển Tiên Đồng (The Beach of the Gods). This giant water park features an enormous wave pool, dozens of fountains, and two giant water slides, all in the shape of dragons. My son and hundreds of others splashed, slid, and certainly did not wait thirty minutes after their ice cream breaks before swimming. At one point, exhausted, he stumbled over to me and said, "Dad, I wish all temples were like this. Can we go to more places like this on your work trips?" I simply nodded. ${ }^{2}$

I came to this place not simply because I wanted to entertain my son, but because it is a Buddhist amusement park. In the center of the park, shimmering in gold next to the Snow Castle and the Beach of the Gods, is a large, fully functioning Buddhist temple, with nuns and monks performing regular liturgies and paying respects before shrines to the historical Buddha, Guanyin, and other bodhisattvas. Many of the images were donated by the Thai Buddhist Sangha.

I had a chance to read some of the liturgical books and interview a nun (who did not want her name publicized) about the activities of the temple. I was surprised to learn that she was chanting from a Vietnamese translation of a Pali liturgical guide that originated in Thailand. ${ }^{3}$ It contained the traditional seven parittas (protective chants/ Thai: Chet Tamnan) chanted every day all across Sri Lanka, Burma, Cambodia, Laos, and Thailand, but not well attested in Vietnam. The book actually contained Pali (in Roman script), followed by Vietnamese translations, and was promoted by Thích He Tông, a Vietnamese monk who had trained in Thailand. She told me that in addition to Theravada liturgical chants, she also chants to Guanyin/Quan Âm the Chu Mãn Nguyện Đại Bi Tâm Đà La Ni (Fulfillment Wishes Great Compassion Dharani), as well as chanting a collection of ten mantras honoring the ten thousand Buddhas compiled by the Vietnamese monks Thích Nhật Từ and Thích Quảng Tâm. ${ }^{4}$ I asked her why she chanted from books from different Buddhist traditions, and she said that she wanted to honor all the shrines in the temple equally and make all people feel welcome. Her attitude and this ecumenical liturgy fit perfectly within the schedule of events at the temple, which included a wide array of parades and chanting events dedicated to Buddhist holidays from many different regions of Vietnam and many different 
schools of Buddhism, alongside large rituals conducted by hundreds of nuns and monks for different national holidays and important nonreligious anniversaries. It was a truly one-stop cultural-religious-entertainment temple.

The eclectic nature of this temple and the amusement park around it reflect the way it was built. It was founded by Đinh Văn Vui, who is called the "king of the Vietnam entertainment industry." He did not have time to meet with me, but I was able to obtain a detailed profile about him and his park from a Saigon business journal. ${ }^{5}$ Đinh Văn Vui, a longtime member of the Vietnamese Communist Party from the Hậu Giang area, purchased the land for the park (which was largely abandoned fields outside of Saigon) in 1987. Helaunched a small farm, python farm, and workshop to produce small Buddhist wooden statues for export. These slowly became popular among markets in Singapore and Taiwan. In 1990 he discovered that underneath this land was a natural spring, and therefore he named it Suối Tiên (Fairy Stream). He decided to make use of the abundant supply of water to start an entertainment swimming area for the swelling Saigon suburban population. To raise the capital to build this leisure park, heinvested in expanding the farm to grow peppers, longans, and papaya. He also raised pigs, pythons, and, eventually, monkeys, local bears, and even imported turkeys and ostriches. People flocked to see his growing zoo, and he expanded the crocodile farm (perhaps inspired by the growing crocodile and tiger farms in Thailand at this time). He claims that he wanted the people visiting his zoo and farm to have something uniquely Vietnamese as a way to honor local history and foster ethnic pride. His dedication to Buddhism also made him want to promote that aspect of Vietnamese culture. It was a gamble, and he claims to have had many sleepless nights worrying about this massive undertaking. He traveled to Hà Nội (Hanoi), Quảng Ninh, and other places to gather information. Healso gained the support of the Ho Chi Minh City council and the Communist Party, which wanted him to celebrate the independent heritage of Vietnam. While he promotes Vietnamese diversity and history, the nuns and monks at the temple promote Buddhist ecumenism. By 2003, he was welcoming over four million visitors a year and today claims that the park is worth 4,500 billion dong (213 million US dollars). ${ }^{6}$

The crowning achievement of the park was the 2003 launch of the Beach of the Gods salt water park, which he wanted to be likea "blue ocean in the middle of the city." He also stated that the motto of the park is, "Culture, people, modernity, always innovating." One of his most recent endeavors has been a wine producing and bottling plant at the park. Now, fewer than one hundred meters from the Buddhist temple, under the direction of the deputy general manager, Huỳnh Đồng Tuấn, it produces Suối Tiên Đệ Nhất Tửu (Fairy Stream Finest Wine) and the Suối Tiên Đệ Nhất Tửu (Underworld Palace Finest Wine). This wine, like the park, is supposed to promotelocal culture and so is made from herbs and fruits "that gather the sun between 4 and 9 a.m." from 
the local forests. It is aged eighteen months before release, and visitors can visit the underground storage areas at the park. Huỳnh Đồng Tuấn claims that

\begin{abstract}
this special and legendary product line is very effective, very good for your health, and used to serve valued customers and higherups, reserved for worldly guests to use in important banquets that will have effects as soon as you drink it. Drink it before bed or during meals to strengthen your health. ... [It] is good for circulation, good for kidneys, virility, strengthen joints, muscles, helps smooth skin, healthy skin, helps in food digestion, prevents backaches, ear tingles, makes your beard and hair black, feel younger, increase in energy, detoxifies, increases longevity. . . . Drink this cup and it takes you to the skies. ${ }^{7}$
\end{abstract}

Although I cannot claim that it took me to the skies, I certainly had a new appreciation for the combination of Buddhist ritual, teaching, and leisure after visiting the Fairy Stream Buddhist temple, the Beach of the Gods, and the underworld palace full of wine.

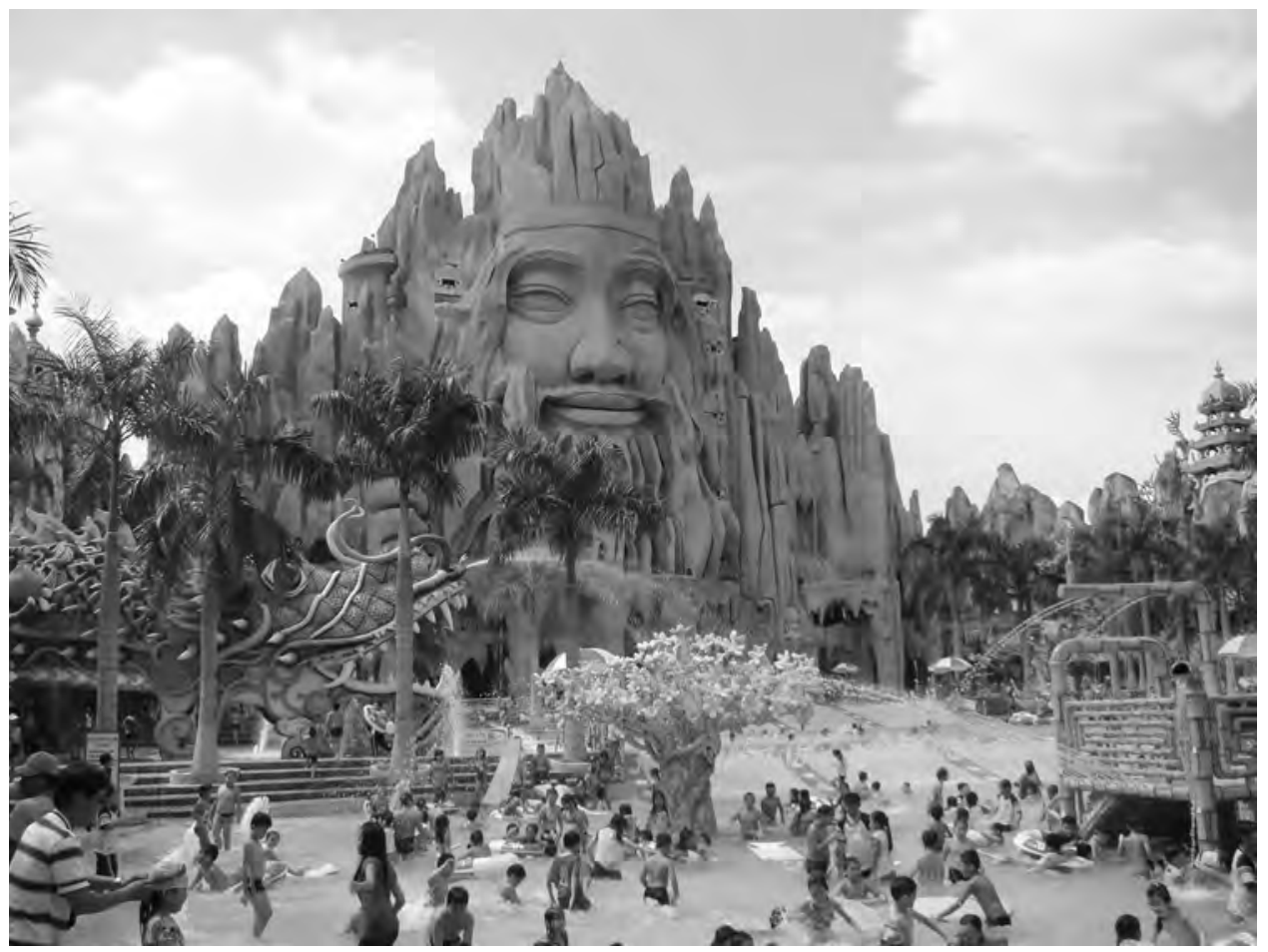

Biển Tiên Đồng, Beach of the Gods water park at Suối Tiên Amusement Park, Ho Chi Minh City 
The park is still not finished; more rides and games are coming, even though it was approved to begin construction in 1995. When we were there in November 2013, there was a large section under construction, but even unfinished there are plenty of rides and sites to fill many days of fun. As of now, it is a fantastic achievement and part of a wave of new amusement parks being built throughout Asia. However, as far as I know, it is the first place with an image of the Buddha next to a roller coaster. The Suối Tiên Amusement Park might seem excessively irreverent to an American like me, who grew up with a strict separation between church and amusement park, but this blending of leisure and Buddhism is not new or particularly strange in the region. ${ }^{8}$

\section{Kenzo Tange: The Reluctant Buddhist Architect}

The Suối Tiên monument to the Vietnamese people is an amusement park, Buddhist temple, zoo, and historical memorial all in one. It was consciously designed to be a place of leisure, where one can make Buddhist merit and learn culture and history on the way. Kenzo Tange's park was consciously designed as a monument, but has been transformed by local tourists, often Muslim and Hindu, into a place of leisure. The history of its development illustrates the importance of understanding Buddhist public and leisure culture and the problems associated with pan-Buddhist ecumenism. It also provides a clear example of the local optima that architects, even famous visionary ones, have to settle with in their pursuit of building religious sites. This is the story of Kenzo Tange and his frustration in trying to memorialize the birthplace of the Buddha.

The famous architect Fumihiko Maki, in his speech honoring Kenzo Tange's winning of the Pritzker Prize (the most prestigious award in modern international architecture), stated that Tange's "ability to distill the very essence of the modern spirit is wedded to a deep understanding of traditional J apanese culture."9 J onathan Glancey, announcing Tange's passing in 2005, stated that Tange fused "traditional J apanese forms with the very latest in structural daring." ${ }^{\text {"10 }}$ Another brief biography states that he "fused the architectural traditions of his native J apan with the contemporary philosophy and traditions of the western world," and that "Kenzo Tange has become an architect of the world largely because his work is so intensely J apanese."11 Speaking of Tange's design of the monumental park to the Buddha's birthplace in Nepal, travel writer Augusto F. Villalon stated, "The subliminal experience is the essence of Buddhism."12

These recent comments, among others, identify Tange's work as "Buddhist" or "J apanese." However, Tange, designer of the Lumbini Sacred Garden in Nepal, seems to have been a reluctant Buddhist and explicitly rejected "traditional J apanese" architecture in most of his work. He never spoke 
of his designs as influenced by Buddhism or Japanese culture. It seems that Tange could not be honored as simply an architect, but always as a "J apanese" or "Buddhist" architect. But he did not set out to design explicitly Buddhist or even "religious" buildings and complexes. Indeed, a study of his life, and especially his design for Lumbini, shows us the problem with characterizing an architectural project along strictly religious or secular, public, or privatelines. Moreover, in this chapter I hope to show how Tange's efforts to design a park and memorial for the birthplace of the Buddha is not only an example of the creation of a Buddhist leisure and ecumenical space, but a study of the way spaces are complex adaptive systems wherein material and people coevolve over time. Despite Tange's efforts to enact his vision on Lumbini, a continual series of interruptions, adaptations, and objections took the space away from him. Instead of the site providing a place where visitors could learn something about the history of the Buddha, Buddhist and non-Buddhist visitors transformed it into a non-teleological and nondidactic leisure space defined by distraction. Ironically, this haphazard coevolution says almost nothing about Tange's "Buddhist" intentions, but has worked to prove Tange's own ideas about architectural "metabolism."

\section{Becoming a Buddhist Architect}

Kenzo Tange was born in 1913 in Osaka, but his father was from Imabari, a small port town, and his mother was from a semirural part of Niigata Prefecture, both far away from the cultural, political, religious, and economic centers of J apan. As a toddler, Tange moved to his father's home. Despite growing up in a thatched-roof farmhouse, he went on to become one of the great international architects of the twentieth century..$^{13}$ Still, he did not grow up particularly poor, as his father had a middle-management position in a bank. He even traveled extensively as a child when his father was assigned to work in Shanghai and Hankou/ Wuhan at branches of the Sumitomo Bank. In Shanghai he resided in a British-style brick home in a neighborhood of mostly foreign residents. After moving back to Japan, his parents wanted more for him than Imabari could provide and sent him away to school in Hiroshima and then to Tokyo’s Imperial University. But it seemed as if young Kenzo was not marked as a future success. Because of low grades in physics and mathematics (not good signs for a future architect), it took him two years to pass the entrance examination for the Imperial University, and he had to enroll in film studies in a lesser-known university to avoid the military draft in the mid-1930s.

Young Kenzo was first interested in astronomy. However, after he saw a photograph of Le Corbusier's 1931 Villa Savoye, and later witnessed drawings of his design for the ill-timed and never built Palace of the Soviets in Moscow, Kenzo moved away from astronomy. ${ }^{14}$ Both buildings adhered to 
the five points of architecture Corbusier (pseudonym for Charles-Édouard Jeanneret) promoted and later published as a collection of early essays in Vers une architecture. ${ }^{15}$ The five points included the use of thin "piloti" columns, roofs that could be used functionally as gardens or terraces, large interior rooms with minimal load-bearing walls, horizontal windows, and subdued facades. The Palace of the Soviets' design was much more ambitious and included a massive concrete arch and a large arched multipaned window besides the iconic horizontal Corbusier wraparound window bands. The Villa Savoye and other buildings he designed in this period had "floating" second floors and roofs. These images made Tange switch his focus to architecture. Le Corbusier's use of sculptural concrete and sweeping rooflines, narrow windows, and open floor plans were revolutionary at the time and would become, through Tange and his teacher Kunio Maekawa, the dominant foreign influences on J apanese architecture for much of the rest of the twentieth century.

Tange found his niche in the Imperial University's Department of Engineering, where the first professor of architecture was a British architect named J osiah Conder, whose statue stands on the campus today. ${ }^{16}$ Conder studied with Hideto Kishida and others. ${ }^{17} \mathrm{He}$ was also probably deeply influenced by the work of Czech architect Antonín Raymond (who trained with Frank Lloyd Wright in the United States), who had designed many homes and buildings in J apan while living there for many years and had worked with Maekawa as well. Raymond left J apan in 1938 just as Tange was graduating and had landed his first job with Maekawa's firm.

Tange began to formally explore Raymond and Le Corbusier's work and design his own projects. However, while Raymond wanted to embrace aspects of traditional J apanese architecture, Tange wanted to create a new tradition and incorporated almost no obvious premodern J apanese elements into his designs. ${ }^{18}$ Although the notions of wakon yōsai (J apanese spirit combined with Western learning), wayō setch $\bar{u}$ (the eclectic mixing of Western and J apanese style), and the more formal teikan heigō shiki (Imperial Synthesis Style) had been popular with Japanese architects from the 1890s to the 1930s, Tange rejected this mixing and the very idea of, as one critic stated, "irrationally adding a Buddhist temple roof to a concrete building."19 For example, Mamoru Yamada was inspired by the curvilinear design of Buddhist temple roofs. Sutemi Horiguchi attempted to combine Corbusier and Raymond's use of concrete with the architecture of Buddhist monasteries and large Japanese villas, as can be seen in his house designed for Motoaki Kikkawa as well as his design for Seinosuke Makita's Double-Bell House (Sōshōkyo), but Tange rarely attempted these types of hybrid homes. ${ }^{20}$ Since his own mother was killed by an incendiary bomb in Imabari on the same day the first atomic bomb was dropped on Hiroshima, Tange might have had real 
reasons to reject Western styles and technological advances in architecture. Instead, before and after the war, he embraced Western styles and rejected traditional Japanese temple design. In this way he stood outside the Japanese architectural establishment of the time and began to usher in a new way.

His early projects throughout the war were almost all unapologetically in the Le Corbusier style. He stated clearly, "I first decided architecture was for me when I saw Le Corbusier's designs in a J apanese magazine in the 1930s. ${ }^{\text {"21 }} \mathrm{He}$ also began to learn from his classmate Ryuichi Hamaguchi, who was an expert on the Italian Renaissance. Kenzo Tange was attracted to the "conversation spaces" that were part of Italian plaza design and that would later have an influence on his design of the garden and park memorializing the Buddha's birthplace in Lumbini, Nepal. ${ }^{22}$ These early projects include designs for the ill-fated Far East Memorial Hall in 1942, the Hiroshima Peace Memorial in 1949, and the Kurashiki City Hall (Okayama) in 1958. His only design that departs from clear Le Corbusier influence was the design for the Bangkok-J apanese Cultural Center in 1943. This design garnered Tange his first major architectural award, but many factors prevented its being built, most importantly J apan's loss of control of Bangkok at the end of World War II.

Kenzo Tange started the planning for the Bangkok-J apanese Cultural Center (J apanese: Bankoku-Nihon Bunkakai) in April 1942, while Japan was still confident in its long-term power in Southeast Asia. By December of that year, the land had been surveyed, soil checked, and meetings held with local construction teams. Tange's design looks different from every other plan he drew in his early career. As a twenty-nine-year-old working during wartime, trying to build a career in a field where winning prizes and high-profile commissions were key to one's reputation, he gave the government what it wanted - a traditional, clean J apanese monastic compound, with long, covered open-air passageways, overhanging eaves, and several courtyards. The layout is reminiscent of Kyoto's Daikakuji Shingon monastery/ imperial residence, complete with a small lake, but its style is closer to the clean lines, subdued eaves, and lack of ornamentation seen at the seventeenth-century Katsura "villa." Tange "Thai-icized" the design by adding color drawings that incorporated the orange roofs distinctive to Thai monasteries and palaces. Unlike his other designs, this one makes more use of wood and shows little evidence of sculpted concrete. The only obvious Corbusierian elements are the narrow piloti(s) instead of wide wooden beams. It is similar in its clean style to Isoya Yoshida's 1968 modern interpretation of traditional palace and monastic halls at the monastery of Naritasan Shinshōji (Chiba). ${ }^{23}$ Tange's design represents an open and welcoming place, as a center looking to foster cultural exchange should be, and speaks to the country's shared Buddhist heritage. ${ }^{24}$ Of course as J apanese military ambitions in Southeast Asia faded, this center was never built, but the prize he received helped Tange consider- 
ably; he was able to launch his own firm and earn a professorship at Tokyo University after the war in 1946. Until the park in Lumbini, thirty years later, it would be the last "Buddhist"-style building, if it can even be called that, he designed.

Kenzo Tange went on to win dozens of international and domestic awards through his firms URTEC (Urbanism-Technology) and, later, Kenzo Tange Associates. He formed an efficient working team based on Walter Gropius's organizational innovations. Gropius, who was one of Tange's greatest supporters, believed that architecture should be functional first. Therefore he resisted decorative elements and sentimentality. While Tange was not as radically resistant to ornament, he did like Gropius's neue sachlichkeit (new sobriety) movement, away from sentimentality and tradition. ${ }^{25} \mathrm{He}$ particularly like the attention Gropius paid to cost of materials and efficiency during the design phase of a project. Like Gropius, Tange did not want to build prestige buildings, only for the elite, but functional architecture for the masses. Tange's Peace Memorial at Hiroshima became world famous, and he gained confidence after meeting directly with Le Corbusier on the construction site of Unite d'Habitation (Marseilles) and discussing that project. ${ }^{26}$ Between 1946 and 2005 he designed some of the most distinctive public and high-profile corporate buildings in J apan, including the Yoyogi National Gymnasium for the 1964 Olympics, the Kagawa Prefectural Government Building, the Tokyo City Hall, the Tokyo Dome Hotel, the Fuji Television Building, the Hanae Mori Building Aoyama, the Municipal Center in his hometown of Imabari, the Dentsu Building in Osaka, the Shizuoka Assembly Hall, the Tsukiji neighborhood plan, the Sumi Memorial Hall in Ichinomiya, the Children's Library in Hiroshima, the Foreign Ministry in Tokyo, the famous Shinjuku Park Tower, which holds the Park Hyatt Hotel as featured in the film Lost in Translation, and many others. He was also adept at designing museums like the striking Yokohama Museum and the Sōgetsu Art Center in Tokyo.

He traveled all over the world designing buildings and neighborhoods (some of which were never actually built) such as the headquarters of the World Health Organization in Geneva, the University of Bahrain, the Minneapolis Institute of Arts, the J eddah Royal Palace in Saudi Arabia, the Japanese Embassy in Mexico City, the Fiera Towers in Bologna, the Kuwait City Airport, the Culture and Sports Park in New York, the Baltimore Inner Harbor, the University of Oran in Algeria, and numerous buildings in Singapore, including the Linear Apartments and part of the Nanyang Technological University.

Tange might be best known, though, not for buildings, but for cities and large public projects. Even his senior thesis was the design for Hibiya Park in Tokyo. In his career, he designed four urban transformation projects which, if completed, would have literally created four cities. For example, in 1960, he 
developed the master plan for Tokyo, which, if completed, would have projected Tokyo over the bay and made much of it a floating city resting on manmade islands connected by a network of bridges and latticed walkways. In other designs he developed ideas for large vertical communication shafts, newly designed elevators, and some pedestrian walkways suspended almost four hundred feet in the air. These radical plans have become a mainstay for architectural and urban studies graduate courses across the globe. In 1963 he designed the rebuilding of Skopje (former Yugoslavia) after the earthquake, and South Saigon (Ho Chi Minh City), Vietnam, in 1993. The master city design for Abuja, the new capital of Nigeria, was the only one completed. ${ }^{27}$

The Tokyo City Plan was the first example of Tange's personal architectural philosophy, which came to be known as "Metabolism." He believed that architecture in the past had been functionalist, dealing with the need for human work places, living places, and recreational places. However, he wanted to structure the "process of coupling these functional units." ${ }^{28} \mathrm{He}$ saw buildings not as isolated monuments or functional structures, but as nodes of energetic couplings, and from early on was interested in cybernetics. Influenced by Renaissance conversation spaces and the idea of the promenade architecturelle, he wanted to design places where informational exchanges can happen whether a person is eating, working, or playing. He also built purposive "voids" into his design to allow expansion and change in the design over time, and he wanted buildings and courtyards to have moveable walls and facades to accommodate change according to occupants' wishes. Indeed, it was this philosophy, and not Buddhist concepts, that would exert the greatest influence on his design for the Buddha's Birthplace memorial monument and park in Lumbini, in which he incorporated conversation spaces, zones of activity, and planned open space to accommodate future change.

The point of all of this for our purposes is that none of Tange's ideas or designs is explicitly "Buddhist." There is no evidence that he was raised in a particularly serious Buddhist household. He actively read Gide, Proust, and Dostoyevsky as a young man. ${ }^{29}$ He never studied Buddhism formally and did not join a monastery at any point in his life; his own son was not sure what sect of Buddhism, if any, his father belonged to, and Tange's funeral services were held in Saint Mary's Roman Catholic cathedral in Tokyo. Tange designed the cathedral, which was built in 1964. I remember the first time I visited the cathedral and attended Mass there in 2010; it is like visiting a futuristic metal city. Anyone who has visited the other Saint Mary's Cathedral, in San Francisco, will see how Tange also inspired that design and others, like the cathedral in Brasilia. Saint Mary's in Tokyo it is like a silver rocket with eight massive "hyperbolic elliptic parabolas," modern stained glass embedded in soaring narrow walls, an abstract baptismal font under a skylight, and a se- 


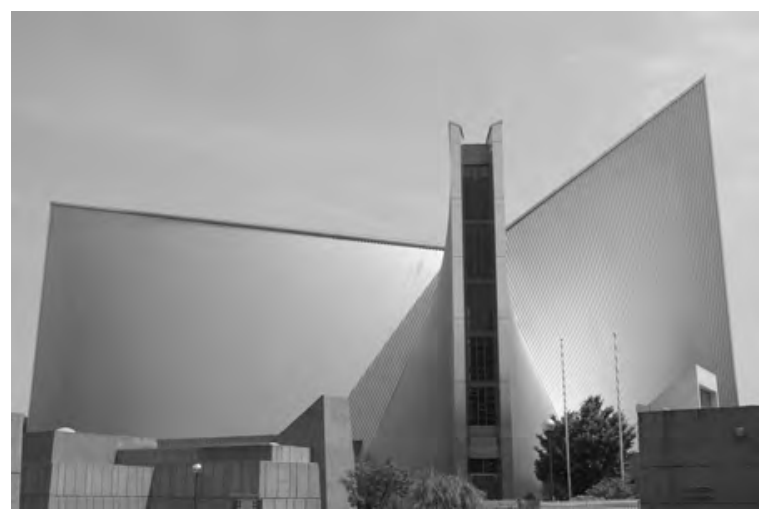

Saint Mary's Cathedral, Tokyo

verely geometrical organ box. Even the stations of the cross and donation boxes are hyper-stylized and modern. Unlike other Buddhist architects inspired by Tange, such as Tadao Ando, Takashi Yamaguchi, and Shin Takamatsu, Tange did not spend much time designing Buddhist temples in J apan.

Tange does not claim to have been inspired much by Buddhist architecture and saw himself as a modernist architect and city planner firmly in the lineage of Le Corbusier. Even in his reflective writings, letters, and speeches, he reveals nearly nothing about his thoughts on Buddhism; his 250-page autobiography in J apanese contains no mention of his thoughts on Buddhism or influence by Buddhist thought or art..$^{30}$ In fact, as Vinayak Bharne notes, led by Kenzo Tange and his design for the memorial at Hiroshima,

Japanese architects, now under the willful embrace of Western modernism, seemed charged like their European and American counterparts to recover the role of the plaza and its traditional urban functions. Attempting to fill a void in the formerly nondemocratic Japanese architectural vocabulary, emerging architects such as Kenzo Tange began developing new public space typologies. His design for the town hall complex of his home town, Imabari, completed in 1959, included an auditorium, office center, and town hall compactly arranged around a public plaza. Tange's interest in such communal spaces dated back to his university studies of the Greek agora as a place where a citizen moved from the private realm to establish connections with society. ... This idea of the Western plaza was an urbanist import alien to J apan's authentic traditions. In traditional J apan, the labyrinthine tenuous street, not the square, had been the center of civic life. In a stratified social structure with the emperor at its head there was 
no communion in the democratic sense, and in historic J apanese capitals like Heijokyo (Nara) or Heian-kyo (Kyoto), no conscious expression of any formal community space. ${ }^{31}$

This idea of a central plaza for conversation between people from all social classes, and public buildings like auditoriums and commercial districts, can be seen in his design of Lumbini (discussed below) and has more connections to the notion of the plaza and the promenade than to Buddhist traditional architecture in Japan or elsewhere in Asia. ${ }^{32}$

This fact is confirmed by Tange's own assessments of his work. In one of his most explicit published essays on his own methods and inspiration, in the journal Gendai Kenchiku, he focuses on Michelangelo and Le Corbusier, and not on J apanese or Buddhist concepts or traditions. ${ }^{33}$ In fact, one of his only comments I have read on religion was in response to a letter in the mid1960s from Pope Paul VI. The pope wrote to Cardinal Doi of Tokyo conveying his gratitude to Tange for the design of Saint Mary's. ${ }^{34}$ He expressed hopes that the beautiful building would remain a "House of God in people's hearts." Tange commented on that message by stating, "Here we can see that the highest hopes are raised on the architectural space. Of course, it might be impossible for the architectural space to reflect exactly the spiritual world. ... We architects have to study hard how to create this kind of spiritual world in a spatial form. ${ }^{\prime 35}$ This is not exactly the most specific advice and certainly not specific to Buddhism.

Tange did not write a great deal, but he did complete long essays on two particular J apanese buildings - the Katsura Palace and the Ise Shrinewhich are included in books he collaborated on with photographers. His studies of these two sites teach us nothing about his views on Buddhism, but much on his views on architecture and public places. The study of the Ise Shrine, a world-famous Shinto shrine, refers to J apanese mythology (especially the tenchi kaibyaku and tenson kōrin, or creation of the Japanese islands and people) and early literature like the Nihon Shoki and Kojiki; natural building materials (especially the sakaki/homorogi tree); the Yamato people/clan; the Yayoi culture; and the techniques for periodically rebuilding the shrine. ${ }^{36}$

The studies include almost no comments on Buddhist influence on later J apanese architecture or his own work. Tange's study of the seventeenthcentury Katsura Palace near Kyoto does mention that Zen monks were involved in the design, but he trusts other historians, who state that these monks were merely advisers and that Prince Toshitada was the driving force behind the building of this palace. He claims that the philosophy behind the design was based on "personal experience or emotion" mixed with a deep expression of mono no aware ("the poignancy of things") or the pensive reflection on that 
which is natural but mysterious. This complex literary reference is often used in reference to Heian literature, especially the romance/ epic Genji Monogatari. Even though it is also used in reference to the Buddhist concept of impermanence, Tange does not connect it in his writings to anything Buddhist. ${ }^{37}$ He also saw the palace as a place that blended elite imperial tastes with the "bubbling energy of the masses" that was rising in influence at that time in Japanese history. The major architectural prototype for this palace, he believed, was the Ise Shrine and not Buddhist monastic buildings. He does note the importance of Zen monks during that time, but states that their intellectual culture grew out of the "accumulated energy of the farming class."38

Tange seems to go out of his way to undermine, although never explicitly, the influence of Buddhism on J apanese architecture and associates Buddhism with imported Chinese styles. He does, though, credit the gardens at Katsura with the influence of the five great Zen monasteries of Kyoto, especially the Tenryūji. Still, he states that these gardens came about through mutual influences from J apanese sense of suki ("taste") and the "rustic life of the peasants," which later seemed "beautiful to Zen priests and tea masters."39 In an ironic twist, it may be that Tange was actually copying Gropius's views on Zen art rather than expressing his own. Several years before Tange wrote these lines, Gropius, in a 1955 article on J apanese architecture (an amateurish piece written as a type of travel journal after his first trip to J apan), wrote that Katsura was "deeply influenced by the Zen sect, which started in China as a Buddhist sect and was influenced by Confucianism and Taoism, creeds which overlap in Asiatic countries without creating much antagonisms to each other. . . . Zen is not a religion, but is a human ideal of self-education by Spartan means." Later in the article he theorizes, as did Tange in 1972, the combination of the natural energy of the rural and impoverished classes and its influence on the philosophy of Zen, initially embraced only by the elite. Perhaps Tange was learning his Zen history from a German architect with no experience studying Zen. ${ }^{40}$

Tange was no nativist, though; he was always most explicit about his debt to Le Corbusier, Antonín Raymond, Ludwig Mies van der Rohe, and other European architects. Furthermore, the idea for the book may not have been Tange's. In 1954, it seems that his friend Walter Gropius, while on a Rockefeller grant to J apan, encouraged Tange to undertake writing a commentary on the palace based on the photographs of Yasuhiro Ishimoto. Gropius wrote the introduction to the book. Later, with Gropius' encouragement, Tange was given a visiting professorship at MIT for one semester. In his introduction, Gropius observes that "the Western mind, in its restless desire to seek new horizons in the physical world, would do well to learn a lesson in spiritual intensification from the Oriental mind." 41 Near the end of that introduction he states, "So deep was my impression of the J apanese architecture of old, that, 
to the surprise of my J apanese colleagues who knowing me as a rebel and innovator expected me to act accordingly, I implored them not to discard the great spirit of their traditional architecture. . . . A vigorous modern J apanese architecture should boldly progress without sentimentality. Its growth, however, needs all the live elements of the past. . . . J apan is still blessed with the most precious heritage of the past - an integrated cultural entity kept cohesive by the subconscious habits of the people." 42 Tange apparently rejected this lesson himself. Indeed, Tange openly criticized some aspects of Buddhist design of the past in Japan. As one architectural historian writes,

Japanese architecture, according to Tange, reflected an essentially passive appreciation of natural phenomena viewed always as something "to be contemplated." Tange berates the "self-emptying" attitude of Zen Buddhist art that draws the Japanese away from reality and causes them to lose themselves in an all-encompassing vastness of thought. . . . For Tange, the sense of openness in J apanese architecture and "the transient, inconstant and feeble expression accompanying it" failed significantly to "comprehend reality as something dynamic." . . . J apanese buildings give no impression of unity because they are unable to combine the "functional and the expressive, the material and the artistic" as the Western tradition has consistently worked to do. ${ }^{43}$

Although he didn't have the money to visit the West until his career was well established, Tange seemed to romanticize Western architecture, starting with Michelangelo, and saw himself deeply within the Western lineage of Corbusier. He later taught in the West, wrote in English, and corresponded about architecture and urban studies with Lewis Mumford. ${ }^{44}$ Even though Western architects like Raymond designed "traditional" Japanese homes for themselves, Tange's own home (the only residential structure he ever designed) in the southern Tokyo suburbs has as many international style elements as Japanese elements (tatami mats, shoji doors). The Graduate School of Design at Harvard even has an endowed chair named after Tange.

Conspicuously absent from all Tange's work and writing is reference to an influence from Buddhism; in the end, he was not trying to use J apanese Buddhist or J apanese traditional architecture. He commented near the end of his life that "architecture must have something that appeals to the human heart, but even then, basic forms, spaces and appearances must be logical. Creative work is expressed in our time as a union of technology and humanity. The role of tradition is that of a catalyst, which furthers a chemical reaction, but is no longer detectable in the end result. Tradition can, to be sure, participate in a creation, but it can no longer be creative itself." 45 


\section{Even the Sal Trees Have Retreated: A Reluctant Buddhist Creates the Buddha's Birthplace}

For most of Buddhism's history, relatively little emphasis has been placed on the supposed birthplace of its founder, Gotama Siddhartha (the historical Buddha). I often wondered why such a long-lasting and influential religious tradition, a "world religion," would grant so little importance to the birthplace of its founder. I was also fascinated by the fact that Lumbini had been confirmed by scholars as the birthplace of the Buddha only at the turn of the twentieth century, and archaeological research was still not complete at the site one hundred years later. Many of the major holy sites of J udaism, Islam, Christianity, Hinduism, and even of smaller religious traditions like Shinto, Sikhism, and J ainism, had long been built up as beautiful monuments and sacred centers visited by millions of pilgrims every year. Other Buddhist reliquaries and religious pilgrimage destinations throughout Asia, such as Wutai Shan, the Temple of the Emerald Buddha, Todaiji, the Shwedagon, Wat Doi Suthep, Ajanta, Borobodur, and even Bouddhanath and Swayambunath in Nepal, had been much better maintained and more visited despite political and economic difficulties in their respective locations. Why not Lumbini? After all, it was the birthplace of the Buddha.

To answer these questions and try to understand the role of architects in the creation of Buddhist leisure and public culture in Asia across the last century, I visited Lumbini. I had put off the trip for far too long. I already had accumulated a large number of documents, photographs, architectural drawings, eyewitness accounts, and historical studies about Lumbini, but being there and walking around Kenzo Tange's creation opened my eyes. As I discovered, there are many ways to "see" Lumbini. ${ }^{46}$

The first morning I was there, I woke up before 5 a.m. and decided to walk to the site from my J apanese-managed hotel. I had wanted to stay in the oldest Japanese-managed hotel, the Hokke, for no reason other than a silly idea that I might "feel" more connected to Tange. However, I was told that this hotel had seriously declined in recent years, with the lack of visitors and change of managers. Instead I stayed at the other J apanese-managed hotel, the Kasai, which also was showing some evidence of declineand certainly a lack of customers, even though it was the height of the tourist season. ${ }^{47}$

I walked in the slightly chilly early morning mist and fog, out along a dirt road surrounded by fields of weeds, past a downed power line and the Sri Lankan pilgrims' guesthouse, which had been abandoned (I was unable to get a straight answer from anyone about whether it would be rebuilt). I was inside the area of Tange's "master plan," but the roads were almost all still dirt, and without sidewalks. The evening before, I had met an American traveler who had driven his Royal Enfield motorcycle across India to Lumbini. He asked where Lumbini was. I told him he was in Lumbini. He asked, but where 
are the sites? I said he was within two hundred yards of the entrance to the park. He was shocked that such an important place for the history of Buddhism had hardly any signs or indications of where pilgrims should go. I agreed.

As I walked through the bus parking lot toward the main entrance, I saw trash everywhere, even surrounding a sign that asked people not to litter in Nepali and English. The one public bathroom was in shambles. One family had set up a bonfire in the middle of the parking lot to sleep around. A man was sweeping piles of plastic bottles and food wrappers out of the back of his tour bus onto the street. Several men were sleeping in their rickshaws. Mangy dogs were everywhere. The ticket office had a man sleeping in front of it. I walked into the park past the weeds and trash surrounding the museum, its windows caked with dirt and cobwebs. The fog was lovely, and it was quiet. Surely, it would be better along the "central link."

Tange designed this central walkway or "link," which has a canal running down the middle, trees lining each side, and resembles a brick version of the long reflecting pool at the National Mall in Washington, DC. However, it clearly was not well maintained. Weeds were overgrowing its sides, and the signs pointing to the East and West Monastic Zones, Maya Devi Temple, and Eternal Peace Flame were in disrepair. ${ }^{48}$ A Nepali construction worker was defecating in the water of the central canal, while three others urinated behind a tree along the main path. Another was using water from the canal to brush his teeth. Makeshift tents were scattered throughout and small fires burned to cook morning meals. Despite a planned completion date in 1985, the Lumbini Development Trust, in charge of carrying out the construction of Tange's plan, was still a long way from finished in 2012. Workers were seriously underpaid and not given even the most basic forms of accommodation, food, or bathrooms. No wonder they did not seem to care about how they treated the site.

As the sun rose, I made my way past the Eternal Peace Flame, which was much smaller than I had imagined and was just ten yards from a manual water well where construction workers could wash their clothes and visitors could hand-pump drinking water. There was an old boat in the canal. I had read of Tange's plan to have a boat that would take elderly pilgrims down the canal so they could avoid walking. However, even though I saw the boat later that day being used for teenage Nepali tourists, who were having a dance party on it, it looked to me as if it would sink at any moment. A group of temporary stands were being set up, all selling the exact same products: plastic buddha images, clocks with buddha faces, prayer beads, solar-powered Tibetan prayer wheels made for the car dashboard, and hundreds of pieces of women's jewelry, bangles, hair clips, water bottles, soda, and bags of candy and biscuits. There were no books for sale. Visitors included Korean monks, Japanese 


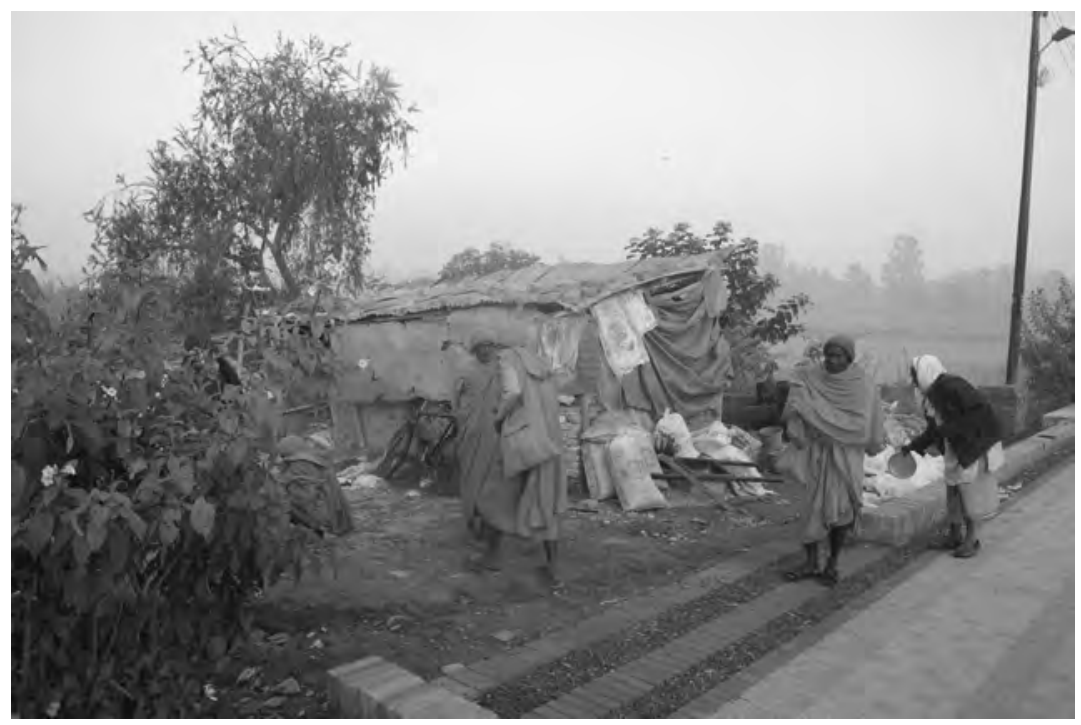

Temporary shanty housing built by Bangladeshi monks along the "central link" in Lumbini Park

women, a group of women from Myanmar dressed in white pilgrimage outfits and sun hats, and three Tibetan women, who did not stop at any of the stands.

We walked across a causeway flanked by a very nice pond. Two Sarus Cranes flew over my head. They are the tallest flying birds in the world and, at almost six feet tall, were an awesome sight to behold as they swooped over the pond. On the causeway a small group of Theravadan monks from Bangladesh accosted me aggressively, asking for money. They ignored the other foreigners, perhaps because they had experience with which types of people gave them money or assumed that I had more money since I was wearing a light sweater and suit coat. Theravada monks are not usually permitted to openly request money, and many Theravadan Buddhists will refuse even to physically touch money. Their request was therefore surprising to me, and I felt somewhat ignorant, since I had so little experience studying Bangladeshi Buddhism. I spoke with one of the monks for a few minutes. His fellow monks had been staying at Lumbini for a few weeks, he said, and had built a shack at the end of the causeway out of old construction material, tires, a few plastic tarps, discarded rice sacks, and cardboard boxes. Their makeshift compound was surrounded by a large trash pile, and they were cooking their own breakfasts (another anomaly for Theravadan monks) on a small bonfire. These monks were clearly desperate for food and income and were making the best of a tough situation. Being right on the main causeway to the central shrine was probably a good place to earn money. I was shocked that the guards and Lumbini Development Trust would permit this clearly dangerous and 


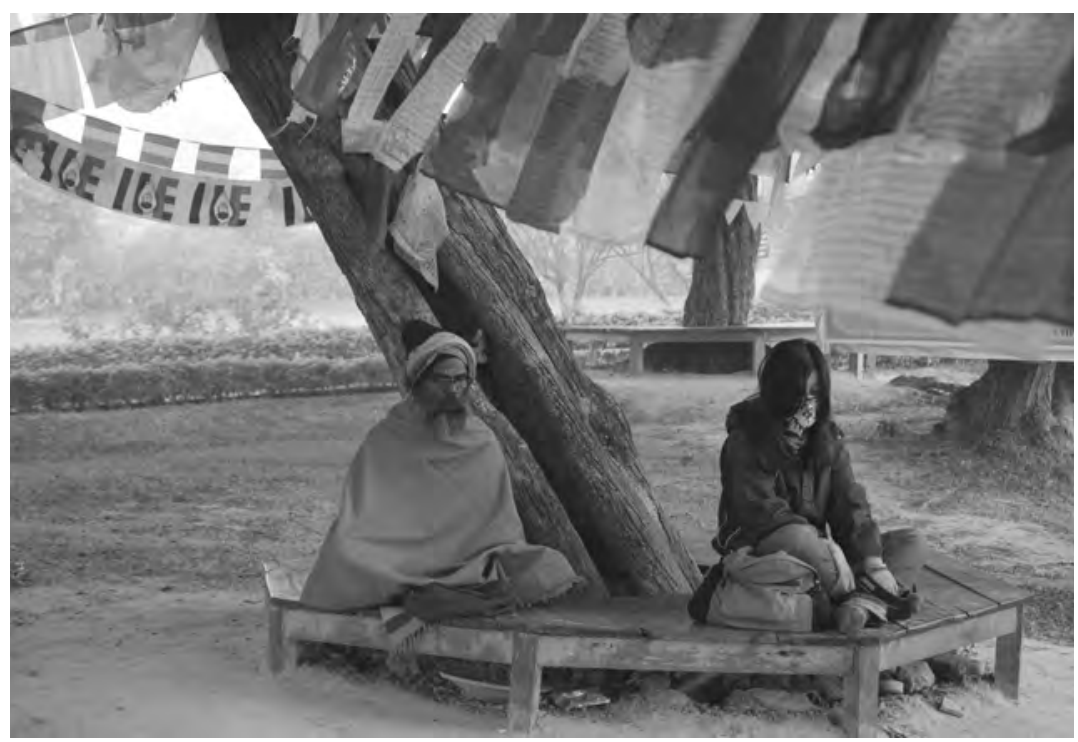

A Hindu sadhu and a Korean tourist, Lumbini Park

unhygienic camp in the center of the park. I was told by a guard at the ticket office the next morning that this type of settlement was not permitted and that I must have been mistaken. He actually suggested to me that even though I had seen the camp firsthand and could show it to him myself, that my eyes must have fooled me. He said that this type of activity was not permitted and that I could not have seen it or met these monks because they did not exist. Later, the head of the Lumbini tourist campaign called "Visit Lumbini Year 2012" would also tell me I was mistaken. I wondered why the Bangladeshi monks had not simply occupied one of the many abandoned monasteries at Lumbini or asked to stay with the Burmese, Sri Lankan, or Thai monks. I later learned why.

As I entered the most sacred site of Lumbini, I had to remove my shoes. I tried to explain to the guards that I did not have a ticket because the ticket office had been closed when I passed it. They understood me but did not care, and told me that paying was not important. I decided to make a donation to the temple instead. Surrounding the Maya Devi Temple is a relatively plain and poorly constructed building that served as a covering to an archaeological pit that had been excavated to reveal what was thought to be the exact place where the Buddha's mother gave birth. Inside there is just a wooden walkway around the pit. Although several signs ask visitors to be quiet and not take photographs, a Burmese monk was giving a sermon to several Burmese women. They were not being quiet. Next to them, many young Korean women were meditating, with a Korean man taking their photographs. Two armed Nepali guards were very friendly and offered me a cigarette at the 


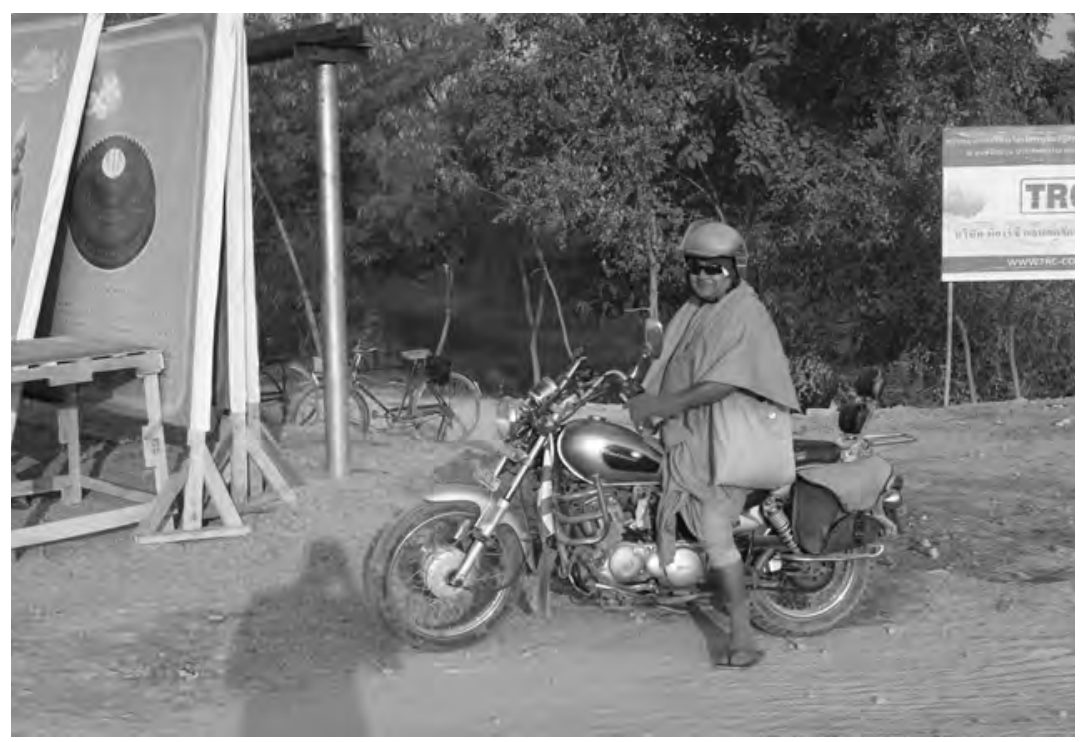

Bangladeshi monk along the central link, Lumbini Park

doorway, but did not pay attention to what was going on inside the room. Around the remains of the Aśokan pillar, which marked the site more than two centuries before the common era, were many Tibetan prayer flags and a large glass donation box filled with currencies from around the world. Next to the small man-made pond where the Buddha's mother was said to have bathed before going into labor was the large tree that she held on to while giving birth. Surrounding the tree were about two dozen Sri Lankan, Bangladeshi, and Korean monks. Later, Thai and Burmese monks would replace them, I was told, as they always got to the site around 8:30 a.m., with large busloads of their lay followers. One young J apanese lay woman sat among them. A sign instructed people not to give the monks money, but two monks were actively asking for money, and one had a large pile of cash on his lap. He asked whether I wanted to take his photograph for the equivalent of three US dollars. I declined, but asked him a few questions. He had moved to Lumbini from Bhutwal (a town not far from Lumbini) and had grown up in a Hindu family. He had "discovered" Buddhism at Lumbini and liked to meet foreigners and practice his English and some J apanese.

As I left the main "sacred garden" and site of the major archaeological finds, I visited the East Monastic Zone, which was the area designated by Tange for "Theravadan" communities. In the original master plan, thirteen plots were assigned there, where foreign and domestic Buddhist schools could build monasteries with private money. Their activities would largely not be interfered with by Nepali authorities as long as they did not bother other groups and maintained respectful decorum. In this zone, monasteries were 


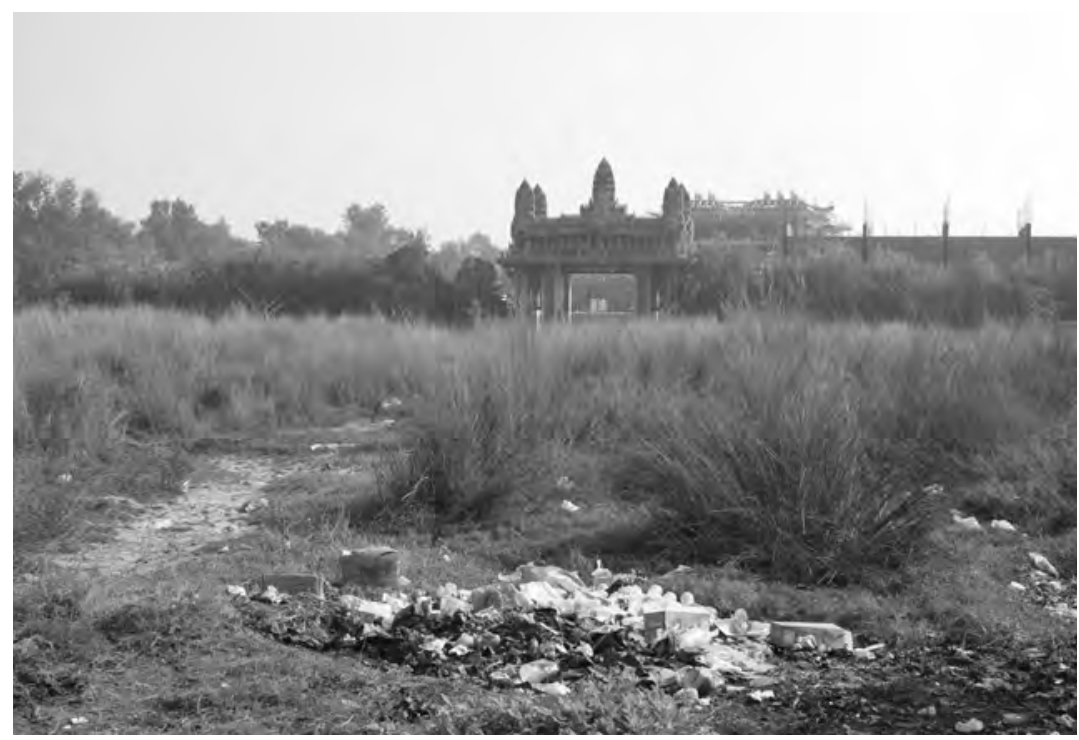

The largely abandoned Cambodian monastery at Lumbini Park

built by groups from Sri Lanka, Burma, Thailand, the Mahabodhi Society of India (although largely occupied by Sri Lankans), and the International Gotami Nun's Association, serving nuns primarily from Burma and largely funded by Burmese donors. ${ }^{49}$

Thailand's monastery at Lumbini is the largest and clearly the most active. It has a large pilgrimage center for Thais to sleep and eat in, a large garden, a parking lot, and a beautiful temple built in central Thai style. Five Thai monks are in residence, and at any given time over twenty monks are visiting. According to the abbot, they get very few visitors who are not Thai, but lots of Nepali and Indian tourists take photographs of the temple, and some Shan visitors also stay there. It is also hard for them to encourage the Thai monks in residence to stay long because, he joked, they miss Thai food and do not like the climate.

Outside the gates of the Thai monastery, a large group of children were begging and occasionally getting screamed at by the Nepali tourists. Even though the sacred garden was only a few hundred yards away from the Thai monastery, the nuns and the other groups of Thai pilgrims preferred to take the tour bus as close to the site as they could in order to avoid what one person called boriwen sokabrok ("dirty areas"). Not one person I met at the Thai monastery had actually met a Nepali or, for that matter, a Burmese, Korean, Chinese, or other tourist; despite the tourists nearby, I was the only foreigner they had met. Of course, I did not have the same language barrier that the other groups had, but I found this lack of interaction indicative of the 
entire site. In fact, the abbot and his assistant, who had been living in Lumbini for over a year, had had almost no interaction with Buddhists from other countries or with Nepalis unless it was for official business. Christoph Cueppers, the head of the Lumbini International Research Institute, had noticed this problem ten years before and set up a joint chanting session so that every nun or monk from every nationality could participate. This event is held once a month. Even though not every monastery sends a representative every time, he says it is relatively successful and, he thinks, one of the only chances they have to interact with each other.

Lumbini is not a great melting pot of Buddhists-more like a series of distinct galleries in an ethnographic museum, each displaying images and cultural artifacts from only one culture and region. Visitors might briefly walk into these different galleries, but they simply look, take a few photographs, and leave.

The second most active site in the East Monastic Zone, it appears, is the International Gotami Nun's Temple. Although the abbotess was not in residence when I was there, and only a few nuns and laypeople were staying there, many Nepali tourists took photographs there and had snacks in their Pilgrim's Rest Cottage. Next door, the Burmese temple also had a restaurant that was popular, and a large bus group was visiting from Yangon. I was able to use my very weak Burmese language skills with a couple of people, but many could speak English, and one spoke Thai well. These Burmese visitors also said they did not visit or fully understand the activities of the other monastic and national groups at Lumbini. However, one Burmese monk said that the other Buddhists he witnessed "acted in nice and good manners." The Cambodian temple, with its one building in Angkorian style, was still under construction, surrounded by a large trash heap, and had no residents yet. Its construction had been started and abandoned many times over the last few years and no date was set on its completion. The Mahabodhi Society of India was empty when I visited. The Goenka Meditation Center was locked, but at least two monastic cells I could see were occupied. The sign in front had rusted and was falling down.

The West Monastic Zone is much larger than the East Zone. Originally, twenty-nine plots were planned, and to date, seventeen have been used. This does not mean that all seventeen have active centers or monasteries, though. The West Monastic Zone, like the East Zone, has large areas full of overgrown weeds, rough dirt paths, and undermanaged marshes. Trash is scattered visibly about, and a number of the monasteries are locked, abandoned, or barely occupied. I was told by Michael Pahlke, a German scholar of Tibetan Buddhism and a longtime resident of Lumbini, that the area is even less active during the hot and rainy seasons, where the temperature can reach above 120 degrees Fahrenheit during the day in April and 
The J apanese Sokyo monastery, a very large pagoda that was abandoned in mid-construction, Lumbini Park

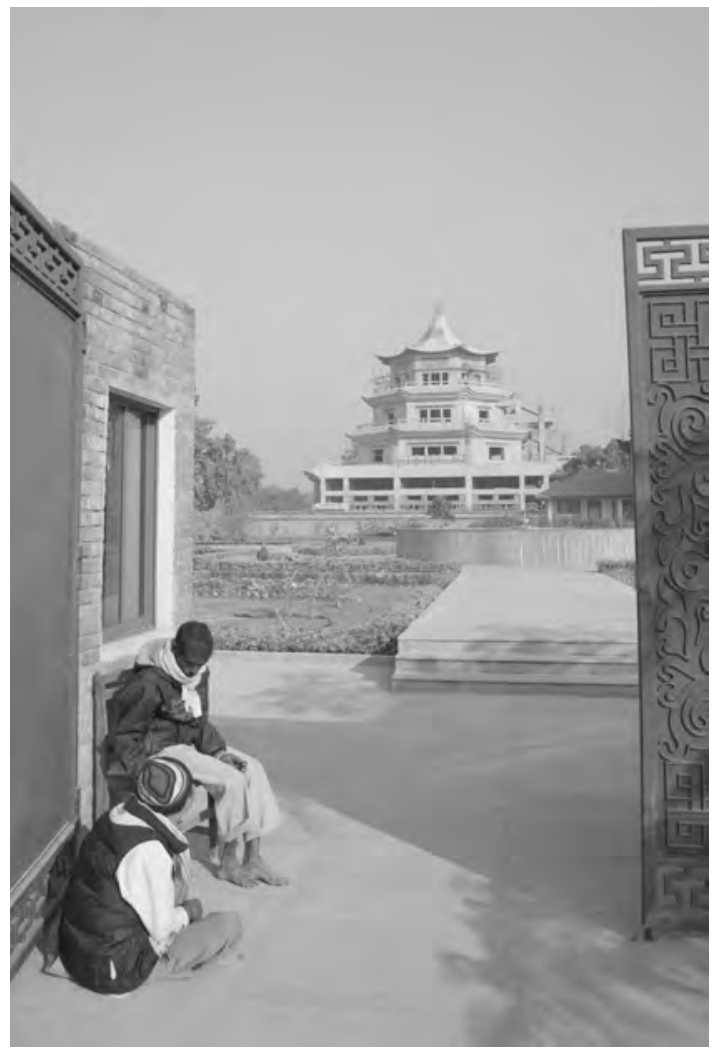

May. He also confirmed that several of the monasteries in the West Zone were unoccupied or seemed to be inactive most of the time. These include the South Korean monastery and pilgrims' house sponsored by the Chogye sect, which is only partly constructed; another South Korean monastery sponsored by the Yong Do Society, which remains unbuilt (even though it was given approval to build in 1993); the Vietnamese Phat Quoc Tu monastery, which is still under construction and not open to the public (even though it was also approved in 1993); the Japanese Sokyo monastery, a very large pagoda that was abandoned in the middle of construction and now stands like a huge empty shell near the center of the West Zone; and the FrenchVietnamese Chùa Linh Son monastery, which had its grand opening in November 2012 but was still largely empty and unstaffed when I saw it ten days after its inauguration.

The Mongolian, Bhutanese, and Russian monasteries and two of the Nepali monasteries that have been approved have never broken ground. The Zhong Hua Chinese Buddhist monastery has been completed but was not accepting visitors when I arrived. ${ }^{50}$ The German Tara Foundation's Lotus Stupa 


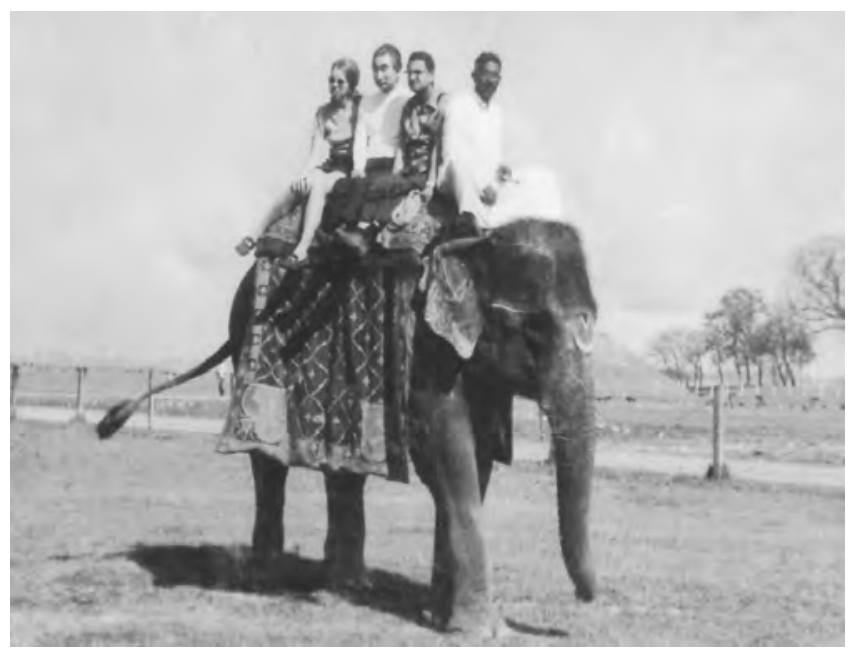

Kenzo Tange and unidentified guides visiting Lumbini in 1972

(discussed below) is complete and active. The Swiss and Austrian monastery sponsored by the Geden International Foundation is also complete. The several Nepalese-sponsored monasteries and centers are mostly run by ethnic Tibetans, Newari, or Sherpas. They are not run or occupied by ethnic groups living in the Terai region of Lumbini and appeared to be barely staffed. For example, the Nepali Manang Sewa Samaj is complete and has a large and beautiful stupa (Tibetan: chörten) mimicking the design of the famous Swayambunath Stupa in Kathmandu. Although there were no visitors and only one resident when I visited, it certainly seemed like an active center. I was told that many Tibetan Buddhist novice children, most born in Nepal, study there, and I certainly saw many Tibetan novices in the town of Lumbini and around the central link.

The Drubgyud Chöling Gompa was finished in 2001, mostly funded by Tibetan and Nepali Buddhist enthusiasts from Singapore, and has many students in residence. The Nepalese Buddhist monastery (Nepal Vajrayān Mahāvihār) has barely started construction and has only bamboo scaffolding. The Tibetan-Nepali Karma Samtenling monastery is complete and has a lovely garden and grounds. Unfortunately (perhaps fortunately for meditators), it does not get many visitors because it is at the end of a long dead-end dirt road. The Burmese Panditarama International Vipassana Meditation Centre is a Theravada center but is in the West Monastic Zone. It is closed to the public but is open for visiting meditators who make arrangements to stay there on retreat.

Each monastery is in charge of maintaining its own grounds, and although some, like the German Tara Great Lotus Stupa and the Chinese monastery, are immaculate, the grounds around many others are unkempt, 
unfinished, or abandoned. Weeds and trash abound. Mostly Nepali teens play on their cell phones, listen to loud portable radios, and run around laughing and taking photos of each other while pilgrims from Japan, Korea, China, Thailand, Burma, and other places try to avoid them. Even though the entire central part of the site, including all the monastic plots, is three miles long and one mile wide, it still feels quite empty. If not for the Nepali tourists who come to party and the horns of the buses and heavy trucks blaring from the main road running through town, it would be a peaceful place. Indeed, during the rainy and hot seasons, I was assured, it was.

Neither Tange's plan nor the Lumbini Development Trust (LDT) (discussed below) can be blamed for the success or failure of these monasteries and centers. Indeed, as mentioned in the introduction, "success" and "failure" are subjective judgments, and people define them in different ways. Of course, no matter how you look at it, the abandoned and never-completed monasteries are failures. The residents of the meditation centers probably prefer the quiet. The large ritual centers would certainly prefer better attendance, and every person I met complained about the local bureaucracy, the poorly maintained grounds, and the lack of basic infrastructure. Moreover, these monasteries and meditation centers at Lumbini are privately run and dictate their own policies with little interference from the LDT. Their finances and management are their own problem and not related to Tange's design.

The fact that the directors and visitors of the various monasteries do not interact cannot be fully blamed on Tange either. He may have had an antiquated understanding of the spurious divisions between the "Theravada" and "Mahayana" lineages of Buddhism, but the design of the place forces the monasteries' residents to be in close proximity to each other. Tange had traveled much more in Europe and the states than in Asia. He knew little of the cultural and linguistic barriers between the Burmese and Thai or the Sherpas and the Chinese. He wanted the master plan to create harmony, but history, language, economics, culture, and human nature got in the way. The groups, despite living close to each other, barely interact, and Lumbini, a grand experiment in bringing Buddhists from all over the world together, has been a nearly unmitigated ecumenical failure.

I have related some of my impressions of Lumbini, and we will later return to information I gathered through interviews. Now, it is best to turn back to Tange.

\section{A Burmese Politician and a Japanese Architect Attempt to Build a Buddhist Park in Nepal}

Is Lumbini today what Kenzo Tange had envisioned? Two months before I was born in 1972, and forty years before I finally visited, Kenzo Tange was getting his photograph taken on an elephant in Lumbini. He had been chosen by a 
team at the United Nations to design the master plan for the Buddhist park at Lumbini. Tange did not spend much time on-site, as there was not much to see. Lumbini was a relatively sparsely populated set of agricultural villages with no major access road from either India to the south or Kathmandu to the north. It sat in a dry, hot, and relatively featureless plain, surrounded by fields and very few trees, with no major industries and, for outsiders, no established hotels or guesthouses. It was off Nepal's already weak electricity grid, in the middle of a malarial zone, and had no plumbing system, reliable water supply, major schools, hospital, or airport. Much of the year, Lumbini was (and is) unbearably hot. Photographed on the back of the elephant, Tange is barely smiling; it is difficult to tell if he was happy to be there. Of the hundreds of photographs of Tange taken over the years, all of his smiles seem reluctant, as if he does not want to offend the person holding the camera but also cannot either harness a modicum of joy or muster enough energy to be angry.

We can imagine that he must have been a bit overwhelmed at the magnitude of the task he had been assigned. He was designated by the United Nations secretary-general himself after being approved by representatives from fifteen nations to create a place for millions of potential Buddhist pilgrims. He was assigned with designing and monumentalizing the birthplace of the Buddha, the founder of the religion of his parents. He must have seen this as a slightly more significant assignment than building a hotel or an apartment complex. He was chosen, however, not for his legacy of designing urban spaces and residential housing, but because of his monument to Hiroshima. Secretary-General U Thant, a practicing Buddhist from Burma, had visited

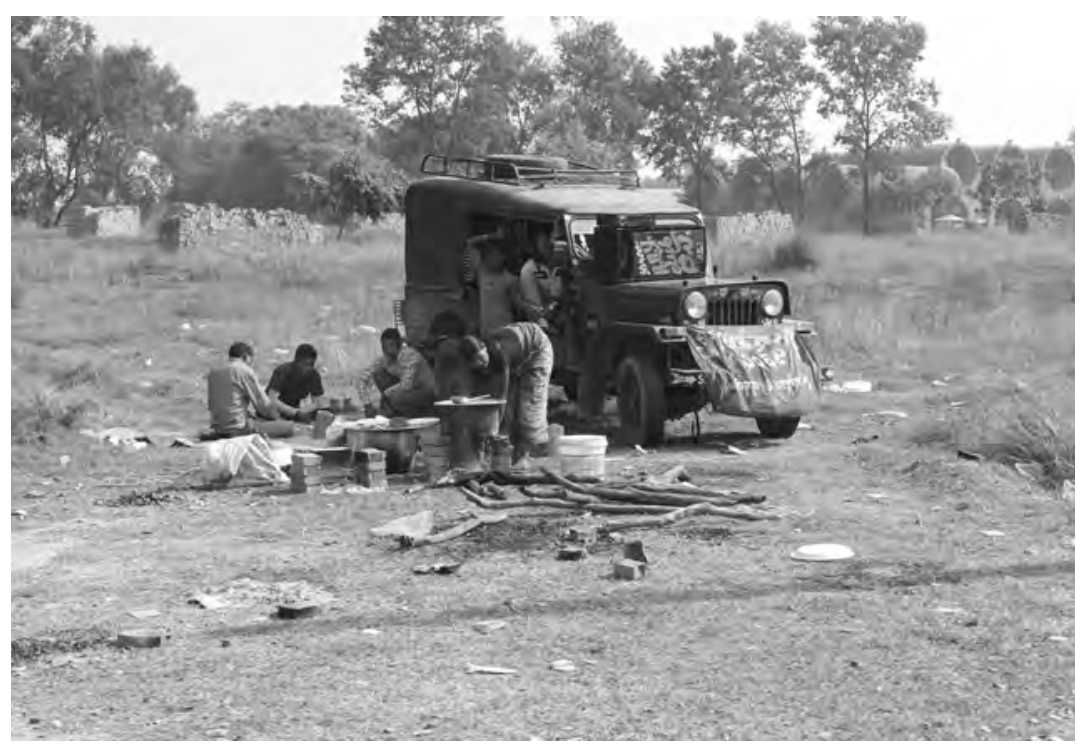

Personal cars and a mixture of buses bring local Nepali tourists to Lumbini 
Lumbini himself in the middle of the hottest part of the year-April 1967. He was deeply disappointed that the birthplace of the Buddha was being largely ignored by the government of Nepal. (Mahendra, the king of Nepal, had visited the site in 1956 for the Buddhist twenty-five-hundred-year jubilee, but had not returned and had committed no funds to the site.) Nepal, the only "Hindu Kingdom" in the world, was not known for being a difficult place to be a Buddhist. Indeed, some of the most visited and honored sites in Nepal are the great Buddhist monasteries at Bouddhanath and Swayambhunath in Kathmandu. However, these sites served largely tourists and the Tibetan and Newari Buddhist populations. The dusty Terai plain where Lumbini is located was populated mostly by the non-Buddhist Taru ethnic group and ethnic Indian Muslims and Hindus from Bihar. These impoverished communities could barely afford to build Hindu or Islamic shrines; it is not surprising that they had not built monuments to the Buddha, even though they farmed on the same land that the Buddha's family had lived on twenty-five hundred years before.

Until U Thant came along, there had not been much pressure on previous monarchs of Nepal to pay attention to Lumbini. Before the tenth century, Lumbini had been a relatively important point along the north-south trading route, or Uttarapatha, between urban centers in present-day North India, like Sravasti to Taxila in Gandhara. ${ }^{51}$ However, it never grew into a major urban center and was bypassed by most traders and settlers. Besides famous visits to important Buddhist historical sites by Chinese travelers such as Seng Zai in the fourth century CE, Faxian and Yuanjiang in the fifth century, and Xaanzang in the seventh century, most Buddhists in Sri Lanka, India, Siam, Burma, China, Tibet, J apan, and the like did not leave records of visits until the late nineteenth and twentieth centuries. ${ }^{52}$

The birthplace of the Buddha was simply not a major destination for Buddhists, and combined with the difficult access, harsh climate, disease, and lack of accommodation, it was largely ignored for most of Buddhist history. Even scholars had limited knowledge of this supposedly important historical site. Interest in Bodh Gaya (North India) - the supposed location of the Buddha's awakening - in the late nineteenth century by foreign scholars and lay Buddhist enthusiasts like Henry Steel Olcott and Angrika Dharmapala, did not necessarily lead to more interest in Lumbini. Furthermore, in the nineteenth century, Nepal's government restricted access to archaeological teams. It was not until 1893 that archaeologists began to be excited about Nepal, when J askaram Singh announced that he had seen an inscription supposedly commissioned by King Aśoka in the third century BCE in Lumbini. The inscription was visited by Anton Führer, and another archaeological team led by Babu Purna Chandra Mukherji a few years later, and, based on records of other Aśokan inscriptions and archaeological remains, Lumbini was determined to be the birthplace of the Buddha. ${ }^{53}$ It was not until 1956 that the royal 
family of Nepal acknowledged the importance of the site. However, it was not promoted in tourist guides to Nepal until well after that date. For example, the royal family produced a tourist guide to their country in 1959; Lumbini is not mentioned at all. ${ }^{54}$ King Birendra Bir Bikram Shah Dev, who succeeded his father in 1972 just as Tange was beginning his work, did not support the development of the site in any significant way. He certainly did not stand in the way, but committed very little funding. Rampant rumors of excessive graft and corruption abound, though, and certainly many government officials gladly took their cut of funds from the United Nations to develop the site.

Only after Tange's design started to be implemented in Lumbini did it begin to be considered a possible place of pilgrimage by Buddhists throughout the world, and it was not until the early 1980s that it started to receive a regular stream of international visitors and pilgrims. This was good timing, as Nepal was developing a road system (although it is still one of the least developed transportation and road systems in the world) and becoming more than just a place for bohemian or hippy tourists traveling on the Kabul, Delhi, Kathmandu, Bangkok circuit in the late 1960s and early 1970s. Lumbini grew, as Nepal grew into a more feasible destination for international tourists, and foreign aid and volunteer organizations like the Peace Corps began establishing long-term programs throughout the country.

In order to receive large numbers of visitors, Lumbini had to become something more than it was. U Thant had a three-member UN team, led by the J apanese scholar Susumu Kobe, make an initial assessment of the site in 1968. ${ }^{55}$ Then in 1970, he established a committee of representatives from thirteen nations (two more were added later), charged with choosing an architect, developing a funding source, and overseeing the initial plan before handing it over to a development trust under the government of Nepal. This committee comprised representatives primarily from South Asian countries like Afghanistan, Sri Lanka, India, and Pakistan, as well as regional, mostly Buddhist, nations like Cambodia, Bhutan, Laos, Thailand, Burma, Singapore, and South Korea, among others. ${ }^{56}$ Choosing an architect to design a monument and pilgrimage center for Lumbini was their first task-a difficult one, since they were not improving a known pilgrimage center, but creating one.

UN documents contain some telling statements that might have given Tange some pause. ${ }^{57} \mathrm{R}$. K. Basu, a member of the UN team report notes the lack of water and the lack of visible monuments, accommodations, and so on. Then it states, "Lumbini presents the architect with a formidable challenge. Almost nothing exists today. Even the Sal trees have retreated. Everything has to be created there, and created in such a way to reveal the universality of the Buddha's message and its significance to the modern world."58 An earlier report by Allchin and Matsushita in 1969 contains a similar warning when speaking directly about trying to choose an architect: 
The Lumbini project . . raises a peculiar challenge. The successful design must incorporate in itself something of the spirit of Buddhism, including its international and universal aspects. And yet, it must be firmly rooted in the soil of the Nepal Tarai [Terai], and be interlocked with the local countryside and population, and with its regional development. The subject matter, it appears to us, is in some ways, very difficult to clarify. For all these reasons, the choice of an architect or planner is peculiarly important. Whoever is selected, must be able to form a very strong concept of the intangible aspects of the project, so that the design as a whole will realize them in creative form. Our experience suggests that an open competition is sometimes not the best way of choosing an architect, particularly in circumstances such as these. We answer that there are two preferable solutions, either to hold a limited competition, or to select a principle architect of high reputation and to associate with him a number of juniors, chosen internationally, as far as possible. ${ }^{59}$

They chose the second path, as Tange was chosen by UThant and the committee without a competition or the submission of competing designs. Tange certainly was an architect of "high reputation," but, besides being Asian and born into a Buddhist family, there was little reason to think he could incorporate the "spirit of Buddhism" (whatever they thought that was exactly) into the design or understand the "local countryside and population." Tange had never traveled in Nepal or South Asia, had never studied Buddhist history seriously, had never gone on a Buddhist pilgrimage as far as I have been able to determine, and did not actively practice Buddhism. He did not have any experience working on religious sites up to that point and had built, although successfully, only one memorial site, Hiroshima. Furthermore, in the late 1960s and early 1970s, Tange had focused his energy primarily on mass urban design and high-density transportation, industrial, and residential design. These skills and interests were of little use in rural Nepal. According to his written records, his autobiography, an interview with his daughter-in-law, and his design firm's self-promotion, he rarely talked about Lumbini, used it as an example, or even listed it as one of his major commissions. Even Tange's biographers either did not know about his work on the site or chose to ignore it because it never was completed and Tange himself seemed to care little for it. Tange's family also had nearly no record of his work on the site and do not remember him discussing it much; they sent me all their materials on the site in Japanese and English, and it did not amount to much. Tange might have been honored to have been chosen by the United Nations and the first Asian 
secretary-general of the international body, but he soon realized that working in Nepal would not be easy and that his vision did not match the site.

Takefumi Kurose, an assistant professor at the Urban Design Lab of the University of Tokyo, and Professor Yukio Nishimura, director general of the Research Center for Advanced Science and Technology at the University of Tokyo - and one of Kenzo Tange's collaborators on the Lumbini project and adviser to UNESCO today-were very helpful in my research. They confirmed that Kenzo Tange had no formal training in Buddhist history, architecture, or art, and had not studied the history of Nepal extensively. They noted, however, that Sadao Watanabe, another planner for the Lumbini project, informed them that Tange, after getting the Lumbini commission, consulted with Buddhist studies scholar Hajime Nakamura. Tange's family and colleagues had no record of what Nakamura told Tange, and the two did not have a sustained working relationship. Since Tange had never designed a Buddhist site before, he wanted to get some basic information about the history of the religion from Professor Nakamura. Kurose and Nakamura believe that it was not only Tange's building of the Hiroshima monument that might have brought him to the attention of U Thant, but also his work in 1965 and 1966 designing a major urban planning project in Skopje, Macedonia, sponsored by the United Nations Development Programme (UNDP). Lumbini was organizing administratively in similar ways at the UN as Skopje. Therefore, the same UN administrators would have been in communication with each other.

Professor Kurose emphasized that Tange was indeed frustrated working on the Lumbini project, because it was supposed to be finished in 1985 and was not even close to being complete then, even though the planning had started between 1969 and 1972. Kurose says there is no evidence that Tange visited Lumbini more than once, but he could not confirm that from internal records. Also, no surviving documents record, and he and Professor Nishimura had no recollection of, conversations with Tange about any Buddhist teaching, artwork, or style of architecture that had particularly influenced his design for Lumbini. The only evidence they found connecting Buddhist inspiration to the design was a 1970 brochure made by the UN Committee for the Development of Lumbini, which stated that

Everything has to be created there, and created in such a way as to reveal the universality of Buddha's message and its significance in the modem world as well as to express the early life of Buddha and the events leading up to the Great Renunciation. ... The whole design should be animated by a strong and clear-cut concept devoid of any narrow sectarian bias. It should, in fact, express the spirit of the host country of Nepal, whose population embraces 
both the Hindu and Buddhist faiths, living together in harmony. . . . The essence of the design should be to create an atmosphere of tranquility, universality and clarity consistent with the idea of the birth of Buddha. All planting and landscaping would reflect this aim and all structures would have to be built to highest standards of design.

This vague statement obviously does not reveal much about the influence of specific Buddhist or Hindu teachings, but does show at least some recognition of the needs of the local Nepali population. Finally, when I asked Kurose and Nishimura about Tange's religious life, the response was similar to those of others who knew him. Kurose stated, “I don't know much about his daily life. One fact is that, he designed one of the most important Catholic churches in Tokyo and was planning project in Muna near Makkah. I don't think he was a very religious person in his life. However, he studied cultural, religious and rural background carefully, especially when he had a project outside of Japan." 60

The project seemed to start off well, though. Under U Thant, the UN promised to commit up to one million US dollars (USD). Phase I of the master plan for the site was approved by 1973, and funding from the United Nations Development Programme flowed in. In 1973, 54,000 USD was provided to Tange's URTEC firm. By 1978, over 764,000 USD was requested by the UN for Tange to complete the design for phases II and III. The estimate for the implementation of the master plan was 5.6 million USD, which included building the "sacred garden" around the tree where the Buddha was born, preparing the land for over forty future monastic compounds, and developing the reserved "green areas" and a "pilgrim's village," which was supposed to includea policestation, tourist shops, health center, accommodations ranging from luxury to "pilgrim class," and a tourist office (which, as we will see below, was never completed), as well as installing plumbing, electricity, and an access road connecting Lumbini with the much larger town of Bhairawa about twenty kilometers away. The costs of developing the Bhairawa airport and building local schools, a museum, and a research center were not included in this estimate. The cost of building between forty and fifty monastic buildings by private Buddhist sects was estimated at around twenty million USD. This, of course, would bring much employment and liquid cash into the region. The design also included a "buffer zone" and tree planting to separate the park from industry, major commerce, and residential settlements.

While U Thant was still in office, until 1971, there was a flurry of activity planning Lumbini. The assessment of the three-member team and a separate on- site assessment by a UN team were very thorough. ${ }^{61}$ Issues of elec- 
tricity and water supply and the costs of bus and air travel were taken into serious consideration. Dozens of interviews and meetings with experts and important officials from Sri Lanka, India, Japan, Germany, and many other places were conducted, including with members of Nepal's finance, planning, and foreign ministries and ministers of tourism and economics from India, Thailand, Germany, and J apan. Ambassadors from many different nations sent letters of support and promised to help raise funds. The king and prime minister of Thailand pledged their support for the project. ${ }^{62}$ Students from Drew University were offered as interns for the project, and the Sri Lankan government made several requests to be a part of the design team and offered technical assistance and management from J ustin Samarasekara, an architect from Sri Lanka. ${ }^{63}$ A series of meetings was held in Kathmandu, New Delhi, Tokyo, and New York.

The UN did their due diligence, and their assessments were not particularly optimistic. They predicted many problems, and when Tange's firm was chosen, they provided him with a thorough set of recommendations and warnings. These problems included the lack of access for tourists, the lack of trained staff in Nepal, the lack of funds provided by foreign donors and the Nepali government, and a general lack of "initiative from Nepal." The assessment noted that the government of Nepal was not taking the lead in the plans and that meetings with government officials had been "more formalistic, only reporting minor activities." 64 Consistent assurances from the government of Nepal reiterated that tasks would be completed, but the UN internal reports indicate a general level of mistrust. Members of the UN team also stated clearly that they would not support the project unless it was part of a larger development of the region's infrastructure, education, health, and political transparency. They emphasized that their vision for Lumbini included two main elements. First, they wanted to promote the development of this region of twenty-five hundred square miles and five hundred thousand inhabitants: they wanted the government of Nepal, with their assistance, to ensure that agriculture, forestry, and agro-economic industries would be supported in order to not only make Lumbini accessible to tourists, but also develop the region and not allow income from tourism and pilgrimages to be held completely in foreign hands. Second, they wanted to develop the much smaller park and monument for pilgrims and tourists. The funding for both was largely envisioned as coming from private donations and income from foreign visitors. However, it was noted that the government of Nepal had not made "any serious effort" toward, or given details of, providing financial support. They did commit to providing the small sum of 10,000 USD to set up an advisory office that would be charged as an overhead cost in their fund-raising activities. They also agreed to cooperate with members of the government of India. R. K. Basu's UN report of October 5, 1971, states that the observer "got the impression 
that the Government [of Nepal] now realizes that the Lumbini project should not be considered only a religious project but the justification for economic and social improvement of the region and overall tourism benefit would warrant a strong support including maximum financial outlay from the countries' own resources." ${ }^{\prime 65}$ This support never seriously came. Indu Nepal, writing in the Nepali Times, interviewed many people in Lumbini who complained that the tourists really do not add any economic benefit to the region, that the people of the region "remain mired in poverty," and that

Lumbini, the birthplace of Gautama Buddha, is a study in contrasts. Inside the three-mile by one-mile compound are a cluster of newly built monasteries ranging in style from Thai wats to Manange stupas. This is a part of an ambitious plan outlined by J apanese architect Kenzo Tange in 1978 to transform Lumbini into an international pilgrimage and tourism centre. ... The result is a mix between a giant construction site and Disneyland. This massive endeavour seems to have brought meagre benefits to the locals who live in the periphery of the compound in mud huts, toiling on fields for landlords. The construction itself is 14 years behind schedule, and the villagers who were displaced at the time are increasingly frustrated. . . . [Tourists] rent cars in India, use their own guides, stop over for a few hours and return to hotels in India. . . . "Getting them to extend their visit is our biggest challenge."66

Tange himself immediately ran into problems. The same UN report prepared by R. K. Basu states that Tange "has been the centre of all actions in trying to enlist government and non-government support for the project. He has, however, found considerable difficulty particularly in the Ministry of Foreign Affairs. J unior officers in the Ministry have advised the higher authorities that this is not an economic development project but one that has been promoted because of a personal interest of the Secretary general, U Thant. . . . I felt that there was stubborn resistance to recognizing any economic value of this project and it may be necessary to deal with this matter at a higher political level." In order to raise the 5.6 million USD needed to complete the project, Tange tried to raise funds in J apan from private and public donors. However, these donors, Tange reported, were reluctant to give funds if they did not have some control over where the money went. Tange and the donors, of course, knew that many of the donations would not reach Lumbini and would end up in the pockets of Nepali government officials. Tange's report also notes that the government of J apan was growing weary of this project and the lack of support by the government of Nepal. The Department of Tourism in India wanted to help Nepal in this project, but had trouble raising funds themselves because of lack of public support in India for Buddhist tourist projects. ${ }^{67}$ 
The decision was made to concentrate on raising private funds for the project outside Nepal, in the United States, Japan, and Thailand. The advisory committee sent appeal letters to fifty major philanthropic institutions, but the response was "not satisfactory," and they considered hiring a professional public relations firm. They also felt that institutions and individuals were not donating because they did not know enough about Buddhist history. ${ }^{68}$ In 1971, UN Chef de Cabinet G. V. Narasimhan drafted a letter to David Cowell of Drew University about his efforts to raise funds. He stated that the "American people, by and large, are generous and dedicated to charitable causes. . . . However, unlike Japan and Thailand, most people in the United States do not know much about Gotama Buddha and his teachings. When they contribute, they have a right to know what they are contributing for. It is for this reason that we could in some degree acquaint the American people about the Lumbini project by way of speaking engagements. Such questions as: What subject did the Buddha Teach? What is the basic message of Buddha-dhamma? .. . What is nibbana (nirvana)? .. . What were the Buddha's last instructions?"69

These efforts did help a little, and during the 1970s, funds were raised, ground was broken, and facilities started to be built. A 1980 Lumbini Development project report, written by the government of Nepal and introduced by King Birendra, states that the Bhairawa Road was completed, conservation work on archaeological remnants was undertaken, trees were planted, and some (temporary) electricity had been provided. There was also a tourist information center built in Bhairawa. The water supply was not complete, drainage was not fixed, and hotels, schools, and other buildings were not even at the design phase. They had raised funds, though. The Lumbini Development Committee received 377,467 USD from various private and public donors. The New York Office for Lumbini Development had received 16,668 USD. However, it was the Reiyukai Buddhist sect of J apan that raised the most funds by far-1.7 million USD to build Tange's vision for the cultural center, library auditorium, and museum. ${ }^{70}$ The local contribution in Nepal, a severely impoverished country in comparison with J apan, Thailand, and many other Asian nations, contributed only 7,968 USD.

Conspicuously absent in the late 1970s and throughout the 1980s and 1990s was activity and involvement from Tange. His master plan was approved by the UN and the royal government of Nepal in 1978 and was scheduled for completion in 1985. As of 2012, it is still not complete, and Tange died disconnected from the project and its outcomes, although the UN and Lumbini Development Trust websites, officials, and documents consistently refer to him. ${ }^{71}$ The UN has maintained a relatively low level of engagement. Kurt Waldhiem and J avier Pérez de Cuéllar each visited the site once during their tenures as general secretaries. ${ }^{72}$ The UNDP contributed a total of 1,805,916 USD for the design and implementation of the master plan; the last contribution 
was made in 1988. Today the site is supported by private donations to the individual monastic compounds, entrance fees, and donations to the Lumbini Development Trust, which was formed in 1985 when Tange discontinued working on the site. ${ }^{73}$ After 2010, more formal support from the J apanese government has come through the Japanese Funds-in-Trust (J FIT), which operates in connection to UNESCO's Kathmandu office. ${ }^{74}$ The J FIT is focused primarily on archaeological preservation and not on the development of the larger site, town, or region. The International Scientific Steering Committee (ISSC), which includes representatives from various Nepali ministries, UNESCO, and the government of J apan, oversees this archaeological work. ${ }^{75}$ A few general meetings have been held at the UN or in Lumbini itself about the site; however, in J uly 2012, the committee met and recommitted to finishing Tange's master plan, as well as exploring the possibility of expanding its work into other regional sites of historical importance. One member of the ISSC, Yukio Nishimura, has been particularly active. He was a student of Tange, a city planner in Tokyo, and has succeeded Tange as a professor at the University of Tokyo. Now in his early sixties, he is reviewing Tange's plan and advising people on the ground in Lumbini. ${ }^{76}$

Tange certainly lost interest in the project after 1978 and almost completely after 1985. Though slated for completion by 1985, the site was less than 10 percent constructed by that time. By 2001, less than 20 percent had been completed. Tange must have been frustrated, and he clearly knew that the project would not be completed in his lifetime. Tange is not solely to blame; no architect ever works alone. Nevertheless I, like other scholars of architecture who enjoy writing biographies of famous architects, am also perhaps contributing to the myth of the lone visionary. Tange liked working with others, though, and readily acknowledged his influences and collaborators. ${ }^{77}$ The actual drawings of the initial master plan were done not by Tange, but by Kazuyuki Matsushita. The contributions of assistants and consultants did not change the fact that Tange did not know much about Buddhist archaeology, art history, or architecture; most of his assistants did not either. He designed Lumbini as he would design other sites-there was nothing particularly Buddhist about it. Despite this, several descriptions of the master plan refer to the eternal Buddhist message of peace that the gardens of the master plan represent. Others wax eloquent on the spiritual nature of the park. For example, one visitor, Augusto Villalon, wrote that Tange's design was "central to spiritual experience" and should be appreciated for the way it invokes the sublime aspects of Buddhism. He writes,

The walkway is central to the spiritual experience elicited by the Tange plan, a subliminal and unexpected experience open to all but, as experiences go, unnoticed by many. . . . The journey, done 
on foot, which begins at New Lumbini Center through the Monastic Zone leading to the Sacred Garden, is a journey that happens on two levels. It can be a purely physical experience, a long twomile walk that gets the pilgrim from one point to another, or from the entrance to the Sacred Garden. However, the subliminal effect of this journey is what gives spiritual value to Lumbini. It is the understated, fine quality that is the core of the Lumbini experience, setting this shrine apart from all other Buddhist shrines. Public perception of architects is that they build structures, but that is only part of what they do. The success of any architect lies in the reaction elicited from people as they experience the modulation of space and light while moving through his work. In a subtle, sophisticated manner, the Tange master plan puts into motion a sequence of spaces that are revealed subtly, as pilgrims experience on foot a procession of events designed to awaken spirituality. The entire experience takes place on a mile-long, brick-paved outdoor walkway running in a straight line from New Lumbini Center to the Sacred Garden. Walking between a navigable canal and row of trees planted equidistantly from each other, the mundane drops away the farther the pilgrim walks from New Lumbini Center. The sky and trees reflect on the canal, sounds of leaves in the wind, birds and the occasional jackal howl pierce the quiet. By the time the pilgrim has walked past the monasteries and arrives at the eternal flame marking the entrance to the Sacred Garden, he has forgotten the mundane, and is at peace and ready for the Buddha. At this point, the walkway ramps down, compresses between high brick walls as if to squeeze the last of the mundane from the pilgrim's consciousness, and becomes a causeway crossing an artificial lake where at last the Sacred Garden at the center of the lake comes into view. The Sacred Garden is open to the sky, visually bound by the Himalayan foothills in the distance, serene, totally connected to the Buddhist universe, and a place of peace and unity. Tange sequences spaces along the walk, to achieve the experience of peace upon arriving at the Sacred Garden. This subliminal experience is the essence of Buddhism. This subliminal experience is misunderstood by many who feel that the Kenzo Tange master plan is irrelevant to Lumbini today, without realizing that this is an outstanding work of 20th-century architectural heritage. ${ }^{78}$

This is a beautiful reflection, and I am sure numerous visitors to Lumbini "feel" something similar when they are there reflecting on the fact that they 
are maybe walking on the same ground that the Buddha once did. I certainly felt relaxed and at ease at 5:30 a.m. as the mist covered the central canal and the sun slowly rose over the pond next to the Maya Devi Temple. However, by 7:00 a.m., the piles of trash, the blaring horns, the makeshift illegal campfires next to Nepali tour buses, and the Indian and Nepali pop music blasting from car radios and low-quality speakers had ended that feeling of peace. I did not see any more spiritual quality to this park than any other park I have been to. There was nothing particularly "Buddhist" about the pathways, canal, or poorly maintained landscaping.

Tange himself contributed to the idea that his park was somehow rooted in Buddhist teachings when he wrote that his master plan was based on Buddhist symbolism of geometric shapes and the path to enlightenment. ${ }^{79}$ According to Tange, "The form of a circle enclosing a square is a mystical universal symbol of purity and simplicity. Architecturally no built structures are to be added to the garden except the essential forms like offices, meditation cells, utility blocks and restoration of Mayadevi Temple."80 This is, to be frank, ridiculous. There is nothing particularly Buddhist about the circle enclosing the square unless one wants to make a vague connection to a Hindu or Buddhist mandala shape. Furthermore, the entire site is not a mandala; only one section could be interpreted that way. The rest is a long path with East and West Monastic Zones (which are really just practically designed plots of land used for monasteries after the design was submitted).

Tange's design is actually closer to other designs he drew for nonBuddhist places; in fact, it is close in design to his city plan for the capital of Nigeria, Abuja. His design for the city of Abuja, which was built in the 1980s and is a much more successful project in terms of completion level than Lumbini, follows the design of a long central thoroughfare with a series of squares and circles at one end, similar to the aerial view of the master plan for Lumbini. Since Abuja's central district was also designed by Tange to house the Nigerian National Mosque and the Nigerian National Christian Centre, I doubt that the Nigerian government would agree that their design was based on the Buddhist "form of a circle enclosing a square is a mystical universal symbol of purity and simplicity." Tange's design for the Tokyo Metropolitan Building includes as one of its prominent features a "citizen's plaza" next to the main walkway, nearly identical to the planned but not yet fully realized crescentshaped plaza he designed next to the main central link canal and walkway as an entrance to the "Theravada" monastic zone in Lumbini. Indeed, Tange's unrealized plans for the redesign of the city of Tokyo also have a central thoroughfare with squares and circles projecting off it, built over bodies of water (the Tokyo Bay). These ideas must have contributed to his plans for Lumbini, as he was working through them in Tokyo when he was commissioned for Lumbini by U Thant. Tange's master plan is not "Buddhist," it is Tange-ist. 


\section{The Metabolism of Nepali Teenagers and Middle Managers}

Although not much about the Lumbini master plan can be called particularly "Buddhist," and Tange might have been frustrated with the lack of progress at the site over the years, in many ways what happened at Lumbini from 1985 until the present is the perfect expression of Tange's philosophy of "metabolism" in architecture. While many who visit Lumbini might see it as a failure, and the master plan as inappropriate for the setting or the religion, it actually proves Tange's ideas about architecture and public culture correct. Let me explain.

First, if we measure the success of an architectural plan by its completion and by the reviews it gets from other architects or powerful funders and patrons, then Lumbini is a complete failure. Most of the reasons for this failure fall squarely on local politics and irresponsibility. The master plan was not particularly ambitious, and the terrain is easy to clear, but bureaucratic inefficiencies, graft, work stoppages, major changes in the $\mathrm{Ne}-$ pali government (including the Maoist insurrection and subsequent takeover, and the still-controversial and mysterious murder of nearly the entire Nepali royal family in 2001) were certainly contributing factors to the delay. More generally, labor strikes, student unrest, infrastructural inadequacies, and a massive "brain drain" of the country's best young engineers, scholars, and business people have contributed to the lack of development throughout the country despite the funds it receives from foreign remittances, aid, and tourism. ${ }^{81}$

However, most of these serious political issues have occurred from the early 1990s until the present. The early 1980s was a stable time politically and saw a major uptick in tourism. Furthermore, Japanese, European, and American travelers were eager to visit Nepal at that time. Despite these factors that would point toward success, there was never much support locally, perhaps because less than 5 percent of the population of the Terai region was Buddhist, but also because it was far from the political and economic center in Kathmandu and the main tourist sites of Pokhara and Solokumbu (Mount Everest region). Tibetan and Newari Buddhist communities are concentrated in the Kathmandu, Patan, and Bhaktapur regions, and not near Lumbini. ${ }^{82}$ Many of the workers assigned by the government to work in Lumbini did not remain there for long, as being outside Kathmandu separates them from more ambitious career tracks. Indeed, two officials I discuss below who work at Lumbini told me of their desires to leave and find other positions. ${ }^{83}$ Moreover, the UNESCO office and many other funding agencies are based in Kathmandu, which for a long time did not have easy flight connections to Lumbini, and the harsh road conditions made the trip a difficult eight hours by car. Lumbini's location also discourages Buddhist pilgrims. D. P. Dhakal 
notes that the three major Buddhist pilgrimage sites in India (Bodh Gaya, Sarnath, and Kushinagar) receive many more visitors annually. ${ }^{84}$ And although it has gotten easier, the visa process has in the past made overland entry from India difficult for many foreigners as well. ${ }^{85}$

The problems with Nepali bureaucracy and corruption have been well-documented elsewhere. ${ }^{86}$ Other problems include local resentment that seven villages and over a thousand people were forced to move from their homes to clear the way to build the sacred garden and the central link and canal, and to reserve spaces for the private monasteries, many of which have never been built. ${ }^{87}$ The jobs, water supply, and electricity many of these displaced villagers were promised have not been realized. Even the high school that was supposed to be built near the site was not completed. ${ }^{88}$ The lack of work has been compounded by the influx of ethnic Nepali refugees who were forced to leave Assam (India). The Lumbini bazaar, which used to be in the area of the sacred garden, was removed, and many shopkeepers were not able to restart their businesses elsewhere. Furthermore, as we saw above, foreign visitors often come to Lumbini by tour bus from India and stay for a few hours before returning to India, and thus do not create a wealthy clientele that would support restaurants, hotels, and shops. Many of the tourists who do stay overnight stay at their respective monasteries, bring their own food, and even produce their own souvenirs. The money from foreigners that does stay in Lumbini stays in the privately owned monasteries or goes to nonlocal, often Indian, tour companies. For example, the Thai community with whom I was able to conduct interviews has amulets made in Thailand that they give to Thai visitors. They have over two hundred beds where Thai pilgrims can stay for free (most offer donations) and they operate their own library and supply their own meals. Today, Thai pilgrims are one of the largest groups that visit Lumbini annually, but other ethnic groups also stay together and do not contribute much to the local economy.

As CK Lal, in his 2002 article, "The Prince of Peace," for the Nepali Times writes, "The fascination of the Nepali power elite with the Buddha and his birthplace is on display in the excesses of the Lumbini Development Trust, where a new set of bosses takes over after every change of government. . . . Besides the usual accusations of cronyism and nepotism that continue to undermine the efficiency of the Trust, the rapid turnover of its key personnel in the last twelve years has also been a factor in its stagnation. A growing discontent is also festering amongst the locals that development works are confined within the walls of the Master Plan, and that they have not received a share from the developments being undertaken, resulting in a lack of emotional attachment. There is no doubt that long term conservation of Lumbini and its sustainable development can be achieved only by considering the economic empowerment of the communities living in its immediate surround- 
ings.” Rachana Pathak, in a highly critical article in 1995, called Lumbini a "Disneyland" and decried the irresponsible archaeology, graft, and Tange's plan. Healso speaks extensively about how managers and donors from South Korea, J apan, and other places ignore the rules and build whatever they like. Helaments Buddhist commercialism, but ends his article with a self-reflective "U Thant would still weep today, and Nepalis have to blame only themselves."89 Furthermore, according to Maksood Ali, head of the Visit Nepali Year 2012 campaign, most foreign visitors to Lumbini do not return. They make their pilgrimage, take their photographs, make offerings, and leave. There is not much to see at the site (all the monuments and archaeological sites can be seen leisurely in a few hours, or less if you hire a rickshaw). The museum is largely empty, with many items already stolen. There are not many things to buy, and the souvenirs sold at Lumbini are largely identical to those sold in souvenir shops in Kathmandu, Bodh Gaya, Sarnath, and the like. Unless a person is an archaeologist or a serious practitioner who wants to spend time meditating and chanting at the site (which is a small group), there is no reason to return. The idea of visiting the birthplace of the Buddha attracts Buddhists, but Lumbini, as a place, does not attract them back. Buddhists, unlike Muslims, have no real religious requirement to make pilgrimages to the places their founder lived and taught. Most Buddhist will never visit Lumbini, and those that do will probably go only once. But there is more than one way to measure success.

If we measure the success of an architectural space by how it allows change and flexibility and fits its local environment, then Lumbini is a success.

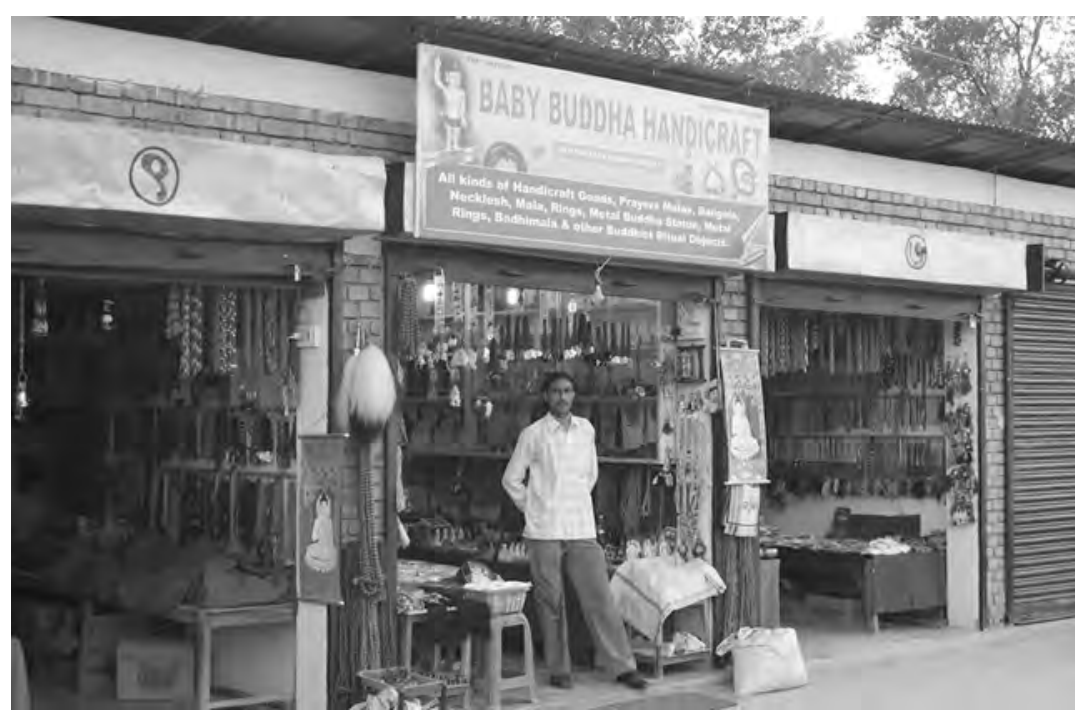

Shops selling largely Chinese-made Buddhist-themed gifts and Indian jewelry, many owned by Nepali Muslims, Lumbini Park 
The site may not be complete, and foreign Buddhists might not flock to it, but it is very attractive to Buddhist and non-Buddhist Nepali and Indian tourists. Although the UN stated that it would focus on attracting donors and visitors from the United States, J apan, and Thailand, they did not account for the excitement the master plan would create for regional and domestic tourists. As described above, the local families, teenagers, young adults, newly married or honeymooning couples, and families from North India who visit Lumbini far outnumber the foreign pilgrims and tourists. Thai, Burmese, Japanese, and, increasingly, Chinese, Vietnamese, and Korean tourists and pilgrims arrive in large buses, stay for a few hours or one night, and leave. They stay in their own monasteries or in the Japanese-managed Hokke or Kasai hotels. While individual backpackers do visit Lumbini, they are of a limited number. The local tourists arrive in private cars or motorcycles or on inexpensive local tour buses. They stay for the whole day (usually on the weekends) and return at night. Since the vast majority of these local tourists are not Buddhist, they visit the site, many told me, because it is a rare open and public space where they can have picnics, stroll freely (often away from their parents and grandparents), eat free meals at different monasteries, watch tourists or foreign Buddhist monks and nuns in their strange clothes, flirt, and, most importantly, pose for photos in front of large and foreign pieces of architecture such as the impressive Royal Thai Monastery and gardens; the Mahabodhi Center; the Myanmar Golden Temple; the International Nun's Temple (which has a "pilgrim's rest house" and a nice sculpture garden and pond to sit around and enjoy cool drinks); the Manang Sewa Samaj Stupa, with its golden stupa that rivals the great stupa of Swayambunath; the World Peace Pagoda; the Greek Revivalist style Mother Temple of the Graduated Path to Enlightenment, built by the Rabten Foundation of Switzerland; Karma Samtenling monastery; Drubgyud Choeling monastery; and what seemed to me to be the most popular temple at Lumbini, the Great Drigung Kagyud Lotus Stupa, which is directed by the German-born Ferdinand Stange and sponsored by the Tara Foundation of Germany. ${ }^{90}$

The well-maintained gardens, sculptures, fountain, and beautifully painted murals and images at the impressive Great Drigung Kagyud Lotus Stupa aren't like anything else seen in Nepal or North India. The colors, the flowers, and the lack of motorcycles and trash are all very noticeable. Hundreds of Nepali and Indian couples, teenage school groups, families, and close friends on weekend trips take turns posing for photographs in front of the stupa and the gardens. I was recruited as a photographer one morning to snap dozens of photographs for people - at one point, a group laughed at me because I had seventeen cameras dangling from my arms and neck. Each time I would be given someone's camera to take a photo, several more people would hand me theirs. Then I was asked to pose in photographs with lots of children. While 


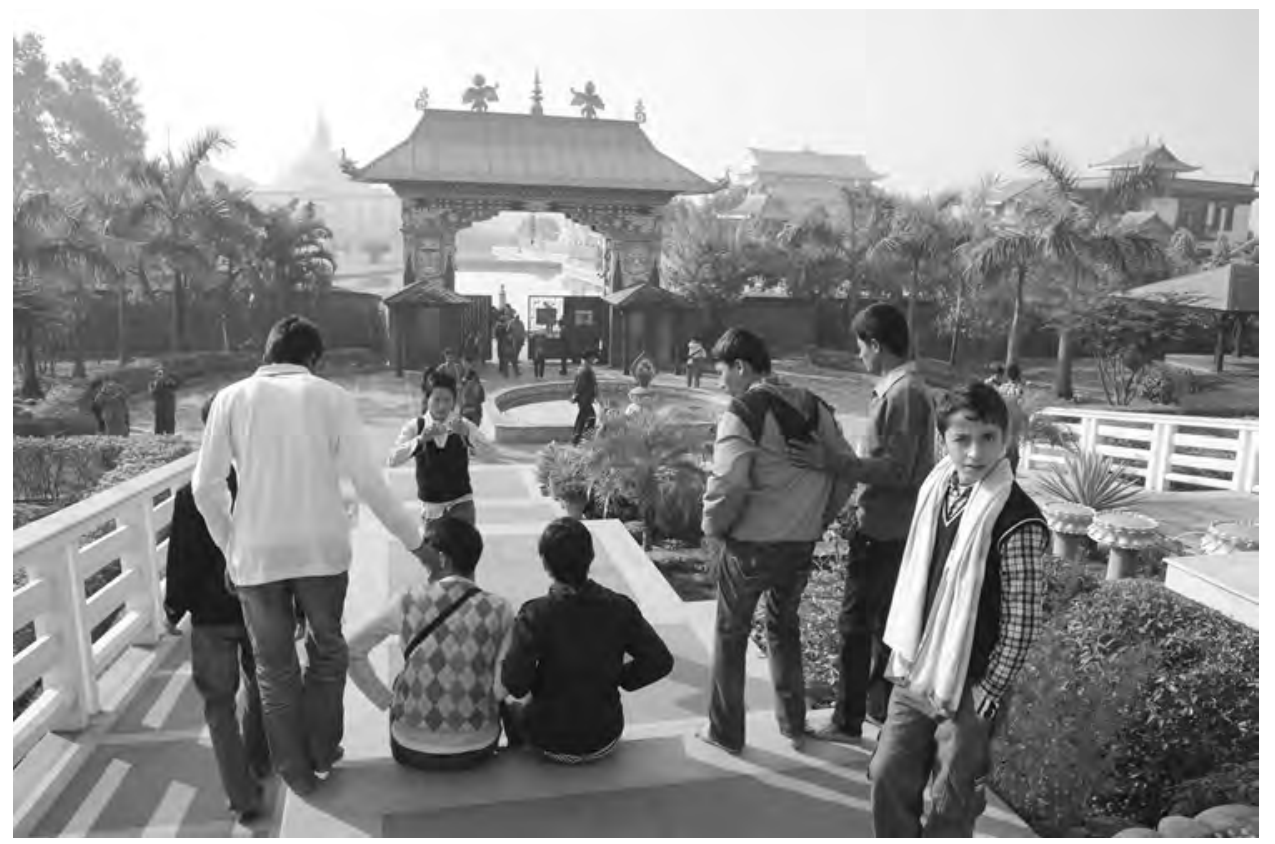

Nepali teens taking photographs outside the German Tara Foundation's Lotus Stupa, Lumbini Park

taking and posing for photos, I casually interviewed as many people as I could; not one was from a Buddhist family and not one cared about or seemed to even know what lineage or teaching of Buddhism the Great Lotus Stupa represented. Even monasteries at Lumbini that are abandoned, unoccupied, or unfinished-which is more than half of them, like the locked Vietnam Lumbini Buddha Bhumi Vihar; the newly finished but still largely empty and unstaffed Linh Son Buddhist monastery (sponsored by a French-Vietnamese group); the abandoned shell of the Sokyo monastery; or the unfinished Korean Mahabodhi Society monastery-provide good backdrops for photographs. The Japanese, Korean, and Vietnamese architecture is unknown anywhere else in Nepal and North India. Its popularity among locals can be compared with the attraction generated by exhibitions of foreign cultures at world's fairs and world expositions in North America, Japan, and Europe, places like the Pitt Rivers Museum in Oxford, the Ethnologisches Museum in Berlin, or even the World Showcase part of the Epcot theme park at Disney World in Florida. Lumbini is the only place in Nepal that a local tourist can experience firsthand the art and architecture of many different cultures in one place, and this display of world architecture has been one of its major attractions. While Buddhist pilgrims are concerned with seeing the spot where the founder of their religion was born, local tourists are interested in seeing the 
Buddhists who have come on pilgrimage, and taking photographs in front of their monasteries. The teaching or books inside are not important for nonBuddhist local tourists because they are in foreign languages.

Local tourists may not be meditating, chanting, circumambulating the stupas, or reading religious material in Thai, Korean, Vietnamese, or Burmese, but they enjoy visiting Lumbini because it is largely free, has foreign and visually impressive buildings, and it is public, so you can dance, play music, picnic, shop, and run around making noise away from disapproving mothers, aunts, or grandparents. Visitors can pose for photographs, exchange flirtatious glances, and chat with or gawk at foreigners. Stands sell soft drinks and chips. Indeed, most of the Buddhist souvenir stands appear to sell a lot more non-Buddhist themed jewelry, stickers, hats, and toys to Nepali and Indian tourists than to Buddhist pilgrims. Regular television reception and Internet connections are becoming more widely available throughout Nepal, but inexpensive vacation and public leisure spaces are relatively rare in the Terai and North India. Lumbini is an easy and cheap vacation if one lives within relatively close driving distance. The Buddhist monastic zones have become attractions for lay non-Buddhists. Tange's design has provided a space, even if unfinished, for the site to be used for more than was intended. The people have changed the site more than the site has changed the people. This is Tange's philosophy of metabolism at work.

These conclusions, garnered from my observations and brief interviews with visitors to Lumbini, were confirmed by long-term administrators and residents there. Christoph Cueppers was one of the first people who emphasized to me the number of lay and non-Buddhists who frequent Lumbini, especially for leisure weekend trips. Whiletheirvisits and support of local merchants are welcome, of course, he did note some problems. Some of the monastic residents and those occupying the meditation centers have complained about the very loud music local tourists play and the amount of garbage they produce. Ferdinand Stange, the director of the Tara Foundation's Great Lotus Stupa, which appears to be the most popular destination for local tourists, acknowledged the problems with noise and garbage but was very happy that the Great Lotus Stupa was popular as a leisure place for local visitors. Indeed, Buddhist cultures had long employed visual displays to attract, amaze, and encourage people to learn more about the teachings of their traditions. While he noted that most visitors were not very interested in the teachings of his lineage or others at Lumbini, he hoped they left with a sense of respect and interest in learning more in the future. He certainly did not see it as his goal to "convert" anyone, but simply to do his best to provide an educational, artistic, ritual, and communal place for serious students and tourists alike.

Thanks to Cueppers, I also had the opportunity for interviews with Acharya Karma Sangbo Sherpa, the general secretary of the Nepal Buddhist Federation and the vice-chairperson of the Lumbini Development Trust 
(LDT); the effective managers of all non-archaeological activities and endeavors at Lumbini; and Maksood Ali, the chairperson of the "Visit Lumbini Year 2012" campaign promoted by the government of Nepal. The general secretary is from the Sherpa ethnic group and grew up near Kathmandu. He is a Tibetan Buddhist monk and keeps an office in Kathmandu for his leadership of the Nepal Buddhist Federation and an office in Lumbini for his work with the LDT. The fact that he has to split his time makes his ability to manage the LDT difficult, even though he is the effective head of it on the ground in Lumbini. Moreover, he told me that his duties (ritual, pedagogical, and administrative) as a monk take precedence over his work at the LDT. Although he has been working at the LDT for five years, he complained that progress has been very slow. ${ }^{91}$ His work at the LDT is not his priority, intellectually, religiously, or professionally. When I asked him specifically what he thought about Tange's master plan, he was very helpful. He said that the master plan deserves respect, but after so many years, it needed to be adapted to meet local conditions, and that is what he was trying to do. He compared the master plan to a naked body that needed clothing: he was skeptical about the master plan ever being finished and said that, when a naked baby grows, its clothes change, and that he needed to concentrate on the clothes and not the naked body any longer. The "clothing" he suggested was not focused on Buddhist pilgrims, which was surprising to me, but on local Nepali visitors. Acharya Karma wanted to add some awnings to provide shade for local visitors in the bus parking lot, a few benches and picnic areas, and a new washroom. The only plan he had for Buddhist pilgrims was to add a large Tibetan prayer wheel to the Maya Devi Temple. These plans had not been funded yet though, and he was unsure whether they would be started before he left his office. When I asked him about the garbage problems and the noise issues, he did not respond other than to say that local visitors were interested in having fun at the site and this did not affect the Buddhist activities. He was hoping the Indian government would fund the $\mathrm{U}$ Thant auditorium in the future and that some politicians from Sri Lanka also had interest in funding projects, but there were no definite plans yet.

Maksood Ali was even more concerned with local tourists and even more skeptical about funding and the future of the master plan. But Ali was most skeptical about his own ability and his expertise for his own position. He was chosen to be the head of the Visit Lumbini Year 2012 campaign by the government of Nepal not because he had connections to the site, but because he was part of the Maoist Party. However, he had recently lost a local election in Bhairawa. To compensate for this loss, he was given another government position as a gift. He had never studied the history of Lumbini, and as a Muslim, he stated emphatically, he had never studied any Buddhist text. He said that he enjoyed when "all the foreign Buddhists repeat their slogans," meaning chanting Buddhist texts, but he did not know what they were saying 
or anything about Buddhist pilgrimage. Indeed, he said he had never conducted a survey with visitors, interviewed any pilgrims, or attended any rituals, sermons, assemblies, or dinners. I found this shocking, coming from the head of the tourist campaign for Lumbini that was supposed to attract foreign pilgrims and funds. He told me that they had promoted the campaign in Beijing with posters and a local radio advertisement in Chinese, and they sent invitation letters to members of the Sri Lankan tourist board. Some Sri Lankan officials did meet with him, but he was unsure how they were promoting the campaign in Sri Lanka, or any other country for that matter. He also was part of organizing a celebration for the Buddhist holiday of Vesakha in May 2012, but only in terms of posters and radio advertisements in Nepal. He was not involved in the arrangements made at the individual monasteries, where he said most of the celebrations took place, not in the public areas of the park. Despite his almost complete lack of knowledge of Buddhist history, archaeology, art, pilgrimage, and languages, he was very engaged with improving the lives of local Nepalis around the park. He wanted them to earn some money from foreign visitors and was very upset that most pilgrims stayed in their own monasteries and did not interact with local people, learn local culture, or patronize local businesses. He had extensive plans to develop a "homestay" program in which foreign visitors would stay and also take their meals in the homes of local Lumbini residents. He was actively trying to get microloans to help interested residents find funding to build one-room additions on their homes with "Western toilets" and "doors that locked" so that visitors could have a private room inside a home and contribute to the local economy and learn local culture. He also said that locals could then learn from foreigners. I asked what he would hope they would learn. He said, "How to be gentle, and how to be neat and clean." He said he thought foreign pilgrims did not interact with the local population because locals were loud and made the site dirty. Clearly, he was torn in his desire to fight for local concerns and wanting the local to change to accommodate foreign tastes. Like Acharya Karma, though, his plans were focused primarily on local Nepalis. I think Tange would be proud to see his master plan being adapted to local conditions-metabolism in action. Unfortunately, Ali admitted, he had no idea whether he would be at his job for more than a few months, as he could be assigned elsewhere or run for a parliamentary position again.

Tange's master plan has metabolized to incorporate local influence and changes. This was Tange's desire for all of his designs. Tange saw architecture not as a blueprint, but as a process. His passion for the free "conversation spaces" exemplified by Italian piazzas and public memorial spaces as seen in his Hiroshima memorial and Tokyo Municipal Building, and his belief in the democratic principles of architecture all are realized in Lumbini de- 
spite delays in construction, local corruption, and the tendency for different ethnic foreign pilgrim populations to self-isolate. Lumbini also reflects Tange's intellect, training, and upbringing, in that it is an international center. It is in Nepal. It is the birthplace of one of the founders of a global religious tradition. Before the nineteenth century, it enjoyed documented visits from Chinese, Tibetan, Sri Lankan, and Indian pilgrims. In the late nineteenth century, its significance as an archaeological site was confirmed by Indian, Nepali, German, and British scholars. It was propelled onto the international stage by a Burmese secretary-general of the United Nations. The memorial park was designed by a J apanese architect. It is directed by a Sherpa who was ordained in a Tibetan lineage, and the research institute is directed by a scholar from Germany who invites scholars from all over the world to use his library and facilities. Monastics from Austria, Bhutan, Burma, Cambodia, China, France, Germany, India, J apan, South Korea, Mongolia, Nepal, Singapore, Sri Lanka, Switzerland, Taiwan, Tibet, Thailand, and Vietnam have either leased, built, or been given permission to reside in Lumbini in monasteries they have designed themselves. Although it wants to receive more, it has and does receive pilgrims from all over the world. All the while, the local population of mostly non-Buddhists has metabolized it into a very popular local tourist attraction and public leisure space.

\section{The Future of Tange's Park}

Both the success and the failure of Lumbini have recently made it a target of controversy - and may eliminate Tange's master plan entirely. In 2011 and 2012, a very serious and aggressive proposal was put forward by a Chinese nongovernmental organization named the Asia Pacific Exchange Cooperation Foundation (APECF) to, basically, purchase Lumbini. APECF, headed by Xiao Wunan, cut a deal with Puspa Kamal Dahal, the director of the Lumbini Development Steering Committee (different from the LDT) to invest over three billion USD to take over the development and management of Lumbini. ${ }^{92}$ Dahal and Xiao Wunan stated that they wanted the Chinese funding, ostensibly, to create a new "international peace city" and bring stability to this region of Nepal. Many were immediately wary of this proposal when it was publicly announced on November 7, 2012, even though three billion USD would be an almost 20 percent boost in Nepal's annual GDP. Dahal (also known as Prachanda) is the former military commander of the Maoist forces that fought a rebellion against the government of Nepal for over twenty years. When the Maoists took over the country, he became the chairman of the Unified Communist Party and designated himself the director of the Lumbini Development National Directive Committee of Nepal (LDNDC) ${ }^{93}$ He signed this deal with Xiao Wunan unilaterally and did not invite the media, the 
LDT, or other government officials to the signing. This immediately caused resentment and suspicion among not only the Indian government, which would now have a Chinese-backed city on its border, but also his colleagues, who wondered whether they would receive a piece of the pie. ${ }^{94}$ The former minister of culture, Minendra Rijal, was one of the more vocal objectors. ${ }^{95}$ Investigative reporter Mikel Dunham and Global Post reporter Jason Overdorf noted that this move by the Chinese was part of a longer "battle of the Buddha" being waged between India and China to exert "soft power" in Nepal and culturally influence the larger global Buddhist community, which has powerful economic and political power in East, South, and Southeast Asia. ${ }^{96}$ Overdorf writes,

In this struggle, India seeks to use its common cultural heritage to overcome China's ethnic ties to the overseas Chinese in Southeast Asia, and China seeks to limit the damage from its repression of religious freedom in Tibet and its incessant sparring with the Dalai Lama. Bizarrely, for instance, China's state-run People's Daily first reported that APECF had inked a deal with the United Nations Industrial Development Organization (UNIDO) to create a "special cultural zone" in Lumbini, only to be forced to retract the story when first UNIDO, then Nepal, denied any knowledge of the pact. Even weirder, it surfaced that not only Prachanda but also the controversial Paras Bir Bikram Shah Dev, Nepal's former crown prince, held positions on APECF's board of directors. "This is part of China's effort to use Buddhism to gain an entry into Nepal, [and] to show to their Buddhists that they're showing equal attention to Buddhism outside the country," Jayaveda Ranade, formerly additional secretary for East Asia with the Indian government, told Global Post of the Chinese proposal for the development of Lumbini.

Dunham writes that

even the LDNDC came under fire from the Buddhist community. When LDNDC was created one year ago, Buddhist leaders pointed out that they had not been consulted, adding that ... the plan was "an attempt to commercialize the sacred place without their consent." . . . APECF and Prachanda keep raising the stakes, hellbent on turning Lumbini, birthplace of Buddha, into a horrid theme park of gargantuan proportions. ${ }^{97}$

Overdorf and Dunham were not the only international journalists to notice the strangeness of the proposal. In the summer of 2011 China Digital Times 
and Al J azeera's Melissa Chan reported that the Chinese wanted to build a premier place for Buddhist tourists. There should be no doubt that despite APECF calling itself a nongovernmental organization, its director, Xiao Wunan, is a member of the Communist Party and "holds a position at the National Development and Reform Commission, a state agency."98 Xiao Wunan falsely claimed that the UN supported his plan and that he "hopes Lumbini will bring together all three schools of the faith: the Mahayana as practiced in China, Japan, and South Korea; the Hinayana as practiced in Southeast Asia; and Tibetan Buddhism." However, despite this claim, no members of these Buddhist schools and traditions were consulted, including, most notably, the Dalai Lama. ${ }^{99}$ The UN had already objected to the Chinese plan. On March 17, 2012, UNESCO announced a formal objection to the plan by the LDNDC to construct the largest Buddha image in the world with Chinese funds, this time not from APECF solely, but with their partner, the Beijing Zhongtai J inghua Investment Company. ${ }^{100}$ The statue would be surrounded by a five-star hotel and take over the LDT's master pan. They would also construct their own museum and research institute (presumably dismantling Tange's designed research center and museum). They want to turn Lumbini intoa "BuddhistMecca." Oneimagines that the Tibetan influence-intellectual, artistic, and ritual-would be severely curtailed under Chinese management. Minendra Rijal, a representative from the Ministry of Federal Affairs, Constituent Assembly, Parliamentary Affairs and Culture (MoFACAPAC), stated, with UNESCO support, that "the plans of the Chinese company . . . go against the spirit of [Tange's] Master Plan."”01

Even though the Chinese plan is still on hold and is a point of controversy in Nepal and among international Buddhist communities, there should be no doubt that there will be major changes at Lumbini over the next few years. Lumbini is not the only Buddhist historical site that the Chinese government is trying to control and profit from, of course. Under way now is a massive project to build a Buddhist theme park in Dunhuang, costing over 450 million USD, to take advantage of visitors to some of the most important archaeological sites where Buddhist manuscripts, cave paintings, and murals were produced. ${ }^{102}$ However, if history teaches us anything, it is that Lumbini has survived many attempts to remove it from its local environment and make it either an international site or a symbol of one Buddhist ethnic group's ambitions. As for Tange, both he (long before he passed away) and his family's architectural firm now have washed their hands of involvement with Lumbini. Regardless, his dream of a site that could metabolically change with the times will certainly be realized.

Kenzo Tange is not the only architect and visionary who has run into problems working in the region of the Buddha's birth. Indeed, over the last century and a half, the creation of monuments in northern India and southern Nepal has been fraught with difficulty. Ever since Edwin Arnold, Angrika 
Dharmapala (Don David Hewavitarane), and other British and Sri Lankan Buddhist "revivalists" started promoting the four great sites of the Buddha's life-Lumbini (birth), Bodh Gaya (awakening), Sarnath (first sermon), Kushinagar (death/parinibbana) -in the 1880s, these sites have been coveted by competing Chinese, Japanese, British, Tibetan, Thai, and other interests looking to lay claim to the origins of Buddhism. J apanese entrepreneurs have been the most successful at establishing expensive hotels at these sites, while Thai and Korean groups have focused more on building monasteries recently. Many groups have attempted to alleviate poverty by building some semblance of infrastructure (schools, health clinics). However, virtually every nation that boasts a large Buddhist population has produced monks, businesspeople, and pilgrims that want to have some foothold in these four sites. The rise of Bodh Gaya as the premier international Buddhist pilgrimage site in the twentieth century has been well documented recently, and it has become a semipermanent home to Tibetan, Thai, Korean, and other ethnic/national/ sectarian monasteries, as well as tour and study groups from all over the world, which regularly hold meditation, history, and ethics courses there. ${ }^{103}$ While Sarnath has not been as successful in building as large as a following on the pilgrimage circuit, it still receives thousands of visitors annually, and recently there have been rumors of a Thai group attempting to erect what would be the tallest Buddha image in the world at the site of the Buddha's first sermon. While some construction has begun, little progress has been made in the last decade, likely because of downturns in the global economy and lack of sustainable investment. In Kushinagar, like Bodh Gaya and Lumbini, monasteries, meditation and yoga centers, and small community buildings have been established by various groups from Vietnam, Burma, Sri Lanka, and the like.

In Kushinagar, though, a much more focused effort has been made in constructing another large image, an image of Maitreya, the future Buddha, which would be over five hundred feet tall, thus dwarfing the Sendai Daikannon and Leshan Vairocana (China). This project, started by a Tibetan refugee to India, Lama Yeshe, and his student, Lama Zopa Rinpoche, and assisted by Tony Simmons and Peter Kedge of the Foundation for the Preservation of the Mahayana Tradition (FPMT), has also made little progress over the past forty years. The politics involved with acquiring huge swaths of land and displacing schools and villages is daunting. ${ }^{104}$ The project has been plagued by controversy, protests, and financial woes. Unlike Tange's architectural vision, though, the FPMT has a much more focused social and political agenda. In comparison, Tange did quite well in attempting to realize his vision, and if anything, Lumbini is, in the end, a largely public and leisurely place where visitors can meditate, learn some history, conduct research, rent a hotel room rather cheaply, and come and go as they please. 


\section{Conclusion: From Monuments to Picnic Sites}

I hope this chapter has shown that leisure is not antithetical to the study of religion. I also hope that it encourages scholars and students of Buddhist and religious studies to pay attention to the ways religious sites have been transformed by tourists, pilgrims, neighbors, and local and international government officials into leisure sites that are open secular spectacle sites (misemono), attracting the devout and the simply curious alike.

While Kenzo Tange's Lumbini master plan has never been fully realized, and he and others after him have had to settle at a series of local optima, other Buddhist parks have been better executed. This is not primarily because the creators had a greater knowledge of Buddhist history and art, but because they had more creative and administrative control over their respective sites. However, like Tange's master plan, these monuments that create public space do not attract only those activities most associated with religion, such as monastic training, supervised meditation and prayer, and ritual, liturgical, and homiletic programs, but also secular leisure activities like exercise, picnicking, and game playing.

For example, Phutthamonthon is a large (2,400-acre) Buddhist park in the suburbs of Bangkok (Salaya) near the historic city of Nakhon Pathom. With the support of the royal family and the elite of the sangha (community of monks), it was designed in 1955 under the directorship of Prime Minister Pleak Phibulsongkhram. Since Phibulsongkhram lost power in 1957, the park's construction was halted, and it ended up not being completed until the early 1980s. Unlike any monastery in Thailand, it is mostly open space, used for kite flying, jogging, bike riding, and picnicking. No nuns or monks are regularly in residence, and the few buildings are used mostly for administrative offices for the Sangha Supreme Council (Mahathera samakhom) and the Office of National Buddhism of Thailand (Samnakngan phra phutthasasana haeng chat). One building looks like a traditional Thai Buddhist vihāra (hall). It does not serve as a meeting or ritual space, but it holds 1,418 large marble stone steles. On each stone is inscribed (in gold) a section of the Buddhist canon of literature according to the Thai assemblage of the canon in the late nineteenth century. The site is stunning and harkens back to a similar array of stone inscriptions containing Buddhist canonical texts (729 in total) in Mandalay (Burma) at the Kuthodaw monastery. However, in Burma the stone canon is part of a monastery, and the texts receive regular visitors and oblations, whereas at Phutthamonthon they receive few visitors and sit largely in silence in an empty hall.

Phutthamonthon does have some religious activity. A few large scale processions of monks and national celebrations are held there in the parade grounds, but it is largely used as an open park for most of the year. The most 
notable feature of the park, regularly depicted on Thai postcards, is the very tall freestanding image of the Buddha walking, designed by the Italian artist Corrado Feroci. Feroci was born in Florence in 1892 and moved to Thailand in 1923. This Italian national ended up becoming a Thai citizen in 1944, adopting a Thai name; he was given a state funeral in 1962. He is a national hero in Thailand, where he is known as Silpa Bhirasri. Considered the "father of Thai art," he founded and directed the first professional art school and, eventually, the first university dedicated to the arts in Thailand. He designed many of the prominent statues of the royal family and a number of important Buddhist and national monuments seen throughout Thailand. A statue of Feroci himself stands on the grounds of Silapakorn University in Bangkok.

The walking Buddha he designed in Phutthamonthon is in the Sukhothai style and is almost fifty feet tall. It stands on a large pedestal, and even though it was designed as a monument in the park, it is often ritually given gifts and prostrated to by visitors, as any other Buddha image would be. The image is simple and graceful; surrounding it are several unadorned monuments, also designed by Feroci but completed after his death, such as the seven large plain circular stones representing the seven lotus flowers that appeared in Lumbini when the Buddha was born. (It is said that the Buddha was born walking and talking and, as a newborn, took seven magical steps on lotus flowers that had spontaneously unfurled from the ground.) Near the stones is a large statue of a dharma/dhamma wheel with five stone seats representing the Buddha's first sermon at Sarnath to his first five disciples, a bodhi tree with a stone seat (Pali: āsana) representing his awakening, and a large stone bed representing the Buddha's death. Every stone lacks color, and they appear largely ignored by park visitors. These relatively abstract and understated monuments are an anomaly in Thailand, where traditional murals and statuary are rarely subtle and unadorned. No regular Buddhist ritual or counseling services are offered at Phutthamonthon. No regular sermons are held and very little directed meditation, except for an occasional meditator that I have heard about but never witnessed.

Indeed, like Tange's park, Phutthamonthon is striking not for what is there, but for what is not-no ritual implements, monks, color, or worshippers. It is a park for leisure repose, allowing children to run around and young couples to hide behind trees. Since this area is low marshland divided by highways, industrial parks, and the nearby main campus for Mahidol University, it does not get many people just strolling by. It is a place you need to plan to visit, and religious ritual or education is not the reason to visit. It is a destination for a picnic. It has remained largely untouched since it was completed according to its original design.

Unlike Buddhist museums, amusement parks, gardens, and ecumenical monasteries, Tange's Lumbini Park and Phutthamonthon are govern- 
ment supported and designed to be memorials to Buddhism as a great world religion. While they might have been designed by individuals with certain visions about the proper way to memorialize Buddhist history and teachings, they have been taken over by lay families and turned into places for leisure activity. The same can be said for other sites, such as the Fo Guang Shan Buddha Memorial Center in Kaohsiung, Taiwan. Launched by a sectarian group and built using government funds, it has been transformed into public leisure and tourist sites; it serves lay families on vacation more than monks and nuns in training. Other smaller places, like the War Memorial (honoring Lao and Vietnamese war victims of the American War in Vietnam) in Phonsavan, Laos, and the Geraldine Mary Harmsworth Park in London (which is connected to the Lambeth branch of the Imperial War Museum) are public memorials that include Buddhist shrines and imagery. The former has statues of soldiers alongside a Buddhist chedi (reliquary) and altar for offering candles, flowers, and other traditional Buddhist offerings. The latter has a small mandala, an inscribed column with a message of peace from the Dalai Lama, a garden plan based on the eight-spoked wheel of the eightfold noble path, and a bronze mandala. All these sites have had some form of government oversight and are public. Their architects therefore had to be as ecumenical and open to all forms of Buddhism as possible (or at least appear that way). Often, their explicit Buddhist sculptures and symbols are not objects of direct worship but are ornamental distractions that provide affective encounters for visitors strolling past. In the next chapter, we will see what happens when the design and management of Buddhist sites of leisure are controlled not by the public, or by state or international organizations, but are the creative and idiosyncratic expressions of (often wealthy) individuals. In short, as we will see, it can get out of hand. 


\title{
2
}

\section{Ecumenical Parks and Cosmological Gardens}

\author{
Braphai and Lek Wiriyaphan and Buddhist \\ Spectacle Culture
}

IN 1937, TWO BUDDHIST BROTHERS FROM BURMA NAMED AW Boon Haw and Aw Boon Par, who had amassed a fortune inventing and selling Tiger Balm (a soothing and cooling camphor-like balm for muscle pain, headaches, rashes, and the like), opened up their own amusement park, called Tiger Balm Gardens. Although it did not have rides, its sculpture gardens, large dioramas, fake mountains, and inviting fountains were a popular place of leisure for families. The park offered regularly scheduled performances of Chinese operas, moralist dramas, concerts, and circus-like acts. While it was not a Buddhist park directly, many of the displays were Buddhist.

The government of Singapore took over the park in 1988 and renamed it Haw Par Villa. It is a site still known to most Singaporeans and a wonderful place to relax and delight the senses. At the park, one can read about the lives of the brothers on mounted posters and plaques, learn about their travels from Burma, and even sit in their old car. Parents can arrange birthday parties for their children, tourists pose for photographs, couples stroll hand-in-hand, and businesspeople eat their bagged lunch on shady benches. Since the Singapore Tourism Board dropped the entrance fee, one can now stroll in and rest among thousands of colorful statues and reliefs. Many of the displays focus on Chinese epic tales like the Legend of the White Snake, the J ourney to the West, and the Romance of the Three Kingdoms. Dioramas display how abusing alcohol, frequenting prostitutes, hanging out at nightclubs, and ignoring one's parents can lead to a life of suffering and crime. I particularly liked the display in which humans turn into rats because of their 


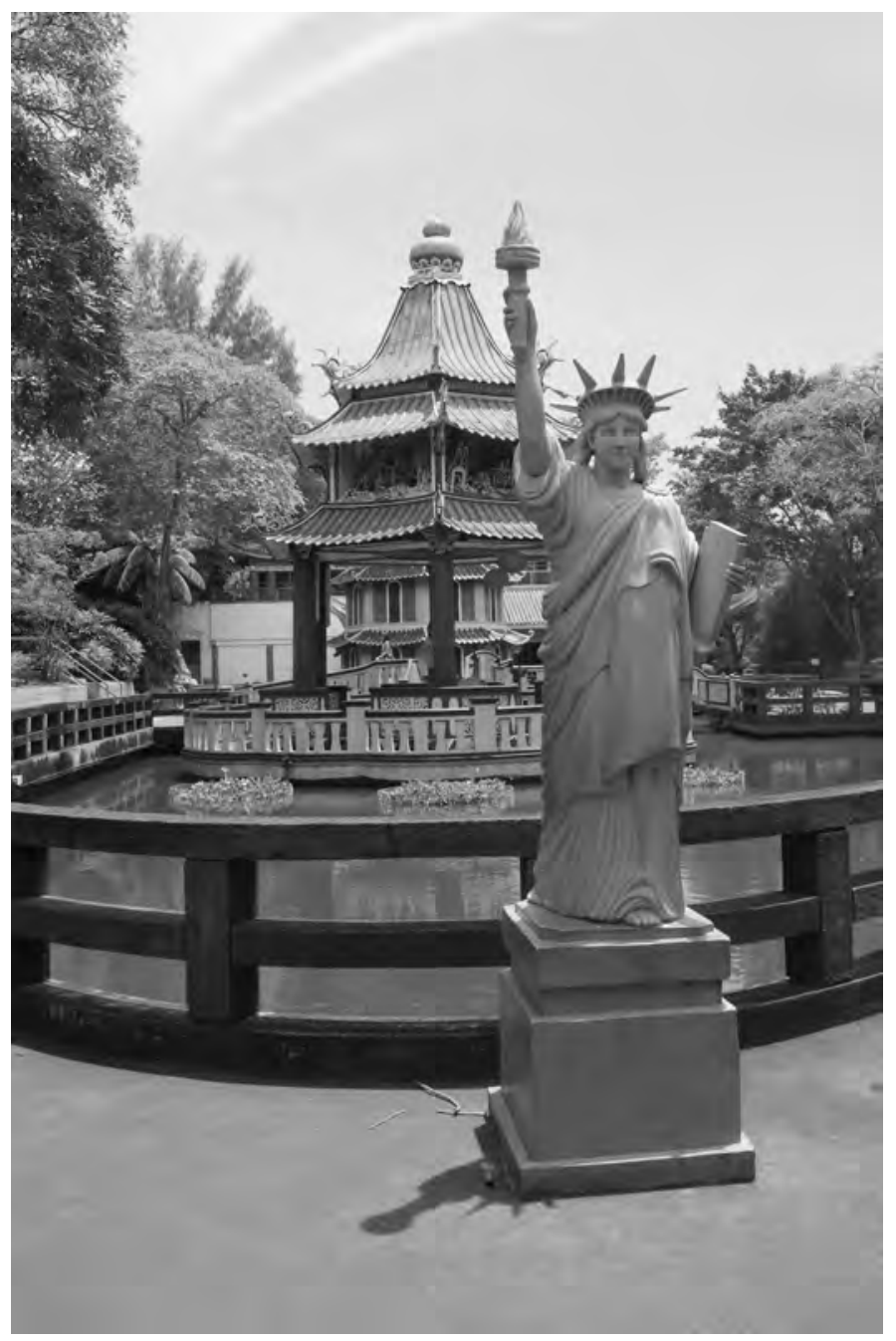

Sculpture garden of Haw Par Villa in Singapore

licentiousness. Alongside these literary and moralist displays stand statues of the Buddha, Maitreya, Avalokiteśvara (Guanyin), and the Daoist celestial masters, such as the Jade Emperor and the Eight Immortals. Statues of sea and land creatures, some mythological and some natural, abound. There is even a miniature Statue of Liberty and memorials to the two brothers and members of their family.

Near the entrance to the park is one of the largest displays-the cave of the Buddhist hells. ${ }^{1}$ This is truly a garish site. Originally a man-made cave inside a large dragon, the cave remains, but today the outer shell looks like a fake mountain. Inside, the lighting is low and it is very hot, as air does not flow well through thelong cave. Each of the levels of hell are depicted in rather 
gruesome detail: bloody corpses, naked women and men being tortured, saws slicing off limbs, stones crushing skulls, bodies floating in pits of lava, and the like. This style of diorama was copied by Buddhist temples in Thailand and Sri Lanka later in the twentieth century, but what is interesting here is that this park is designed for entertainment. ${ }^{2}$ Vendors are selling ice cream, fruit, beer, and snacks, and there isn't a nun or monk in residence.

Haw Par Villa is a perfect example of the way pan-Asian Buddhist stories, local and regional folktales, an accumulation of commonly known cultural cues, and new technologies and building materials fit together comfortably and both reflect and contribute to the local cultural repertoires in many places in "Buddhist" Asia. The designers, Sino-Burmese brothers working in a culturally diverse (Tamil, Chinese, Indo-Malay, British) urban space, succeeded in blending the religious and the secular, the public and the private, the didactic and the leisurely to form a sensory experience that is accessible, affordable, entertaining, and educational. However, because Haw Par Villa is not connected to a specific sect, a specific religion, or a specific nun or monk, like many places discussed below, it has been overlooked by religious studies specialists; and because it was not designed by an internationally recognized architect, and is characterized more by abundance and eclecticism than by a singular vision or message, it has been overlooked by art and architectural historians. In this chapter welook at the work of Braphai and Lek Wiriyaphan in Central Thailand, as well as the designers of other Buddhist ecumenical sculpture gardens and leisure parks both in both public and monastic spaces. We will examine the various local optima that have tempered their architectural visions and observe what forces have changed their creations over time.

\section{Lek and Braphai Wiriyaphan and the Remaking of the Cosmos through Ecumenical Architecture in Thailand}

As fun, garish, and spectacular as Haw Par Villa is, it is dwarfed in comparison to the work of Lek Wiriyaphan. Lek passed away from kidney failure on November 17, 2000, after making his mark as one of the greatest eccentrics, and arguably the greatest builder of Buddhist theme parks and promoter of the aesthetics of Buddhism, of the twentieth century. He was also more focused on universal and ecumenical themes, especially later in his career, than on building cultural parks with Buddhist aesthetic features. He founded the Sanctuary of Truth and the Ancient City in Central Thailand. The former claims to be the largest wooden structure in the world and is covered with carvings of Hindu deities, planets, stars, buddhas, animals, and flowers. The latter is a 230-acre replica of Thailand, complete with giant monuments and temples, as well as man-made miniature rivers, lakes, and mountains. However, Lek's greatest endeavor was the Erawan Elephant, the world's largest 
metal animal, which houses an impressive museum, among other things. The scale of this undertaking is hard to describe: The giant, three-headed, iron elephant statue stands 130 feet tall, is 120 feet long, and weighs 250 tons. Inside the elephant's leg, an elevator takes people to its belly, in which visitors find a very large Buddhist sermon hall and an altar where they can prostrate, offer gifts, meditate, and regard the ceiling covered with stars and mermaidlike creatures. The park below displays elaborate fountains and gardens. Lek was not trained as a monk or a scholar of religion. He drew on his individual repertoire of cultural and religious influences and creatively improvised. Although he resisted compromise throughout his lifetime, unforeseen circumstances led him and his wife (and now his children) to settle at a series of local optima in the pursuit of their constantly shifting plans and ambitions.

Lek's "newage" projects could be considered the creations of a wealthy, megalomaniacal, elderly man; however, behind his rather bizarre parks was a man with clear reasons and a certain vision of the future of Buddhism. Despite these large projects, nothing of significance has been written about him in any language, and were it not for a chance I had to speak with some members of his family and business, a short autobiography and collection of his poetry, and a family history published on the occasion of his cremation, I would have little information about his life. ${ }^{3}$

Lek was born in Bangkok, a few months before Kenzo Tange, in 1912. Arguably more important, his wife, Braphai, was born in 1914 . Without her, he admitted, he most likely would have been just another Sino-Thai businessperson trying to climb the ranks of Thai society. She enabled him to develop his business and complete his massive parks, and she was central to his publication series and preservation work.

Lek was the child of a small Chinese drugstore owner who worked in the crowded alleys of Sampeng (Bangkok's "Chinatown"). His father, like many Chinese immigrants of that generation, did not want his children to lose their Chinese heritage and so sent Lek away to study in Shanghai before the war. This move would prove significant, as Lek claimed that much of his intellectual and religious inspiration came from reading Chinese Daoist and Confucian texts, and most of his book collection was in Chinese. When his father fell very ill in Bangkok at the age of fifty, Lek was summoned home because of lack of funds and a need for him to run the pharmacy. His father died soon after Lek returned, and so Lek never completed his studies. While trying to develop the fledging business and keep the family together, he went to several chemists and pharmacists to develop new products.

On one of these visits, he met a young nurse and chemist named Braphai. She had just returned from completing a degree at the Nanyang Technological College (now university) in Singapore. Coincidentally, it would be Tange who would redesign the main campus of Nanyang (although long 
after she had graduated). She had had an easier time than Lek. Her parents, Wichian and Yairun, were second-generation Chinese immigrants and successful businesspeople. Her grandfather was a steamship worker from Southern China, and her mother was a tax collector. As a steamship worker, her grandfather had worked closely with Captain Narin, who competed with Western traders and exposed the family to different lifestyles and products. Narin ended up helping her grandfather's whole family, and they were able to open a shop that later turned into the very successful Wiriyapanich Company. Their main products were pharmaceuticals, and they made a small fortune on a virility drug and general elixir called "Blataphian thi Mahanak," which had a symbol of an Indian Brahmin R̦și (soothsayer/seer) on the label and is still known today as "Mahanak" brand elixir. Perhaps influenced by growing up in pharmacies, Braphai excelled in chemistry and the Chinese language (at the Chinese school called, in Thai, Sangta khrusaba rian), made international connections herself, and, by the time she met Lek, was independent and wealthy for her young age. She was not initially impressed by Lek and concentrated on her work in her laboratory. However, because of her diabetes, which she had had since a young child, Lek won her heart (according to their daughter), by cooking healthy dishes and bringing them to her. ${ }^{4}$ Soon, they wed, had six children, and built a massive fortune together. He was charming, energetic, and ambitious. She was diligent, cautious, responsible, and had a mind for accounting. It was this combination, Lek acknowledged, which made his success possible. His autobiography includes an entire chapter about her and many photographs of her. ${ }^{5}$ Their family biography includes numerous photographs of them at work, on vacation, poring over blueprints, and the like. They were inseparable.

As they grew wealthier, the couple started not only purchasing new businesses, but also collecting art and books. The most significant business Braphai and Lek were able to start was the first major Mercedes-Benz dealership in Bangkok. This business, along with their pharmacies, generated a steady income and allowed them to hire managers and travel throughout the country together frequently. Lek became an active collector of books, especially books in Chinese on Daoism and Confucian ethics. He also liked antiques and, with Braphai, traveled almost every weekend to various provinces collecting buddha images, manuscript storage chests (tu traipidok), and architectural pieces like lintels, shutters, architraves, and columns, mostly in Nan, Kampaengphet, Loei, Uttaradit, Petchabun and other provinces in Northern Thailand along the Mekong River. Eventually, his children claim, they were able to visit every province in Thailand. Because of difficulties with diabetes, Braphai retired young and started to manage the family finances and explore investment opportunities. She also started purchasing large tracts of land. 


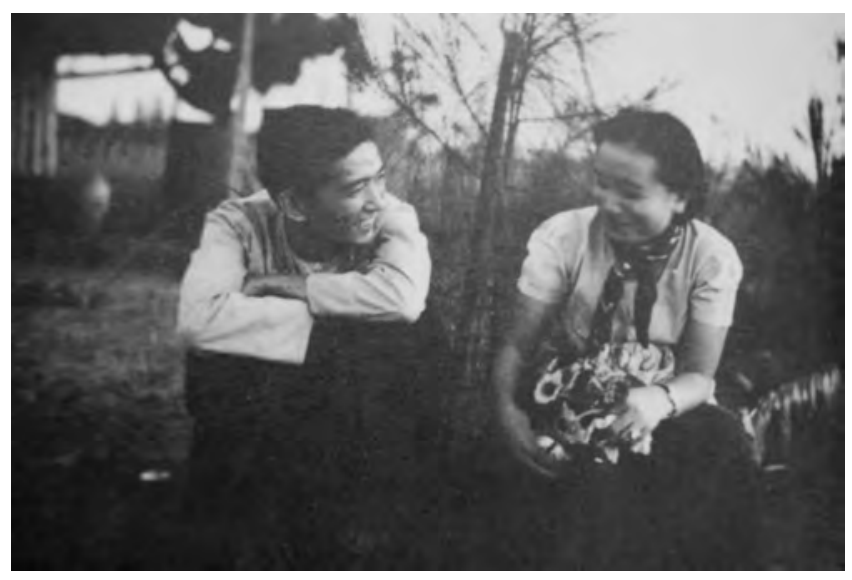

Braphai and Lek in the early married years in Bangkok

Lek liked to consult with scholars such as Manit and Sisak Walliphodom and Wilaisak Songsiri, who were specialists in Thai art and folklore. ${ }^{6} \mathrm{He}$ was a frequent visitor after work on weekdays to the River City antique market next door to the high-end hotels like the Oriental and Shangri-La. Although he never studied art or history formally, he surrounded himself with experts and traded with Cambodian and Burmese art dealers. Their pan-Asian collection grew so much that storage, never mind display, became an issue. A friend, Bhiam Bunyachot, encouraged Lek and Braphai to invest in golf courses, especially mini-golf. However, while this was of some interest to Lek, he thought that the land Braphai had bought could be put to better use and that they could start using their wealth and land for their country.

According to Sisak, one of the reasons Lek's Benz dealership was so successful was that he knew how to master the art of the "showroom." This concept was new to Thailand in the 1960s. Lek thought that he should create a showroom for his art and for Thai history. He decided to take a large tract of land Braphai had purchased in the southern suburbs of Bangkok (in Bang Bhu, Samut Prakan Province) and use it as an outdoor history park, which he named Muang Boran (Ancient City). He also started a bookstore and publication series to promote Thai history and art, which is still one of the best bookstores in the country, although Lek did not write any books, besides a guide to the Ancient City, himself. ${ }^{7}$ At the Ancient City site, he wanted to recreate a miniature version of Thailand, complete with fake mountains, lakes, rivers, monasteries, palaces, markets, villages, and waterfalls.

A comparable site is Taman Mini Indonesia, also called Beautiful Indonesia in Miniature Park, on the outskirts of J akarta, which was started around the same time as the Ancient City in the early 1970s (construction first 
started in 1972). It has grown over time to include not only miniature versions of famous examples of Indonesian architecture, religious sites, and cultural monuments, but also cultural performances, an IMAX theatre, and amusement rides. Unlike Lek and Braphai's Ancient City, the buildings at Taman Mini Indonesia are replicas and not actual buildings moved to the site. Also, Taman Mini Indonesia was a government-sponsored project, whereas Lek and Braphai received no government direction or funding. I have not found direct evidence that the Ancient City was modeled on the Taman Mini Indonesia, or that Lek and Braphai even knew about the Indonesian project, but the parks clearly reflect similar motivations to showcase a nation's beauty and accomplishments as seen in national displays at world's fairs and the early cultural displays at Disney's theme parks. ${ }^{8}$

For over thirty years Lek slowly worked with Braphai, artisans, his children, historians, and landscapers to clear the land, move entire monastic buildings from various places in the country, and build new monastic buildings and miniature versions of palaces, fortresses, city walls, manuscript libraries, and the like. By the time of his death in 2000, there were 116 buildings in the park, as well as full-size replicas of Chinese junks floating in a lake and a bridge painted with a rainbow. ${ }^{9}$ Restaurants, gifts stores, salons, and ice cream shops all occupy a setting of premodern Thai villages, with period furniture, oil lamps, and winding pathways. One can sit along a man-made canal while merchants in traditional clothing bring food to you in their small canoes, mimicking the floating markets in Ratchaburi and Samut Sakorn Provinces that have long been popular with tourists. One can stroll around and enter into nearly full-size replicas of traditional Northern, northeastern, Central, and Southern Thai monasteries and palaces, including full replicas of the Hall of Wat Tramit in Trat, the Buddha's Footprint Shrine in Saraburi, the Wat Chedi Chet Yot in Chiang Mai, and the Phra That Ta Khu in Kalasin Province. Lek even built a copy of a floating Thai Catholic church. Serious attention has also been paid to non-Siamese/ Thai art, since he includes replicas of the Angkorian temples and pavilions in northeastern Thailand such as Prasat Phanom Rung and Phimai. Lao libraries and stupas like those in Nong Khai and Nakhon Panom sit near Shan- and Burmese-stylemonasteries based on originals in Lampang, Chiang Rai, Tak, and Kanchanaburi Provinces. Although Buddhist buildings dominate, there is also a replica of a 1893 French colonial building from Chantaburi Province (on the Cambodian border), as well as court of public appeals from thirteenth-century Sukhothai and the Ayutthayan Sanphet Prasat (palace). Lek was involved in every aspect of the park and spent nearly every free day he had there, and also constructed a place for Braphai to rest while there.

From Lek's own comments about his work and from Sisak's biography, it appears that creating a history museum or an accurate miniature version 


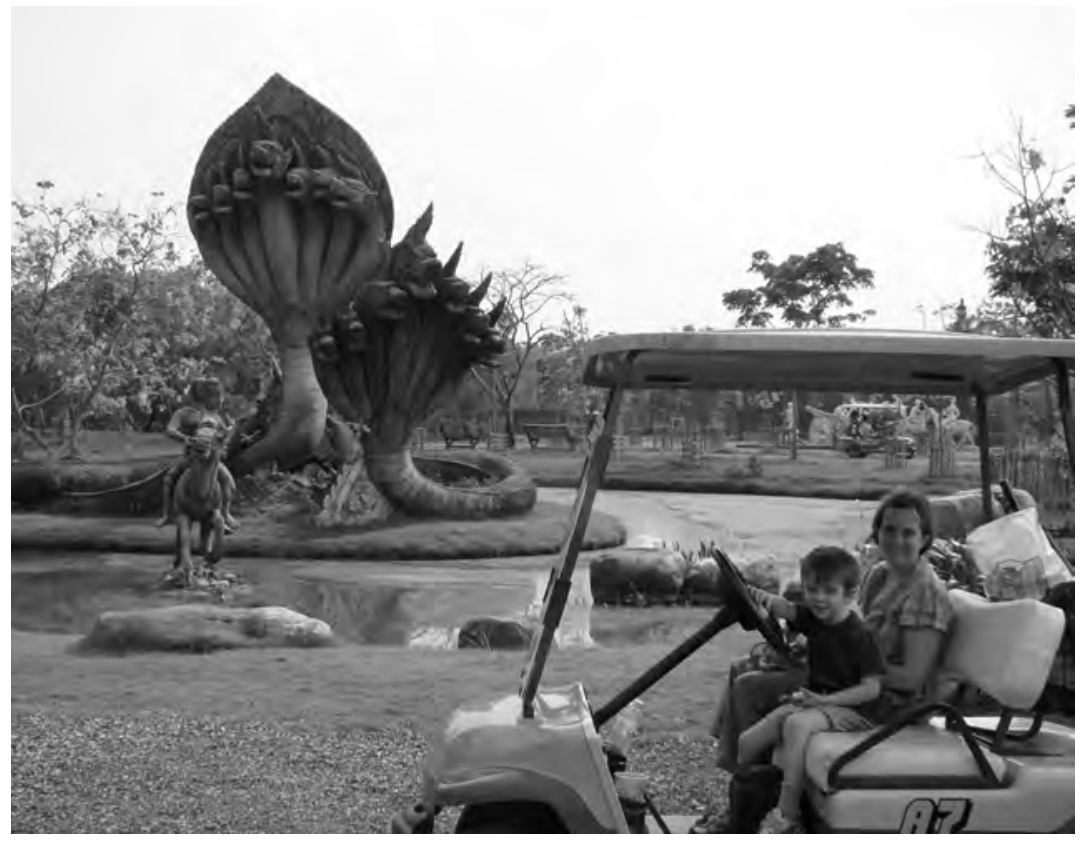

The author's family stopping at one of the dozens of large statues at the Ancient City, near Bangkok

of Thai architecture in the Ancient City was not Lek's objective. Unlike art historians or museum curators, though, Lek did not like to create "complete" collections and often admitted that he was not overly concerned with authenticity, age, rarity, or preservation. Visitors can touch the buildings, walk on their floors, and prostrate to their statues. Visitors can offer gifts, light incense and candles, and chant in front of Buddha images in the monastic buildings in the park. Indeed, Lek bought what he liked, even entire pavilions, walls, ceilings, and gates, from dilapidated rural monasteries. He wanted to create a living aesthetic experience in which foreigners and city dwellers could experience the mostly Buddhist art in his collections. Indeed, he explicitly emphasized that historical accuracy was not his intention. Most of the structures at the Ancient City were not brought to the site but constructed on the site from a mixture of new and old material. Oftentimes the old material was not taken from the actual palace, market, or monastery that was labeled in the park. Lek said that he bought what Braphai and he liked and enjoyed mixing styles, time periods, and materials. ${ }^{10}$ The labels on the buildings (usually in the form of small signs on the paths) provide some basic information on the date and provenance of the building in question, but do not claim that the buildings are accurate. Some signs are detailed, but most are descriptions of the types of wonderful activity that might have taken place in a building like 
this in the veiled past. Moreover, there are a few small museums in other buildings, such as a replica of a village home and a hall containing manuscript chests. Here we find materials mixed together with little effort to create an accurate view of life in the past or to coordinate building dates with the style of the furniture inside. There is even a complete eccentricity to the way Lek planted trees at the park, where he mixed and matched species from different regions and climate zones. ${ }^{11}$

To compound this lack of authenticity, Lek hired an artisan from Shanghai (who is not named in sources I have found) to undertake most of the carving of Thai, Khmer, Lao, and Shan shutters, lintels, doors, and the like throughout the park. This artisan had not been to Thailand before and did not speak the language. Lek openly stated that he did not care what historians thought about his site and referred to vague criticism from nameless detractors of his park. Even Sisak criticized Lek for this attitude and lack of scholarly fastidiousness. ${ }^{12}$ Lek had a large library and traveled extensively, but seemed to have a slight resentment against academics and did not himself have advanced degrees or a scholarly pedigree. Sisak notes that Lek was a man who thought for himself and did not see the point of being rich if you could not do what you wanted. Lek often quoted sayings from Daoist literature and stated that true meaning was not in history, because history is constantly changing. His park should constantly evolve and change. ${ }^{13}$

Braphai largely agreed with him. In both the Thai and English forwards to the Guide to the Muang Boran, Braphai stated that she wanted the park to inspire people. She wanted buildings and art to be symbols to invoke profound thoughts. She believed that the rise of technology was distracting the young. ${ }^{14}$ Lek wanted to inspire the young and impress Westerners with Buddhist art and history. He wanted to create a peaceful yet entertaining place (the park has regular music and dance performances, a tram that takes visitors around, several picnic areas, etc.) where families could let their children run around, people could freely take photographs, and young couples could stroll in a shady relaxing atmosphere (rom reun). He stated that his park should be a sathan thi thiao yon jai ("a place to visit and ease the mind and heart"). ${ }^{15}$ His park should allow people to think big (tham hai goet khwam kit thi kwang) and challenge the imagination (thathai chintanakan). ${ }^{16}$ Although he notes that history is important, "suitability and beauty have no boundary in age . . . [they] have no nationality, no religion, no limit in time." ${ }^{\prime 17}$

Other binaries that Lek wanted to surpass were between literary and recorded history and between the religious and the secular. One of the most striking things at the park is the way buildings and characters that exist only in Thai romances, epic poems, or folktales are presented alongside buildings and statues that are known from archaeological and historical records. For 
example, there are monuments to Manohra, Khun Paen and Khun Chang, Phra Ram, Phra Lo, and Phra Apaimani, among others-all characters from famous works of Thai literature or stories drawn from Pali and Sanskrit literature. Only one, the story of Manohra, is directly taken from an apocryphal Buddhist Pali jātaka (Sudhana Jātaka). The others are heroes of Sanskrit and Thai epics and folktales. There is no natural barrier placed between these fictionally inspired monuments and buildings and replicas of actual places. Khun Paen's house, for example, is next to the old city hall of Chonburi Province, where General Taksin supposedly rested his troops in the late 1700s. Khun Paen is a character from a Thai epic poem about a love triangle that involves violence, abduction, and the use of protective magic. Manohra's garden is next to the famous Southern Thai Buddhist stupa at Wat Mahathat that can be dated back to the sixth century. Manohra was a half-woman/ halfbird (kinnarī) character who fell in love with Prince Sudhana (the Buddha in a previous life). Other than the Buddha himself, there are no characters in the entire park taken from canonical Buddhist literature. One could argue that the Ancient City is a celebration of all beautiful things, both secular and religious, in Thailand. It is a showroom of Thai religion, literature, and art. It is not a xenophobic place, however, and celebrates ethnic diversity and acknowledges the influence of Lao, Khmer, Shan, Burmese, and even Western architectural styles on Thailand. What is a bit strange, though, is that the Chinese influence on Thai society is hardly noticeable - especially strange since the park was designed by Lek and Braphai, who read and spoke Chinese. Braphai seems to have been the motivator behind Lek's Thai Buddhist projects. He was not particularly religious and rarely visited monasteries or attended liturgies. He spent his free time reading Chinese philosophy and novels. He had a large cabinet of rare Chinese books on religion, art, and philosophy in his office. $\mathrm{He}$ particularly liked reading Confucian philosophy (Thai: khong jeu) and often had a book of Confucian quotations with him, which he liked to translate in Thai for his friends as they were caught in traffic jams in Bangkok. He stated that Confucius knew the importance of the obligation of a person to their society, and Daoist philosophy taught inner strength and perseverance. A person should maintain a balance between developing their mind and helping others develop theirs. ${ }^{18}$ These sentiments are reflected in his own poems, which read like quotes attributed to Confucius. His book, Bantheuk khwam kit (Collected Thoughts), contains eighty original poems (or maxims of worldly wisdom, all between four and twenty lines), all untitled, and was published a year after he passed. Many of the poems invoke the need to remain calm and happy, but to never accept failure and to act for the sake of others when needed. For example, in two particularly punchy poems, he wrote nai chiwit khong khon rao mai mi wan dai thi mai samkhan ("in our lives, there isn't a single day that is not important") and khwam samret mai mi khwam lilap otthon 
lae sarup bot rian chak khwam lomlao ("success is not a secret, persevere and learn from failure"). ${ }^{19}$ Additional thoughts on the meaning of life, the power of architecture, and the relationship between national heritage and everyday life were recorded in his autobiography, in a chapter called "Bhrachiya thi cheun chob" (Philosophy that Delights [Me]). One maxim that I think sums up Lek's attitude and fearlessness in building these gargantuan sites is khon chalet somneuk tua eng khon ngo cha rawaeng phu eun ("intelligent people are aware of themselves, stupid people are concerned [with the intentions and opinions] of others"). ${ }^{20}$ Lek certainly did not care much about what others thought.

Although Lek seems to have drawn his philosophy from mostly Chinese sources, Braphai, even though she was also of Chinese heritage, did not spend her time reading Chinese philosophy or history. She frequented monasteries (Chinese-Thai as well as Thai), studied murals and Buddhist texts, and became an avid reader of Buddhist writer and social activist M. L. Dech Sanitwong. She and Lek came to see Buddhism, and religion more broadly, as the way to promote poverty reduction, national pride, political stability, and world peace. As Braphai grew increasingly ill in the early 1980s, and certainly after she passed away at the age of seventy-nine in 1992 (her ashes were placed in a stupa in the Ancient City), Lek's interest in Chinese philosophy and art became more pronounced, and his concentration on Buddhist art and history waned. He had a shrine to Guanyin built as one of the last projects at the Ancient City. He designed a shrine to Chinese deities (the Jade Emperor, the Eight Immortals, and Mazu, among others) for his eldest daughter, Araphan. However, his interest in Chinese religion and thought was soon replaced by grander dreams that he had put on hold while he was working on the Ancient City. ${ }^{21}$

When he turned eighty, he began the aforementioned giant elephant. It was finished in 2004, but he was able to see most of the exterior finished before his passing in 2001. Here Lek reinvented himself again and moved from promoting "Eastern" wisdom to promoting a new vision of the cosmos. The Erawan Elephant, besides being extremely large and a wonder of engineering, also has a shopping complex, museum, gardens, and a planned hotel. The construction has largely been the responsibility of Lek's oldest son, Pakpian Wiriyaphan (Khun Daeng), ${ }^{22}$ who, during the construction, was the president of the Thonburi Auto Assembly Company and a senator. The ceiling of the central temple, in the belly of the Erawan Elephant, was done by German artist J acob Schwarzkopf, and the copper on the skin was completed under the direction of Ratchat Srichanjan with copper imported from J apan. The ceramic work was done by Samruai Amoot, who had previously done statues only at Buddhist monasteries and was excited by the challenge of creating something entirely new. Lek's son asked him to create something that incorporated 


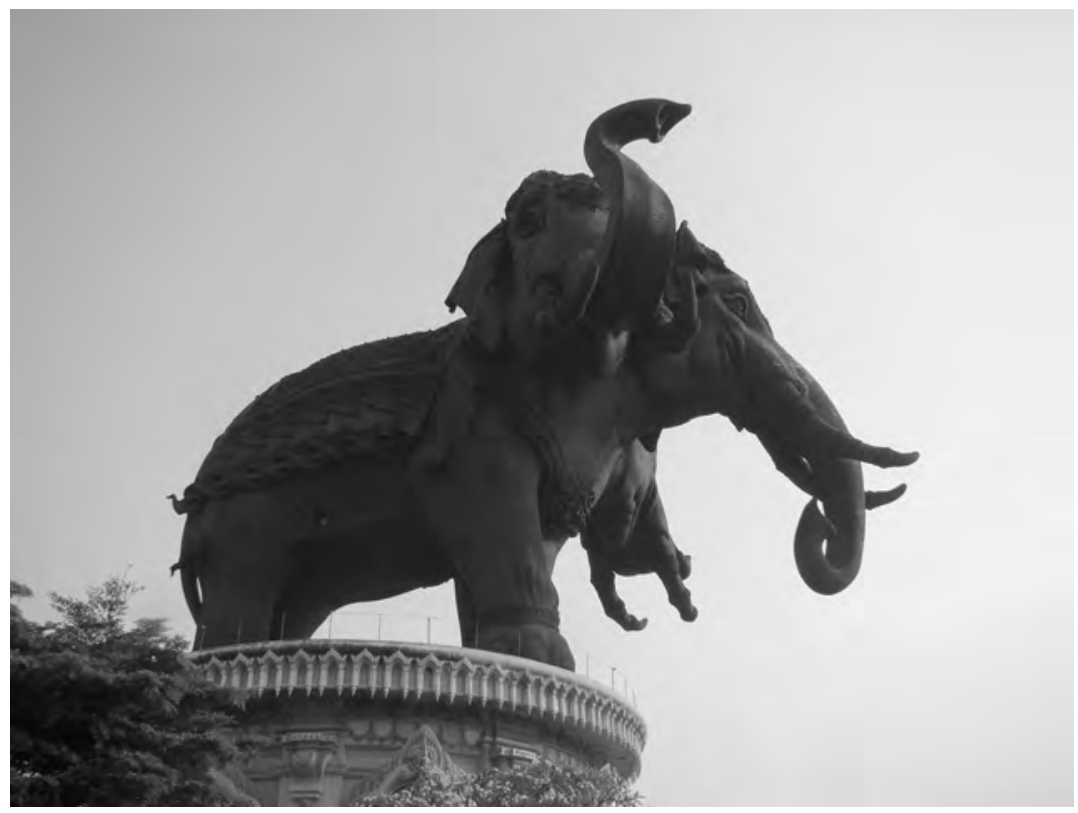

The Erawan Elephant exterior, near Bangkok

Khmer, Ayutthayan, Chinese, and Western designs. The architectural drawings were completed by Charun Mathanom.

Originally, Lek claims, he got the idea for the Erawan Elephant from an unnamed foreign visitor to the Ancient City who stated that he should build a giant apple in homage to worldly wisdom. However, Lek noted that the apple was not universal because no apples grow naturally in Thailand, whereas the elephant is universally known (in zoos and nature programs, at least, I suppose). Underneath the giant elephant is a museum of Chinese, Thai, Indian, and European artifacts with a particularly large collection of Ming dynasty Chinese bowls. The massive iron support columns underneath the elephant's belly are covered not only with Buddhist (primarily Chinese), Daoist, and Hindu bas-reliefs, but also with scenes from the Christian Bible (J esus Christ on the Crucifix, Moses holding the Ten Commandments, and the like). Each of the columns further represents the four Buddhist virtues of metta (compassion), karuṇa (love), upekkhā (equanimity), and mudita (rejoicing with others' success). Lek believed the elephant protects Thailand since it was the mount of the king of the gods and therefore the center of the universe. The planets are symbolized by sculptures of a cow, lion, buffalo, horse, dragon, tiger, deer, the god Viṣnu riding the mythological Garuda, and another elephant. The god Siva protects the entrance to the museum and the base of the complex, and Guanyin is the main sculpture in the interior before 
ascending the staircase or elevator to the Buddhist temple, which contains Buddha images from many different countries. The entire ceiling is a stainedglass representation of the Western zodiac. The construction methods also took "green" technology into consideration, as the glass chandeliers and ceramics are made of recycled material including Heineken, Singha beer, and fish-sauce bottles. Lek believed that global spiritual renewal is needed for the salvation of humanity, and that renewal should begin in his elephant at the center of the world.

Lek was not finished, though. One of the places Lek and Braphai liked to visit was on the coast near Bangkok, in the heavily ethnic Chinese area between Chonburi and Pattaya. Here, he said, on a small peninsula that he liked to look out at the sea and expand his mind. He and Braphai had purchased the land, but it was not until late in his life that Lek turned his attention to it. On the peninsula, he would construct one of the largest wooden buildings on earth. Although the building was still under construction (like the Erawan Elephant) when he passed away, it had already reached 345 feet in height. The building, in the shape of a huge temple resting on a ship, is covered with over five hundred statues and reliefs, entangled together, similar in some ways to the great Meenakshi temple complex in Madurai (Tamil Nadu, India). Although it shows clear Chinese, Indian, and Thai influences, no one style dominates, and there is nothing like it anywhere. Indeed, as Lek stated, it is a building not for the people of Thailand, but for all humanity. He believed that materialism was overtaking humanity and that "Eastern" wisdom could combat this by inspiring people to return to religious and philosophical thoughts and conversations. ${ }^{23}$ His introduction to the philosophy of the Sanctuary of Truth (Thai: Prasat Sacchatham), written in English and Thai, says that

Man cannot be born and exist without seven creators. The Sanctuary of Truth presents seven creators through carved wood sculptures which adorn its interior. They are: Heaven, Earth, Father, Mother, Moon, Sun and Stars. On top of the four spires of the sanctuary, the four elements that will lead to the ideal world according to eastern philosophy are presented: a wood sculpture of a celestial body (Deva) holding a lotus flower, representing the establishment of religion, the pillar of the world; a wood sculpture of a celestial body holding a child and leading an elderly person, which represents life bestowed upon human beings; a wood sculpture of a celestial body holding a book representing "the continuation of immortal philosophy"; a wood sculpture of a celestial body with a pigeon perching on his hand, symbolizing peace. On top of the tallest, central spire is Kalaki mounting a 
horse, the symbol of Phra Sri Ariyametrai [Sanskrit: Maitreya]. Phra Sri Ariyamethai was the last Bodhisattva to achieve enlightenment in the world and become the fifth Buddha in the Bhadhra era (i.e., the present era). ${ }^{24}$

Lek goes on to explain that a battle is being waged between technological forces (associated with the West) and religious forces. A series of carvings of scenes from the Mahābharata and Rāmāyaña symbolize this battle. The battle between parents and children is symbolized by the avatars of the Hindu god Viṣnu; children must learn to respect their parents. There are also sculptures of Chinese immortals, bodhisattvas such as Guanyin and Mañjuśrī, and numerous animals.

Lek's thoughts grew increasingly disconnected from any tradition as he moved from creating a replica of Thailand's religious and cultural treasures to creating a monument to his own vision of the universe. This may explain why the royal family of Thailand has visited only the Ancient City and not Lek's other two projects, and why Thai scholars have largely ignored his work while Western scholars have completely ignored it. His creations do not fit into national, ethnic, religious, or other categories and are more like amusement parks (sans roller coasters) than like monasteries, monuments, or museums.

Since Lek's passing, the Sanctuary of Truth has become more and more like an amusement park. I imagine Braphai and he saw the potential of the Pattaya resort region and prime oceanside property when they purchased the land: this area would growin the late 1980s to the most visited tourist area on the entire Thai coast. It is still hugely popular, and the Sanctuary of Truth is now surrounded by several high-rise resorts and expensive condominium buildings. This particular neighborhood north of Pattaya has also become a hot spot for Russian tourists over the past eight years. Most restaurant signs and menus are in Thai, Russian, and English. Many Thai business owners, waitresses, and taxi drivers in the area (especially in Sois/Sidestreets nos. 12- 16 off Na Kleua Road) speak a smattering of Russian for the many sunburnt Russian retirees wandering around in flip-flops and bathing suits, and there is also a large Russian Orthodox church.

Members of the Wiriyaphan family have adapted to the changing times and have added many features to the site to entertain visitors who are probably more interested in leisure pursuits on their holidays than in reflecting on the meanings of the spiritual war Lek saw coming or the meanings of individual images from the Mahābharata. The site is now run by one of Lek and Braphai's sons, Pichan, who spends much time at the site but does not grant interviews and rarely seeks out chances for publicity or provides updates on the construction. His chief of staff gave me much information, though, and one of the artistic directors guided methrough the workshops and the grounds, 


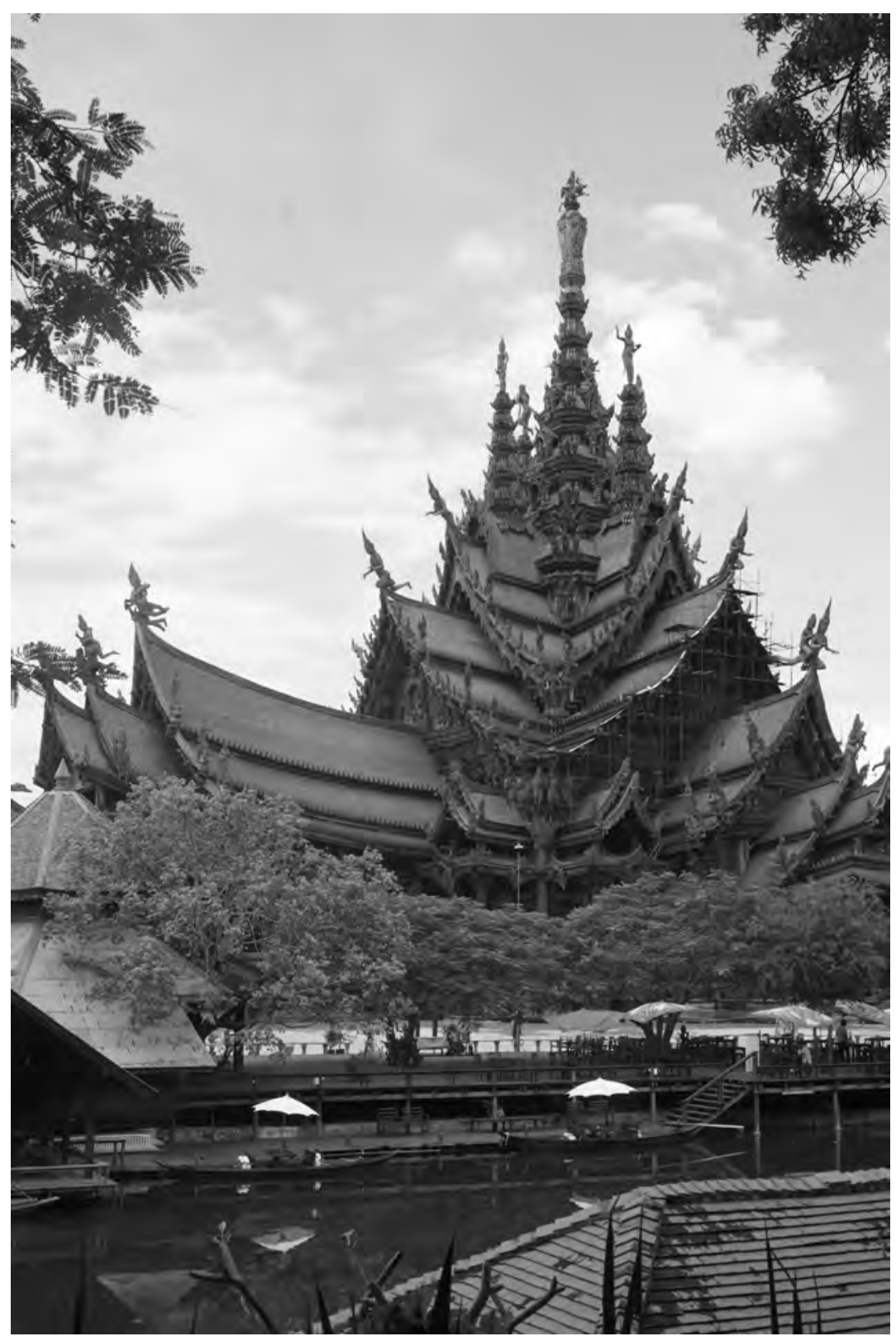

The Sanctuary of Truth exterior, near Pattaya 
which are impressive. Inside the large entrance gate is a ticket booth and the management office. Visitors can rent all-terrain-vehicles (ATVs) to ride for fun along the beach and around the grounds. Young couples and families can also ride horses, rent horse-drawn carriages, have their photographs taken with live elephants, or even take elephant rides. There is a petting zoo, a fish feeding area, a shark observation area, photo booths, souvenir stands, and paddle boats to tour around the man-made ponds. One can even go parasailing or take a ride on a speedboat. A children's camp on-site has a stage for children's music performances and a campfire area.

All this surrounds the huge sanctuary itself. Although it is an active construction site, and all visitors who enter it have to wear hard hats, what has been accomplished is stunning. Inside, a visitor is dwarfed, looking up at massive wooden carvings, thick teakwood beams, and the faces of Ganesha and Brahma speckled with light filtering through the elaborately carved windows. Since it is still an open-air building with no doors or glass, the sound of the waves crashing on the stone ramparts echoes through the large rooms and corridors. Signs in Russian, Thai, and English explain the images in great detail, and staff is available to explain the stages and technology of the construction. There is also a small museum and restaurant. The construction crew consists of 350 workers, most of whom live on-site in a large dormitory. Many of the workers are Burmese and Mon, while some are Lao, Cambodian, and Thais. They make an average of 290 baht a day (about eight US dollars, which is a good lower-class wage in this area) and receive housing and meals. The chang kae salak (wood carvers) are primarily women, and many speak Burmese to each other; they are trained on-site, work eight-hour days, and have chances for advancement. Crew managers can make up to six hundred baht a day.

After interviewing a few workers who spoke Thai (and practicing my minimal Burmese language skills with a few others), as well as a crew manager, I had a nagging question that the chief of staff answered for me, although she preferred to be quoted anonymously. I asked, "How can this site make a profit?” I asked because each visitor is numbered; I was visitor number 132 that day, a Sunday, often their busiest day. When I was there before, on a weekday, I was one of the only visitors. If I was visitor number 132, late in the day on a Sunday, at the height of the tourist season, then the Sanctuary of Truth must be losing tens of thousands of baht every day. My suspicions were right. The siteloses lots of money, although she preferred not to say how much. Some days, like on holiday weekends, they had over six hundred visitors, but most days they averaged under a hundred. The entrance fee is five hundred baht per person, with extra fees for speedboat rides, ATV rental, elephant rides, and the like. These activities brought in little more, however, and income from visitors hardly dented the payroll, housing, and food costs for the staff and 


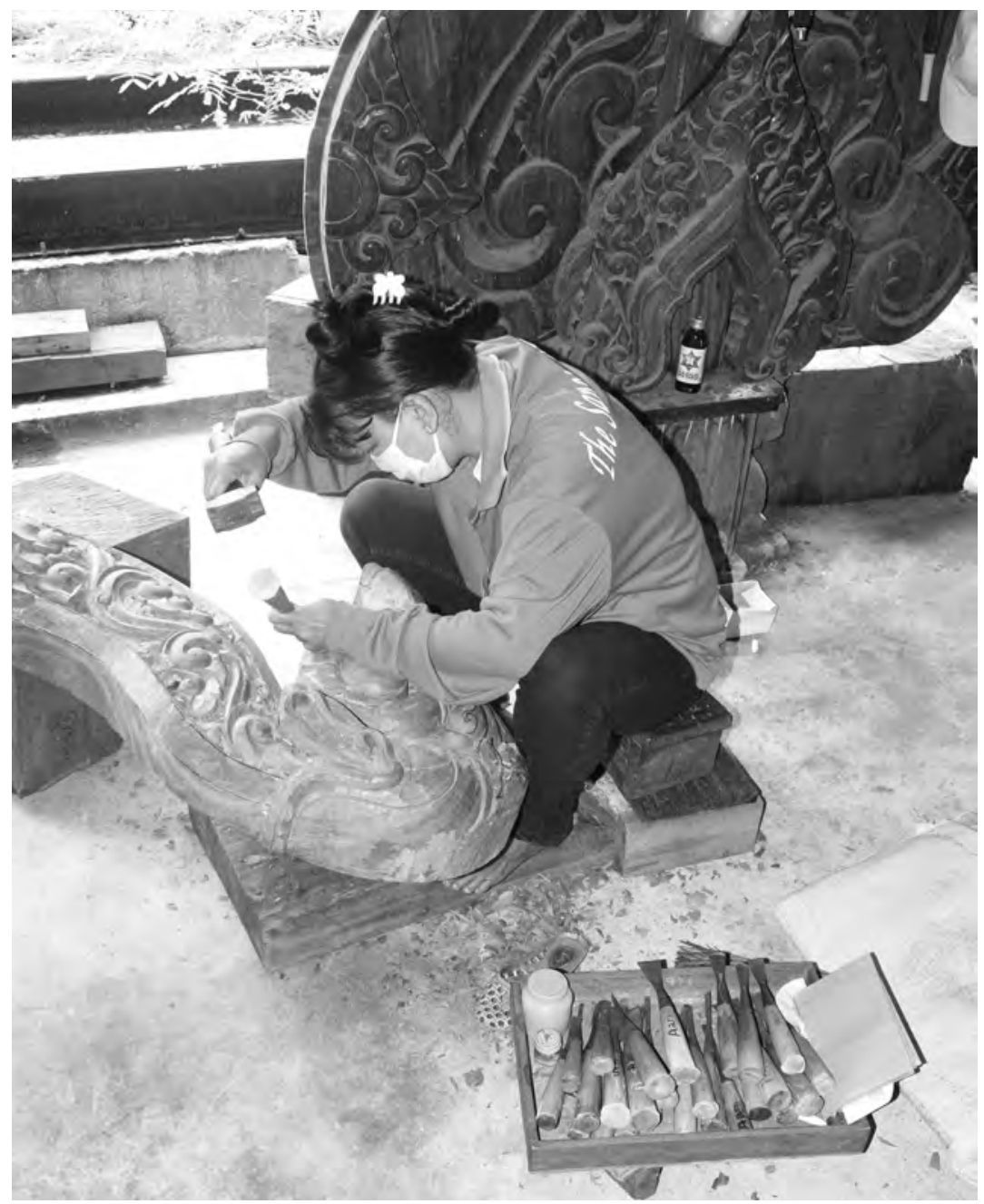

Burmese laborer at the Sanctuary of Truth, near Pattaya

artisans. Then there was the increasing cost of wood, taxes, landscaping, and taking care of the animals. The motive for keeping the site open was clearly not profit. The site was funded by the Wiriyaphan family's many businesses, including the Mercedes-Benz franchises, the local Thai Tata (from India) truck franchises, the publishing house (which also did not make much profit), and the very large Wiriyaphan Insurance Company (Wiriyaphan Brakanphai Chamgat). It was explained to me that Lek's family did not turn the site into an entertainment zone to make a profit, but saw family entertainment a great way to attract people to reflect upon the "truths" that Lek and Braphai wanted to offer the world (about 70 percent of visitors are Thai families and couples, 


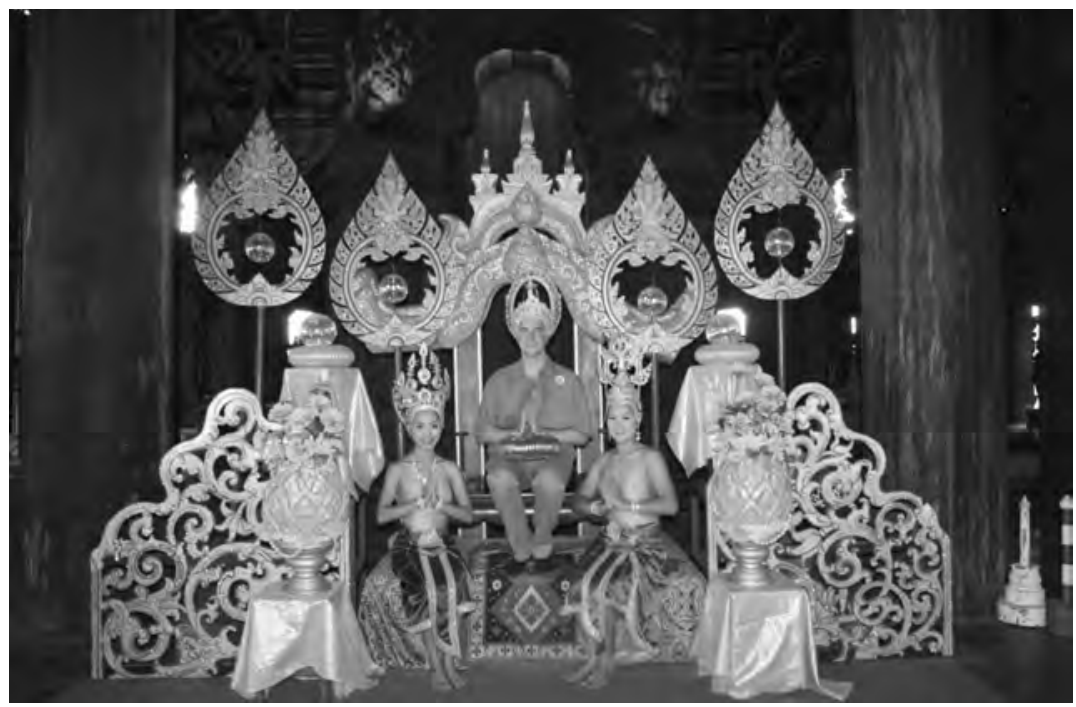

The author taking part in one of the many leisure activities offered at the Sanctuary of Truth, near Pattaya. For a small fee, visitors can dress up as a celestial being.

and the rest are foreigners). Pichan Wiriyaphan, admirably, wanted to continue his parents' legacy. He did not need the money.

The success of Lek's three sites is difficult to assess. They are not particularly promoted by the Tourism Authority of Thailand, are hardly known to scholars of Buddhist studies or Thai studies, and are not promoted heavily on billboards, tourist company tours, or in newspapers. Many visitors who do go to these sights use them as picnic sites for their families and free space to let their children run around without entering the museums or buildings (and avoiding entrance fees, which are not extremely expensive anyway). Others prostrate and offer candles and gifts to certain images in the three sites, although they were not designed for this activity.

It seems that early criticisms of the Ancient City may have been correct and that tourists and scholars are interested in that which is "authentic." Why visit replicas of Thai monasteries and palaces when you can visit the actual sites in Thailand? Why visit Thailand to see parks representing the universe (with an emphasis on Chinese art and Hindu art and religion)? Why go to a wooden temple on the beach when there are resorts surrounding it? Why go to a replica of a monastery when there are no monks in residence, no sermons being given, and no rituals being performed? Unlike Lumbini, which attracts pilgrims, there is no ritual or historical reason to visit these sites. Lek stated clearly that he was willing to sacrifice accuracy for inspiration, and sacredness for aesthetics and awe. He built it, but they did not come. Still, Lek said that he did not care about profits. Indeed, he was already very wealthy, 
and the costs of these sites clearly outweighed any possible short-term return on his investment. Moreover, his children were well taken care of, and he had left a thriving auto and pharmaceutical business (among other smaller businesses) to them. Profit was not his goal. Historical authenticity was not his goal. Ritual efficacy was not his goal. After the Ancient City, clearly Thai nationalism and the promotion of Thai or Southeast Asian Buddhism was not his goal. Buddhism is the primary religious aesthetic force at these sitesalthough even that is debatable at the Sanctuary of Truth and the Erawan Elephant-but it is not the primary intellectual force behind the sites. According to his own account and his main biographer, Sisak, Lek read much more extensively in Confucian and Daoist philosophy than he did in Buddhism. He was never a monk, which is unusual for a Thai male citizen, and never studied Pali or Chinese Buddhist texts formally. His sites are universal in intention: he wanted to entertain, inspire, and create beauty without overly didactic religious or political agendas.

\section{Pseudo-Monastic Hellscapes and Ecumenical Flights of Fancy}

Lek and Braphai's creations are extreme examples of a new type of ecumenical religious amusement park that has been developed at many sites throughout Asia over the past twenty-five years. There is little evidence that the two directly influenced the creation of other sites. However, the long Buddhist tradition of building large-scale statues, stupa, and monastic complexes is demonstrated by the famous 150-foot-tall, sixth-century buddhas at Bamiyan (destroyed by the Taliban in 2001) and the 230-foot-tall, eighth-century, seated Leshan Buddha in China, among others. In the last 150 years, large buddha and bodhisattva images, built disconnected from specific monasteries, have become much more common and popular throughout Asia because of modern building techniques, global capital, and the rise of Asian economies. However, Lek and Braphai were some of the first architects (although untrained) to create largely ecumenical, nonsectarian, non-pedagogical (formally), nonecclesiastical, non-ritual, and non-monastic spaces on this scale, where no one school of Buddhism or specific buddha or bodhisattva is being promoted. Looking specifically at Thailand, a number of new spaces like this are worth describing, to put Lek and Braphai's work in context. Unlike Lek and Braphai's creations, though, these sites are embedded within or next to monasteries or are connected to particular monks or holy men. Neither Lek nor Braphai ever claimed for themselves any particular religious insight, meditative power, magical or healing power, or specific political agenda (besides vague calls for national pride, less dependence on technology, and world peace). First let us look at a few sites in Thailand and then expand to other examples in Laos, Korea, and Japan. 
Within twenty kilometers of the Sanctuary of Truth, dozens of leisure spaces take advantage of the crowds visiting Pattaya and Chomtien Beach. There is the Million Year Old Rock Park, the Sriracha Tiger Zoo, Coco Park, the 4D movie theatre, a local chapter of Ripley's Believe It or Not!, the Nong Nooch Tropical Botanical Garden, a Four Seasons Culture Park, as well as some very large Buddhist monasteries like Wat Photisamphan and a large mosque. There is also a large Buddhist college. However, one set of sites dwarfs them all in terms of the number of visitors and the sheer size of the complex: the Buddhist sites of Wat Yansangwararam, Wihan Sien, and the tallest buddha in the world. These three Buddhist sites are located within three kilometers of each other and are part of a large leisure park set in a lush jungle surrounding a man-made lake and dotted by limestone outcrops. Wat Yansangwararam Mahaworawihan is a relatively new (built in 1976), royally designated monastery that has been turned into a museum and sculpture park, more than an active training site for monks, on fifteen hundred acres. The main patrons and builders were a couple named Phaekkichon and Nithiwadi Antrakan, and the present chief monk (sangharat) in Thailand, Phra Yansangwon, was assigned by the royal family to look after the site. More recently Sanit and Bhriya Chimchom, among others, have also donated much to the monastery.

Like a similar site in Kanchanaburi Province along the Burmese border, Wat Yansangwararam combines many different architectural styles, including a very tall replica of the Indian Buddhist temple at Bodh Gaya, a Chinese pavilion, a modern glass temple for public assemblies, and a traditional Thai ordination hall (ubosot). In the front of the monastery is a large parking lot for tour buses, increasingly occupied by the Chinese tourists that have been pouring into Southeast Asia and slowly replacing the crowds of Germans, Danes, Israelis, Japanese, and Australians who used to dominate the tourist crowds. Next to the parking lot is a monument to the present king and queen of Thailand and a large flower garden and fountain. I was struck when I first visited that I did not see one monk in residence. I finally found the abbot's office and was told that the day-to-day operations of the monastery are separate from the tourist area, where people picnic, take photographs, and hear explanations about the different buildings from tour guides over megaphones.

Within a short walk of the "monastery" (although most people take the buses) is the tallest buddha image in the world. Now, this statement needs qualifying: this is not a freestanding statue like the Sendai Daikannon or Statue of Liberty, but an outlined image of a seated buddha carved into a limestone cliff face and painted bright yellow—not a relief that projects from the cliff face, but an etching into the rock. Called Phra Phuttha Mahawachirauttamopatsasada, or more commonly Khao Chi Chan, it is extremely tall, 
measuring over four hundred feet. The carving was done by the Department of Geological Resources in honor of the king of Thailand's fiftieth year on the throne. This particular cliff face was the ideal site because of the surrounding park and lake and because previous mining activity had rendered the mountainside steep and flat. The stone from the mountain was used to build the runways for the Thai-US military airbase, Utapao, during the Vietnam War. Now the mountain is used for a very different purpose. The carving has no monastery connected to it; it is a campsite, garden, and picnic grounds.

Walking from the Khao Chi Chan image across a grassy plain flanked by the Wonder Farm horse-riding center and the coffee shop, one comes to one of the most seemingly out-of-place museums and gardens in ThailandWihan Sien. Wihan Sien, or the Anek Kusala Sala (Chinese name: Ta Pu Ei), is a Chinese museum built by Chinese businessman Sa-nga Kulkopkiat, who made his fortune in Thailand. He was given the land by the king of Thailand in 1987 so that he could build a structure to house his very large collection of Chinese art as a gift to the royal family.

The museum is very large, in classic Tang style, with a sculpture garden outside, two levels of art inside, and a rooftop shrine and veranda holding dozens of large statues of the Daoist immortals and other Chinese deities.

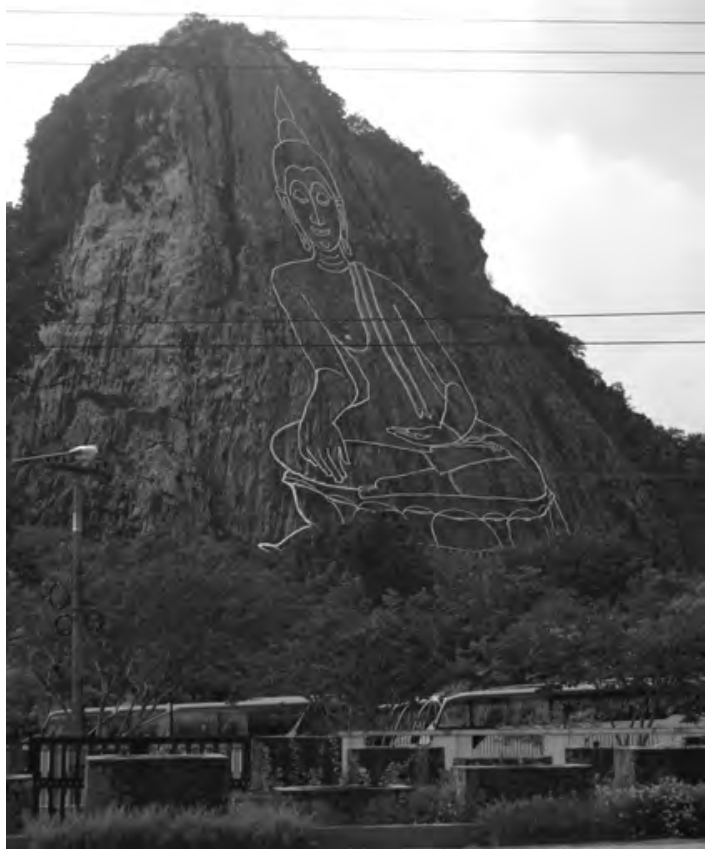


After paying a small fifty baht entrance fee, one enters to encounter a large outside sculpture of the eight immortals in front of a statue of the museum's founder dressed in traditional Chinese robes and seated on an impressive throne. He is flanked by two other statues of Chinese sages, Chou Mang U and Lew Chun Huang. ${ }^{25}$ Sa-nga Kulkopkiat was born in Thailand in 1925 and, like Lek Wiriyaphan, moved to China for his education and spent most of his youth there. He became known as a master of Feng Shui, and his building projects, including the museum, were based on these principles. Before he died in 2003, he built a similar museum in Chaozhou (Guangdong Province, China). Inside the museum are over 350 statues from Chinese Daoist, Buddhist, and Confucian traditions: for example, statues of Maitreya; the Diamond Kings of Heaven; the Twenty-Eight Daoist deities known as the "lunar mansions" like Geng Chun, U Han; the Eighteen Arahants (Chinese: Lohan); the J ade Emperor; the Deity of Soldiers "Guan Di"; Xuan Zang, the Buddhist pilgrim who was helped by the Monkey King on his journey; and other deities like Zhen Wu Ch'iao-sheng Hsien-shih, anChung-t'an Yuan-shuai; Xi Wang Mu (the Chinese Queen Mother of the West); Lu Dong Bin (a famous sword fighter and healer from the Tang dynasty and a personal favorite of Sa-nga Kulkopkiat); Yao-shih Fu (the Medicine Buddha); and at least fifty statues of Guanyin. There are also replicas of Dun Huang Cave paintings, replicas of the Xian terracotta warriors, and a large miniature version of the Great Wall of China.

In a separate room next to the gift shop is a shrine to Sa-nga Kulkopkiat himself, including his personal chairs, his bed, family photographs, writing desk, and the like, as well as photographs of him with the royal family of Thailand, paintings of him with his sons and with the late Sangharat (head of all Buddhist monks in Thailand) Phra Yansangwon, and a life-size resin and wax statue of him. His son, Winai, now runs the museum, which displays a large painting of him as well. In order to maintain the appearance that this is not an attempt to promote Chinese religion, history, and art over Thai heritage, on the top floor above the Chinese deities is a very large Thai-style image of the Buddha with a shrine for making offerings in front of it. A separate room promotes Thai Buddhist art, and paintings of the nine Thai kings of the Chakri dynasty are also placed above statues of the three main Daoist deities and a large image of Guanyin on the main floor. Like Lek's Sanctuary of Truth, built a short drive away, the Wihan Sien does not make a profit. It cost over 220 million baht (seven million US dollars) to build and has a large staff. The art work alone is priceless. The entrance fee is less than a dollar but the manager said that many tourists, even from China, skip visiting it, as they came to Thailand to see Thai things, not a regional, although impressive, Chinese museum. For Thai families, though, it has become a popular site for photographs and even for Chinese-Thai weddings and family reunions. 
Moving away from the coast, we find many other Buddhist leisure sites that are not built in tourist areas. In a previous study I looked closely at the life of the most famous monk in Thai history-Somdet Phra Buddhācāriya Brahmaramsī To (Thai: Somdet Phra Phutthachan Phrohmarangsi To) hereafter Somdet To ( 1788 to 1872). He was a famous magician, healer, teacher, scholar, and had connections to the Thai royal family. Thousands of statues of Somdet To are found throughout Thailand and among Thai communities abroad. In fact, two new images of Somdet To, in Prachuab Khiri Khan Province and Nakhon Ratchasima Province, both finished in 2007, are now the largest statues of any monk in Thailand; each is over sixty-five feet tall.

While most of these statues are located within monasteries, the largest is in a non-monastic compound, open to the public and built under the supervision and funding of Sorapong Chartree, the award-winning star of numerous major Thai films. He believes that he is indebted to the power of Somdet To for helping his career. In 2004 he commissioned a huge sixty-fivefoot-tall statue of Somdet To, as well as an entire image hall and garden, built along a highway in Si Khiu District in the rural northeastern province of Nakhon Ratchasima. Somdet To's signature Pali-language chant, the Jinapañjara (Verses on the Victor's Armor), is played on a giant stereo system at this complex. Sorapong is the self-designated president of the Somdet To "fan club" (called by that name, in English) and has spent the equivalent of several million US dollars on this site.

When I visited the site for the first timein February 2008 I was struck not only by the immense size of the statue of Somdet To and the ornate mixed Thai- and European-style building that was built specifically to house this image, but also by the over fifty acres of gardens, reflecting pools, waterfalls, and fountains. The entire complex is served by several restaurants and shops selling Somdet To t-shirts, umbrellas, CDs of the Jinapañjara, amulets, and the like. I spoke with one of the tour guides, Somchit, who kindly gave me two amulets and a book describing the J inapañjara, and he explained that the entire building, which was still under construction, would be covered in Italian marble. He also showed me a large glass panel inscribed with the Jinapañjara in gold leaf and lists of the thousands of people, besides Sorapong, who had donated hundreds of thousands of Thai baht to help build the building and forge the image (which is claimed to be the largest in the world). Besides building the image of Somdet To, the foundation started by Sorapong had donated over one hundred computers to a local rural elementary school, several cars to an orphanage, and supported other charity projects. For the groundbreaking ceremony, a stadium was rented and marching bands entertained the crowd of several thousand. While there are many very tall statues of the Buddha in Thailand, like those mentioned before in China, Japan, and Burma, in Thailand there is a growing movement to create large public statues of fa- 
mous monks like Somdet To and the famous Southern Thai monk Luang Pho Tuat. These statues are often connected, loosely or directly, to monasteries, but many people who visit these statues offer gifts, prostrate and perform short chanting rituals, and have a picnic or shop, but do not participate in more formal monastic ceremonies.

Lek and Braphai never became monastics; conversely, some Buddhist public and leisure places have been started by monks but are not monasteries. ${ }^{26}$ For example, in rural Petchaburi Province, near the Thai-Burmese border, the monk Luang Pho Ariyawanso Bhikkhu (lay name: Dr. Suchat Kosonkitiwong, also spelled Suchart Kosolkitiwong) (1943-2005) founded the Guanyin Inter-Religious Park in 1997 after a failed attempt to open a similar park in the late 1970s. ${ }^{27}$ He had been a monk only since the age of fifty. He did not train monks, receive much formal monastic training himself, or reside for long at a monastery. The park he founded is nowhere near the size of the Ancient City or the Erawan Elephant, but it boasts many objects on its small compound.

Luang Pho Ariyawanso/ Dr. Suchat wanted to create a space that was open to people of all religions. He claims that he had spent years in the 1950s and 1960s working as a thammathut or Buddhist "emissary," working for the Thai government in their attempts to weed out Communists in northeast Thailand, especially in the city of Nakhon Phanom (near Laos). After this work, he saw the value of religion in general to fight communism and started ecumenical interfaith meetings; spoke with representatives of the Sikh, Christian, Catholic, and Hindu communities of Thailand; and began collecting and commissioning objects from these different traditions. He launched the Office of the World Peace Envoy, which had a letter-writing campaign to urge world leaders to commit themselves to peaceful resolution of their domestic and international problems and offered awards (in absentia) to those international leaders who worked for peace, likeYitzhak Rabin, Yasushi Akashi, J esse J ackson, and others. He invited the Dalai Lama and other prominent Buddhist leaders to visit his park, and held meetings that included Catholic priests, Brahmins, rabbis, Imams, and others. But, it appears, most invitees did not visit the park. He even tried to host ecumenical prayer sessions and ceremonies honoring the dead at Nagasaki and Hiroshima, pray for the health of the Thai monarch, and conduct rituals to prevent future disasters; Brahmin ritualists and Buddhist monks conducted most rituals.

The park reflects the purported values (and perhaps paranoia) of Suchat. He claimed that he started the park because he was concerned with the impending disasters that were going to face the planet environmentally and militarily (at first in 1999 and then, when that did not come to pass, he predicted massive destruction in 2007). After Suchat passed away, Dr. Thongmoah Champangern (secretary-general of the Office of the World Peace 
Envoy) posted a disturbing letter on the front page of the organization's website, containing a mixture of Buddhist cultural and religious beliefs about the role of the evil figure of Mara, as well as vague references to traditional and systematic jhāna meditations well known to certain lineages of practitioners throughout South and Southeast Asia. Apparently, he was also concerned with aliens and wanted to build images protecting the Earth from what he believed were imminent asteroids. No one at the park wanted to speak with me about these claims. The letter reads

H.E. the World Peace Envoy, the Most Venerable Ariyawanso Bhikkhu, Dr. Suchart Kosolkitiwong who had obtained a very important information emerging from his meditation, told me that the world is experiencing severe disasters during these coming threeyears. You certainly have expert scientists who can prove that an asteroid or meteor is moving towards our globe and will hit the earth on the 14th February 2005. H.E. the World Peace Envoy prayed for help from the enlightened souls in the universe, as well as the aliens, to deviate the direction of the asteroid from our globe. However, in spite of the deviation, the globe might shake tremendously and could entail great natural disasters such as earthquakes, tidal waves (tsunami), eruption of volcanoes, explosion of stockpiled nuclear weapons capable of completely destroying the world. The universe might burst into parts because the astral circuits could lose their balance. Moreover, as a revenge for the eight Venusians dead in the UFO shot down by the U.S.A., the World Peace Envoy told me that the Venusians and the Martians are preparing to wage war against our world. With his firm resolution, the Most Venerable Ariyawanso Bhikkhu, Dr. Suchart Kosolkitiwong, the World Peace Envoy, who dedicated himself to the World of Souls to work towards protecting 5,000 year era of Buddhism, and to save the world and the universe, has decided to abandon his body (no long alive) on the 7th J anuary 2005, bringing away his mind and soul through the Fourth Level of Meditation Attainment (J hana). This procedure is a dedication to save mankind and the world. H.E. the World Peace Envoy who hoped to live to negotiate with aliens when they invade the world, has decided to discard his life after he disclosed the coming asteroid. He wanted to disclose further secret of heaven and earth on the doomsday of the world [but] Satan (Mara-Devil) prevented him by destroying his body and the functioning of his life. Therefore, on behalf of H.E. the World Peace Envoy, I wish to forward this information to you and other peace leaders of the world, pleading for your help to unite 
people's power to pray to God so He protects you and the people, as meditation power will halt military power. I should be most grateful to receive your message of condolence which will be entered in the book published in memory of H.E. the World Peace Envoy Dr. Suchart Kosolkitiwong (the Most Ven. Ariyawanso Bhikkhu). I am sincerely looking forward with high hope and respect that you will join hand with other world leaders to protect the world to eternal safety. With best wishes for humanity and may humans live together in peace. ${ }^{28}$

Although Suchat grew up in the Thai-Pali Buddhist tradition and was ordained as a monk in the Thai Sangha, the park is named for its focal point, Guanyin (Sanskrit: Avalokiteśvara; Japanese: Kannon; Thai: Guan Im). The statue is of Chinese design and was carved in Shanghai. Dr. Suchat claims that it is the largest wooden image of Guanyin in the world. It has a thousand arms that are supposed to reach out to support humanity. ${ }^{29}$ Although this is the central image of the park, it is not the only focus. Indeed, there are statues honoring what he called the "twelve great world religions." There are images of Śiva, Brahma, Maitreya, goddesses and spirits like Nang Torani, an entire section of the park called "the Land of Mahāyana-Tao" (Thai: Taen Mahayan-Tao) with statues of the J ade Emperor and other Daoist immortals and painting images of the yin-yang symbol. Although the park is supposed to honor many religions, not only those based in Asia, little is built there in honor of Islam, Christianity, or J udaism, although they are respected in the brochure and on the website. In my brief interviews at the site, no one seemed to know why these sections of the park were not built. Since Dr. Suchat's passing in 2005, there appears to have been little growth. Since most of the images and the participants are Thai, and services are conducted and literature is written in Thai (even if many invited guests adhere primarily to the Sikh, Hindu, or Daoist traditions), it is a local site that is concerned more with local politics and economics than promoting ecumenical values and world peace.

Another site started by a monk, the hell park at Wat Muang, in the province of Angthong, further questions the relationship between the secular and religious roles of a monastery. Like Soropong's non-monastic park surrounding the giant statue of Somdet To, and Suchat's Guanyin Park, this park also has a large statue, this time of the Buddha. The Buddha image, representing Śakyamuni (the historical Buddha) is in the Earth-witness gesture (Sanskrit: bhūmisparśa mūdra), seated in meditation with one hand touching the ground. It is the largest seated image of a buddha in the world, measuring over three hundred feet tall, and is located on the edge of the monastery grounds in the center of rice paddy. Visitors have started a tradition of touching their heads to one of the massive fingernails of the statue for good luck. 
Wat Muang does not attract many foreign visitors, because it is not located near any major city or beach and is difficult to reach by bus or train, but it does attract local school groups learning about Thai history and religion, and curious Thai pilgrims, especially those interested in protective tattoos, although this practice has waned since the passing of the abbot in 2001. You can see the statue from many miles away; it is a dramatic scene, since it is covered in gold paint and, from a distance, looks like the Buddha is floating in the middle of a giant expanse of verdant paddy. However, the statue is not alone. As you get closer, you realize that it is surrounded by hundreds of smaller statues and several fantastic buildings. The statue was finished in 2008, but Wat Muang itself was built in the 1950s. Since that time it has grown incrementally and now encompasses dozens of acres. The monastery is now a small afterthought next to a sprawling sculpture garden.

Wat Muang was started by the monk Luang Pho Kasem Achansupho (also known as Phra Khru Wibun Achankhun), who passed away in 2001. When he was active at the monastery, he struck a fearsome pose..$^{30}$ Unlike most Thai monks, he wore dark maroon robes and was almost completely covered (except for his face) in protective tattoos. Tattooed monks are relatively common in Laos, Cambodia, and Thailand, but the extent of Luang Pho Kasem's tattooing was striking. He was well known for being able to predict winning lottery numbers, perform healing ceremonies, and meditate for long periods of time. His mummified body is still at the monastery in a glass coffin within a monastic hall (Pali: vihāra; Thai: wihan). The interior of this hall is completely covered in mirrors (ceiling and walls) and is blinding when you enter. Most people don't enter, though, when they visit this monastery, because they spend a great deal of time in the sculpture park. Thai school and tour groups have limited time, and the park and the giant Buddha take up most of that (many try to rush the groups through three or four monasteries or historical sites in one day, and folks are always being bellowed at over megaphones to hurry up and get back on the bus. I worked as a public school teacher in Thailand in the early 1990s and remember pestering my own students to get back on the bus and stay on schedule). Luang Pho Kasem's corpse sits lonely in his hall of mirrors; he has been overshadowed by the creation that he started in 1990. His park and statue weren't completed until almost a decade after his death. Even today, the lay committee working at the park is planning new developments that will probably further marginalize his work.

The role of thelaity is even promoted in the monastery, though, which houses prominent statues of two local lay patrons and teachers, Kaeo Khamwibun and Thianchai Rungruaiyat, now deceased. Their statues are placed among other statues of previous monks and abbots at Wat Muang, and they are depicted sitting in meditation like the monks and wear white robes in a style similar to the monks' saffron-colored robes. This placement works to 
subtly elevate their status as nearly equal in the lineage of teachers at the monastery.

Today not many monks are managing day-to-day activities at the monastery or the park at Wat Muang (during the rainy season of 2010 fifteen monks and fourteen novices were in residence). It is largely run by Buddhist nuns (mae chi) and lay women and supervised by Phannipha Kulabut, a wealthy retired woman from Bangkok (although she likes to stay behind the scenes in an office). She was a government official before deciding to dedicate her life to the sculpture garden. She helps bundle donations from wealthy people in Bangkok and wants to promote Angthong as a place to visit because it was the site of a famous battle (Wiset Chai Chan) between Thai and Burmese forces in thelate sixteenth century. As a history and literature buff, she wants Thai children to be taught Thai heritage in a creative way. Besides her work managing donations and overseeing construction, Phannipha is assisted by numerous lay gardeners, artists, and handymen. The sculpture garden, known in Thai as Suan Narok (Hell Garden) is largely free to stroll around in, with no formal tour guides and no entrance fees, just a series of signs identifying the names of the statues. Considering that the published cost of this sculpture garden and giant seated Buddha was 104,261,089 baht (three and a half million US dollars) and the mirrored vihāra was 25,497,789 baht (835,000 US dollars), this entire monastic project was not an afterthought by a strange lay fanatic.

Most of the statues at the Wat Muang hell park are depictions of people suffering in the various levels of Buddhist hell (Thai: daen narok). For a visitor unaccustomed to Thai Buddhist grotesque aesthetics (which are largely shared by Cambodian, Sri Lankan, Burmese, and Lao Buddhists, as well as having overlapping understandings with North and East Asian Buddhist cultures), featuring graphic depictions of hell, this park can be part traumatizing, part absurd, and all surreal. There are hundreds of garish and amateurish statues of partially naked women and men being tortured, burned with hot irons, stabbed, sawed in half, crushed by rocks, ground up in winches, forced to eat each other's flesh, eaten by wild animals, boiled in large iron cauldrons, or having their bones broken or having molten lead poured down their throats. One statue, about thirty feet tall, depicts naked lovers being forced by ogres to climb a tree covered in spikes. There are two forty-foot statues of hungry ghosts (Sanskrit: preta) with bulging eyes, stretched-out tongues, and the bloated stomachs of starvation victims. These stories are found commonly in Thai folklore, on monastic murals, and in illuminated manuscripts, as well as in modern religious guidebooks and even comic books. Standing next to the hell sculpture garden are rather large statues of Indic Buddhist monks popular in Southeast Asian narrative traditions, Phra Malai and Phra Sivali.

The park has several other sections besides these with the gruesome depictions of hell. A pond full of fish invites feeding by children and adults 


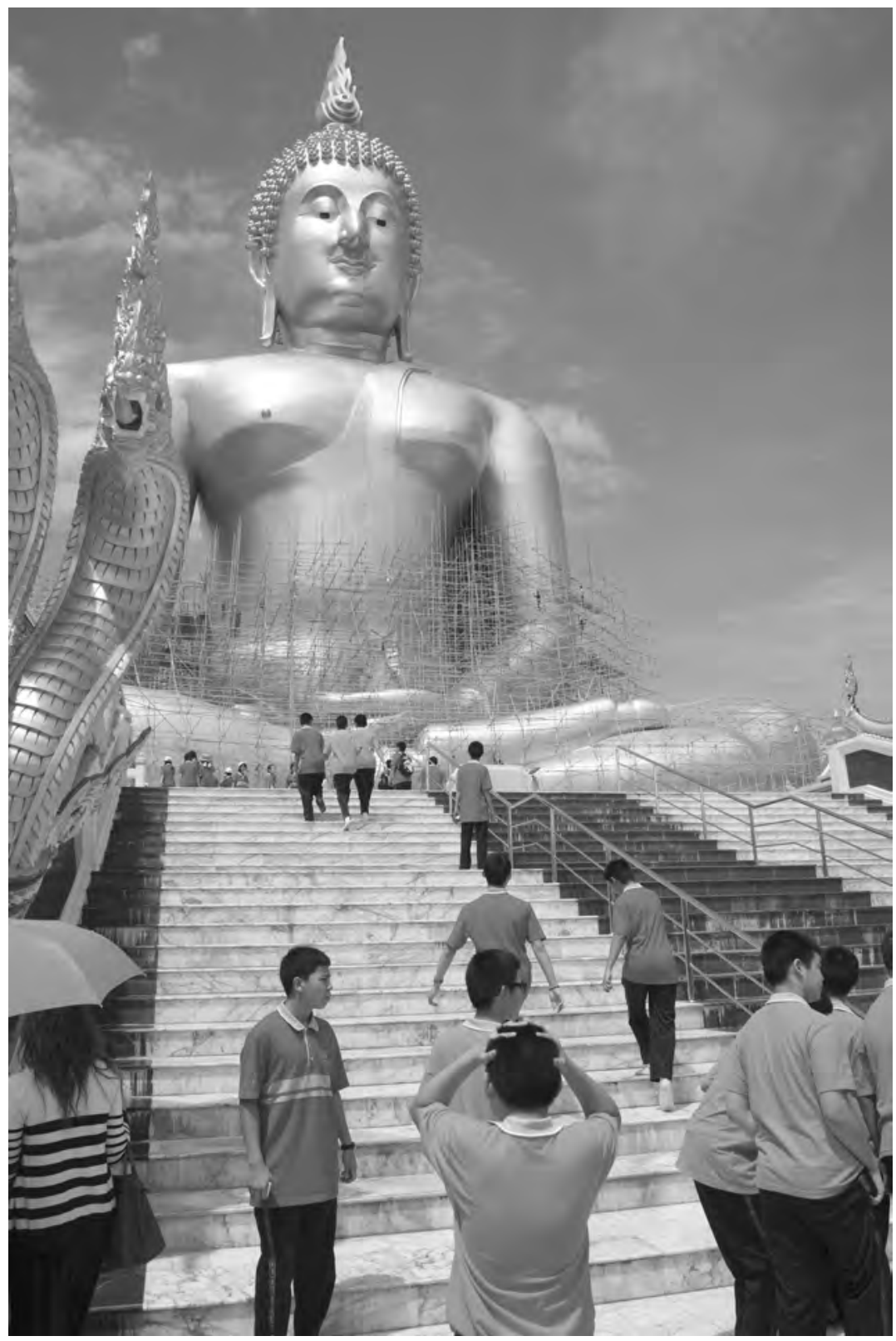

Giant Seated Buddha at Wat Muang, Ang Thong 
and brightly colored paddle boats provide pleasure trips in the pond. A section on Thai history features life-size statues and dioramas depicting famous battles, like the one at Wiset Chai Chan led by King Naresuan, next to mythological battles featured in the Indic/Sanskrit epics the Mahābharata and the Ramāyāna (Thai: Ramakian). ${ }^{31}$ The local Angthong war heroes Thong Dok and Thong Kaeo are raised to the level of national and mythological statues by being placed next to these sets of statues. Thai literature is well represented, and all thirteen chapters in the Thai telling of the Pali Vessantara J ātaka are depicted, alongside scenes from the Thai epic poems, Khun Paen Khun Chang, and Aphaimani, and Thai ghost stories.

Wat Muang is not just a site promoting Thai history or Thai Buddhist stories. As at Suchat's Guanyin Inter-Religious Park (but much larger.), the park includes a section featuring the eight Daoist immortals (Thai/Teochiu: Boi Sian) such as Cao Guojiu, He Xiangu, and Lan Caihe, as well as other Chinese gods and sages like the J ade Emperor, Confucius, Lao Zi, and Mazu. Also featured are the three planetary deities $\mathrm{Fu}, \mathrm{Lu}$, and Shou (Mandarin Chinese) or Hok, Lok, and Siu in the Teochiu Chinese dialect written and spoken among many ethnic Chinese speakers in Thailand. ${ }^{32}$ They represent good fortune, prosperity, and longevity. Another section features local Thai female deities such as Mae Nang Thorani, Mae Pho Sop, Mae Takhian Thong, Nang Kwak, and Mae Nang Phayakalong. The eighteen Buddhist arahants popular in

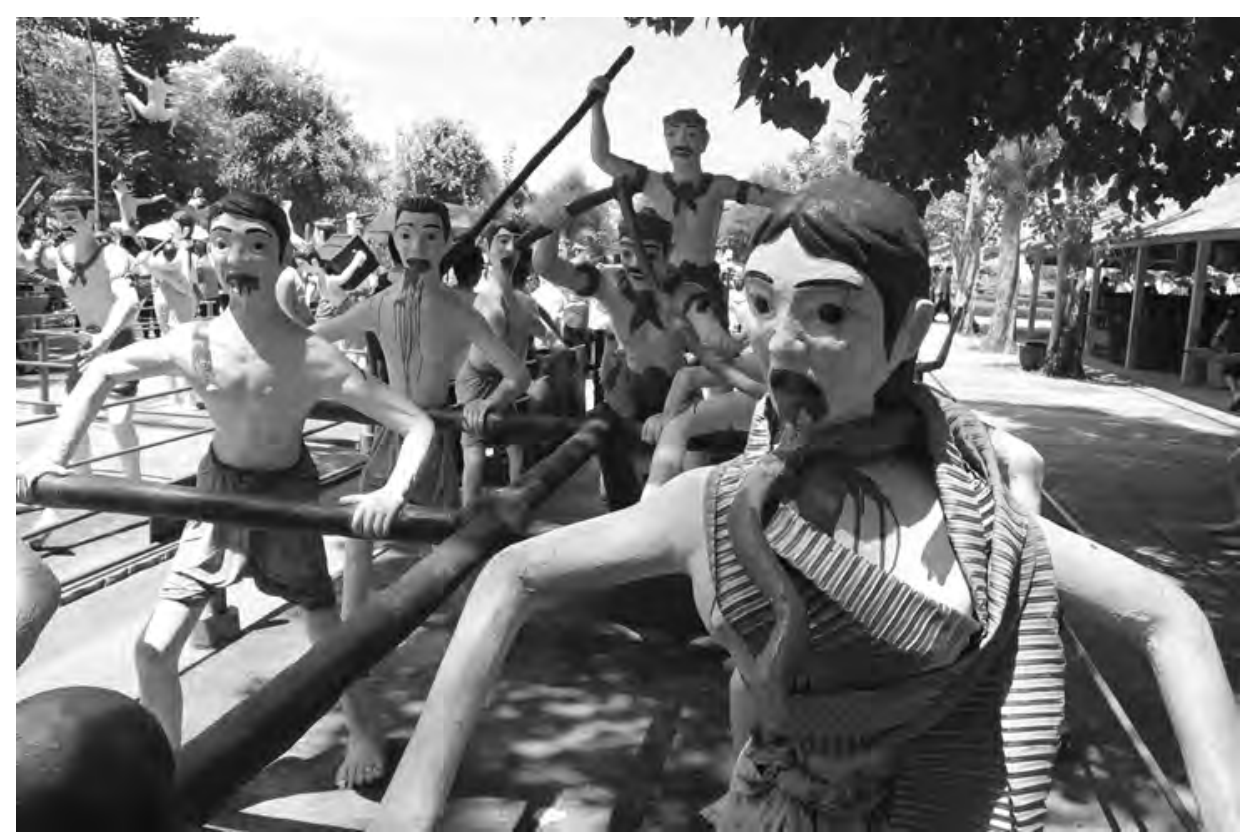

Hell park at Wat Muang, Ang Thong 
Chinese Buddhist art (like Vajraputra, Nāgasena, Kālika) are placed next to the Indic gods connected with the days of the week and the planets. In addition, a Chinese pavilion of approximately seventeen stalls sells amulets, food, and souvenirs, and a small museum features local archeological pieces.

About fifty meters outside the entrance to Wat Muang's hell park are two other impressive sites. The first claims to be the largest ubosot hall (English: ordination hall; Pali: uposatha) in Thailand. This very large building is built on top of a sculpted lotus flower painted in bright pink. A stone's throw from this building, not to be outdone, is a pavilion with a gold statue of the Thousand-armed Guanyin (Thai: Phra Mae Guan Im Mahaphotisat Bhang Phan Meu), which also claims to be the largest of its kind in Thailand (a claim to which Suchat, if he was still living, might object). Unlike the hell park, this pavilion and statue were sponsored independently by patrons from Bangkok named Sompong and Saowalak Thimongkhonkun and completed in 2002. It has its own shop, ritual instructions, and was initially consecrated by Chinese Mahayana monks (Thai: nikai jin) from Bangkok. This type of independent patronage for particular images and buildings at Thai monasteries is common and is comparable to buildings and rooms of concert halls, universities, or museums being sponsored by wealthy families in North America.

In order to convey the detail and the ecumenical nature of this sculpture garden, permit me to simply list the variety of one set of statues. One of most impressive is the Phra Reusi (Sanskrit: Rși), or hermits, usually associated with Hindu religions but commonly depicted in Thai Buddhist monasteries and narratives. Each is in a different pose, with different ritual implements. They are united in that they all wear tiger fur or skin robes, have long white beards, and sit in meditative positions. I briefly mention their notable features here: Pho Bhu Reusi Phrohmalok (seated deep in meditation), Pho Bhu Reusi Isuan (cobra around neck), Pho Bhu Reusi Thosamungkhon (conical hat), Pho Bhu Reusi Palaigot (wearing a crown), Pho Bhu Reusi Ta Fai (third eye), Pho Bhu Reusi Ta Wua (large "cow" eyes), Pho Bhu Reusi Narai (Indra holding a conch shell and lotus flower), Pho Bhu Reusi Narot (Narada, very long beard), Pho Bhu Reusi Borom Kru Horasat (writing on a scroll depicting, I imagine, his calculations of astrological charts, or Horaśāstra), Pho Bhu Reusi Kru Wan Ya (using a mortar and pestle to crush herbs into medicine, or ya), Pho Bhu Reusi Borom Kru Phra Wet (reading a manuscript, I imagine, representing the Vedas/ Phra Wet), Pho Bhu Reusi Kassapa (Kaśyapa, seated deep in meditation), Pho Bhu Reusi Uchu (wearing beads), Pho Bhu Reusi Muni Tapasa (holding a walking stick), Pho Bhu Reusi Chiwok (Jivaka, unlike the others he is dressed in white and doesn't wear a hat). ${ }^{33}$

This sculpture garden works as an outdoor classroom for the panoply of Thai religion, history, and culture, and Phannipha promotes this. Since 
I have written about Buddhist teachings and depictions of hell realms, Phannipha asked me one day whether I would be interested in helping give a tour for two school groups from regional Thai public schools-one preschool (threeto five-year-olds) and one middle school (twelve- to fourteen-year-olds). I agreed to walk around with the children and their teachers. The teachers had flags and megaphones, and everyone was wearing brightly colored uniforms except me. I knew a little of what to expect, since I had given a similar tour of murals depicting gruesome hell scenes to a group of eight-year-olds in Luang Phrabang (Laos) in 1995 when I was a Buddhist monk. As in 1995, the children were not particularly upset by the bloody images they saw. Some of the kids said the Thai equivalent of "Ew, that's gross," but most just joked around, pinched each other, participated in mild flirting, and generally were happy that they were not in class memorizing multiplication tables or lists of historical facts. They were used to this type of thing. None of them showed any sort of reverence or seemed to me to spend intense time considering ethical conundrums. I imagine a few wrestled with certain issues in the confines of their own minds, but most seemed to enjoy themselves. The questions the Thai teachers and I fielded were generally detail oriented, such as "What level of hell is this?" or "Who is this god?" and the like. Afterward most bought ice cream.

School groups and casual tourists throughout Buddhist Asia visit hell parks like Wat Muang. One of the most public and graphic depictions of hell is found in the hell theme park on the outskirts of southern Bangkok near the resort town of Bang Saen. Visitors to the park are greeted with a sign in English and Thai, "Welcome to Hell," and in the park, life-size Styrofoam and plastic dioramas depict each level of hell. In one, a woman is being ripped limb from limb by ogres, and in another a saw is separating a man's legs from his torso. Giant worms devour sinners in a vat of molten lava and iron tongs pry open a man's throat. All of these scenes are in a garden on the grounds of a Buddhist monastery-Wat Sang Saen Suk. Perhaps the strangest thing, to a non-Thai visitor, is that this park is not strange to a Thai Buddhist. J ust as for Southern Baptists, Mexican Catholics, or Pentecostal Christians in the United States, for Thais, constantly imbibing scenes of and listening to sermons about hell are part of daily religiosity. The serene and compassionate Buddhism depicted in most Western textbooks and documentaries is hard to find while watching chicken and goat men feasting on human entrails. Parks similar to this hell theme park are found at Wat Thawet in Sukhothai, Wat Phairongwua in Suphanburi, Wat Aham in Luang Phrabang (Laos), the Daoist-Buddhist J ade Emperor (Ngoc Hoang) Pagoda in Saigon (Vietnam), Aluvihāra Monastery in Matale (Sri Lanka), and in the massive hell sculpture garden in the forested grounds behind Wat Bha Rak Roi in Nakhon Ratchasima 


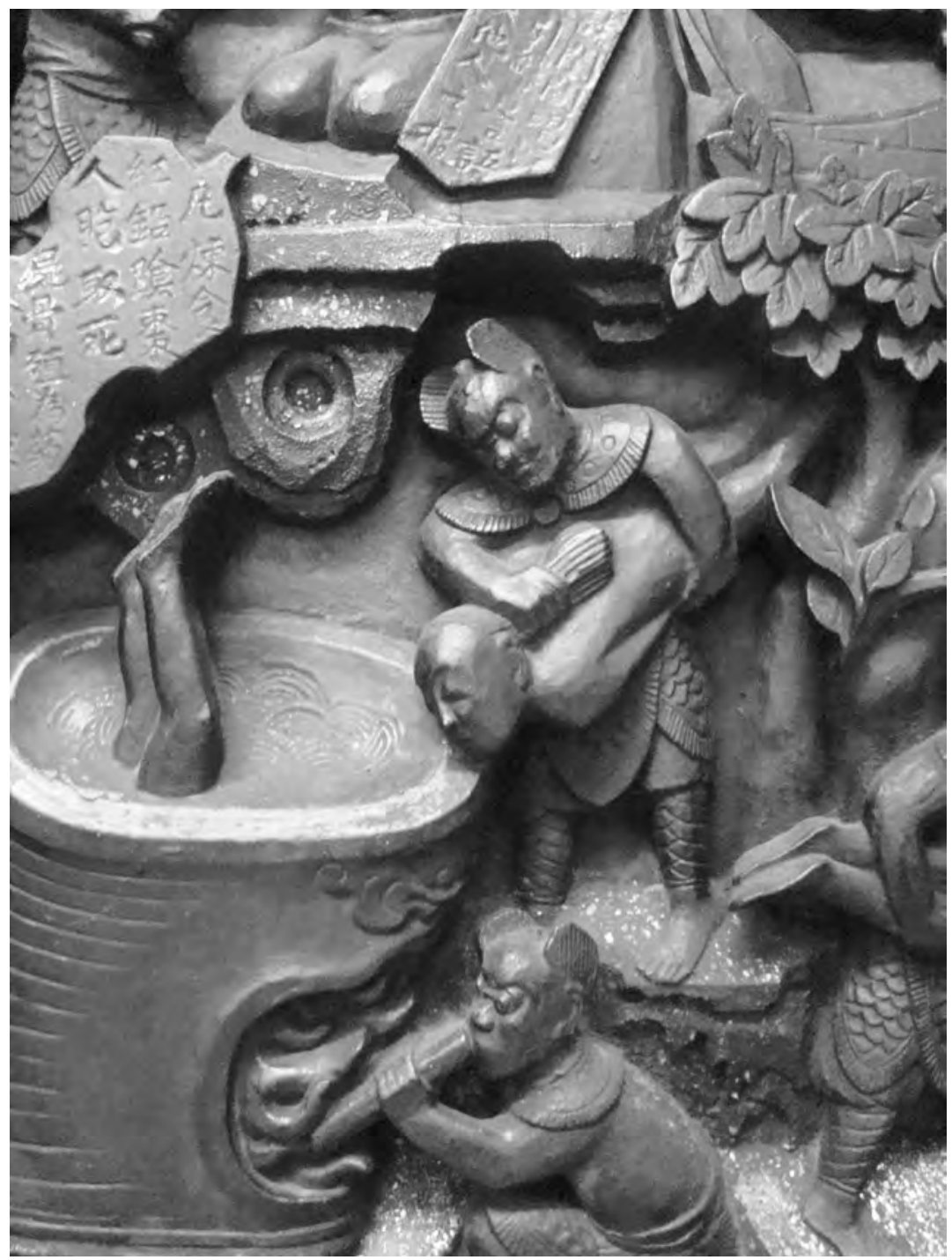

Relief depicting a scene from hell, the J ade Emperor Pagoda (Vietnamese: Chùa Ngọc Hoàng; official name Ngọc Hoàng Điện), Ho Chi Minh City

(northeastern Thailand), among many other places. ${ }^{34}$ Between 2001 and 2006, I had the chance to visit each one of these hell theme parks and was struck not only by the garishness of the sites, but also by the number of children and families who visit them. In Northeast Asia, descriptions of hell are popular in J apanese and Korean literature about the Bodhisattva Jizo (Sanskrit: Kṣitigarbha), who vows to empty various hell realms of all sentient beings before reaching enlightenment. 


\section{Contemporary Architects as Ecumenical Buddhist Builders}

Thailand is not the only Buddhist country that produces eclectic modern builders of Buddhist sculpture gardens. Numerous other Buddhist leisure and ecumenical parks have been built in Asia over the past few decades that break down the distinction between religious and secular spaces and that are worth looking at briefly.

In the former Portuguese colony of Macao, near Hong Kong, an ambitious ecumenical center was recently completed that celebrates the Chinese religions of Daoism and Buddhism, and Confucian traditions, as well as the Portuguese-Chinese friendship that was promoted at the time that the control of Macao was transferred to the People's Republic of China in 1999. The center is called the Centro Ecuménico Khun Iam (Guanyin Ecumenical Center). The Portuguese designer of the center, Cristina Rocha, wanted not only to create a center that promoted harmony among all Chinese religions, but also, according to a staff member I interviewed in August 2014, to use Guanyin as a female symbol that connected the Virgin Mary, Mazu (the Southern Chinese Goddess of the Sea, often called Tian Hou in Macao), and Guanyin. The statue is sixty-five feet tall and stands on top of a lotus-shaped museum that houses a bookstore, library, and meditation space. It stands at the end of a causeway on an artificial island in the bay next to the Maritime Museum, the Modern Art Museum, the Symphony Hall, and an imitation Roman amphitheater, and near several large casinos such as the Sands, the MGM Grand, and the Lisboa. It is an ecumenical site in the center of a much larger leisure and entertainment district.

About an hour outside of Seoul, Korea, one of my old friends, Soonil Hwang, took my family and me to a sprawling Buddhist garden, workshop, and sculpture garden established in 1994 by the artist Chan-soo Park (b. 1948). Park designed the buildings to resemble a monastery campus, even though not a monastery with nuns or monks in residence. These workshops serve as Park's sculpture studios and exhibition halls, but also as places where he can train young students in Buddhist art. His specialty is wood carving (Korean: mokjongkjang) ${ }^{35}$ He also opens up his gardens for weddings.

Park named the garden and workshops "Moga," which means the bud of tree and is also his own nickname. As one travel writer said, "It is a complete place for Buddhist culture. It is set in a beautiful garden backdrop which releases the total fatigue of the journey, if you had any. ... The journey to the serene museum too is very pleasant as the climate and the road trip will make you relaxed from the hustles and bustles of the city. It's truly worth a trip."36 It is indeed meant to be a place to learn a bit about Buddhist art, but more importantly, it seems, a place to relax, enjoy the scenery, and have some sweets. Park's art also is meant to be playful, with dozens of delightful totem-pole-like 
Centro Ecuménico Khun Iam, Macao
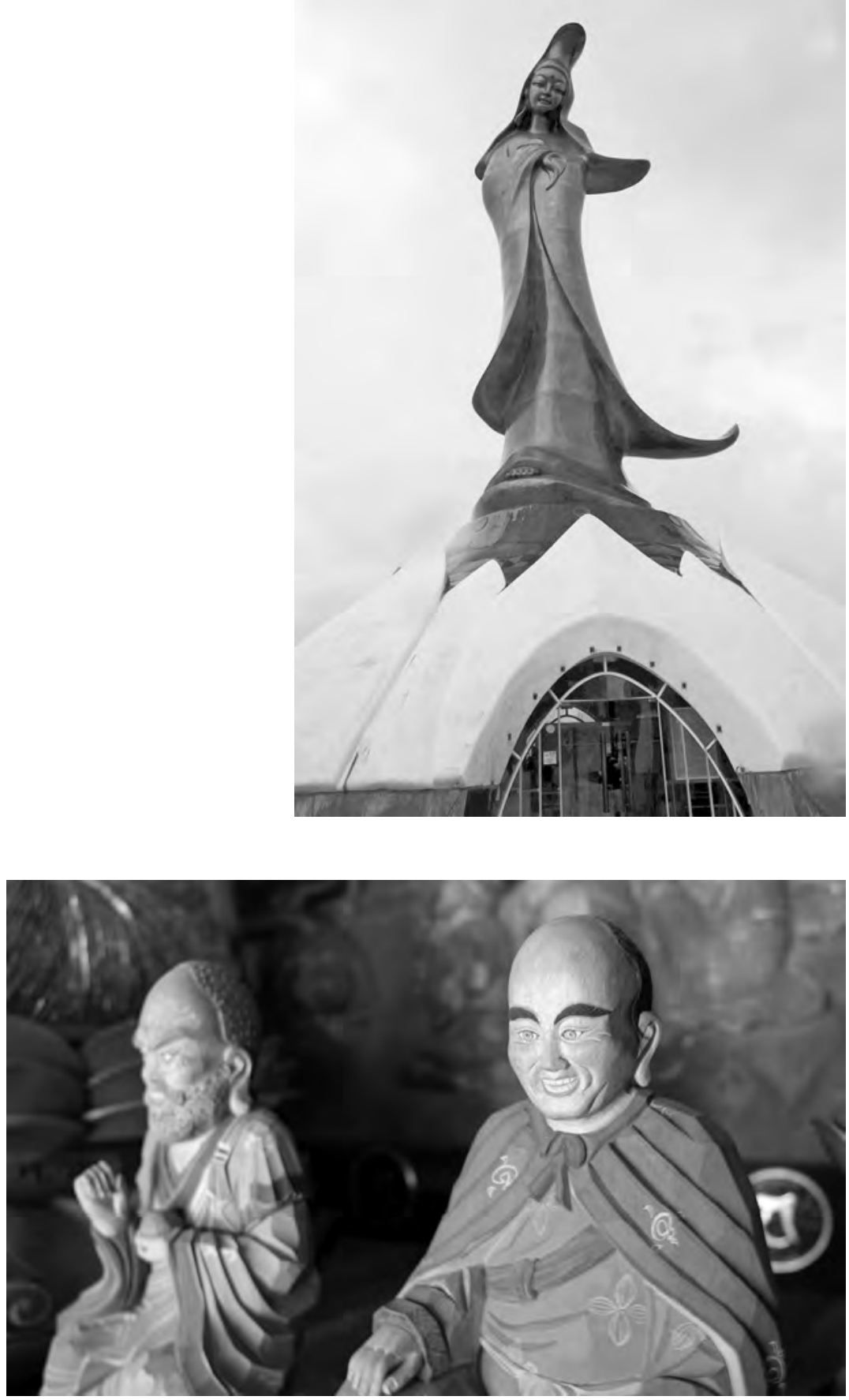

Two of the five hundred individual buddhist arahants carved by Chan-soo Park and displayed on an "altar" in the Moga Buddhist Museum, South Korea 
wooden sculptures used to scare off demons, statues of the five hundred buddhas, and animals. Nothing like it, though, is found in other Buddhist monasteries in Korea. For example, Park sculpts traditional-looking buddha and arahant statues except for the fact that their heads are slightly tilted to the side, and instead of serene half-smiles, they have garish and jovial gaping smiles showing a full set of teeth. One cannot help but laugh when seeing these faces, especially if you are used to seeing the Buddha in a trance-like state. At a recent exhibition in London, he displayed a set of sculptures of buddha-like figures that celebrateleisure. One appears to be drunk. Another is playing with what appears to be his grandchild. In an interview, Park said that he had spent time visiting the Daewonsa Buddhist monastery in Sancheong (Korea), where a monk in residence had emphasized that the message of the Buddha was to "enjoy yourself. Be happy. Don't be so serious." ${ }^{37}$ The interviewer continued, "He pointed out that Buddhism does not ban alcohol (though it is prohibited to monks): the emphasis was more on its moderate use. Reinforcing the message, The three stages of drunkenness depicts three wood carvings in the shape of soju [Korean liquor] bottles with human faces. The first shows a benign jollity, the second has entered the tipsy stage, while the third looks like he is about to engage in a late Friday night brawl. The set is charming, amusing and has a simple message." He also carves statues of monks taking naps, or himself laughing. ${ }^{38}$

My student, Joon-Youb Lee, kindly interviewed Chan-Soo Park, since I cannot speak Korean. In the interview, Park said that he was inspired by a buddha image he had seen as a young artist, and that he "could sense the blood running through the face, hear Buddha's whisper, and feel the wood breathe." He wants to capture that initial affective moment by not just creating Buddhist art, but by making art a performance. Therefore, as Lee summarizes,

In addition to exhibiting his works, he has also developed a unique woodwork performance. Although most of his sculptures take months, Park's mastery allows him to hew a simple yet elegant work within minutes. In his 2009 performance titled "Reconciliation," he began by playing the Korean drum buk, followed by meditation on a high chair. Only then did he start carving the camellia tree that he had cut himself. After making initial cleaves with hammer and nail, he switched to moktak, a wooden percussive stick used by Buddhist monks for meditation. The audience remained mesmerized by both the dynamic movement of the sexagenarian maestro and the meditative echoes of his moktak. His performances are abbreviated forms of his woodworking process. Before he starts carving, he meditates, sometimes by a waterfall, to purify his mind to produce a true image of Buddha. The roots of 
the tree become the head because they hold moisture, and the southern part becomes the face because it receives more sunlight. After six months of arduous labor, Buddha is completed and Park holds a ceremony to infuse life into his woodwork. Buddha is veiled for this ritual, and the Buddhist scripture, seven Buddhist treasures, five incenses, five grains, five medicines, and five kinds of clothing are offered, along with chanting and prayers from monks.

Lee also informed me of Park's efforts to break down divisions between Korea's Christian and Buddhist communities through his work. For example, while the museum is primarily a Buddhist museum, some of the first sculptures greeting visitors are the Virgin Mary and J esus Christ that Park sculpted. "It's bad enough that our nation is divided, and I am tired of Buddhist and Christians fighting each other in Korea," Park says. "J esus and Buddha had the same message. Jesus just emphasized love, and Buddha compassion." This work has garnered Park much fame throughout South Korea, and he has been invited to present his work in over thirty countries.

Two Thai artists/architects have gone even further than Chan-soo Park and have created their own "monasteries" within their sculpture gardens. In the northernmost province of Thailand, Chiang Rai, stands a new monastery and sculpture garden that is the brainchild of a modern artist. When I

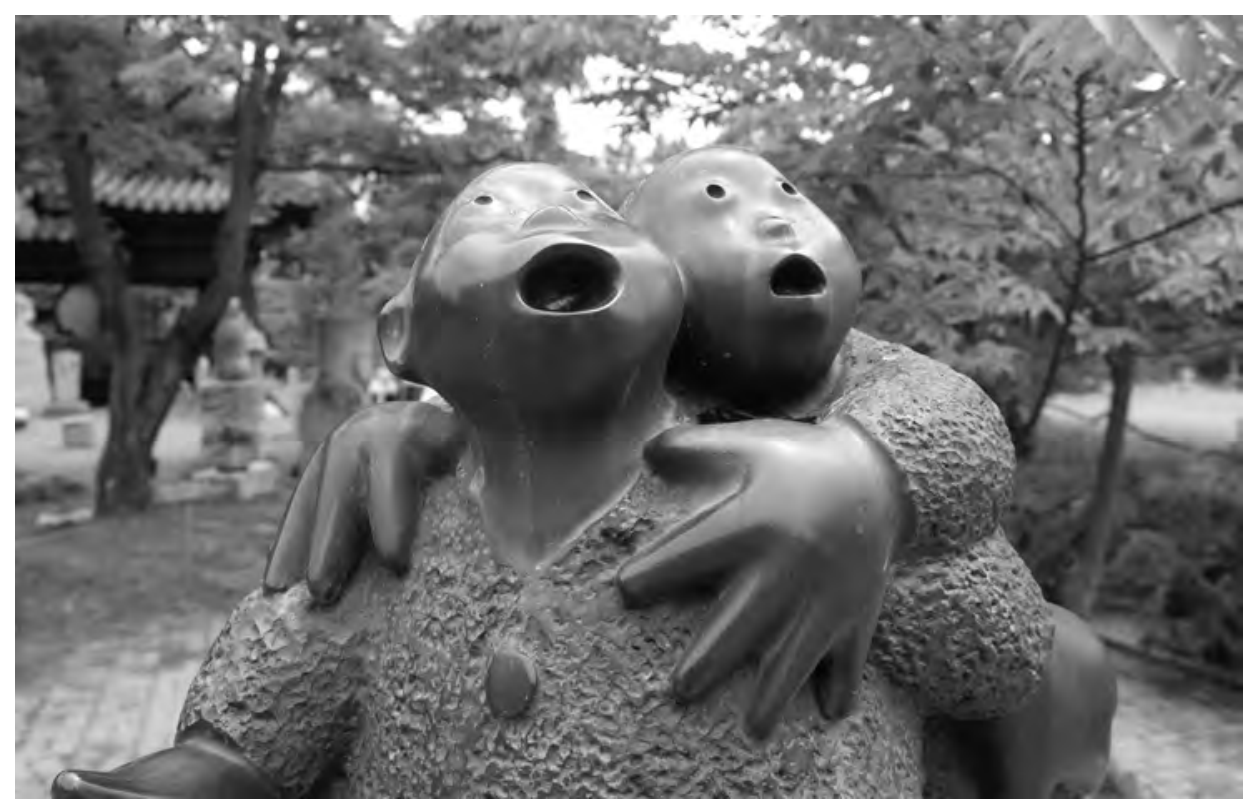

Untitled sculpture of monks looking in amazement at the other sculptures in Chan-soo Park's sculpture garden, South Korea 
first visited Wat Rong Khun in March 2008, I knew immediately that I was at a monastery unlike any other in the world. It is the creation of Chalermchai Kositpipat, one of the most well-known Thai artists, who has had gallery shows in many different countries and has been featured in numerous reviews. Recently Chalermchai has branched out into architecture. The wihan (image hall) of the monastery, similar in size and architectural structure to Central Thai monasteries, is completely white, with carved leaping flames, statuary of Brahmanic gods, and skulls-lots of skulls-and there are dozens of small statues on the grounds as well. The front entrance to the monastery includes a bridge over a wide pit. Hundreds of sculpted hands are reaching up from the pit, which is supposed to depict hell. The hands are asking for alms, for mercy. Murals hand-painted by Chalermchai are displayed inside the wihan.

Most murals on the walls of Thai monasteries depict the life of the Buddha, the lives of famous monks and nuns, and the previous lives of the Buddha (Pali: jātaka), as well as depictions of stories from Indian and Southeast Asian epic poems such as Khun Chang Khun Paen, the Ramāyāna, Inao, and the like. ${ }^{39}$ However, Chalermchai's are completely different. Among other phantasmagoric images on these murals is a depiction of the American actor Keanu Reeves dressed as his famous film character, Neo, from the Matrix trilogy, wearing a black trench coat and dark sunglasses. He is standing in a macho Kung Fu- like pose next to a pod-racer from episode one of Star Wars. Near him is a painting of Ultraman, a well-known J apanese animated hero (and, by far, my young son's favorite mural character in Thailand). Besides these fictional and randomly assembled heroes are also images of a demon holding a cell phone and the World Trade Center in New York City

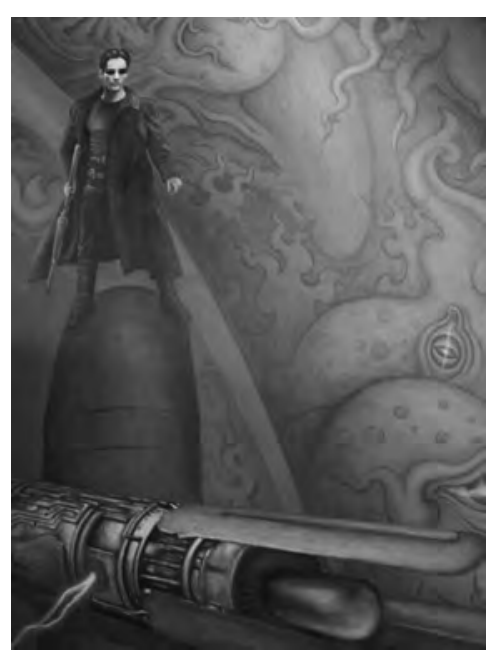

Mural inside Wat Rong Khun monastery, Chiang Rai 
being hit by a commercial jet. Depictions of the terrorist attacks on September 11, 2001, and international pop culture heroes are interspersed with paintings of AK-47 machine guns, gas pumps, flaming skulls, and satellites.

Chalermchai's work is very popular in Thailand, but he has not been well-received by critics or other artists. Heis a businessperson, and runs shops and a large gallery at the monastery selling his art. Life-size posters of him are hung in several places on the monastic grounds. People prostrate, offer alms, and chant Pali incantations to images of the Buddha as they would at any other monastery, but Wat Rong Khun attracts more visitors who want to view its striking architectural features and shop at the several tourist and handicrafts shops surrounding it or have a picnic on the grounds. ${ }^{40}$ Recently, this rush of visitors, especially large groups of Chinese tourists, has caused some problems. Next to the main temple, Chalermchai designed and built what may be the most beautiful public bathroom in the world. The bathroom is designed like his temple and is painted entirely gold and glimmers in the sun. When it was first built, one of its caretakers told me that many people assumed it was a sermon hall and were surprised to find that the toilet facilities were so spectacular. However, this golden bathroom apparently has attracted some rude behavior. According to a report in the Bangkok Post that has been replicated in many other online newsfeeds, Chalermchai is planning on building "Chinese" and "non-Chinese" toilets, because many Chinese tourists had not followed standard public bathroom customs and "had defecated on the floor, urinated on the walls outside and left sanitary pads on the wall of the bathrooms," said an official who requested anonymity. Chalermchai said in a television interview that it was "impossible" for other tourists to use the bathrooms after the Chinese tours, so he would build new ones. ${ }^{41}$ Openness and leisure can have their downsides, I suppose.

Less than a ten-minute drive from Chalermchai's glowing white Wat Rong Khun is another "monastery" built by the modern Thai artist, Thawan Duchanee, who passed away in September 2014. It is named the Black House (Thai: Ban Dam). Thawan trained under the Italian artist Feroci (mentioned in chapter 1), and for four years in the Netherlands (Royal Academy of Visual Arts in Amsterdam). He juxtaposed modern and traditional Thai Buddhist art and had a particular focus on skeletons, insects, and death. Like Chalermchai, he was a shameless self-promoter, and there is no shortage of photographs of him with his Tolstoy or Whitman-esque long white beard on his website or in the many Thai and English newspaper and YouTube videos that discuss him and his work. ${ }^{42}$ For example, in Thai and English on his website, one can read, "Born in 1939 in Chiang Rai, one of the foremost Asian painters, Mr. Thawan Duchanee has pursued his career throughout the world. His paintings are in an original genre, rooted in a unique Buddhist perspective. These paintings 
depict the insanity, degeneration, violence, eroticism, and death lurking in the heart of modern man. The artist has shocked the world by creating a uniquely Asian artistic expression. Mr. Thawan is indeed worthy to be called a master of modern Asian art." One also finds this rather magnanimous call to the people who see his art: "Do not seek for understanding, in the temple of mysterious. Feel them my friends from heart to heart. Do not ask the meaning of the stars in the constellation. Smile of the baby in the cradle of mothers. Sweet fragrance in the pollens of flowers. It is the work of art! My friends . . . In the deepest of my mystic mind, come closer to my spirit. Listen to my heartbeat, without word." 43

While the Thai original versions are more poetic, the self-indulgence is no less obvious. What concerns us here though is not his personality but his architecture, and his creation of a sculpture park similar to Lek and Braphai's. The Black House is a wonder to behold. It is not a monastery, but was the artist's own residence and galleries holding his collection, much of it created by him. Forty separate structures are spread out in a large campuslike setting. Most of the buildings are reminiscent of traditional Northern Thai monastic architecture, but painted black with some dark brown trim (with a few exceptions, like three small white stupas [Thai: chedi] with plain black doors). These structures contain large collections of mostly abstract sculpture, as well as skeletons of elephants, oxen, and water buffalo, skins of various animals, and found objects like old Thai canoes and canes. Much of the strangely shaped furniture was hand-carved by Thawan. One building is shaped like an abstract boar, and even one of the bathrooms is filled with wooden carvings of monkeys and birds. Some of the sculpture gardens consist largely of natural stone arranged in patterns. While the buildings certainly look like largely unornamented Thai monasteries and monastic library buildings, the art in the buildings is in striking contrast. As in Lek and Braphai's Ancient City, visitors can walk around freely among the buildings, as in a village, but no effort has been made to present a history of Thai art or collect pieces representing different styles, ethnic groups, and regions. No direct comparisons are made between the artist's ideas and Buddhist texts or well-known teachings. There are no ritual or liturgical services, no nuns and monks in residence, no direct pedagogy, and, it appears, no central "message." Indeed, many visitors just seem to walk around with their mouths slightly open in a state of wonder and bewilderment. ${ }^{44}$

One does not necessarily have to be wealthy or famous to build a modern Buddhist monastery or sculpture garden. Indeed, one of the oldest public sculpture gardens in Southeast Asia was started on the outskirts of Vientiane, Laos, in 1958, by a relatively poor man named Bunleua Sulilat (1932-1996), who had no formal training in art. Like Sabato Rodia, the famed creator of the Watts Towers in Los Angeles, or Martin Sanchez, who started 
the sprawling sculpture garden in Riverside, California, Bunleua had few resources besides time, mixed concrete, and found objects. He was born across the river from Vientiane in Nong Khai (Thailand), and even though he was not a monk, he is sometimes referred to by a title usually reserved for monks, Luang Phu. He started constructing the massive statues on his park supposedly after meeting a powerful hermit (Lao: pha leuxi) name Keaoku, who could take on the shape of a magical giant snake-spirit (Lao: Phaya Nak). Soon Bunleua's little garden had dozens of statues, but the war in Vietnam spread to Laos and the communist forces (Pathet Lao) formed a new government in 1975. They were not supportive of religion in any form for the first two to three years after they took power. Therefore, he decided to escape to the land of his birth-Thailand. He left his statues in Laos, but started another park across the river in 1978. He named this park after his magical mentor, Sala (pavilion) Keaoku. Bunleua actually trained as a shaman in Vietnam. He told many of his followers that he was half-man, half-snake and had been granted his talents when he fell in a hole as a child and was instructed by snake spirits. His body was mummified when he died, and some of his followers believe that part of him continues to live on as a snake.

Like its first incarnation in Laos, this park grew quickly, and when I first saw Sala Keaoku before Bunleua's passing in 1994, I was dumbstruck. It is highly idiosyncratic and draws on common iconic images known throughout the region - it is the mind of Bunleua on display. There is no effort to present either history or local culture in any systematic way, or to replicate Buddhist or local religious or Indic literature in sculpted form. Thirty-foottall statues of the Buddha stand next to fifty-foot-long statues of protective giant snakes, along with statues of foreign soldiers, mermaids, and Hindu gods like Siva and Brahma. One of the larger statues, of a giant ogre, has a gaping mouth that one can climb into like a cave. Bunleua did not leave behind much writing about why he dedicated his life to his sculptures. There seems to be no message and no agenda. The entrance fee is less than one US dollar for foreigners and nearly free for Thais.

Outside of Korea and Laos, Chan-soo Park and Bunleua Sulilat are largely known only to a small group of international enthusiasts of modern Buddhist art and architecture. Park has had small exhibitions in different countries, and one of his sculptures is on the grounds of former US president George W. Bush's Texas ranch. ${ }^{45}$ Tadao Ando, however, is world famous. Ando is one of the most internationally recognized architects, or "starchitects," in the world, best known for his innovative designs of religious buildings in modern J apan. Ando won the Pritzker Prize in 1995 and nearly every other major international architecture prize over the past thirty years. His lofty status did not come easily though. Like Tange, he was not born to an elite family in 
Tokyo or Kyoto, but was born in the inauspicious year of 1941 in Osaka (where he still lives today). His youth was spent eclectically. His twin brother was raised by his parents, and he was raised by his grandmother. He never excelled in school and as a teenager worked as a truck driver and even moved to Bangkok at seventeen years old to be a boxer. He has said that it was the style of Thai Buddhist monasteries that inspired him to become an architect. ${ }^{46}$ After wandering in Africa, Europe, and the United States and training himself about architecture through books, he boldly opened a design firm in Osaka instead of Tokyo at the age of twenty-eight, managed by his wife Yumiko.

Ando notes that he was explicitly influenced by Kenzo Tange's work. While Tange's work is not traditional J apanese or Buddhist, and he did not design Buddhist monasteries himself, his influence, ironically, may have partially led to the development of modern monastic architecture in J apan. Furthermore, like Tange, he acknowledges that Le Corbusier was one of his main influences, and his use of large panels of concrete reflects that. Ando even named his dog Le Corbusier (he is often photographed with his dog and supposedly brings him with him everywhere). Originally, hejoked, he wanted to name the dog Tange, but he did not feel it would be respectful ordering Tange around. However, unlike Tange, Ando remained dedicated to building homes and monasteries in J apan for most of his career, primarily in Osaka and Kobe. Indeed most of his early works are small homes like the one in which he grew up. He was not, for most of his career, a builder of large public places and spaces like Tange. It is not until very recently that he has taken on some contracts outside J apan and, between 1995 and the present, has designed buildings like the Benetton Communication Research Center in Teviso (Italy); the Museum of Modern Art in Dallas/Fort Worth, Texas; the Pulitzer Foundation for the Arts in Saint Louis, Missouri; the expansion of the Clark Art Institute in Williamstown, Massachusetts; and the Piccadilly Gardens redesign in Manchester (England); as well as designs for noncommissioned projects for the Ground Zero site in New York, the Calder Museum in Philadelphia, and a stunning home built into a cliff in Malibu, California. Probably his most well-known public work is the Chichu Art Museum on Nao Shima, a small island in the Inland Sea near Shikoku. ${ }^{47}$

Ando's Buddhist monasteries are what concern us here. Ando, unlike Tange, thought seriously about Buddhist design and teachings. He creates what is called the "Haiku Effect," with simple structures, measured spaces, use of striking and singular filtered shafts of light, and lack of ornament. He has designed several Buddhist monasteries based on this principle, as well as several Christian churches in Japan. Perhaps his most famous Buddhist monastery is the Water Temple (1991) on Awaji Shima (Hyōgo Prefecture, across the straits from Kobe). The temple is unlike any Buddhist 
monastery in the world, with almost no ornamentation. Nearly the entire monastery is buried underground and can be entered via a long staircase that descends through a large circular pond, which forms its roof-it is literally an underwater temple. There are long, curving, windowless, concrete corridors, and one room bathed in red light. It is officially a Shingon temple, but one would be hard-pressed to figure that out since, like Tange, Ando did not adhere to one sectarian style in his designs; the wood, the Buddha images, and the painted screens and ceilings typical of Shingon temples are all missing. This series of empty spaces was inspired perhaps in part by Tange's work: his conversation spaces, floating concrete, and massive heavy roofs (the support structure for a large pond on a roof was necessary) are all present, but, unlike Tange's Lumbini Park, this is not a public memorial or a non-sectarian place. It is a private monastery, although tourists and researchers are always welcome.

Ando, unlike Le Corbusier and Tange, likes walls and private spaces. He also has occasionally shifted away from the use of concrete. A perfect example of this shift is seen in the Komyo-ji Temple in Ehime (Shikoku). Here, Ando has built a wooden temple for the Jodo (Pure Land) school. The lack of ornament, the wide eaves, and the narrow piloti-like wooden columns show the Tange/ Le Corbusier heritage, but the wood and the placement of the main building floating in a pond harken back to traditional J apanese monasteries and, even more so, to Thai wooden monastic libraries, which are often placed on stilts in ponds. It is a light and delicate monastery, built on the grounds of a much older monastery, and unlike his other religious structures, has an active ritual schedule and small coterie of monks who come and go. It is open to the public, but like many J apanese monasteries, it is often closed to visitors except for designated hours during the afternoon. This temple was not intended as a part of Buddhist public culture necessarily. But Ando's fame has made it public, as it has other sacred buildings he designed.

Other examples of his work include three Christian churches in Kobe, Tomamu (Hokkaido), and Osaka, respectively, called the Chapel of Rokkozan (Mount Rokko), the Church on the Water (1988), and the Church of the Light (1989). The Chapel of Rokkozan and the Church on the Water have many of the same qualities as the Water Temple, but the Church on the Water is oriented toward the forest outside its walls and does not have the feeling of being enclosed in cubes and circles of massive slabs of concrete. ${ }^{48}$ It is also a chapel connected to the Alpha Resort Hotel and so does not have a regular congregation or regular ritual services and is open to all visitors. The Chapel of Rokkozan and the Church of the Light are near his home in Osaka. Although the Chapel of Rokkozan is quite small and perched on a cliff with a single road past it, it was visited often as it was part of a vacation resort. However, the 


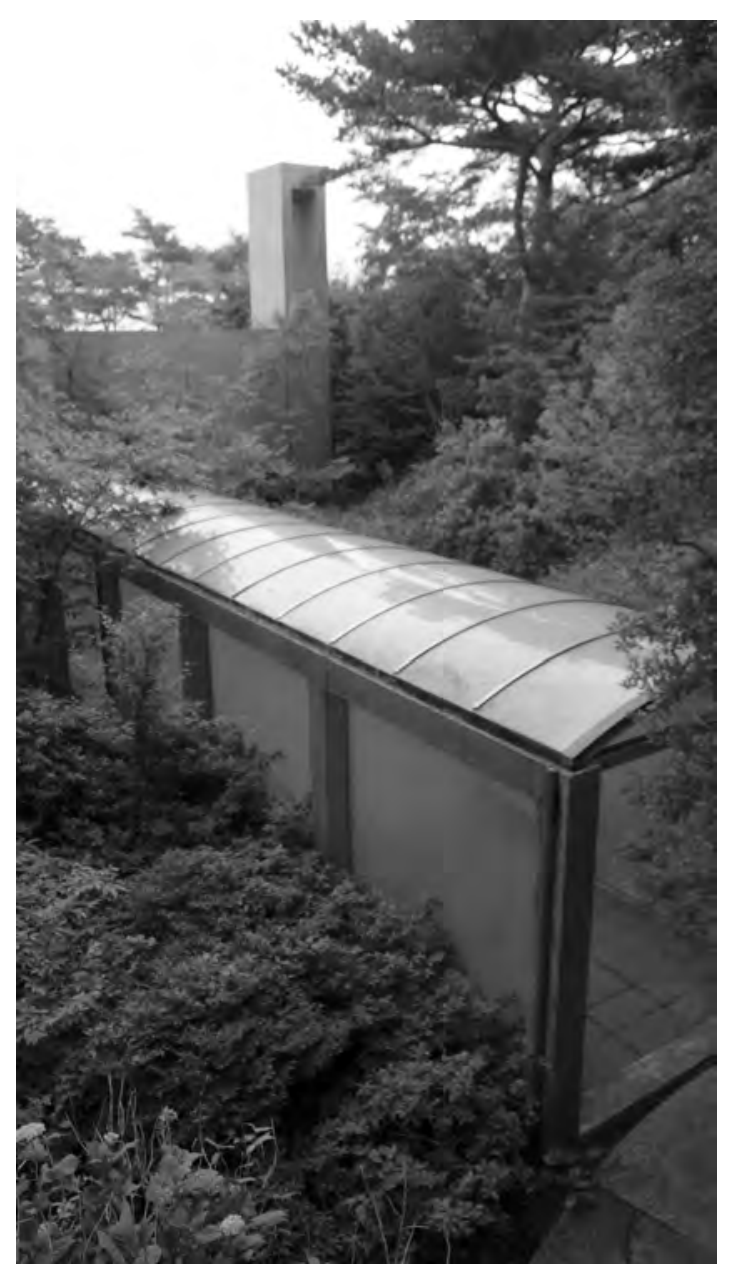

Tadao Ando's abandoned chapel at Mount Rokko, near Kobe

resort eventually failed financially and the Chapel at Mount Rokko is now abandoned. I visited the site on a rainy day in J une 2014. The Rokko Oriental Hotel it was attached to is now shuttered, and the grounds are overgrown with weeds, with broken glass seemingly everywhere. I piled up old construction material and stood on that to scale the fence. I tore my shirt on some jagged metal. Once in the garden behind the hotel, where the chapel sits and is slowly falling apart, I was able to see the power of the building sitting in silence in the rain. It was stunning and at its height hosted a number of weddings. It is now forgotten. The Church of the Light, on the other hand, while quite small (1,200 square feet), was commissioned by Reverend Noboru Karukome of the Ibaraki Kasugaoka Church (United Church of Christ) and they hold regular 
services. ${ }^{49}$ It is a striking place-a single concrete box with only wooden benches facing the front of the roof. The front does not have a traditional altar or statues, but two large slices in the concrete allow light to pour in to the closed room in the shape of a crucifix. ${ }^{50}$ However, like the others, Ando's fame has made the small Church of the Light a public place for leisure weekend sight-seeing trips in addition to a place of private contemplation and prayer. What is important to note is that, like Tange, Ando has had no formal training in Buddhism, and the philosophy behind his designs did not change because a building was designed to be used by Buddhists or by Christians: design trumps religion.

Two other notable new Buddhist monasteries, designed by Takashi Yamaguchi and partly inspired by the designs of Tange, can be seen in and near Kyoto. The first, called the White Temple, is located in a rural mountainous area between Kyoto and Kobe, in a valley noted for its family resorts, children's camps, and hiking. The grounds include a lovely lake where one can rent paddle boats and go fishing, and a few wedding halls. Above the monastery is a hill with a café, ice cream shop, and sculpture garden featuring colorful animal statues on which children can climb. Yamaguchi designed a glowing white box, completely lacking ornament and windowless, the size of a small one-story house. The contrast is striking, as it sits behind an old traditional wooden sermon hall of the Zuisen-ji monastery. Its design mirrored, the day I was there, the clouds reflected on the lake surrounding the temple's grounds on three sides. The White Temple serves as the monastery's ihaidō, or place

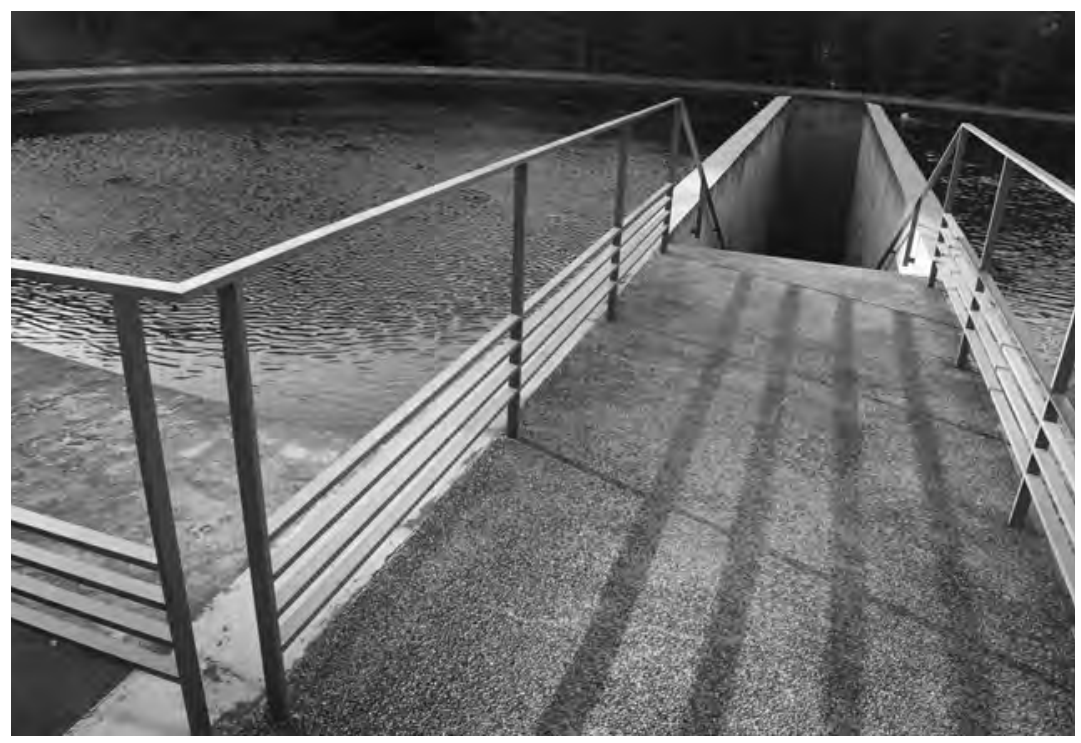

Exterior entrance of Tadao Ando's Water Temple, Awaji 
to pray to ancestors. While most ihaidō are dedicated to the paternal line of ancestors, the White Temple is dedicated to the maternal line and so, according to Yamaguchi, is supposed to resemble the purity of the womb. The light that pours in through the open front entrance of the long plain white box is designed to change the color of the interior naturally and make the room seem as if it is breathing and moving. The building is nearly surrounded by water, which adds further to the womb-like feeling. Although the self-effacing abbot of the temple would not permit me to enter the box, as it is restricted to relatives who honor their deceased ancestors there, the Yamaguchi firm has published the architectural plans and photographs of the interior, which largely mimics the exterior and is completely white with a series of white steps. In the middle is the only nonwhite object - a plain sandalwood statue of Kannon (Guanyin). ${ }^{51}$ While the White Temple (or more accurately ihaidō) certainly is not a temple designed for leisure activity, it is a stop-off for visitors who are on vacation in the area and seems to be the only reason nonlocals visit this otherwise small, nondescript, and non-sectarian monastery tucked in the mountains.

Yamaguchi's other temple is called the Glass Temple (2000), an underground guesthouse on the grounds of the 1638 Imperial (Rinzai Zen) temple of Reigenkō-ji. ${ }^{52}$ Thanks to the great assistance of Yoko Hayami of Kyoto University, I had the chance to visit the Glass Temple and interview its caretaker, the wonderfully informative and frank Kakui Nabesawa. Nabesawasan is ninety-two years old and, despite her tiny frame, runs the entire monastery, including being its cleaner and security guard. This is no small task since the monastery comprises multiple buildings, mostly built in the seventeenth century. On a cold winter's morning she greeted us and rushed from room to room of the temple, telling jokes and explaining its history. She had worked there for over sixteen years and cleaned every day, taking only one hour off to walk down the hill to pick up her daily meal. The abbot of the temple is the sixty-seven-year-old Zenjyō Nakayama. He rarely shows his face, is often out of town, and lives on the second floor of a small apartment building outside the monastery's walls. He has been there only three years and is from Tokyo. He was assigned to be the abbot, it seems, from the Imperial household, who felt that the temple, which had sat empty for years, should have an official monastic head.

The Imperial family has shown interest in the monastery because Emperor Gomizuno-o established it in 1638 for the priest Isshibunshu. After Isshibunshu's death in 1671, the retired emperor moved his quarters from the Imperial Palace to this temple for its reconstruction as a Butsuden (main hall). This move, supposedly, was also political and helped an imperial official avoid a planned marriage. Regardless of the historical importance of the monastery, the abbot does not work there often, and there are few ceremonies, except for 
the establishment and annual rites for the relatives of the monastery's graves. These graves are the main source of income for the monastery, as is the case in most Japanese monasteries today. ${ }^{53}$ Nabesawa-san told me and my colleagues and travel companions, Yoko Hayami and J ohn Holt, that the monastery has no regular danka (official congregation members) who support it or her, but they do get the occasional architectural student visitor, mostly Japanese students, but some, like me, from abroad. ${ }^{54}$ She speaks only Japanese language; she has seen many students from Hungary, France, Canada, Russia, and many other places, but usually does not speak with them. When I asked her about the Glass Temple, the very thing that draws these students and fans of modern architecture to the temple, she laughed. She said that Yamaguchi oversaw the building of the "temple" sixteen years ago, but that after it was built it has never been used, and it remains locked today. Built underground, with only the top visible, it is a striking place. A large glass box surrounds a smaller pure white box; the glass top, which is about forty feet long and twenty feet wide, reflects the surrounding mountains, bamboo, and sky, giving the impression of a reflecting pond on the grounds of the monastery. Indeed, it echoes an actual koi pond on the other side of the monastery. A visitor descends underground, like at Ando's Water Temple, down a stark black slate and concrete stairway to a white door. Even though the box was locked, I know there was nothing to see inside. It is unornamented and nearly furniture-less: it holds a screen and a projector, a bathroom, a bedroom, and a television. Nabesawa-san also told us that it was wired for the Internet.

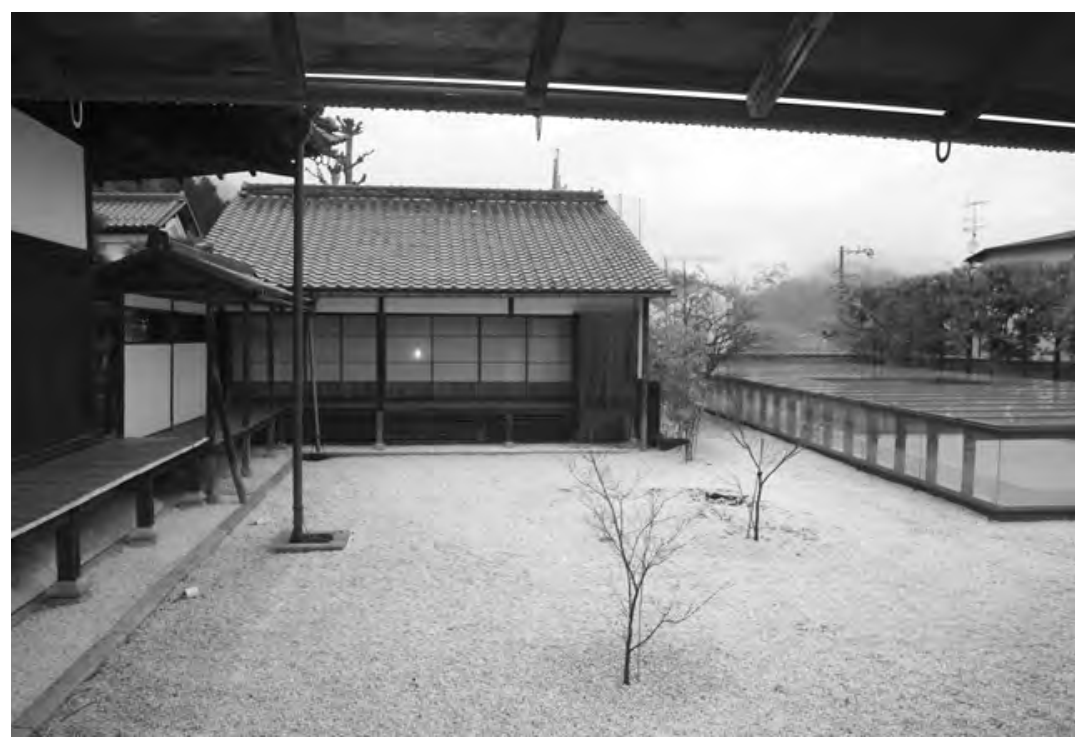

Glass Temple designed by Takashi Yamaguchi, Kyoto 
Nabesawa-san seemed to think the whole project was a bit arbitrary. I tend to agree. It was designed to be a special guest room for a visitor, but no one stays there, and it appears that no one has ever stayed there in sixteen years. The screen and projector have never been used. There is no altar or offerings. When it first opened, it was considered a good place to display the monastery's historic treasures and imperial implements (gohōmotsu). However, the treasures were displayed once, for one day, and then put back in storage, never to be shown again.

John Holt, a friend and scholar who visited the monastery with Hayami-sensei and me, agreed that the best part of the visit was meeting Nabesawa-san and hearing her impressions and stories (many of which I will not relate to protect her privacy). He said, "You went looking for a temple and found a person." All the better.

\section{Conclusion}

Many of the sites mentioned above designed by Ando, Lek and Braphai, Yamaguchi, and others are a mixture of religious buildings, leisure and tourist sites, and spectacle sites (misemono). They produce certain types of associations. Some of these associations, experienced as diversions and distractions, are complex, even confusing, as we saw with the Sanctuary of Truth or the Erawan Elephant. The individual objects and architectural features of the sites are not "seen." They do not teach in the form of a systematic lesson. They don't offer a single vision of Buddhism that is supposed to be accompanied by a regimen of specific rituals, liturgies, and moral restrictions. They overwhelm instead of instruct. They encourage distraction, not focus.

Other associations created by these sites, as particularly noted in this chapter (and which take on a life of their own as a building evolves) are not just delightful, but horrifying. Much of the misemono throughout the Buddhist world are characterized by the assembling of the grotesque. This chapter describes hell gardens, bloodthirsty beasts, demons, torture chambers, and the like, which are depicted in Buddhist installation art, murals, and sculpture gardens. However, like serene ponds, flower gardens, fine art museums, and sumptuous, palace-like Buddhist spaces, these sites are promoted as places for families to visit as sites of relaxation and casual Buddhist learning. ${ }^{55}$ Buddhist adults and children do not shudder in fear at these horrifying sights, but laugh, tease, and pose for photographs. This may not be a sign of desensitizing, as purportedly caused by violent video games and the nightly news, but an important part of carnival culture and religious art. Baudelaire, Bakhtin, Hugo, Thomas Wright, Karl Friedrich Fögel, Wolfgang Kayser, and many others have seen the links in art, architecture, and literature between the horrifying, the absurd, and the comedic. ${ }^{56}$ As the famous nineteenth-century 
architectural historian J ohn Ruskin pointed out, the "grotesque is, in almost all cases, composed of two elements, one ludicrous, the other fearful." He saw the grotesque as further divided into the "sportive grotesque" and the "terrible grotesque" and often saw Venetian churches, the main area of his research, as combining the horrifying ridiculous and the slightly fearful-as clearly seen, for example, in the figure of the gargoyle or the troll. Laughter is as appropriate a response as the shudder when witnessing these churches and their grotesque ornament. Much Buddhist ornament, whether in illuminated manuscripts, architectural features, stone reliefs, or statuary, combines these elements, as well as informs the larger aesthetic of spectacle. ${ }^{57}$

These sites, as I emphasized with the work of Kenzo Tange in the previous chapter, are not solely the product of the vision of the architect. They are complex adaptive systems, and studying them must take into account the way administrators, contractors, building material suppliers, government restrictions, repair crews, and, most importantly, the thousands of visitors, change the sites. This difficult-to-predict nature of buildings, especially largely open, public, and leisure spaces in which the architect and the manager have less control about how a space is used and experienced, is seen most clearly in the next chapter. Buildings have a life long after the architect has left the site and rolled up her or his blueprints. We will see that museums, supposedly places to teach visitors about the history and significance of individual pieces of art or rare artifacts, have taken on a life of their own in the modern Buddhist world. The museums are experienced as leisure sites, as places of distraction and apperception, as affective encounters, despite, in many ways, the efforts and intentions of their designers. 


\title{
3
}

\section{Buddhist Museums and Curio Cabinets}

\author{
Shi Fa Zhao and Ecumenism without an Agenda
}

IN 1894, A FREEMASON WHO WOULD LATER CREATE the first Buddhist temple museum in the United States traded a collection of engraved gems for a professorship at the University of Pennsylvania. His name was Maxwell Sommerville. This eccentric collector was a prominent member of the Grand Lodge of Free and Accepted Masons of Philadelphia, where a portrait of him still hangs, and spent much time walking between the large lodge next to city hall on Broad Street and the new University of Pennsylvania Museum of Archaeology and Anthropology on Thirty-Third Street. On the streets he was the picture of a wealthy Caucasian aristocrat, in a black topcoat and tie. Inside the museum, he often changed into an embroidered Chinese silk robe and Mandarin scholar's hat. He was comfortable playing multiple parts in the strange play he wrote for his life.

Sommerville was born in 1829. Like Lek Wiriyaphan, he was not particularly wealthy and did not have much formal education from prestigious institutions. However, also like Lek, he was ambitious, eccentric, and he married well. He was born in what is now Clarksburg, West Virginia, to a middle-class family who moved to Philadelphia for work, and because Maxwell's grandfather had come into some money. Maxwell graduated from the public Central High School, not a prestigious Quaker private school like Penn Charter or Germantown Friends School. He never attended university, but moved to Bethlehem, Pennsylvania, to take a job as a small-town newspaper editor. He eventually moved back to Philadelphia and married Anna Julia Sherman, in 1863, after serving as a Union chaplain in the Civil War. Through that relationship he garnered a position at his new father-in-law's print company. Eventually taking over the company, he amassed a small fortune and 
tried to buy his way into the elite social society of Philadelphia. This proved more difficult than he had imagined, however, and he spent much of his time out of the country. He traveled to China, India, Japan, Siam/Thailand, the Sahara Desert, and parts of Europe. ${ }^{1}$ Like other wealthy Americans of the time, when he traveled, he collected many antiquities in Asia and Africa. ${ }^{2}$ He studied languages and history, although he was never formally trained in any academic discipline. He was most keen on collecting engraved gems and small Buddha images.

His gem collection came to the attention of Dr. William Pepper, the provost of the University of Pennsylvania. ${ }^{3}$ Dr. Pepper had established the university museum in 1887 and was planning a massive building project to house the university's art and artifact collection. The museum would become one of the premier institutions in the country (and one of the main reasons I moved there from my former job in sunny Southern California back to my home state of Pennsylvania to teach and research). Dr. Pepper wanted Sommerville's collection for the new museum, and in exchange for the collection, Sommerville got what he craved - academic recognition and social prestige.

Pepper made Sommerville the chair and only faculty member of the newly created Department of Glyptology (the science and study of engraved gems). ${ }^{4}$ As far as I know, it is the only chair and department of its kind ever to exist, and it lasted as long as Sommerville did. The effect of this was likely opposite what Sommerville had intended, as he supposedly became the punchline of many a joke. ${ }^{5}$ A document in the university archives written by former Asia collection curator Stewart Culin, who had a difficult relationship with Sommerville and was likely dismissed from his position as a result of their altercations, described "the Professor of Glyptology [Sommerville]" as pompous and overweening and also as performing séances at his home, accompanied by a mysterious J apanese body servant speaking in an unknown tongue.

Sommerville wanted to display the artifacts he had collected in a ritual setting and invite members of the local Buddhist communities (mostly ethnic J apanese residents who had moved to Philadelphia in large numbersabout two thousand people-to help build the Japanese exhibition hall and massive displays for the Centennial International Exhibition in Philadelphia's Fairmount Park in 1876) to conduct services in the museum. The "temple," as he called it, was a J apanese Shingon altar (butsudan) with dozens of images of buddhas and bodhisattvas from China and Japan such as Avalokiteśvara (J apanese: Kannon), Kșitigarbha (Japanese: Jizo), and others, alongside silk banners, brass censers and lamps, Tibetan thangkas, brocade and silk scarves, ornamental and ritual items, and a sizable statue of a white elephant (that has disappeared) from Siam/ Thailand. Sommerville transformed himself into a type of Buddhist priest and walked around the temple in silk Mandarin scholar's robes. 
According to photographs, this crowded forest of material would be much more familiar to visitors of Buddhist temples than to museum visitors. No item was labeled or well lit. Individual pieces were covered or behind others and were hard to see. A framed photograph of Sommerville himself was placed among the buddhas. Photographs of the temple show items from India, China, J ava, and elsewhere (these fascinating photographs are what first sparked my interest in Sommerville in 2009). Sommerville staged the photographs and

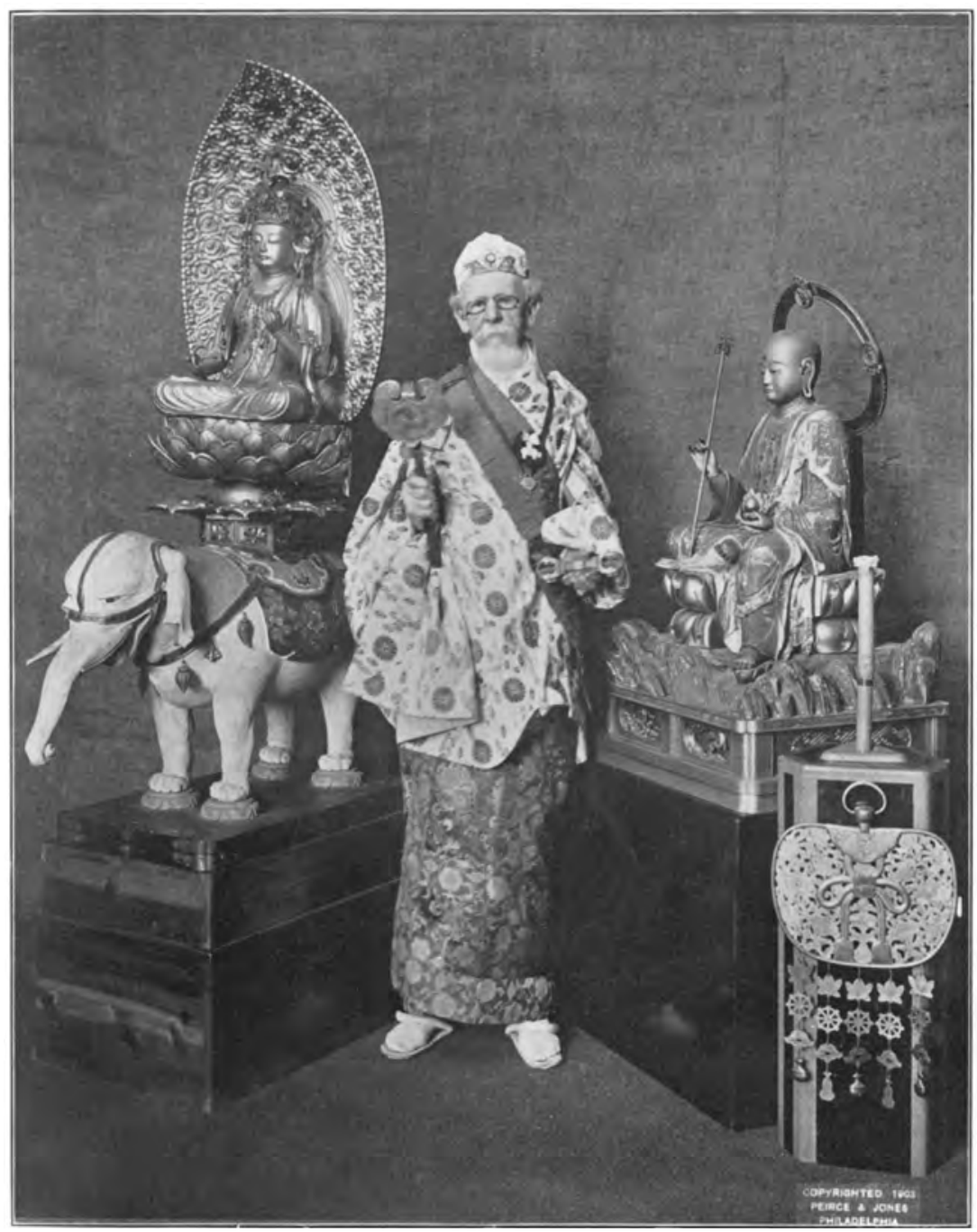

Maxwell Sommerville, dressed as a mandarin and attempting to blend into the great menagerie of statues, paintings, and furniture he collected, in the Penn Museum. I thank Stephen Lang of the University of Pennsylvania Museum of Archaeology and Anthropology for providing me with this image. 
placed himself in his formal robes hidden among the statues, ritual implements, and hangings. I often play a type of "Where's Waldo?" game with my students when they first see the photographs, to see if they can find Sommerville, standing like a statue among his collection.

Sommerville was not focused only on making himself and his collection the object of display: he wanted to transform the raison d'être of the museum itself. He gave sermons in front of the shrine he set up in the "temple" and encouraged Buddhist visitors to chant and make offerings. His monograph on the Buddhist temple, first published in $1900,{ }^{6}$ describes Sommerville's ecumenical intent in detail. He writes, "The Temple you enter here is not Korean, Tibetan, Chinese, or J apanese, not of any one Oriental nation. It is a Buddhist temple, constructed here of material purchased of priests in charge of Buddhist temples in many Eastern lands. It is so installed in the Free Museum of the University of Pennsylvania that all may form an idea of such a place of worship, while through its completeness, Mongolians and Buddhists will generally recognize a shrine where they may perform their accustomed acts of devotion." ${ }^{\prime 7}$

Sommerville was partially stymied in these escapades when he and his fellow worshippers were banned from lighting incense and candles for fear of fire. However, according to newspapers and university publications from the late nineteenth century, his "temple" received thousands of visitors. ${ }^{8} \mathrm{He}$ notes that "of particular note are reports that J apanese visited during the Russo-J apanese war to pay homage to the Fudo image."9 We also have hint of a negative reaction in North America regarding the theft of images intended for the temple: "It is known that Professor Sommerville's Buddhist Temple ... has been a source of annoyance and humiliation to the followers of Buddha in the United States, who consider the model in the light of a sacrilege. The Chinese Buddhists in San Francisco are numerous and devout, and no one questions that they would steal the guardians if they got an opportunity."10

Sommerville's temple was dismantled after he passed away in 1904, but for eight years a Buddhist place of worship existed on the campus of the oldest university in the United States-a university founded on the Benjamin Franklin ideal of a secular and rational education, free of the interference from divinity school faculty that characterized America's oldest colleges like Harvard and Yale. There has not been a Buddhist temple or ritual center on the campus or near the university since. No museum in North America, as far as I have been able to surmise, has ever had a curator (or a professor of glyptology) attempt to establish such a functioning (albeit ecumenical, and with an eccentric West Virginian collector as its head priest) Buddhist temple in its galleries. Indeed, the separation of Buddhist artifacts and images from their ritual and liturgical context is one of the most consistent realities about the establishment of Asian wings and galleries in Western museums. Buddhist ob- 
jects in museums are meant to educate and perhaps enrapture mostly nonBuddhist viewers, not serve practicing Buddhists. Of course, images in museums can't be touched. Sommerville wanted to erase the distinction between the museum and temple, the collector and the monk. He might have been before his time, but he wouldn't be the last. A century later, many curators, especially Shi Fa Zhao, as we will see, are erasing this distinction again.

In this final chapter I investigate the rise of Buddhist museums in contemporary Asia. Chapters 1 and 2 looked at how local conditions and material agency affected the way architects, monks, and creative visionaries executed their ecumenical and eclectic public leisure projects. This chapter looks at private and sometimes explicitly sectarian Buddhist museums that have attempted to appeal to a wider audience and have abandoned the rituals, liturgies, symbols, and teachings of particular sects to promote a new vision of Buddhism without borders. This opening up of their collections, as well as the active acquisition of new material, demonstrates a particular type of Buddhist ecumenism - an ecumenism without an agenda. What follows are stories of curators, architects, and monks who favor display over dogma, curiosity over conversion, spectacle over sermon, and leisure over allegiance. They show that one can build a Buddhist museum that is not necessarily a religious museum.

\section{The "Other" Temple of the Tooth Relic}

'You scholars might like things old and dusty, but we want our museum to be clean and open for inspiration and education, not just history and scholarly things," Ee Tiang Hwee said as he laughed and apologized for the third time about the mixture of "museum-quality" statues, photographs on poster board, and newly forged "low-quality" statues in the Buddhist Culture Museum. Like Lek Wiriyaphan, Ee Tiang Hwee, the executive director of the Buddha Tooth Relic Temple in Singapore, saw the function of Buddhist art not as a record of the past, valued for the rarity of its material, its age, style, or provenance, but in its value to tell a story, to educate, and to inspire visitors. Unlike Lek, Ee Tiang Hwee did not resent the importance scholars placed on historical authenticity and artistic skill. Indeed, heand the director of the museum (housed within the temple), Goh Aik Sai, who completed his degree in European Renaissance Art in England, both requested my help in identifying museumquality pieces, which they regularly bid for at Christie's Auction House in New York. ${ }^{11}$ Goh Aik Sai often bids on individual reliefs and statues (often Gandharan) costing as much as 80,000 USD.

The Buddha Tooth Relic Temple was founded by the monk Venerable Shi Fa Zhao in 2007. It is not to be confused with the famous sixteenthcentury Temple of the Tooth Relic (Sri Dalada Maligawa) in Kandy (Sri Lanka), which is one of the most ritually and historically important monasteries in 
Asia. However, by giving his temple this name, Shi Fa Zhao is clearly trying to share in the prestige of his temple's Sri Lankan namesake. Previously, from 1989 to 2007, Shi Fa Zhao had been the abbot of the much smaller Golden Pagoda Buddhist Temple in Singapore. Like Sommerville, he is a bit of an eccentric. His temple was a strange temple for Singapore because instead of having a Thai, Chinese, Malaysian, Tamil, Japanese, Sri Lankan, Burmese, or other easily identifiable national and ethnic origin, it had art and texts from many different Buddhist and linguistic traditions. Singapore's government heads, over the past sixty years, have promoted a system of quotas, multilanguage signs and schools, and tourist zones and ethnic neighborhoods that promote Singapore's diversity (at least to tourists and foreign investors) and highlight how the country's ethnic and religious groups live parallel and peaceful lives. In the same way, Shi Fa Zhao has promoted bringing together the ethnic divisions of Buddhism. While most of the visitors at his temple were Chinese speakers, and aesthetically the temple was Chinese, Shi Fa Zhao wanted to create an ecumenical space, and he started with diverse pieces of art. The Temple grew in popularity thanks in part to Shi Fa Zhao's advertising, his trips abroad (especially to India, Burma, and Sri Lanka), and his aggressive efforts to work with the Singapore Tourism Board. ${ }^{12}$

Shi Fa Zhao had identified a rare free lot on the edge of Chinatown on Sago Lane. Sago was famous as the "street of the dead" or "street of ghosts" because of the large number of end-of-life hospices for poor, mostly Chinese, immigrants on the street, which had operated between 1880 and the 1970s. There was a small temple in this location called Toh Peh Kong, but most of the houses on the edge of the street and the shops selling funerary items had closed by 1997. Shi Fa Zhao's original design for the temple was a modern high rise, with floors serving several functions. However, the tourism board wanted a "traditional" Chinese-looking temple instead, to attract tourists and blend in with the architecture of Chinatown. They also wanted an open-air stage for Chinese theatre and other events. Shi Fa Zhao agreed, and by 1998 had drawn up a design for what was called the Gajah Ratna Buddhist Temple that would attract tourists but also serve temple needs.

The fortunate meeting of both free space and government support was further supported by a gift Shi Fa Zhao received - a tooth, supposedly of the historical Buddha from Mrauk-U in the Arakan region of Burma/ Myanmar. ${ }^{13}$ The story in several of the temple's publications and on their website was kindly related to me by Ee Tiang Hwee in our long interview in J uly 2012. ${ }^{14}$ At the Bandula monastery in Mrauk-U, a Burmese monastery of the Pali Buddhist tradition, was a tooth relic of the Buddha along with some very rare buddha images and relics of local monks from Arakanese history. Shi Fa Zhao was shocked to see how little security and safety was employed in protecting 
these images and the relic. Although there is very little archaeological or historical evidence for this claim, the relic was supposedly given to King Min Yaza by a delegation of monks from Sri Lanka in $1513 \mathrm{CE}$. A stupa to house the relic was constructed under the orders of Prince Min Bar Gyi in 1531. The relic was moved a few times over the centuries, but after the fall of the Arakanese dynasty in 1748, the relic was lost. It was supposedly found by an Indian Muslim who was looting old stupas, and when he was caught, his wife threw the relic and some jewels out of their window. The bag was found in a pineapple tree. The relic was sent to Phayabaw monastery, was lost again, and then eventually turned up and was given to U Pandissa of Bandula monastery in 1900 and passed down to Venerable Sakapala, the abbot, in 1988. Shi Fa Zhao was impressed with Sakapala's outreach efforts among the poor in the region and his attempts to build a proper museum at Bandula. He donated 10,000 Singapore dollars (SGD) to the monastery and subsequently invited Sakapala to visit Singapore and bring the Buddha's tooth on a tour there. He gave him an additional 80,000 SGD. Sakapala passed away in 2002. The elaborate description of Sakapala's funeral in the Buddha Tooth Relic Temple's publications adds weight to the importance of Sakapala's fame and therefore adds authenticity to the story of the relic. ${ }^{15}$ Shi Fa Zhao claims that Sakapala agreed to give the relic to Singapore on August 4, 2002, before he passed, on the condition that Shi Fa Zhao build a museum to house it (something that Sakapala had been struggling to do for years in Mrauk-U). To make himself worthy of possessing the relic, Shi Fa Zhao took on a one-year silent retreat to mentally prepare himself, a tradition that some members of the temple undertake to this day. Shi Fa Zhao knew that his old small Golden Pagoda Temple would be inadequate to hold the relic and therefore worked hard with the Singapore Tourism Board to get construction started on the new temple, which he renamed the Buddha Tooth Relic Temple.

The temple broke ground on March 13, 2005, and was completed in 2007; it was officially called the Buddha Tooth Relic Temple and Museum or Xīnjiāpō fóyá sì lónghuá yuàn (Singapore Buddha Tooth Temple Longhua [Dragon Floriate] Court) in Chinese. ${ }^{16}$ Dignitaries from the various Buddhist lineages of China, Burma, Sri Lanka, Thailand, Malaysia, Indonesia, Korea, and Bhutan, as well as heads of state and foreign ministers have been invited to the temple. Photographs of all these important delegations are displayed on a continuous loop on two large flat-screen television monitors at the entrance to the temple. Gifts from visiting nuns, monks, corporate heads, famous musicians, and the like are prominently displayed in glass cases in the temple. The ceremony to complete the exterior of the temple on J une 5, 2006, was attended by the tourism board's director, Lim Neo Chian. The president of Singapore, S. R. Nathan, helped with the ribbon-cutting on Vesak Day (the 


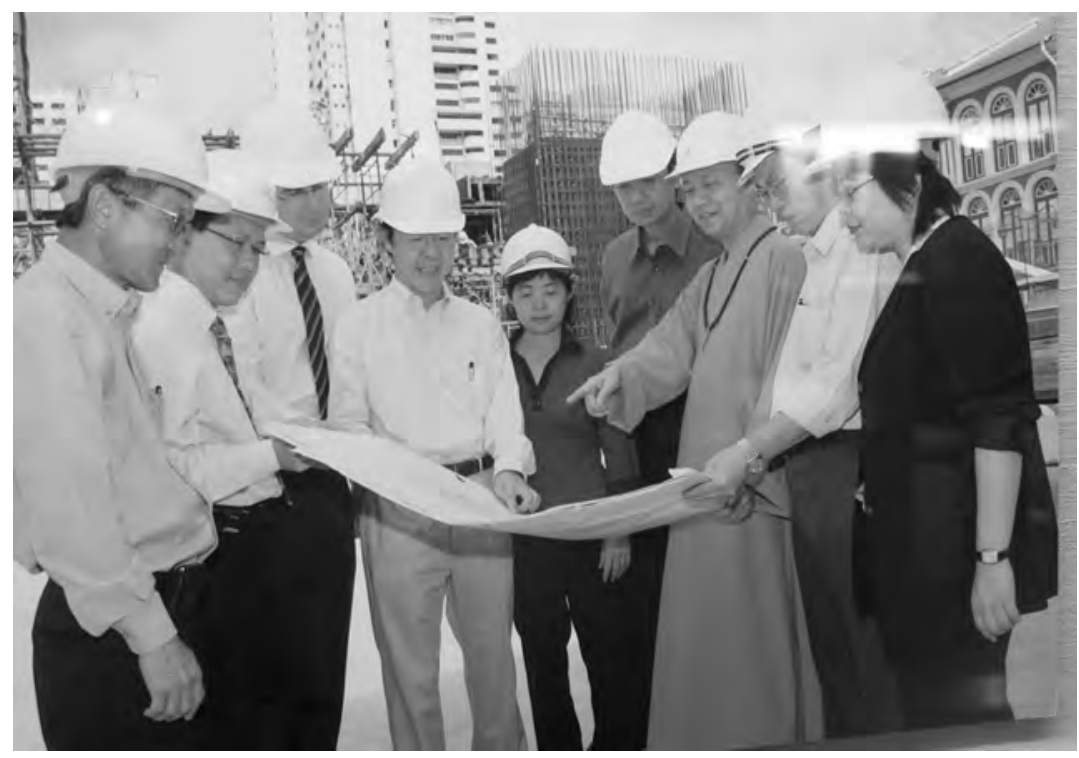

Shi Fa Zhao on the construction site of the Buddha Tooth Relic Temple, Singapore. I thank Ee Tiang Hwee for providing me with the photograph.

largest annual Buddhist holiday in many Pali Buddhist countries, like Laos and Burma, which has also grown in popularity in other Buddhist places recently) on May 30, 2007. ${ }^{17}$

The temple and museum were designed by Shi Fa Zhao, in consultation with designers from the Satō Kōgyō architectural firm of J apan and other firms. Photographs of Shi Fa Zhao wearing a hard hat, surrounded by piles of dirt and construction equipment, and looking intently at blueprints for the temple are on display at the temple and in publications. Like Lek, Shi Fa Zhao wanted to be involved at every stage of design and construction for this project even though, unlike Tange, he had no formal training in architecture. The temple and museum are impressive.

Ee Tiang Hwee repeated to me several times that the site is meant to bring together many different Buddhist traditions, but the overall style of the temple, because of the request of the tourism board, is Chinese. However, it is not architecture from the Hakka-, Hokkien-, Hainanese-, or Teo Chiuspeaking regions of the southern Chinese littoral (primarily Fujian and Guangdong Provinces), even though most of the ethnic Chinese in Singapore are from this region and Sago Street was dominated (and still is) by Cantonese (Yuè/Guangzhou-dialect) speakers. ${ }^{18}$ The architecture is inspired by J apanese interpretations of Northern Chinese Tang dynasty architecture. This was emphasized to me by Ee Tiang Hwee because there is very little actual Tang dynasty monastic architecture preserved well in China proper, and 


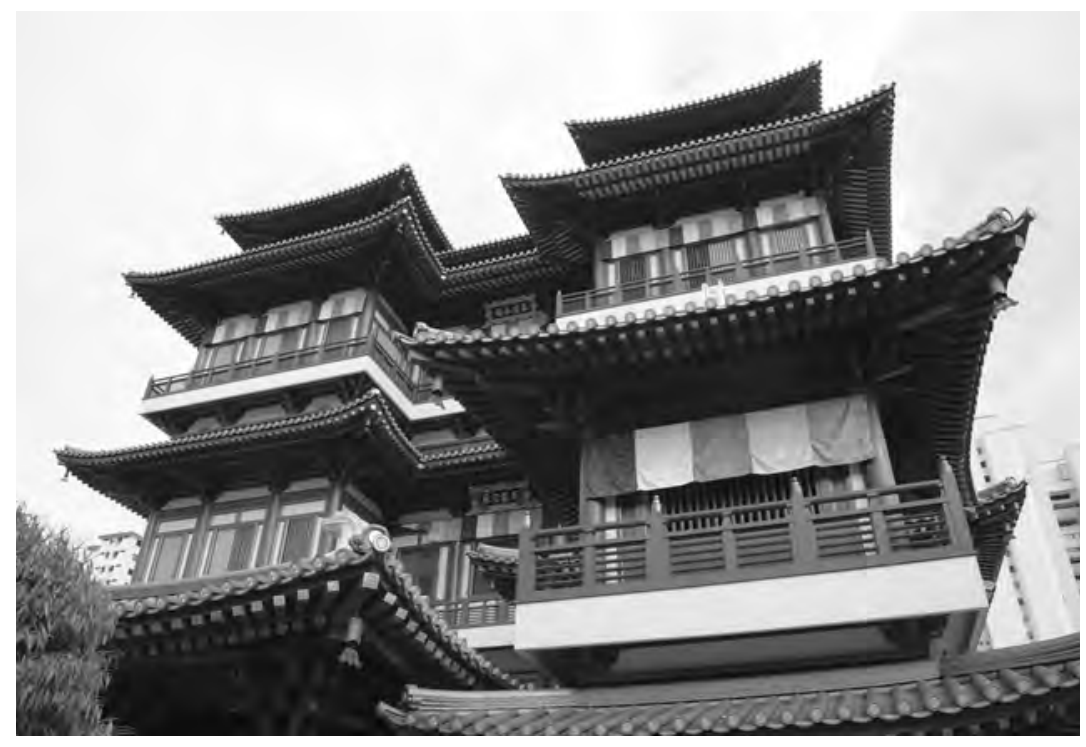

Exterior of the Buddha Tooth Relic Temple, Singapore

Japan's great temples in Nara, especially the Todaiji, preserve this style well. Moreover, the Tang dynasty was the greatest period of Buddhist cultural and intellectual flourishing, according to Shi Fa Zhao. He wants to bring back the glories of the Tang dynasty in Singapore.

One of Shi Fa Zhao's goals with the Tang design is to clear up misconceptions that Singaporeans have about Buddhism. He believes that after the Tang dynasty, Daoism and Buddhism were mixed, and "true" Buddhism existed only during the Tang. ${ }^{19}$ Shi Fa Zhao made trips to China and J apan to see architectural examples and has an entire library of architectural books at the temple. The lacquer, lamps, columns, roof beams, and other major architectural elements are all Tang era from J apanese exemplars in Nara and Kyoto. ${ }^{20}$ Artists were invited from Japan and China to help with the window frames and roof design. Ee Tiang Hweejoked that Shi Fa Zhao's temple was a museum of Tang design for the rest of the world to see in Singapore. The only non-Tang elements on the exterior of the temple are four small Naga trees donated by the Sri Lankan government. Two are thriving and two seem to be dying. They are Naga trees, not the more traditional Bodhi trees, because Maitreya, the temple's primary sacred patron figure, is associated with Naga trees. I examined some of the books in his private collection on my last visit (most in J apanese and Chinese language) and was amazed at the number of notes Shi Fa Zhao had made in these volumes. He took this design extremely seriously.

As for the cost, Ee Tiang Hwee was not shy about this issue at all. Prices for ceremony fees, gifts, buddha images, and the like are prominently 
displayed throughout the temple and on the temple website. Donations and purchases can be made online. The temple cost seventy-six million SGD to build (sixty-one million USD) initially, and staff costs and utilities are high. Through donations, service fees, and sales, the temple makes a surplus of about 20 percent per month and uses that money to open up eight foreign charity and ritual centers, mostly in Burma, and ten centers in Thailand, including an entire school in Chiang Rai (Northern Thailand). The surplus also helps fund the "world metta society" with centers in Thailand, Sri Lanka, and Burma (especially the Arakan region). The temple also uses this surplus to bid on Buddhist art for the museum and hire artisans to come to the temple. Free films and vegetarian food are offered in the basement of the temple. The place is extremely open and friendly, and the executive staff answered every question I had without suspicion or skepticism.

The temple's interior art and ritual areas are not so homogeneous in their aesthetic as the J apanese-inspired Tang Chinese exterior. Indeed, they reflect Shi Fa Zhao's attempt to create an ecumenical Buddhist center. The first floor is primarily for ritual and large meetings. Every day, chanting sessions are led by one monk with four assistant monks. On my numerous visits there (nine times between 2007 and 2015), the size and makeup of the audience was very similar: about forty-five people, mostly middle-aged to elderly ethnic Chinese laywomen and one or two older laymen, sit and chant while listening to the lead monk and reading along in their liturgical books. The chanting and the books are in Mandarin Chinese, and usually the chanting is very fast without cadence, musical accompaniment, or changes in rhythm or pace. During one visit, I witnessed the chanting of the Chinese-language edition of the Mahāparinirvāṇa Sūtra (Chinese: Nièpán J īng). The temple's edition has six hundred chapters, and six chapters are chanted per day for one hundred days of the rains retreat (usually late J une to October every year). The temple has a special room where the six hundred chapters are held. These texts were handwritten by a team of monks in China, specially commissioned by Shi Fa Zhao. Most of the lay chanters cannot understand the meaning of the sutra, because it is in classical Chinese and orally/aurally it is chanted too quickly to understand. The texts given to the audience have phonetic aids (Pinyin Romanization) to help them sound out the words. Besides this ritual chanting every morning and the occasional evening chanting, other ritual activities on this floor include offering gifts (usually incense, flowers, packaged food, and cash) to the main images and theimages in the antechamber behind the main images. A very large donation bowl in the Thai style in front of the room measures six feet across.

The main image is the future Buddha Maitreya. Shi Fa Zhao did not want the main image to be the Song dynasty style "fat" Maitreya, but the Tang style. The main inspiration, according to Ee Tiang Hwee, is an image of Maitreya found at two temples on Mount Wutai (Foguang Si and Nanchan Si). 
An artist from J apan carved the large image out of a single piece of wood, and he also created new images for the museum on the third floor. The silk and gold thread embroidered wall hanging behind the main image was also made in J apan and features a dragon. Goh Ee Choo, a local artist, helped paint and design many of the large images based on Tang design. Surrounding the walls of the main chanting room are several hundred buddha images in Tibetan style gau or niches, which could be donated to the temple for a cost of 5,000 SGD each. There are also some larger Buddha images that cost 100,000 SGD each. The entire balcony of the main hall is covered by relief carvings of dragons based on a design from Xian (Northern China). The antechamber contains a dozen images of different bodhisattvas and buddhas including Mañjuśri, Samantabhadra, Vairocana, and Acala. Each represents a different year of the Tang zodiac, and instructions are included about how to offer gifts based on the year of your birth to each image. They all surround a large image of Avalokiteśvara (Kuan Yin) carved from a large tree from Taiwan. Behind the image is the full text of the Heart Sutra in Chinese (Sanskrit: Prajñāpāramitā Hṛdaya Sūtra; Chinese: Bōrěbōluómìduō Xīnjīng). The work was done by a Chinese artist named Zhang Jian (from the Shanghai You Shan Guan Decorative Design Company), who trained in J apan for eighteen years. At the rear entrance to the main floor, next to the outside stage, sits a large statue of the dragon, Kulilah, and the protector god Dzambala, based off a Nepali design. The dragon was originally black, but Shi Fa Zhao had it painted many colors because he wants his temple and museum to be an open and bright place, not a mysterious smoke-filled hall. He does not want it to be intimidating to foreigners. Both of these images are associated with Tantric Buddhism.

The mezzanine level, which is largely a wide balcony overlooking the main chanting hall, can be reached by elevators or stairs. Like the upper floors, it is much quieter. The few visitors here find a small shrine to Avalokiteśvara and a rather large Eminent Sangha Museum, a series of display cases that feature the most prominent monks (as well as two nuns) in Singapore's history. Initially the designers wanted this to be a wax museum for the famous nuns and monks, but the cost was too high. ${ }^{21}$ Figures here include Venerable Guang Qia (1900- 1994) from Fujian (China), who moved to Singapore in 1937; Venerable Song Nian (1911- 1997) from J iangsu (China), who moved to Singapore and became the abbot of Phou Tai Kok Monastery in 1964; Venerable Tan Chan (1919- 2006) from Fuzhou (China), who became the abbot of ShuangXin Monastery in Singapore in 1975; as well as eminent nuns like Venerable Fa Kun (1927- 2002), who came to Singapore in 1936 and over time did considerable social service work; and Venerable Jing Run (1908- 2006) from Guangzhou, who moved to Singapore in 1924. Other monks either taught or inspired Shi Fa Zhao, like Venerable Zhen Dun of Taiwan, who headed the Fo Guang Center in Bangkok; Venerable You Tan (1908-1993) from Anhui; and Venerable Galboda Gnanissara from Sri Lanka. Shi Fa Zhao is given prominent 
position in the center of the exhibition, surrounded by photographs of him meeting the King of Thailand and political and religious leaders in East, South, and Southeast Asia.

Behind this museum is a small but surprisingly busy room, one of the two places (the other being the relic chamber) that restricts photography: the funerary hall named after the Bodhisattva Kșitigarbha, for people to offer gifts to their ancestors. The main image, however, is of the J apanese Bodhisattva Jizo (Sanskrit: Kșitigarbha). Ee Tiang Hwee was unsure why this J apanese style image was chosen over a Chinese one. This hall was generally not advertised to foreigners, only family members of the deceased.

Until 2015, the second floor contained the Aranya Gallery, along with a tea room, library, and gift store selling amulets, clothes (including monastic robes), candles, paintings, small statues, ritual tools, tourist items, and books (primarily in English with some Chinese) on Buddhist art, ethics, and history from mostly academic presses. The tea room received few visitors, however, so it closed in 2009 and has since gone through a series of renovations. When I visited, in November 2013 and March 2015, another series of renovations has been completed. A new meditation and meeting space, some books, large tangkhas, and a new altar had been finished, which replaced the old bookstore, which is now temporarily housed on the first floor. Behind this new reflective space is a small exhibition hall named after Mañjuśri, which holds temporary shows of certain types of Buddhist art. The six hundred handwritten chapters of the Mahāparinirvāṇa Sūtra are also held here.

The fourth floor contains the tooth relic. Another small relic hall behind the museum on the third floor contains relics supposedly of the Buddha's heart, brain, liver, nose, among other relics of prominent monks. These were given as gifts from visiting Burmese monks in gratitude for the several Buddhist educational and outreach centers donated by Shi Fa Zhao to Burma (mostly Arakan region). The tooth relic has its own separate floor. The room is divided into two sections: the carpeted meditation and relic viewing space. This part of the room is also the only part of the temple in which visitors have to take their shoes off. The second half of the room is off-limits to all visitors. The floor of this secure space is made of solid gold and was made through visitors donating their old gold jewelry to be melted down by the temple. ${ }^{22}$ The gold sheets on the floor are held between two sheets of thin crystal. Placed on this floor is the shrine holding the relic stupa. The entire space holding the stupa and relic cannot be stepped on and is shielded from visitors with bulletproof glass. The relic itself is inside a six- to seven-foot-tall stupa made entirely of gold and designed by a Thai artist from Chiang Mai named Amnuai Kantian (director of the Art and Culture Promotion Center at Chiang Mai University). The artist based his design on a combination of two stupas, one on a piece in the Calcutta (Kolkata) Museum in India and the other from the na- 
tional museum in New Delhi. On it are carvings of the eight major episodes from the life of the Buddha (birth, awakening, death, and the like).

The roof of the temple supports a beautiful and lush outside garden and is a rare quiet outdoor place in one of the busiest parts of Singapore. In the center of the garden is a large bronze Tibetan prayer wheel, about fifteen feet tall and eight feet in circumference, covered in the Tibetan script of the Mahāvairocana Sūtra. Surrounding the rotating prayer wheel are small shrines to the five "wisdom" or dhyani buddhas popular in Tibetan and Chinese tantric schools: Akṣobhya, Ratnasambhava (Ratnaketu), Amitābha, Amoghasiddhi, and Vairocana.

The third floor in the museum is called the Buddhist Culture Museum or the Nagapuspa (Sanskrit: nāgapuṣpa; English: flowers of the Naga tree or Mesua roxburghi) Buddhist Culture Museum. Like the old Aranya (Sanskrit: aranya/forest) Gallery and store on the second floor, this room also uses a Sanskrit title. ${ }^{23}$ As in most places in Singapore, the English name of the temple is the most prominent and used on all of their publications and signs. The Chinese name is not as prominent. It is rare to have Sanskrit names for rooms or shrines in Singapore, and this is a conscious choice by Shi Fa Zhao to promote the ecumenicalism of the museum. The museum is only one large room, but it is impressive considering it has been open only eight years. It is set up historically, moving from early Buddhism to modern Buddhism, but essentially having very few pieces or documentation after the Tang period. The structure of the museum is divided into three areas, described as teaching the path toward enlightenment, the story of the future Buddha Maitreya, and the story of Avalokiteśvara. As noted above, it is a mixture of new pieces representing older styles, photographs, poster boards, and rare older pieces bought at auction. It is professionally designed and well laid out, and the signage and displays are easy to follow.

The museum has very little in the way of intimidating security measures. Indeed, as Ee Tiang Hwee emphasized, it is designed to be educational and open. He stated that there are no "closed image shrine boxes" that hide the images of the buddhas and bodhisattvas like "you see in J apan." "We want our art to be seen, not hidden and preserved." The sign at the entrance to the museum states in English "Greetings and Welcome to the Buddhist Culture Museum. Get touched by the Buddha's stories, be enlightened by His Dharma. This is our mission to you." They want to "tell the story behind the artifacts" in the museum in order for the visitor to get a "deeper understanding of Buddhism." They use the rhetorical style of quoting loosely from Buddhist canonical texts (although the sources are not given) to have the Buddha "personally narrate" his story. The first person is used on the signs, as if the Buddha was directly speaking to the visitor. The sign also says, "Most artifacts in our museum are acquired using public donations and are opened for public 
adoption. It reflects the spirit of dana, or making offerings - the act of giving, the most fundamental form of teaching and cultivation that Buddhism emphasizes incessantly. ... The purpose of setting up this Museum fund is to preserve Buddhist art, promoting Buddhist culture, and inviting people from all walks of life, from around the world, regardless of race or religion, to have a deeper understanding." Most pieces are Thai, Burmese, or Chinese, as well as some Gandharan, J apanese, Tibetan, Korean, Sri Lankan, Indian, Cambodian, and Lao pieces.

The first section of the museum clearly shows that Shi Fa Zhao promotes ecumenicalism, with a Gandharan statue of the Buddha, Burmese oil lamps, a poster board with a large photograph of buddha images from Laos, a Shan Buddha image, a large carved "footprint" of the Buddha from Thailand, and a photograph of the Shwedagon temple in Yangon, Burma. Each of the first niches and signs goes through the life of the historical Buddha, but the images and photographs are eclectic, taken from different locations, time periods, and styles. For example, in an early section on the Buddha's asceticism and preaching is a Gandharan image, donated by a high court judge in Singapore, which was hand-painted by the judge's wife because she thought the gray color of the stone was boring. As the museum display goes on, though, this ecumenicalism declines, and the Tang period is again emphasized. Goh Aik Sai explained that this is because most pieces have been donated by Singaporeans, resulting in an usually large number of later pieces from China or Singaporean replicas of Chinese images. However, the emphasis placed on Chinese notions of Maitreya and Tang- and pre-Tang-style Avalokiteśvara images and teachings would of course demand a concomitant use of Chinese art. Although the ecumenicalism of the temple and museum are emphasized, the background of the Chinese staff, and Shi Fa Zhao's own training, naturally lend itself to a nearly unavoidable, although subtle, promotion of Chinese Buddhism.

Chinese Buddhism is not one thing, though. Therefore, I asked Ee Tiang Hwee about Shi Fa Zhao's own training and lineage. This was the first question he could not answer-not because he was hiding anything, he just did not know. Ee Tiang Hwee did not know the school, sect, or lineage of his own teacher or his own temple either. I was shocked. He was embarrassed a little too, and immediately picked up his cell phone to call Shi Fa Zhao. They spoke in Chinese (which I cannot understand) and laughed, and then he hung up and said "Good question; the venerable stated that his teachers were Tiantai and Linji, one from China and one from Singapore."24 I found this surprising, because even though the Tiantai reached its apex in China during the Tang period, Shi Fa Zhao certainly does not promote the Lotus Sutra (Saddharmapundarīka Sūtra) at the temple. The Linji also flourished during the (late) Tang period and is one of the five schools of Chan Buddhism (J apanese: Zen). It is known as a small but particularly strict form of Chan that 
grew in Japan under the Rinzai and Obaku schools of Zen, but remained relatively small in China. However, little at the temple would suggest Shi Fa Zhao's Linji Chan training. His promotion of Maitreya and Avalokiteśvara, as well as his focus on the Mahāparinirvāna Sūtra and the Mahāvairocana Sütra, are not intellectually firmly connected with Tiantai or Linji, and the focus on ecumenicalism, year-longsilent retreats, relic collecting, Kșitigarbha, and the Tang zodiac are not connected to these Chinese schools particularly, or to any one Chinese teaching lineage.

Shi Fa Zhao's own thoughts on Buddhist teachings (a collection of ten articles originally appearing as a series in the Nagapuspa museum's bimonthly magazine, Dharma Rain) in his book (in Chinese and English), The Pursuit of True Happiness and Other Life Observations, do not reveal his allegiance to a particular known school of thought but are, in a sense, like Singapore itself, made up of a wide variety of influences-forward thinking, eclectic, consensus-building, but with a certain emphasis on Chinese aesthetics. The only connection to Chan is found in two sentences mentioning the wellknown Buddhist text called the Shurangama Sutra (Sanskrit: Śūrañgama Sūtra; Chinese: Léngyán jīng); however, he does not refer to any specific teaching in this text.

In his book, Shi Fa Zhao is rarely specific. He commends Buddhist art, but decries materialism. He encourages respect for tradition and parents by promoting accumulating "merit" by "making icons, contributing to monastery construction, and so on," but emphasizes the need to build your own character. ${ }^{25}$ As he states, "Present blessings accumulated by our forefathers are to be cherished, but we must now cultivate future blessings. ${ }^{26}$ He relates several Buddhist stories from the life of the Buddha and eminent monks, but he does not cite sources or directly connect these stories to any particular school of thought. He mentions Master Xuanzang once, in regard to his travel to India to collect texts and promote the need for "action" and effort in religion. He also mentions the Chinese master Fan Zhongyan and the calligrapher Wang Xizhi briefly, to promote honesty, and the Tea Master Lu Yu, to promote "frugality." ${ }^{27}$ He just uses the phrase "according to the Dharma" as his authority. Hementions Confucius once in connection to the discouragement of "superstition" and the promotion of moral discipline. He mentions the word "Chan" once, but uses it to mean "meditation." To describe what "wisdom" is, he quotes Heraclitus instead of any Buddhist master. Photographs in the text are taken from the temple, but also from monks and temples in Burma, Tibet, and Thailand, children in China, and nature scenes from the desert, snow-covered lakes, the New England seashore, and forests.

Shi Fa Zhao quotes (loosely and without citation) only a few texts, with no obvious connection to each other: the Mañgala Sutta (a Pali text particularly popular in Southeast Asia and Sri Lanka), the Dhammapada, the "Garland Sutra" (I assume he means the Mahāvaipulya Buddhāvatam saka 
Sūtra/Huáyán Jing), the "Shurangama Sutra," and Tim Sanders's book, The Likeability Factor, which, as Shi Fa Zhao states, "explores the positive effects of an attractive personality on one's life and career."28 He also quotes a New York City restaurant owner and an unnamed Yale psychologist quoted in the Harvard Business Review (no specific citation provided). He promotes happiness, knowledge of the impermanence of all things, nonattachment, and gratitude in many articles. His is a delightful, accessible, and conversational type of writing suited to sermons for a general audience. It reflects a type of worldly wisdom peppered with pithy maxims from many traditions and time periods and perfectly reflects the intentions of the temple and museum. Shi Fa Zhao does not particularly promote his own background or temple. He makes nearly no mention of the temple and offers no teaching about the tooth relic. He provides the reader no autobiographical clues and does not use the first person. His writing is not intended for scholars or even serious Buddhist practitioners.

Other temple publications do focus solely on the temple, like the two-volume Perspective: Buddha Tooth Relic Templeand Museum through the Eyes of the People (Shi Fa Zao, published by the temple in 2008). These two volumes describe sections of the temple and museum as well as contain photographs of the activities there. Many of the photographs come from a competition that Shi Fa Zhao sponsored (along with the Singapore Tourism Board and the Photographic Society of Singapore) for what he called the Temple of the Heart Nagapuspa Photography Competition.

The first competition received forty-three hundred entries. Shi Fa Zhao stated in the introduction to another one of his books-Perspective- that "the teachings of the Buddha manifest in multiple forms, and whether as artefacts, architecture, paintings, the arts, multimedia or any other medium, they serve the purpose of providing enlightenment and cultivating wisdom. Modern Technology has actively influenced the spread of Buddhism in the world. Photography as a medium of expression can also become a channel for promoting the Buddhist faith. ${ }^{29}$ In another of his books, From Dawn to Dusk: The Buddha Tooth Relic Temple and Museum, he describes each room and floor of the temple, as well as the history of its construction and the origins of the art and architecture. Neither volume, though, promotes Shi Fa Zhao's own teaching, his biography, or a particular school of Buddhism. From Dawn to Dusk remarks only that Shi Fa Zhao was the mind behind the architectural design of the building, the design of the Nepalese-inspired gau image shrines in the main hall, and the vegetarian menu in the restaurant. ${ }^{30}$

The main floor is clearly the busiest of the entire temple, and my observation was confirmed by Ee Tiang Hwee. He noted that people come to the temple for different reasons, but most local and regular visitors came for the ritual chanting and to offer gifts to their zodiac buddha or bodhisattva or to the main image. Many also bought small amulets associated with the zodiac. Shi Fa Zhao wanted the temple to be more of an inspirational cultural center 
and Buddhist museum focused on the tooth relic, but it had become in many ways a traditional Chinese ritual center since it opened in 2007. Intellectually, though, Shi Fa Zhao was focused on the work of the upper floors. So far, his "temple" has become both a traditional local Chinese ritual space and an ecumenical pan-Buddhist leisure, artistic, and cultural center. This dual role is one of the reasons it has grown so successful, and so quickly.

Shi Fa Zhao has been able to develop a combination of spectacle, leisure, ecumenicalism, and ritual services that attracts local (and repeat) visitors, as well as foreign tourists and pilgrims visiting Singapore perhaps only one or two times in their lives. The lack of focus on any one school of Buddhism, the promotion of one particular style of art (at least on the interior of the temple), the relatively ecumenical and eclectic museum, and the lack of focus on the particular biography and specific teachings of the abbot, combined with the internationally trained staff, all contribute to the temple's mission to be open and welcoming to foreigners. However, the exterior Tang style, the chanting of texts in Chinese, the ancestor hall, and the promotion of both Avalokiteśvara and Maitreya are familiar to most local and translocal ethnic Chinese visitors, even the southern Chinese population of Singapore. ${ }^{31}$ This combination of ritual and spectacle keeps the Buddha Tooth Relic Temple busy despite the fact that it has no school to train new monks or nuns, no ordinations at the temple, and no large group of monastic actually residing at the temple. Nor does it offer day care, school, or summer camp for children, which are common functions at many modern Buddhist temples throughout Asia. However, it is a place that both tourists and locals can bring their children for a few hours of distraction and perhaps some casual Buddhist education without entrance fees, membership requirements, or religious coercion. If the parents do have money to spend, the gift store has many items for children, including clothes, books, toys, and jewelry. Furthermore, the web designer has been developing an animated Jàtaka (stories about the previous lives of the Buddha) series for children, as well as other online Buddhist ethics programs for children, including games. Ee Tiang Hwee emphasized that these games need to be colorful but simple for children, because "Angry Birds [the online game] is popular, but it is simple, we want to do something like a Buddhist Angry Birds." He believes that the temple and museum need to stay relevant to new generations and that such developments are a great way to make children and young adults see Buddhism as fun. Similar techniques are found in North American evangelical mega-churches like Harvest Christian Fellowship and Vineyard which have a large web presence, games and videos for children, and the like. ${ }^{32}$ The aim of the temple and museum is to generally make people aware of Buddhism, but without systematic training. The temple and museum focus on art display and sound projection instead of didactic instruction and problem-solving (ordination, ritual protection, direct prognostication, meditation, and counseling). 


\section{From Curio Cabinets to High Security Vaults}

Shi Fa Zhao, assisted by Ee Tiang Hwee, Goh Aik Sai, and a large staff have done considerable work building the museum, tea shop, and roof garden in a very short time, and I have no doubt that the Buddha Tooth Relic Temple will grow significantly in the near future. Shi Fa Zhao's vision for the temple differs from that of most other new Buddhist museums in Asia, as it attempts to be comprehensive (at least until the Tang dynasty) and chronologically linear. Most other collections of Buddhist art in Asia are part of more general museums of either history or fine arts, without a focus on Buddhism as a religion. Such examples include the Asia Civilizations Museum in Singapore, the Tokyo National Museum, the National Museum of Thailand, the Hong Kong Museum of Art, the National Museum of India in New Delhi, and dozens of other smaller museums. These museums all have either dedicated galleries of Buddhist art or frequent special exhibitions of Buddhist art, as do the larger examples of the Metropolitan Museum of Art in New York, the Guimet Museum in Paris, the Asian Art Museum in San Francisco, the Art Institute in Chicago, the Los Angeles County Museum of Art, the Cleveland Art Museum, the Freer Gallery of Art and Arthur M. Sacker Galleries of the Smithsonian, Museo Nazionale d'Arte Orientale in Rome (Tucci Museum), the Walters Art Museum in Baltimore, the Pacific Asia Museum and Norton Simon Museum in Pasadena, the Seattle Museum of Art, the Rubin Museum in New York, and the British Museum. ${ }^{33}$ Usually, however, these galleries are called "Asian," and not specifically Buddhist, unless there is a special exhibition. No rituals are performed, no candles or incense are burning, nuns and monks are not in residence, no sermons or guided meditations are presented, and no offerings made. For example, I gave a talk and wrote a chapter on Buddhist amulets for the exhibition book for a special exhibition on Thai Art for the Asian Civilizations Museum in Singapore in February 2013. Most of the art in the exhibition was Buddhist ritual and monastic art. The exhibition before that one had been on Islamic art in Indonesia and Malaysia. One large gallery in the museum was transformed into a display of Thai, mostly Buddhist, art. Shi Fa Zhao's Nagapuspa Buddhist Culture Museum finds itself somewhere between Sommerville's experiment in bringing Buddhist ritual, liturgy, and art together in a museum and the Asian Civilizations Museum, Guimet Museum, and others' attempts to remove Buddhist religious activity from the museum floor.

Shi Fa Zhao is not alone in modern Asia. Many attempts have been made to place museums within Buddhist monasteries. Thailand has dozens of small monastery museums. You do not need to be rich in Thailand to start your own museum; personal religious repertoires are often expressed through small monastery and house museums. Louis Gabaude and Paritta Chalermpow 
Koanantakool have recently written on Thai monastery museums, and Gabaude notes that Thai monasteries have often had small rooms that display gifts that the monastery has received as well as "local crafts, or local archaeological finds, curiosa collected by the abbot, or collections of Buddha images or amulets." ${ }^{\prime 34}$ Added to these museums are some new museums dedicated to certain famous monks like Than Achan Fan Acaro or Achan Man Phurithatto. My own monastery in Ubon Ratchathani Province in Thailand had a small museum for Luang Phu Sao Kanthasilo, the former abbot, and famed teacher of Achan Man. Paritta shows that these museums also do not contain solely Buddhist objects. They promote local handicrafts such as fisher's bamboo cages, wooden bowls, and silk skirts, which are not for sale but give villagers a place to protect and be proud of their family's heritage. Paritta notes that this "tangible heritage" is extremely important in these rural monasteries, which promote local cultural items without reference to national ideals. ${ }^{35}$ However, just as these museums are not strategic tools of the powerful, I would also caution against seeing them as solely tactics of the rural poor to usurp power and prestige. These monastery museums are often storehouses of items that are seen as historically or ritually valuable but that are not being used in daily religious or pedagogical activities. They are often locked, dusty, and unorganized. For example, the museum at Wat Lai Hin in rural Lampang Province, when I visited in 2001, had not been opened for some time and, according to the abbot, remains locked for long periods of time. The museum at Wat Indrawihan dedicated to Somdet To is opened only once a year for ten days and even then is not a popular place in the monastery to go even during the festival. The library and museum at the Samnak Santisuk, the oldest nunnery in Thailand, is not open to the public and is rarely even visited by the nuns in residence there.

Modern Thailand is a land of museums: museums of Medical Oddities (Sirirat Hospital in Thonburi), Prisons (Mahachai Street in Bangkok), History of Asylums and Mental Health Museum in Thonburi), the House Museums in Nan, Pichit, Trang, and other provinces, and many others. Anake Nawigamune has studied a variety of house museums throughout Thailand, especially in his home province of Songkhla in the deep south. ${ }^{36}$ These include a museum dedicated to cameras and a museum dedicated to clocks. I mention these various small "secular" museums because they are similar to monastery museums in their size and extremely local patronage. Their opening hours are limited, they have few trained staff, and they are designed for the purpose of simple display rather than providing detailed information, a coherent theme, or raison d'être. Often they are the personal creation of local historians and eccentric collectors. ${ }^{37}$ Sometimes they are assembled for particular occasions, like a visit from a royal family member or for an anniversary of the founding of an organization. A good example is the personal museum 
of the monk Phra Athikansian Thitayano of Wat Ko in Phetchaburi, which displays various items, from Chinese lacquer to old currency from various countries to elephant tusks, to palm-leaf (mostly medical) manuscripts.

Outside Thailand, many other examples of Buddhist museums are open to the public and run largely by thelaity. These museums find themselves in the interstitial space between the eclectic personal collections of monks and the desacralized, deritualized, and obsessively organized and secure spaces of national and regional museums.

One of the earlier examples of a Buddhist museum is the Ōkura Shukokan, established by Kihachiro Ōkura as Japan's first private museum in 1917. The museum was nearly completely destroyed by the Kanto Earthquake of 1923, but rebuilt by the famous J apanese architect of religious structure, Chūta Itō. ${ }^{38}$ Ōkura was a shameless self-promoter and entrepreneur who established one of J apan's finest prewar hotels across the parking lot from the museum. He was also a nationalist and nativist who wanted to preserve traditional J apanese culture, but did not support Shinto over Buddhism as the true religion of Japan like many of his contemporary wealthy politicians and businesspeople. Today a colossal statue of Ōkura himself, sitting in traditional robes, stands to the right of the main entrance to the museum. It is taller than the statues of Jizo and buddha next to it. The museum resembles a Buddhist temple preaching hall, and the bulk of the collection is focused on buddha images, scrolls, and ritual items. Many of the more than two thousand pieces in the collection are considered national treasures or important cultural pieces. Rotating special exhibitions feature new Buddhist art; for example, an exhibition of Buddhist-themed quilts made by Hattori Sanae was showing on my last visit there. ${ }^{39}$

A larger collection of rare Buddhist images and ritual objects is found in the now closed Nei Xue Tang museum in Singapore, the first museum in Singapore to be classified by the government under the Special House Museum program. The museum closed because it lacked funding to install proper climate conditioning machines and pay for the security measures needed to open the collection on a regular basis to the public. The objects (over forty thousand pieces) were collected by Woon Wee Teng. He and his assistant, Bella Wu $\mathrm{Bi}$, were extremely gracious to give me a private tour of the museum, which closed in 2009. Woon Wee Teng also has been very forthcoming and kind in interviews and on advice on the study of Thai art in person or over e-mail since that time. He was born in 1957 to a family famous for running the oldest coffee shop in Singapore-Killiney Kopitiam-specializing in kaya (a type of delicious coconut and egg jam). At nineteen, Woon Wee Teng enlisted in the Singapore Army, and thereafter he went to Northumbria University to read law. He became a barrister in London in 1983, was later called to the Singapore and Australian bar, and ended up practicing law in Singapore in con- 
struction, commercial, and banking law. He is married to Christine Storey, and they have two sons, J eremy and J onathan. At age fifty, he retired from law practice to dedicate his time and passion on collecting art and antiquities (particularly Buddhist and Hindu artworks), as well as promoting art and culture at the Nei Xue Tang Buddhist art museum and other museums, writing articles on Buddhist art, and working on his upcoming book on Yunnan's Buddhist artworks from the Nanzhao and Dali Kingdoms. Woon Wee Teng started collecting as a child and student, and over time amassed more than forty thousand pieces to establish the Nei Xue Tang house museum. It is the first ecumenical Buddhist art museum of its kind in Singapore, where the collector's home is also permitted for public display of exhibits. Through the museum, he helps promote Buddhist art from diverse Buddhist countries (particularly Thailand, Cambodia, Burma, and China).

As a result of a serious illness in 2006, and his desire that a larger and more publicly accessible museum be built, Woon Wee Teng made the painful decision to part with all his art collection in Nei Xue Tang to Mr. Oei Hong Leong, a Singapore tycoon. He continues to serve Nei Xue Tang as an art consultant and helps promote Buddhist and Hindu art through such museums. He is still an avid collector. Besides collecting, his family donates a great deal to preserve the arts and arts education. For example, they initiated the biggest annual art prize in the United Kingdom (The Woon Foundation Painting and Sculpture Art Prize) amounting to 40,000 GBP. He has donated to the Pho Chang Academy of Fine Art to promote traditional Thai Buddhist art, and has given generously to temples to make amulets as a special art form.

Unlike other collectors of Buddhist art and builders of museums, Woon Wee Teng concentrates his efforts on Buddhist ritual and protective objects that traditionally have been ignored by curators. He is one of the only internationally and ecumenically minded promoters of this little-known tradition in Southeast Asia. Among the thousands of important ritual and magical objects that he collected, it is worth mentioning the many precious protective Somdet amulets of Wat Rakang in Bangkok, which are considered some of the rarest and most sought-after in the world. Healso has many Luang Phu Tuad amulets and personal religious items such as takruts (rolled-up metal sheets with inscribed yantra) and humpback pidta amulets personally made by renowned Thai Master Tok Raja from Malaysia.

What also makes Woon's collection unique is his equal focus on collecting magical and protective objects as well as the paintings and large statues usually preferred by collectors and scholars. Further, he collected amulets and ritual implements directly from magically powerful monks in Southeast Asia. Moving from monastery to monastery and ritual to ritual, he amassed not only objects, but also extensive ethnographic information and wonderful stories. He has even witnessed the shooting of amulets to test their efficacy. 
From Khun Ko J un in Thailand, he received the hair relic and amulets of Photan Klai, and from Maha Bodhi Tahtaung Sayadaw in Burma he received special talun (i.e., philosopher's stones made from mercury through alchemy, incantation, and meditation). His collection of protective ritual diagrams (Thai: phra yan; Sanskrit: yantra), Thai amulets, and Khmer, Shan, and Burmese statuary (as well as Chinese, J apanese, Korean, Bhutanese, Sri Lankan, and other pieces, including a collection of large Luoyan images from the Ming dynasty (China) and gold votive images from Kandy, Sri Lanka) is one of the finest I have ever seen. The list goes on and on. He is the only Buddhist I have ever met who knows equally about the ritual traditions and translocal monastic lineages of Malaysia, Singapore, Thailand, Cambodia, China, and Burma (and, increasingly, Bangladesh). His vision and tireless work reveal a network of Buddhist magicians and teachers, unseen by scholars, who focus on their own specific, often country-based, field sites and language groups. He believes in giving back to the teachers who have taught him. He donated to build images and stupas in Southeast Asia and is as much a practicing Buddhist as a self-trained historian, anthropologist, and specialist in art. He has learned from lay and ordained masters across sectarian divisions and national boundaries. The personal connections and friends he has made are as valuable as the amulets he has collected.

The museum currently occupies two old row houses (seven total floors) near Chinatown in Singapore and the hope is either to improve those spaces or build a new facility. One of Woon Wee Teng's sons is a collector and appraiser of antiquities in Italy. At his museum, unlike in most, he encouraged me (and other visitors, when the museum was open) to look closely and, in many cases, touch individual pieces. He respects each item's ritual power and material and sacred history. He shares stories about individual amulet's miraculous or healing power. He tries to maintain a balance between his own religious dedication and an art historian's proclivity (although he has no formal training) to document, preserve, and display. He also supports the preservation of Burmese, Thai, and other regional art through his support of several monasteries. Woon Wee Teng also lends out some of his rare pieces to the Asian Civilizations Museum in Singapore. All told, Woon is unlike most curators of Asian collections in formal museums.

The Nei Xue Tang museum is very different aesthetically from two of Asia's newest museums of Buddhist art-the Reception Office (J apanese: Sanpai Settai Sho) on the grounds of the massive Higashi Hongan-ji monastery, and the Ryukoku Museum. Both are in Kyoto and are situated just a few short blocks away from each other. The Reception Office is a marvel of architectural design, as it is built almost completely underground in a hypermodern concrete and glass bunker. It was designed by Shin Takamatsu, the architect of the Star Peak on Mount Myōken, mentioned in the introduction. ${ }^{40}$ 
The Higashi Hongan-ji (or Shinshū Honbyō) is a thirteenth-century monastery and is the headquarters for the largest sect of J apanese Buddhism, the Shinshū Ōtani-ha branch of Jōdo Shinshū (Shin Buddhism). It split from the Nishi Hongan-ji, representing the Western branch, in 1602.

The Higashi Hongan-ji and the Nishi Hongan-ji monasteries, situated nearly next door to each other, conduct activities separately. When I first visited the site, I nearly missed the museum despite its massive size. I attended the ceremonies for the 750th anniversary of the passing of Shinran Shonnin (the sect's founder) in spring 2011 in Kyoto, and over five thousand people visited every day I was there. There were bus tours, guided walking tours in various languages, video installations, mass chanting sessions, religious product and book exhibitions, performances, sermons, and the like. Smaller but similar celebrations were held at their large sister monasteries in Los Angeles, Honolulu, and other sites. This was certainly a public celebration, but it was also sectarian, and most events were focused on ritual activity.

The Reception Office museum is underground, and despite several signs indicating its location, it is hard to find and is unexpected. From the outside, the only indication that it exists is a large glass floor in the center of a garden. That glass floor is actually the skylight of the museum and amphitheater. After entering the very traditional hall, which mirrors the architecture of the main monastery's gate, founder's hall, Amida hall, and ritual spaces, visitors descend into a distinctly nontraditional place. A long, gradually descending ramp features galleries along its side. One exhibition I saw there was about a Shin Buddhist woman named Hisako Nakamura, who lost both her arms and legs as a child because of an infection. In the 1930s she was befriended by Helen Keller and went on world tours promoting the rights of the disabled. Her life story and an exhibition of her clothes, photos, and the like were meant to inspire visitors to "turn rubble into gold," which is a Shin Buddhist metaphor for optimism in the face of tragedy. After descending the long corridor, visitors see the museum open up into a very large (three-story) light-filled gallery, where wooden sculptures are kept next to a five-hundredseat amphitheater where lectures are held. ${ }^{41}$

The Ryukoku Museum opened in the winter of 2011. Even though it is a sectarian museum, like the museum at the Higashi Hongan-ji, it is not on the grounds of a monastery. This museum is very modern, architecturally, and nothing about the building (symbols, style, prototypes) would indicate to passers-by that it is a museum dedicated to Buddhist art. It was designed by Manabu Nihei and Tomoyuki Hino of the Nikken Sekkei architectural firm (or Nikken Space Design). The designers conceived a series of stone, wood, and metal elements that all possessed "ripples," because the project team at Ryukoku University wanted the museum to represent Buddhism flowing all over the world. ${ }^{42}$ The project was funded by Ryukoku University, a Shin 
Buddhist institution that began as a school for monks from the Nishi Honganji (rival to the Higashi Hongan-ji) in 1639 and became a private university open to lay applicants in 1876. Although the university itself is characterized by Victorian- and Queen Anne- style buildings, their new museum is hypermodern, and although no one confirmed this in my conversations, one wonders if it was built partly in competition with the Higashi Hongan-ji's museum or the Otani University Museum (which is the academic partner of the Higashi Hongan-ji). The way the art is displayed, though, partly betrays the possible sectarian allegiances and motivations of its funders. However, their intention to make the museum ecumenical and comprehensive is impressive.

Thanks to a tour of the Ryukoku Museum and interviews with the curator, Shunpei Iwai, and the deputy director, Takashi Irisawa, I learned much about the origins of the museum and its vision. This museum of Buddhist history claims to be the first one of its type in the world. Indeed, it is the largest of its kind. Like the Nagapuspa Buddhist Culture Museum in Singapore, it is designed to present Buddhist history as a linear story moving from South Asia to Central Asia and the Silk Road and then to China, Korea, and Japan. J apan is presented as the destination for and culmination of Buddhism. This is similar to the way in which the Nagapuspa museum presented the Tang dynasty as the culmination of Buddhist history, although, as we saw, the story is much more complicated at Shi Fa Zhao's museum. ${ }^{43}$ However, the dominance of Shin material is more the result of the material available to the museum's curators; because of the great expense of building a new museum and

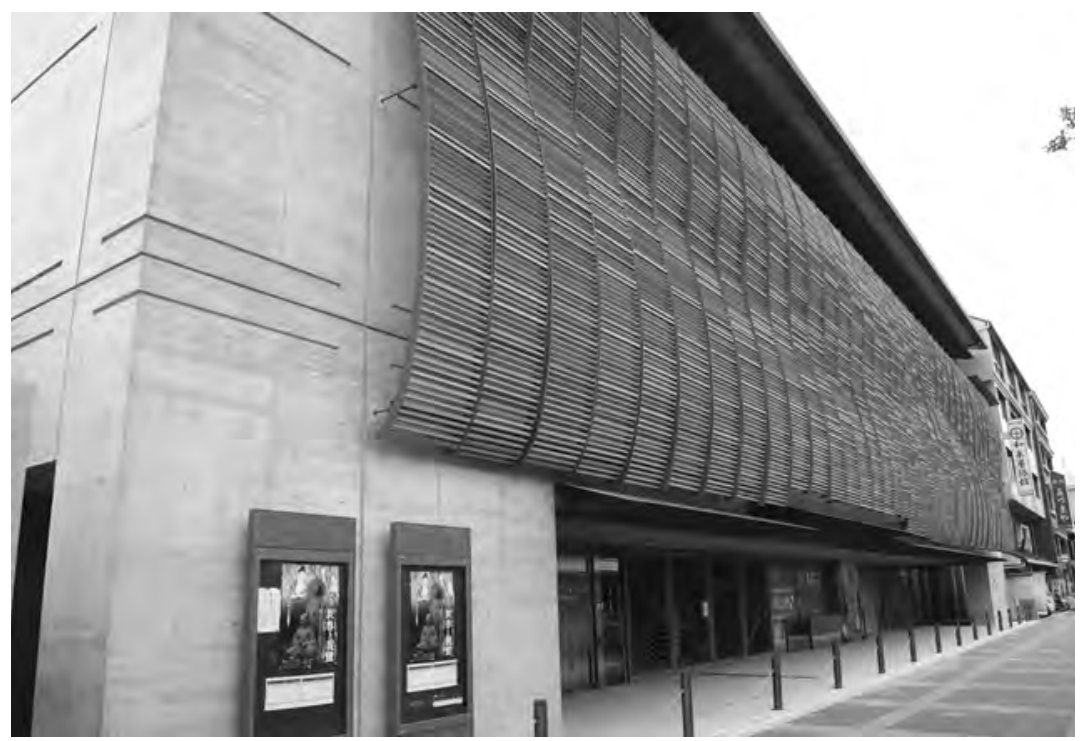

Ryukoku Museum, Kyoto 
filling it with interesting and rare material, the curators had to use the present holdings of the Ryukoku University. So much was spent on the architecture that the initial funding is limited for purchasing or borrowing new pieces.

The display style of the art and the galleries of the Ryukoku Museum is free from ritual, liturgy, and sectarian religious activity; Shin Buddhism, while strongly represented in art, is always the main focus. For example, the first two special exhibitions in the inaugural year for the museum were very different. One was called the Bezeklik Cave Temples Restoration, and displayed art from these caves in a specially designed corridor that makes visitors feel as if they are in a sixth-century cave in Turpan (Xinjang Uyghur Autonomous Region, China), painted with scenes of Uyghur Buddhist art. On the same floor as this "cave" is a video monitor on which visitors can hear and see different ritual practices and chanting styles from non-J apanese and nonShin Buddhists, such as chanting from Cambodia and Burma. There is even a mannequin dressed as a traditional Thai Buddhist monk, designed by a Thai professor at Ryukoku University.

The second exhibition on the Shin Buddhist floor was called, in English, Buddha and Shinran, and opened in March 2011. ${ }^{44}$ The exhibition displayed statues and paintings of the historical Buddha next to the founder of Shin Buddhism, Shinran, which is a less-than-subtle way of suggesting that the Buddha himself would have approved of Shinran's teachings and that Shinran was in a direct line of descent from the Buddha. To be fair, however, the museum did open at the time of the 750th anniversary of Shinran's death, and several nonsectarian museums in Japan had small exhibitions of Shin Buddhist art at that time, including a very large special exhibition at the Kyoto Municipal Museum that was very successful and had galleries filled with crowds of visitors who had come to Kyoto for the anniversary celebrations. Furthermore, the Ryukoku Museum did not take advantage of these crowds, as it was closed for a month (May 2011) during the celebrations, preparing other exhibitions. Crowds did not appear to mind visiting a museum on the other side of the city in a separate non-monastic place (with a relatively large entrance fee) instead of visiting a free museum on the grounds of the Higashi Hongan-ji. The content of the collection and the research documents certainly are overwhelmingly Shin, since they were collected by Shin Buddhists connected with the Nishi Hongan-ji. The second floor, which focuses on Buddhism in Japan, emphasizes Shin Buddhism over the Shingon, Zen, Ritsu, Tendai, or other historical sects in Japan. Indeed, the very title of one of the main exhibitions on that floor is Shinran Shōnin and Shin Buddhism, which introduces the teachings of Shinran Shōnin, the development of Shin Buddhism, and the history of Hongan-ji. ${ }^{45}$ Next to this is an exhibit about the history of Ryukoku University. On the third floor are the objects collected by teams of explorers dispatched by Kōzui Ōtani, the twenty-second head of the Nishi 
Hongan-ji, in the early twentieth century during his travels to South Asia and Tibet, as well as the writings of J ippan Nakagawa, another leading Shin Buddhist teacher from the twelfth century.

Even these Shin-focused exhibitions attempt to connect Shin Buddhism to pan-Asian Buddhism and its Indic origins. As we saw in chapter 1, many J apanese artists, scholars, practitioners, and collectors have long had an interest in the Indic origins of Buddhism. The Ryukoku Museum, like the Nagapuspa in Singapore and other smaller private collections in Japan, has a particular interest in the oldest examples of Buddhist art, particularly from Gandhara. This is likely because these pieces were plentiful (and still are) in the art markets of the twentieth century and were collected by wealthy Japanese and European travelers. Other pieces were bought up by Japanese collectors in the 1980s at the height of the J apanese economic boom and during the rise of smuggling of Buddhist art out of the conflict zones of Afghanistan and Pakistan. A similar rise in interest in Shan, Mon, and Burmese art was seen in the early 1990s because of poverty and conflict in that region, and Khmer art in the 1970s, 1980s, and 1990s. However, it is also due in part to the long history that the many Japanese Buddhist thinkers, artists, and collectors share with India and the origins of Buddhism, as demonstrated clearly in the study of Lumbini in chapter $1 .^{46}$

Despite the sectarian nature of the Ryukoku Museum, the director, Akira Miyaji, like Shi Fa Zhao, emphasizes the public and leisure objectives of his museum. This is a museum meant to inspire and be easily accessible:

The first full-fledged comprehensive museum on Buddhism in J apan. This is the Ryukoku Museum. Covering the vast and deep theme of "Buddhism" from its founding to the spread of Buddhism into Asia to its development in J apan, and the connection to modern day Buddhism. The research and investigation into the concepts and history, as well as the art of Buddhism are all connected to our exhibits. All of these points are conveyed not in a strict, difficult manner, but in fun and enjoyable events and exhibits using sound and visuals where visitors can experience the world of Buddhism. The Ryukoku Museum aims to be a museum open to all citizens that conveys the "fascination" of Buddhism. We are focused on making our events and exhibits easy to understand and interesting. We hope that men and women, young and old, who previously had no experience to come into direct contact with Buddhism, will come to the museum and that this will trigger a greater interest in Buddhism. In addition, we hope that this museum will be a scholarly facility where students studying Buddhism as well as people interested in Buddhism and people 
researching Buddhism can visit and deepen their knowledge. Although this museum is one of the facilities of Ryukoku University, it is open to everybody and we hope that many of you will be able to come by and visit us. People who come to visit Kyoto, worshippers who come to Kyoto, even students on school trips visiting temples and shrines can increase the enjoyment of these temples and shrines tenfold by visiting the Ryukoku Museum first. ... This is one way to enjoy the museum that we recommend. In addition, although Horikawadori in Shimogyo-ku, Kyoto is already home to many famous locations and historical sites including Nishi Honganji and Dendoin, which are UNESCO World Heritage Sites, we hope that the addition of this museum will lead to an increased vitalization of the area. A museum that is friendly and approachable, but at the same time one where you will feel depth and richness. ${ }^{47}$

Further, the visitor learns that the museum's design team wanted to utilize

\begin{abstract}
its location of being across from Nishi Honganji, a World Cultural Heritage, as a museum open to the public, the museum will contribute to the vitalization of the local community. The museum will provide an east-west path that will connect Horikawa-dori and Abura-no-kouji making access to the Dendoin, a historical architectural building, located on the Abura-no-kouji side easier. In addition, a section of the 1st floor will be open space that will be open to everyone. The museum also houses a museum shop, a cafe, and a courtyard filled with natural light. ${ }^{48}$
\end{abstract}

Finally, let me briefly mention one fascinating but small Buddhist leisure place that is quite hard to find and can be easily overlooked. It is the Sarasvatī Museum and Daibutsu garden on the grounds of a small Sōtō Zen monastery in Nagoya, Japan, that promotes Tendai history, Pali teachings, Shingon art, and an annual festival to a Hindu goddess. This monastery, known as Tōgan-ji (Peach Rock Monastery), is not a modern experiment. It was founded in 1532 by Oda Nobuyuki near Kyoto and moved to Nagoya in $1714 .{ }^{49}$ Nobuyuki was the nephew of the famous leader Oda Nobunaga. Kai Genshun led the monastery in Nagoya with Kannon (Kuan Yin) as its principal deity (made by Eshen Sōzu) and served as abbot to other major monasteries like Jigen-ji and Ryūsen-ji.

This impressive lineage is not the reason I am mentioning this place. The present abbot, and only permanent resident, Oda Baisen, has turned this old monastery into a type of hyper-sexualized pleasure garden. He visited Sri 
Lanka and India in 1964, and this trip greatly influenced him. He met with a monk named Samarata and received a bone relic of the Buddha (although it is unclear from what temple) in a formal ceremony. ${ }^{50}$ Hanging in the main hall of the monastery are photographs of this trip, as well as photographs of a helicopter moving an important stone, a Buddha footprint, and a sōrin (a ringed finial that tops many Japanese pagodas) from the famous Okuno-in mausoleum of Kūkai the founder of Shingon Buddhism (on Mount Kōya near Osaka).

Like Woon in Singapore and Lek in Thailand, the abbot appears to be a master at collecting unique items. It seems that every inch of the monastery houses a collected object, and very few of the objects make sense next to each other. In the main hall are large beehives in glass cases, Sōtō Zen liturgical chanting books, and a framed letter from Indira Gandhi. The ceiling is painted with Shingon designs from Mount Kōya, and the main Buddha image is surrounded by statues of the Eighteen Arahants (usually only sixteen are depicted in Japan and eighteen are associated with Chinese Buddhist schools). Outside, the garden has carvings of the Ușṇișavijaya mantra in Siddham script (another possible Shingon influence), as well as a large Śaivite linga (phallic stone object used in many different Hindu rituals) with an image that resembles Kūkai (often known as Kōbōdaishi) on its side. However, the inscription on its side reads "Daisōjō Ryōkei kyūjū hassai” (Master/ Highest Ranking Monk of the Order Ryūkei who passed away at 98 years old) followed by "Seimei no kongen" (King of the Bioforce or Life Essence). ${ }^{51}$ I asked the abbot, who was reluctant to explain the meaning of this to me, and I assume this was dedicated to one of the abbot's teachers. Several experts in J apanese Buddhist studies were also perplexed by this term.

In the small valley near the back of the temple is a large (but hard to see from the street because of the trees) garish green Gupta-style (North Indian) buddha image with bright gold lips. The statue, known as the Nagoya Daibutsu (large Buddha of Nagoya) was dedicated in 1987 in a ceremony with monks from the Tendai Enryaku-ji monastery under the direction of Hagami Shōchō and is thirty feet tall. The sides are covered with bas-reliefs of Indian monks, deer, and dharma wheels, as one would find at Sarnath in North India. This image clearly does not fit in style or iconography to any J apanese lineage. The main inscription can be translated from the Japanese as "Peace, Impermanence, and non-Self." However out of place this large statue seems, nothing can prepare the visitor for the surprise waiting in the monastery's library.

In the dark room are collections of books including a nearly complete Pali canon, books of the Artharva Veda (labeled in English as the "Arthur Veda"), Tendai and Shingon books, and a very large collection of wooden, brass, and silver phalluses. These are not traditional Hindu linga, but anatomically correct phalluses like the ones seen throughout Cambodia and 


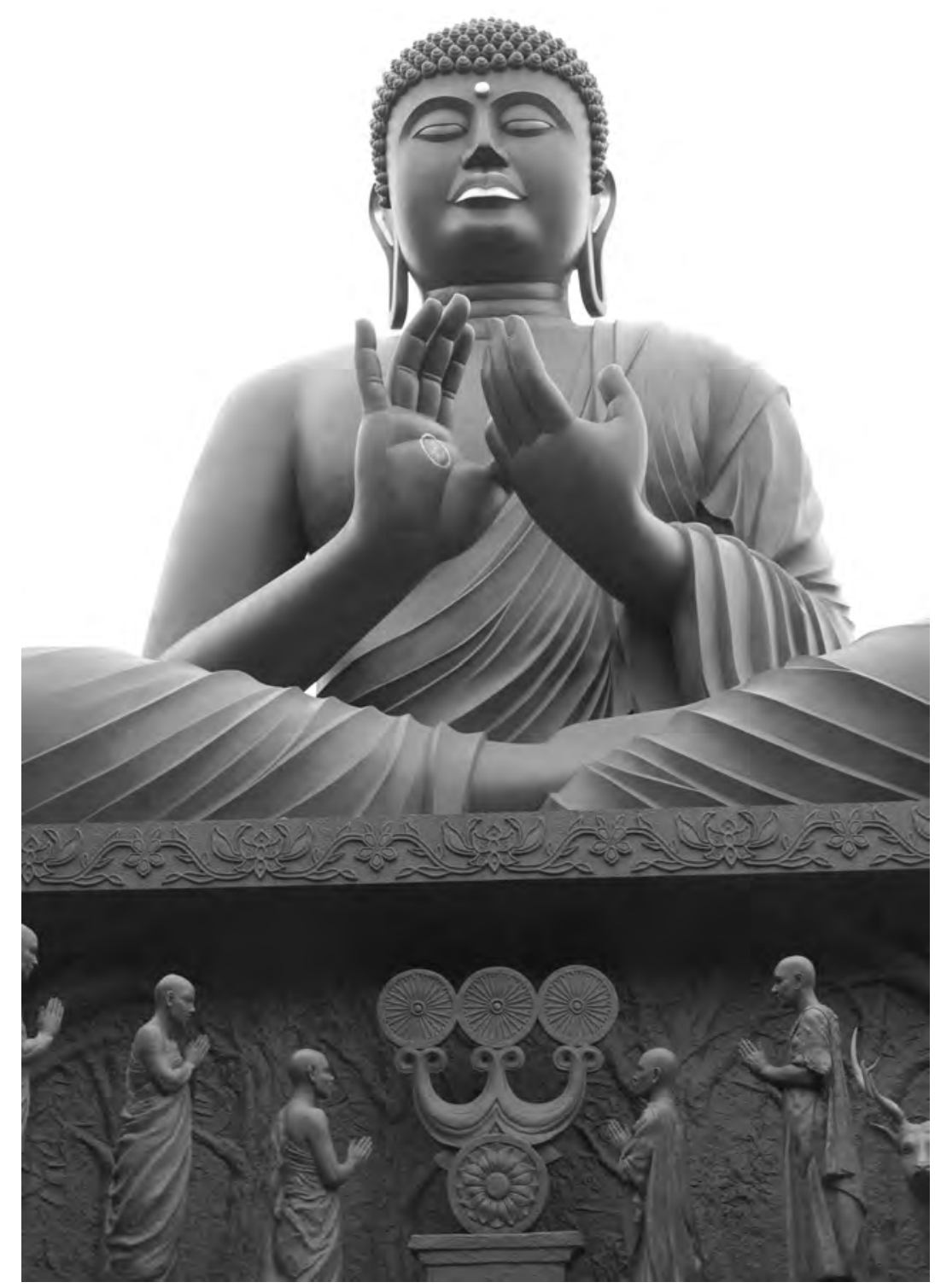

Nagoya Daibutsu located at the Tōgan-ji Monastery, Nagoya

Thailand that are used for protective rituals and rituals to increase male virility. These provocative phalluses have caused quite a bit of joking among visitors, as is evident from the many blog comments on J apanese travel websites. $^{52}$

I am glad that I was not the only person befuddled when visiting this complex garden, monastery, and shrine. Besides this large collection are 
several small statues, graphically featuring women and men in sexual poses. In the room immediately adjacent to this is a backlit window separating the visitor from a life-size statue of Sarasvatī, the goddess of wisdom, music, and art and consort to the god Brahmā. Usually Sarasvatī is depicted dressed in white, playing veena (traditional Indian stringed instrument), and often with a peacock. Here in the Tōgan-ji, she is lying naked on a bed, seemingly in the middle of an amorous dream. Another clothed statue of Sarasvatī in the library is holding a sword like the Bodhisattva Mañjuśrī. This statue supposedly belonged to Oda Nobuhide, who brought it originally to the temple. In J apanese she is called Benzaiten, and there is a festival at the monastery every May dedicated to her. Apparently, this festival is one of the only activities that takes place at this monastery. There is no school. The abbot does not train anyone. My colleagues, who teach Indian and Buddhist studies at Nagoya University (less than two miles from the monastery), had never been there for a ritual. People stroll around the gardens and are shocked by the room full of penises, but in many ways, this is a monastery in name only and is more like a home, open to the public, of a rather reclusive and eccentric older monk.

\section{Conclusion}

Museums are one of the greatest tools of the powerful and the elite. Many people have echoed Foucault's criticism of the negative way museums shape and control the way we come to know beauty and history. ${ }^{53}$ Douglas Crimp, Eilean Hooper-Greenhill, Craig Cunlas, Ruth Phillips, and others have seen museums as imperialist tools. ${ }^{54}$ Svetlana Alpers coined the term "museum effect" to describe the ways museums culturally construct ways of seeing. ${ }^{55}$ They enforce a "detached viewing" of objects, 56 which become distant and untouchable. This criticism of museums has been taken up in Asian studies as well, most notably by Stanley Abe and Maurizio Peleggi. ${ }^{57}$ The latter sees the establishment of the National Museum, the National Library, the Siam Society, and the Archaeological Society, among other royal and colonial semi-institutions in Siam in the early twentieth century, as tools of elite power and display. Peleggi states that this "antiquarianism [promoted by the elite] signaled a departure from the worldview orientated by the Buddhist doctrine of impermanence, which postulates the inexorable decay of all physical entities."

While these institutions of social control certainly can be seen as the subtle and not-so-subtle ways foreign scholars and princes attempted to define history, beauty, tradition, and science for the people, a number of museums in Asia, mostly Buddhist, operate largely independent of state control and national interests and are spaces where individual agency is celebrated and 
ecumenicalism and eccentricity abounds. Looking closely at Shi Fa Zhao's Nagapuspa Buddhist Culture Museum, which is part of the larger Buddha Tooth Relic Temple and Museum in Singapore, and the other new Buddhist museums in this chapter, I hope it is clear that these Buddhist museums are neither a series of neatly configured display cases, perfectly presenting a linear narrative of Buddhist history, nor propaganda tools of profit-minded religious visionaries. To study them is to study a series of local optima in which Shi Fa Zhao and other museum designers and curators have had to sacrifice the instructive power of religious art to the affective experience of visiting a museum. The multiple affective encounters these museums allow create ecumenical environments that eschew explicit agendas and allow visitors to leisurely experience Buddhist distraction. 


\section{Conclusions and Comparisons}

THE SCENT Of CAMELlia HUNG IN THe thickjungle air. One at a time, beads of sweat clung to the tip of my nose before dropping onto the camera hanging from my neck. I stared through the tree branches at the centuries-old wooden buddha image. The intensely spicy breakfast I had eaten was agreeing with my stomach no more than my nerves were agreeing with the fact that I had seen several crocodiles on my jungle trek to the shrine. I had trouble understanding the local dialect, had gotten lost several times, and kept wondering if this trip was worth it. I had come a long way. Finally, I was seated in front of a very rare Chinese statue of the Buddha on a stone bench next to a small J apanese bridge. It was a place neither the Buddha nor I thought we would ever end up-Avery Island, Louisiana.

The bayou around the Gulf of Mexico has large patches of thickjungle covered in Spanish moss. On the southern edge of New Iberia Parish, Avery Island is the home of crocodiles, white egrets, and chili peppers. They share the land with Acadians (more commonly known as Cajuns), Lao and Vietnamese immigrants, and oil workers. Avery Island is also a private estate and the production center of Tabasco brand Pepper Sauce, the most commonly consumed commercial spicy condiment in the world (available in 120 countries) and the 167-year-old recipe of the McIlhenny family. ${ }^{1}$ I was there in August, at the height of the hot season, to see one of the earliest Chinese Buddha images brought to America. Perhaps a ninth-century statue, it has been in the McIlhenny family for over seventy-five years. It was the centerpiece of their leisure gardens and bird preserve.

Edward "Ned" Avery McIlhenny was the third McIlhenny to run the Tabasco Company, and his marketing and organizational skills in the 1920s, 1930s, and 1940s made this once-local hot sauce purveyor into the multinational condiment empire it is today. Perhaps his greatest marketing ploy was linking Tabasco brand Pepper Sauce to the popularity of the Bloody Mary 


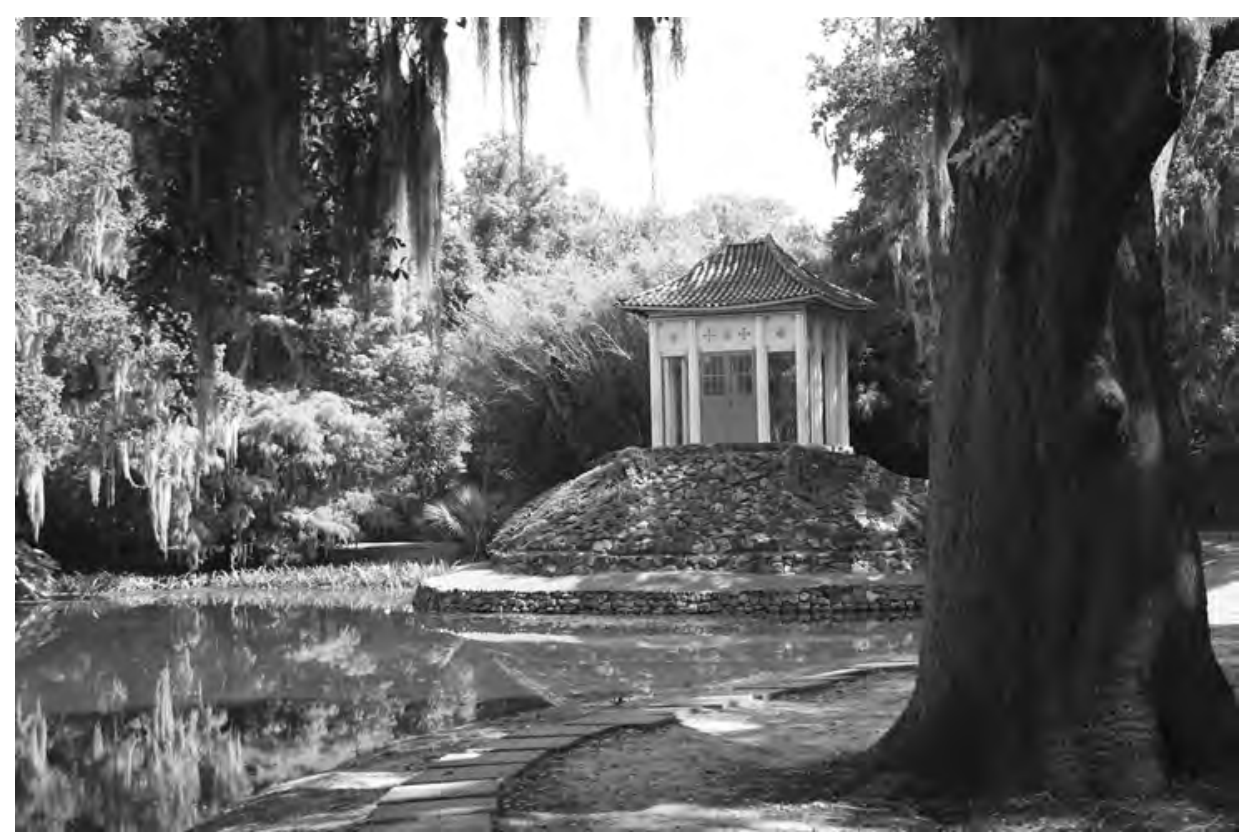

Buddha image at Avery Island, Louisiana

cocktail in the public consciousness, ${ }^{2}$ making his sauce a household name. Tabasco bottles have made it to the top of Mount Everest, onto the dining room table of the British royal family, and into American soldiers' mess kits. Like other captains of industry, Ned McIlhenny used his newfound wealth to throw lavish parties. He didn't indulge only in conspicuous consumption, however. He saw that the success of Tabasco was based on two things-Avery Island and the loyalty of his workers.

Avery Island is a relatively unique piece of real estate. Long a sugar plantation, shortly before the Civil War it was discovered that the entire island was actually made out of salt. The tall trees and swamps were sitting on a mountain of salt, perhaps the largest single salt deposit in North America. This is the main reason Union soldiers went out of their way to secure this otherwise nonstrategic backwater: they wanted to prevent Confederate soldiers from having access to salt rations. Although the true story of how the Mexican Tabasco peppers came to be cultivated on the island and where the original recipe for the sauce came from is controversial, after the war this nearly unending supply of salt combined with vinegar and the mashed peppers (which grow easily in this climate) allowed the sauce to be cheaply produced.

This perfect climate, combined with a mountain of salt, needed just one more thing - the happy worker to mine the salt, pick the peppers, mash 
the ingredients, and bottle it up. Ned housed and fed most of the workers for free on the island. They shopped at the company store on the island. He organized schooling for their children, games for their off hours, and celebrations for their community. ${ }^{3}$ He created a giant egret reserve, protected the waters, and created leisure gardens. In the middle of this Eden, thanks to two friends from New York, he placed the old Buddha image in a specially made glass pagoda on a stone altar reminiscent of Chinese philosophers' stones. In front of the shrine is a decorative pond with a J apanese bridge seemingly taken right out of a Monet-it is idyllic. Ned wanted to surround the island with beauty and keep his workers happy. For him, this Buddha was the perfect focal point.

The six-foot-tall seated Tang-style buddha added to Ned's mystique. Many of his workers supposedly believed he had magical healing powers, especially "bone healing." He surrounded the statue with Chinese irises, creeping juniper, Tibetan podocarp, and bamboo. He was given a rare Wasi orange tree by the Japanese Imperial family because, while Ned was exploring in the Arctic, he had saved the lives of three J apanese explorers. At that time, this type of tree supposedly existed in no garden in the world besides the emperor's private estate. It became popular for workers to picnic in front of the Buddha and even propose marriage there. ${ }^{4}$

The statue originally came from the now-destroyed Shonfa Temple in northeast Beijing (although this is not confirmed by art historians). It was stolen by a local military officer, who ordered it shipped to the United States sometime in the early 1900s and wanted it sold to a museum so he could profit from it. The person, whose name is lost, was supposedly captured in Beijing and executed. The statue was stuck in a New York warehouse and was sold at auction to two friends of Ned's in 1936, who thought it would make a great present for their eclectic friend. ${ }^{5}$ McIlhenny was a collector of exotic items and did not like organized religion. He believed in the sacredness of nature and was an enthusiast of Buddhism. He even wrote a poem inspired by the statue that is on a plaque at the shrine's base: "Long days of travel have brought me from my home, yet I have known no hour of calmer rest. My thoughts are like the swaying bamboo's crest waved to and fro above the rippling stream, clear and blue as from a glorious dream."

According to both Shane Bernard, the McIlhenny's family historian, and Donna Neuville, one of the managers of the gardens, people often leave small gifts like fruit and candy in front of the shrine. They have also witnessed annual chanting by local Lao Buddhists in front of the image. ${ }^{7}$ I saw many people leaving coins when I visited. The gift shop for the gardens on Avery Island sells t-shirts with the poem and a photograph of the Buddha, buddha candles, and small buddha statues. Another gift store on the island sells every flavor of pepper sauce imaginable alongside Tabasco golf shirts, chocolates, beer mugs, and spicy ice cream. The Buddha sat comfortably while my children 
and many other families leisurely enjoyed their day strolling, shopping, and dozing off.

Ned McIlhenny was not alone at this time in creating beautiful gardens with large buddha images in the West. Over the past few years I have visited the Asian gardens - which often feature replicas of Buddhist temples and buddha images - in Powerscourt in the Wicklow Mountains (Ireland); at the Duke University Gardens in Durham (North Carolina), the Huntington Gardens and Library in Pasadena (California), and the Japan House (Shofuso) in Fairmount Park (Philadelphia); and the replica of the Byōdō-in Temple (original in Uji, near Kyoto, J apan) in the Valley of the Temples Memorial Park in Kahalu'u, O'ahu (Hawai'i), among others. In these leisure gardens full of families picnicking, couples strolling romantically, and joggers, buddhas and Asian decorative plants and statues have become almost expected. This is part of the way Buddhist culture has been seen as synonymous with serenity and nature among Western enthusiasts. This is a story of the typical distortion of Buddhist culture that scholars often write about, though - this is not simple Orientalism. As this book has shown, a similar phenomenon has happened over the last century in Asia. Although a Buddhist roller coaster and water park, a quasi-ecumenical Singaporean museum, or a giant metal elephant might not trigger feelings of serenity, they do link leisure activity with Buddhist material culture. Furthermore, they provide spaces for Buddhists and non-Buddhists to be distracted with Buddhist stuff without monastic, liturgical, or ritual requirements. They actually allow Buddhists to experience Buddhist things divorced from obligations, doctrines, and regulated dress and

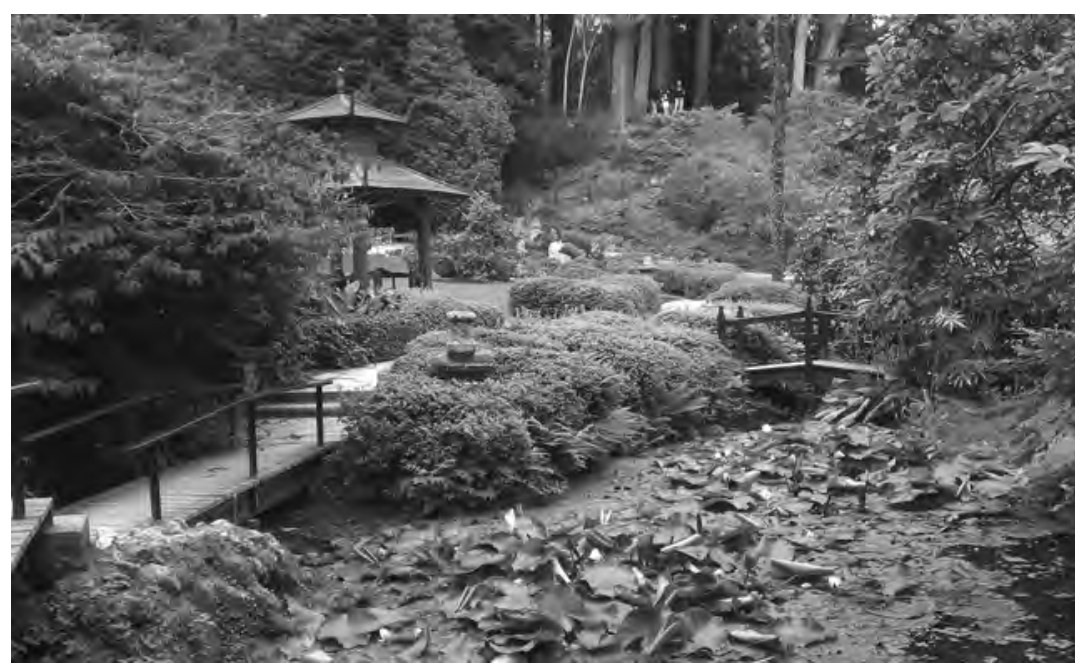

Asian Gardens at Powerscourt, Ireland. I thank the Fitzmaurice family (my cousins) for taking me to the gardens. 
body postures, the way that often happens in Western gardens, museums, and exotic curio shops. Buddhists often are tourists in their own and neighboring countries.

If any reader decides to take the research in this book further, I think the next logical step would be to compare some of the Buddhist leisure spaces in Asia to places like Powerscourt or the Huntington Gardens; or museums like Shi Fa Zhao's to the Buddhist collections at the Metropolitan Museum of Art or the Louvre. Comparing Buddhist misemono or collections of Buddhist objects across the globe would tell us much about the way people learn Buddhism outside of formal monastic education or within the ritual cycle of a Buddhist family.

\section{Comparative Gestures}

Although my research here has looked at specific places in Nepal, Singapore, and Thailand, as well as other examples from Vietnam, Japan, Hong Kong, China, India, Laos, and Louisiana, I do not necessarily see this as a comparative study. I am not comparing individual spaces site to site, but identifying trends and motivations across many sites divided into categories. Like many scholars, I am suspicious of large comparative projects. Buddhism, like Islam or Christianity, is such a large and diverse subject that comparative projects have the tendency, despite the efforts of their authors, to overgeneralize. Furthermore, scholars often play to their strengths. An expert on southeast Chinese ritual from the seventeenth to the eighteenth century might attempt to write a large comparative study on Buddhist ritual, but of course will favor southeast Chinese ritual evidence from that time period. A specialist in early Sri Lankan Buddhist texts has a tendency to view the rest of Buddhist studies from a premodern Pali textual perspective. I tend to view Buddhist studies through a Thai and textual perspective because of my language skills and training. Moreover, there is sometimes more use in comparing a Polish Catholic ritual from the fifteenth century with a Thai Buddhist ritual from the same time period than in comparing a Korean ritual and a Nepali ritual from the same time period. J ust because two or more places, rituals, concepts, or events happen to be Asian or Buddhist does not make them necessarily more naturally comparable. There is no "Asian essence" or "ideal Buddhism" that exists.

When I first started studying world religions I tended to favor comparing beliefs, doctrines, and concepts. As a student, I compared big things, like two religious traditions' views on soteriology and the afterlife, or two traditions' understanding of the nature of the human person and the existence of evil. I was fortunate enough early on to follow the good advice of J. Z. Smith and make not only a taxonomy of likes, but also of differences in these 
concepts. ${ }^{8}$ However, I have found that the possibility of comparison is limited in this approach. Polish (Roman) Catholic and Rinzai Zen Buddhist understandings of evil or faith are so vastly different that comparisons do not yield much and are rarely undertaken by serious scholars. Now though, I want to stay away from these big comparisons and instead compare the tangible architectural structures and the art and ritual material objects, as well as the practical and stated purposes of sites as expressed by the architects themselves. In this book I was particularly interested in the ways architects from one culture, say, Japan or Singapore, attempt to display or connect to another culture through their designs. This, I hope, was evident in the work of Kenzo Tange and Shi Fa Zhao especially. The way one artist, writer, or architect displays a foreign culture often tells you a lot more about her or his own views on art, religion, or design than it does about the culture they are trying to display. This is usually not seen in explicit attempts to justify their work, but in the series of choices they make.

To accomplish these comparisons, I have tended to focus on the material, visual, ritual, and practical categories of comparison versus the eschatological, soteriological, or philosophical. In this I was following the lead of my sources. I found that many of the architects were much less articulate about the "bigger" concepts and Buddhist philosophies that led them to design their sites the way they did than they were about the hundreds of practical choices they had to make about where to place a certain statue or how to construct a staircase or provide access from a particular parking lot or bus stop. Many of the Buddhist architects mentioned above were not necessarily much more knowledgeable or more extensively trained in Buddhist teachings, history, and art than was Ned McIlhenny. They were not productive scholars of Buddhist history, philosophy, art, or literature, and their sites are generally not sites of advanced Buddhist training.

This does not mean that comparing what some may consider the middling or superficial material of the sites is less telling than comparing seemingly profound religious concepts. Each of the architects had a vision for a particular way of teaching Buddhism that didn't involve rigorous training in art and textual history or critical intellectual methods. If the designers and most of the visitors seem unconcerned or inarticulate about these profound ideas, then perhaps it is important to pay attention to what they are concerned about and what they find entertaining, invigorating, inspiring, and educational.

I do not think large comparative projects need to be preempted by a series of authors' caveats and apologies about the impossibility of "summarizing" Buddhism, or come in the form of textbooks or loosely connected volumes of collected articles. Can we be comparative, rigorous, and detailed in one study? I tried here, by focusing on specific people, places, and events 
within a specific time period, and compared only these specific examples. I presented them in parallel, with tentative statements pointing toward the development of general principles. This type of parallel play hopefully allowed the reader to start seeing patterns emerge. My hope is that presenting the evidence in as much detail as a short essay allows helps readers see connections, pose questions, and generate their own general principles. In many ways, I am following the method of my sites, which all attempt to present Buddhism in general through a series of parallel examples taken from different schools, locations, and languages, all presented in one public place. By juxtaposing many different examples, we can suggest new comparative possibilities, as well as significant differences.

Therefore, the preceding chapters were a series of what I like to call "comparative gestures." Instead of dictating what should and should not be comparable, whether by ethnic, sectarian, linguistic, or historical designations, I present these sites and allow readers to make the comparisons themselves. I picked the examples, and so I am gesturing to comparative possibilities, but not stating what aspects of these sites are proper to compare. I hope that this will facilitate the rise of "semblances." As Ulrich Timme Kragh has noted, comparison in modern Western literary theory involves four components in language: "comparatum, comparandum, semblance, and comparative phrase."9 These correspond to terms used in Sanskrit literary theory (alaṃkāraśāstra), which was often used by Buddhist thinkers and writers: upamāna, upameya, sādhāraṇadharma, and upamāpratipādaka. For example, Kragh writes "in the comparison 'The water sparkled like diamonds,' the 'diamonds' are the comparatum (upamāna), i.e. the poetic image or object to which the water is compared. 'The water' is the comparandum (upameya), i.e. the subject of the comparison. 'Sparkled' is the semblance (sādhārañadharma), namely the common quality of the comparatum and the comparandum, whereby the comparison is enabled. 'Like' is the comparative phrase (upamāpratipādaka) that effects the comparison." ${ }^{\prime 10}$

The semblance is the "quintessence of any comparison" because it unites "the image with its subject."'11 Applying this way of thinking about the components of literary comparison to the much broader type of comparison between religious sites, I have found some semblances: not objects to compare, but ways of comparing-comparing verbs, not nouns. My hope is that the semblances that I have not thought with begin to sparkle in the readers' minds. That way we can start to productively think of ways of studying Buddhism across national, sectarian, and linguistic borders without reducing it to a series of vague overgeneralizations. This is what teachers often do. They present many different examples to students to generate discussion. My students have always led me to see new semblances. Discussion of the differences and similarities are often very engaging and productive, especially when I do 
not insert myself too much into their debates. I wanted to do the same with this book. I did not want to overreach and point out every possible way we can compare a museum in Singapore to a museum in Kyoto, for example. I think some comparative possibilities are obvious, others less so. I presented three general types of public and leisure Buddhist places in modern Asia. I assume semblances and distinctions arose on reading and seeing these examples alongside each other.

\section{So What Do We Make of All of This?}

While I want readers to delight in the examples and images I provided of Buddhist leisure sites throughout Asia and see their own semblances, I hope they will permit me to make some explicit comments about what we can learn from these monuments, parks, and museums when we put them side by side-give me the last word, so to speak. As noted in the introduction, these spectacular leisure sites are characterized by their public accessibility, their ecumenism, and the long and complicated processes involved in their construction. Their architects and ensembliers had to compromise and settle at a series of local optima along the way, and therefore, I could not simply present a series of biographies of visionary architects, but had to take a material culture approach that looked at the shared agency of creators, materials, laborers, licensing agencies, funders, critics, and visitors. This is a type of "art nexus" approach in the tradition of Gell. ${ }^{12}$ To show this nexus (between the material, artist, creation, and sociohistorical context or artistic lineage), I had to balance extreme empiricism and the detailed presentation of many different examples with attempts to identify structures and processes. I struggle with this, but certainly leaned to the empiricist side, and agree with the methods of J ohn Bowen and Roger Petersen. In referring to the struggle between empiricism and identifying patterns in comparative work, they write, "The world's complexity demands some respect even as we try to understand or isolate processes and mechanisms. . . . We believe that exemplifying is more effective than prescribing."13 While I avoided direct comparison, I allowed some overarching suggestions and processes and mechanisms to emerge.

These ecumenical leisure sites are linked in certain ways. First, they generally lack formal, formidable, ritual, ecclesiastical, or sectarian boundaries. They make themselves distinct and apart from other sites in particular ways. They might have opening and closing times, small entrance fees, and alarm systems, but they place virtually no restrictions on religious affiliation, gender, or ethnicity, and actively attempt to offer information in multiple languages. These are not sites for the ordained or for specific members.

Second, they make little sustained effort to be "authentic." Studies of Buddhist modernity have often emphasized an effort by many (especially 
nineteenth-century) monastic and royal reformers in Japan, Thailand, Sri Lanka, Cambodia, and other places to promote the study of "original" canonical texts and classical languages (Sanskrit and Pali) in order to return to a more authentic practice of Buddhism. The architects who designed these sites, however, often explicitly emphasize that authenticity is not their goal. These sites emphasize display, performance, and juxtaposition and anachronistic mixing (not systematic reconstruction) of various Buddhist cultures, teachings, languages, objects, and symbols. This is important, because it provides us with a completely different image of contemporary Buddhism that emphasizes innovation and ecumenism instead of purity and authenticity. I agree with scholars like Alicia Turner, Erik Braun, Craig Reynolds, Anne Hansen, and others who have pointed out the clear efforts of monastic and royal reformers over the past two hundred years to reform, renew, and return to a simpler, purer Buddhism (which never actually existed). However, the designers of these new Buddhist monuments, parks, and museums have, in large part, not participated in this drive to reform and return to a less-complicated past. ${ }^{14}$ Lay and monastic architects and visionaries like Kenzo Tange, Shi Fa Zhao, Braphai and Lek Wiriyaphan, Shin Takamatsu, Chan-soo Park, Bunleua Sulilat, Tadao Ando, Luang Pho Kasem Achansupho, Đinh Văn Vui, Aw Boon Haw, and Aw Boon Par, among many others combine(d) the past and the present (and in Lek's case, the future), the leisure and the ritual, the liturgical and the casual, the secular and the religions, often in haphazard ways. Their sites don't work to purify Buddhism, to simplify Buddhism, to demystify Buddhism, or to reform Buddhism, but to create a Buddhist ecumenism that they know never existed. Tange, for example, created not a central hall where a uniform Buddhist group could be formed, but instead a series of interconnected plots where the diversity of contemporary Buddhist practice could coexist, but not necessarily be required to mix. Shi Fa Zhao allows statues, texts, and paintings from many different Buddhist traditions to sit comfortably together. This makes these ecumenical sites unlike the ecumenical movements in the history of Christianity that attempted to reform, repair, and reunite many Christian sects that had, they believed, sadly grown apart. It is also strikingly different from larger Islamic and Hindu reform movements. These sites present different Buddhist traditions, images, and aesthetic expressions as united but not uniform, collected but not concise-a gathering, not a movement. This focus on ecumenism and leisure and not on conversion or overly didactic social commentary has also enabled these sites to remain largely free from government sanction, public ridicule, and sectarian conflict. This is where, I argue, Buddhist studies, and religious studies more broadly, can learn from these contemporary, often lay, Buddhist architects-this is ecumenism without an agenda. 
Third, these ecumenical leisure sites are, in a sense, "non-places."15 They actively resist attempts to label them. By eschewing the local and authentic in favor of the timeless, ecumenical, and universal, they become difficult to categorize. Like certain chain restaurants, shopping malls, and amusement parks, they sacrifice local flavor to universal appeal. However, to the disappointment of some of their creators, as we saw, the places that attract the largest crowds are usually the ones that appeal to local aesthetic, ritual, and linguistic expectations, as well as broad and diverse ecumenical arrangements. Indeed, the most successful sites combine some opportunity for visitors to perform rituals, offer gifts to images, and participate in liturgies (often through repetitive chanting) alongside visiting museums, riding amusement rides, listening to music, eating meals, and other leisure activities. These rituals often generate extra income for the leisure spaces even if that was not the intent of the design and displays. For most sites, however, profit is clearly not the motivation: many are not necessarily profitable, nor solely built to generate income, and oftentimes they lose money for their founders and managers. These fantastic projects, supported by many different hands, are designed to be spectacles. Many, but certainly not all, of these sites are outside the centers of cities or major capitals. Since transportation to them is not always convenient, their creators and managers need to create fantastic spectacles in order to make them worth the trouble to visit. They are not "on-the-way" places, but destinations in and of themselves. They make visual statements, for sure, even if they don't attempt to create single messages or provide coherent teachings.

Fourth, the builders of these sites did not seem concerned with promoting a particular type of Buddhism or a particular way of living religiously. But, besides the fact that most are male, are there clear patterns in the way they designed, proceeded, and promoted their respective creations? The short answer is no. Kenzo Tange, Braphai and Lek Wiriyaphan, and Shi Fa Zhao came from different cultural contexts, were trained by different teachers in different artistic and architectural mediums, and had widely different explicit motivations and explanations for their work. The three architects whose personal lives I attempted to explore in detail also had very different personalities and pasts. Kenzo Tange defined himself as flexible, innovative, and democratic, but he was actually quite rigid and careful in his work. Lek and Braphai defined themselves as almost messianic in their efforts to save Thai culture and history, but actually their work (and especially Lek's work after his wife passed away) speaks to more universal structures and truths, as they saw them. Shi Fa Zhao emphasizes ecumenicalism and openness, but his tightly controlled organization and aesthetic presentation reveals a strong focus, without his intention, on his particular way of being both Chinese and 
Buddhist. However, on a deeper level, they nearly all proudly promoted the idea that their art or architecture was independent of particular sectarian affiliation or adherence to specific Buddhist monastic rules or specific teachings.

Finally, this type of relative artistic freedom could have happened only during the last century (especially after the World War II and the colonial period in Asia). Many bureaucratic barriers (most of which were solved by money) were in place in Singapore, Nepal, Laos, and, to a lesser extent, in Thailand, Korea, and J apan. But since most of the funding for these creations came from private patrons, personal wealth, or collected donations, local monastic sects, ministries of religion and culture, and governments had little control and made minimal effort to stop or strictly regulate these sites. The increased ease of communication and travel, the rise of international corporations and entities like the United Nations, and the ability to advertise on the Internet and "crowd source" for funding have allowed these sites to appeal to a wider audience. Now, even if a person can't travel easily to Singapore or Japan, they can view photographs of these sites online and even make donations. While people outside local areas might still have financial and other barriers restricting them from physically visiting these sites, they can virtually visit them and chat about them on blogs, Facebook, Flickr, and the like. This allows artists and architects to appeal directly to those beyond their borders and lessens the ability of local governments and religious organizations to place restrictions on them. Although creative artists and architects certainly are not products of "modernity," using modern technology to reproduce and disseminate photographs, pamphlets, and web pages to reach wider audiences quickly has provided new types of lay and ordained audiences for these creations. Certain architects and artists described in this book have certainly gained more recognition outside their own cultures than within them.

These advances also inhibit scholars, and you might detect a slight lamentation in my writing, because our job - to engage in noncomparative research in modern Buddhist studies - is getting harder and harder. Very few, if any, individual Buddhists in Asia could be described anymore as being influenced only by local understandings and expressions of their religion. Whereas in the pre-television and pre-Internet age, a Buddhist would certainly "know" they were part of some vague translocal Buddhism, but would practice in highly local ways, now most Buddhists "see" other Buddhist ways of expression through television, the Internet, art exhibitions, coffee-table books, or these new types of Buddhist leisure and public spaces. They still might "do" Buddhist things locally, such as ordinations, funerals, healing rituals, and the like, but they see others' Buddhist things not necessarily as part of a ritual occasion, but as objects for aesthetic, experiential, and educational appreciation. In a similar way, studying individuals like Kenzo Tange cannot be done 
in the framework of studying a J apanese architect. He and most others I discuss in this book, because of the freedom of travel and the ease of communication, have studied, traveled, worked, and developed colleagues far outside their hometowns or countries. Indeed, as we saw, Tange could be called a French architect more than a J apanese one. Shi Fa Zhao was not even ordained in Singapore, and Lek Wiriyaphan spoke Chinese as easily as Thai. None of them are especially representative of a particular Thai, Chinese, J apanese, or other way of being Buddhist. Their ethnic traits and religious affiliations have little determining effect on the way they decided to express themselves artistically and religiously.

Case in point, at the end of my first trip to Sendai, Japan, to see the giant Sendai Daikannon mentioned in the introduction, I went with a distant cousin (through marriage), who lives in Japan, to the Yokohama Museum of Art. I had a few hours before my flight to Bangkok and thought I would see one of Kenzo Tange's buildings before I left. My cousin kindly drove me. The museum is a study in flow and light and was well worth the side trip. However, I actually became inspired to write this book (which was originally conceived as an article about Kenzo Tange and Japanese Buddhist misemono specifically) when I saw the exhibition of the prints of Kiyoshi Hasegawa (1891-1980) in the space Tange designed. Hasegawa was a French-trained artist from Yokohama who largely worked outside Japan and designed French book jacket covers and painted or drew French landscapes. None of his work incorporated J apanese, Asian, or Buddhist techniques, scenes, or subjects. The museum was displaying his work because it is part of their mandate to promote the work of artists from Yokohama. However, Hasegawa's birthplace seemed to have little to do with his art.

In the second-to-last room of the exhibit, I saw one dry point sketch by Hasegawa that made me reassess the way I thought about writing about Tange and modern Buddhist architects and artists. The sketch is called Niwa, or "Garden" and was done in France in $1943 .{ }^{16}$ It is a strikingly peaceful sketch, and it is hard to believe that it was executed in the middle of Nazi-occupied France. In an overgrown and lush garden scene, hidden among the plants and trees on a small pedestal, is a single stone buddha's head. The head, disconnected from both its body and its country and sitting on a Greek pedestal, made me wonder to what extent we can even label a person like Hasegawa, who was born Buddhist and J apanese, as a "Buddhist" or "J apanese” artist. Can Lek and Braphai Wiriyaphan's creations be called representative of Thai Buddhism? Is Shi Fa Zhao a Chinese Buddhist? It is difficult to say, after more than half my life studying in or learning from Asia, whether I am an American researcher, an Irish-American father and husband, a scholar of Southeast Asian Buddhist studies, or a Catholic with a half-J ewish wife who teaches Buddhism at a "Quaker" school. Just as temples, museums, parks, and 


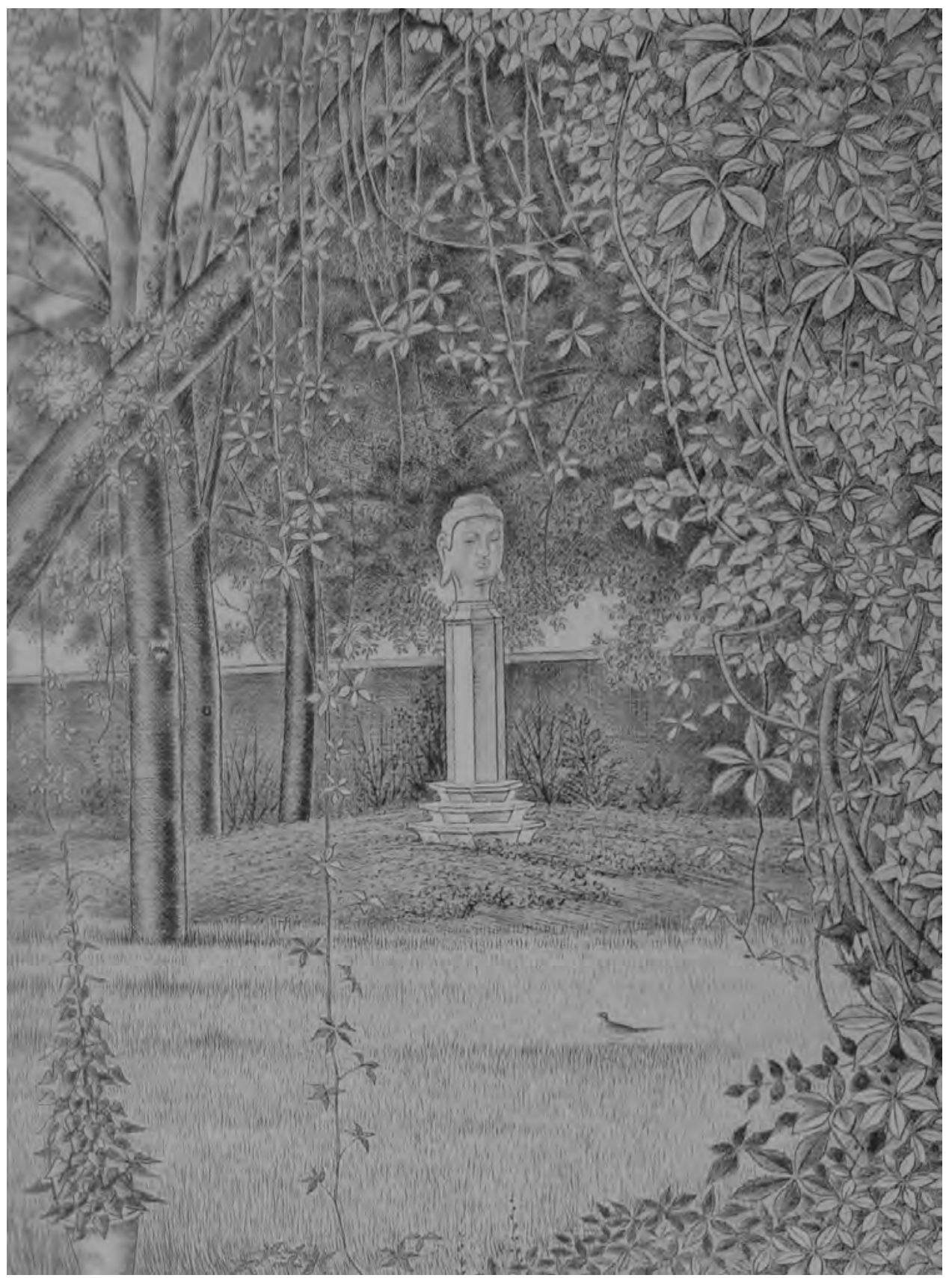

Niwa by Kiyoshi Hasegawa, from the Yokohama Museum of Art, designed by Kenzo Tange 
schools change over time and are occupied by hundreds of thousands of different people over time, the people that occupy, study, or build them change as well. These in-between people and in-between places make comparison more complicated but, I believe, more illuminating. Because, frankly, many of us are slightly more complex than the traits that define us, and many of us often feel like Hasegawa's buddha-disembodied heads in overgrown foreign gardens. 



\section{Notes}

\section{INTRODUCTION}

1 These three scholars were very generous with their time on my visit to Sendai.

2 I thank Michael Feener for accompanying me to this site and others in the Kobe/ Osaka/Awaji region. His navigational and language skills, as well as his sense of humor, made the trip very enjoyable indeed.

3 There is a very new giant standing Buddha image at Wat Thipsukhanaram in Kanchanaburi Province (Thailand) that is 114 feet tall. I thank Chris Baker for kindly sending me a beautiful book describing in great detail its history, design, material, and the like. It was funded by no less than 48 different corporate sponsors. See Khanakammakan fai bhrachasamphan lae phoipae khrong kan jat sang phra phutthamettabhrachathaitrailokanatha khanthanratha-anuson nai phra baromrachinubhatham, Phra phutthamettabhrachathaitrailokanatha phutthamettabhrachathaitrailokanatha khanthanratha-anuson (Bangkok: Amarin Printing and Publishing, 2558 [2015].

4 For example, Klemens Karlsson shows that locals in Chiang Tung (Kengtung) in the Shan region of Burma have largely avoided visiting the huge Khemarattha Standing Buddha built in 1995 because it was not made according to local tradition, it is not in a monastery like most Shan Buddha images, and it is associated with the Burmese central government- sponsored nationalism versus Shan aspirations for independence. See his "Material Religion and Ethnic Identity: Buddhist Visual Culture and the Burmanization of the Eastern Shan State," in The Spirit of Things: Materiality and Religious Diversity in Southeast Asia, ed. Julius Bautista (Ithaca, NY: Cornell Southeast Asia Program Publications, 2012), 61- 78, esp. 69- 73.

5 I use Michel de Certeau's distinction between space (the various human actions and physical properties that characterize the experience of a physical place) and place (physical location). Space is the "intersections of mobile elements" and is changed by these elements over time. "Space occurs as the effect produced by the operations that orient it, situate it, temporalize it, and make it function in a polyvalent unity of conflictual programs or contractual proximities" (117). See his The Practice of Everyday Life, trans. Steven Rendall (Berkeley: University of California Press, 1984).

6 There is even a thirty-foot-tall Buddha image at a Sri Lankan Buddhist monastery near Princeton, New J ersey.

7 The official (yet not completely successful) abolishing of the danka seido (system) or the jidan seido, which connected each J apanese family to a particular Buddhist temple, together with Buddhist priests being able to marry, have secular careers, and raise families in Japan in the Meiji period contributed to this. These changes have been extensively researched. See particularly George Tanabe 
and Ian Reader, Practically Religious: Worldly Benefits and the Common Religion of Japan (Honolulu: University of Hawai'i Press, 1998); Richard J affe, Neither Monk Nor Layman: Clerical Marriage in Modern Japanese Buddhism (Princeton, NJ : Princeton University Press, 2002); and Mark Rowe's Bonds of the Dead: Temples, Burial, and the Transformation of Contemporary J apanese Buddhism (Chicago: University of Chicago Press, 2011), among others.

8 See Patricia Graham's description in her wonderful groundbreaking survey of contemporary Buddhist art in J apan, Faith and Power in J apanese Buddhist Art, 1600-2005 (Honolulu: University of Hawai'i Press, 2007), 228- 235.

9 In the Western academy, the history of the term "spectacle" in the social science has been linked to the intellectuals of the 1960s Situationalist International, and Guy Debord in particular, as well as Marxist critiques of commodities. Debord argued that in modern capitalist societies commodities are valued not for their actual use-function, but for their social value. Modern capitalism, the rise of the advertising industry, and the push to create new markets has transformed the markers of a "good life," the critique goes, from "being" into "having." Accumulation of commodities came to be seen, over the twentieth century, as an end it itself. Debord's The Society of the Spectacle was a groundbreaking study that harshly derided the superficiality of spectacle, and turned out to be a very accurate predictor of the power of celebrity culture and international corporate power (1971). I am not, however, referring to Debord's notion of spectacle, but rather to the J apanese notion of misemono. Misemono is spectacle as purposeless delight.

10 Not to be outdone, a group of engineers and artists has recently, in Nantes, northwest France, created Les Machines de L'ile, a large shipyard made into an area with huge mechanical animals including flying herons, a giant metal elephant, and a carousel revolving with deep-sea creatures. The collective creators of the site are called "La Machine," a street theater company "famous for such creations as the 15-meter spider that crawled through Liverpool, in Britain, as part of the city's Capital of Culture celebrations in 2008." http://edition.cnn.com /2013/05/16/travel/machine-theme-park-france/index.html?hpt=hp_c3.

11 See especially David Leheny, The Rules of Play (Ithaca, NY: Cornell University Press, 2003).

12 Ibid., 231.

13 This has been a larger problem in the "affective turn" in philosophy, intellectual history, and cultural studies. How do scholars limit the fields of their study in visual culture? Are the traditional distinctions between high art and low art, monumental architecture and vernacular architecture, and the like useful anymore? Martin J ay discusses this issue at the heart of visual studies in "That Visual Turn," J ournal of Visual Culture 1, no. 1(2002): 87- 92, esp. 88. See also Patricia Ticineto Clough's introduction to the volume she edited with J ean Halley, The Affective Turn: Theorizing the Social (Durham, NC: Duke University Press, 2007).

14 See Michele Renee Salzman, On Roman Time: The Codex Calendar of 354 and the Rhythms of Urban Life in Late Antiquity (Berkeley: University of California Press, 1990); and Victor Turner, Dramas, Fields, Metaphors (Ithaca, NY: Cornell University Press, 1974).

15 It was originally published in 1962. I'm using the 1991 printing of Jürgen Habermas, The Structural Transformation of the Public Sphere (Cambridge, MA: MIT Press, 1991 [1962]). Seealso Daniel Brouwer and Robert Asen, eds., Public Modalities: Rhetoric, Culture, Media, and the Shape of Public Life (Tuscaloosa: University of Alabama Press, 2010); Nancy Fraser, "Politics, Culture, and the Public Sphere: Toward a Postmodern Conception," in Social Postmodernism, ed. Linda Nicholson and Steven Seidman (Cambridge: Cambridge University Press, 1995), 
287- 314; Mustafa Emirbayer and Mimi Sheller, "Publics in History," Theory and Society 27, no. 6 (1998): 727- 779; Nick Crossley and J ohn Michael Roberts, eds., After Habermas: New Perspectives on the Public Sphere (Oxford: Blackwell, 2004): Ken Hirschkop's contribution there, “J ustice and Drama: On Bakhtin as a Complement to Habermas" (49-66), was particularly useful for my purposes.

16 Crossley and Roberts, "Introduction," in After Habermas, 19.

17 I provide a long list of the most important sources in the field in my Lovelorn Ghost and the Magical Monk (New York: Columbia University Press, 2011), 257n9. The most recent collection on the subject in a Western language is Ian Harris's (ed.) collection of essays, Buddhism, Power, and Political Order (London: Routledge, 2007). An astute criticism of my tendency to undervalue the importance of politics in everyday Thai Buddhism is found in Erik Davis's review in the J ournal of Asian Studies 71, no. 2 (2012): 585- 588.

18 See particularly Lawrence Chua's Building Siam: Leisure, Race, and Nationalism in Modern Thai Architecture, 1910- 1973 (PhD diss., Cornell University, 2012); Philip J ablon's work on the history of Thai cinemas can be seen at http://www .seatheater.blogspot.com/; Fumihiko Maki, Alexandra Munroe, and Arata Isozaki, New Public Architecture (Ann Arbor: University of Michigan Press, 1985). More general works include Philip J odidio's Public Architecture Now! (New York: Taschen, 2010); Aurora Fernández Per and Javier Arpa, The Public Chance: New Urban Landscapes (Madrid: a+t architecture publishers (2008); Simon Henley, The Architecture of Parking (London: Thames and Hudson, 2009). Recently (2013), two innovative studies in the development of public spaces, particularly zoos and historical buildings, in Japan have been published by the University of California Press: Ian Miller, The Nature of the Beasts: Empire and Exhibition at the Tokyo Imperial Zoo (Foreword by Harriet Ritvo), and J ordan Sand, Tokyo Vernacular: Common Spaces, Local Histories, Found Objects.

19 There have been many studies of the former including Rory Mackenzie, New Buddhist Movements in Thailand: Towards an Understanding of Wat Phra Dhammākaya and Santi Asoke (London: Routledge, 2007), and Catherine Newell, Monks, Meditation and Missing Links: Continuity, 'Orthodoxy' and the Vijjā Dhammakāya in Thai Buddhism (PhD diss., School of Oriental and African Studies, 2008). The monasteries' websites are http://www.dhammakaya .net/ and http:// www.dharmadrum.org/, respectively.

20 In December 2013, Nicolas Sihle (a scholar of Tibetan Buddhism at the Centre National de la Recherche Scientifique) and I visited the "L'esplanade des religions" in Bussy Saint-Georges, France. On one street is a series of newly constructed religious centers: a mosque, a Lao Buddhist temple, a Fo Guang Shan Taiwanese Buddhist temple, and future plots for a J ewish synagogue and Christian church. There we met a middle-aged Chinese woman who promotes Tibetan practices in a suburb of Paris and a Lao refugee who spends his days arguing in French with local plumbers and carpenters to finish a temple that will be led by a Thai-born monk living in Marseilles.

21 Michael Warner, Publics and Counterpublics (NewYork: Zone Books, 2002), 66. See also Charles Hirschkind, The Ethical Soundscape: Cassette Sermons and Islamic Counterpublics (New York: Columbia University Press, 2009), and Thomas Csordas, ed., Transnational Transcendence: Essays on Religion and Globalization (Berkeley: University of California Press, 2009).

22 Warner, Publics, 68.

23 For a discussion on the study of episodic social meetings and unexpected coherences, see Michel Maffesoli, “Post-Modern Sociality,” Telos 85 (1990): 89- 92; and Chris Rojek, Decentering Leisure (London: Sage, 1995), 151- 153. 
24 Warner, Publics, 69.

25 Exceptions include the recent work of Jamie Hubbard, a project called The Yamaguchi Story: Buddhism and the Family in Contemporary Japan (BBC/ Education Communication International, 2009 [1988]). Vanessa Sasson has edited a volume, Little Buddhas: Children and Childhoods in Buddhist Texts and Traditions (New York: Oxford University Press, 2012). Ingrid J ordt's work, Burma's Mass Lay Meditation Movement: Buddhism and the Cultural Construction of Power (Athens: Ohio University Press, 2007), is a good example of a number of recent works on lay Buddhist political movements. See also Sarah Pike's "Why Prince Charles Instead of 'Princess Mononoke'? The Absence of Children and Popular Culture in "The Encyclopedia of Religion and Nature,'” J ournal of the American Academy of Religion 77, no. 1 (2009): 66- 72. She looks at the popularity of Princess Mononoke and the Spirited Away films by Hiyao Miyazaki. For example, whereas US children in the 1950s and 1960s often were presented with a picture of J apanese Buddhism as austere and aesthetically clean and plain, American children today are learning about Buddhism through the Miyazaki films, comic books (manga) and anime, and the eight-volume life of the Buddha comic book by Osamu Tezuka.

26 See, among many others, the classic by Thorstein Veblen, The Theory of the Leisure Class (New York: Modern Library, 2001 [1899]); and, more recently, see Chris Rojek, Ways of Escape (Boston: Rowman and Littlefield, 1993), and his Leisure and Culture (London: Macmillan Press, 2000); Roger Mannell and Douglas Kleiber, A Social Psychology of Leisure (State College, PA: Venture, 1997); Heather Mair, Susan Arai, and Donald Reid, eds., Decentering Work (Calgary: University of Calgary Press, 2010); Karl Spracklen, Constructing Leisure (New York: Palgrave, 2011), and his The Meaning and Purpose of Leisure (New York: Palgrave, 2009); Tom Winnifrith and Cyril Barrett, The Philosophy of Leisure (New York: St. Martin's Press, 1989); Chris Rojek, Susan Shaw, and Anthony Veal, eds., A Handbook of Leisure Studies (New York: Palgrave, 2006).

27 J ohan Huizinga, Homo Ludens: A Study of the Play-Element in Culture(Boston: Beacon Press, 1955). See a good introduction to Huizinga's work in Thomas Henricks, Play Reconsidered (Urbana: University of Illinois Press, 2006), chapter 1.

28 Susan Schearer, ed. and trans., Petrarch: On Religious Leisure (New York: Italica Press, 2002).

29 Mikhail Bakhtin, Rabelais and His World (Cambridge, MA: MIT Press, 1968); Rojek, Decentering Leisure, 85- 87; a good comparison with the work of Victor Turner is found in Rojek, Leisure and Culture, 148-150. For Turner, see his Image and Pilgrimage in Christian Culture: Anthropological Perspectives (New York: Columbia University Press, 1978), and Process, Performance, and Pilgrimage: A Study in Comparative Symbology (New Delhi: Concept, 1979).

30 Lauren Rabinovitz, Electric Dreamland: Amusement Parks, Movies, and American Modernity (New York: Columbia University Press, 2012), 2. This is, of course, similar to the argument Ray Oldenburg makes about spaces like barbershops and bars - they are "third spaces," being neither work nor home. Oldenburg did not see religious places as "leisure" spaces, or "hangouts," as he calls them. However, many of the Buddhist leisure places I discuss in this book could easily fit his definition of "third places." See his The Great Good Place: Cafes, Coffee Shops, Community Centers, Beauty Parlors, General Stores, Bars, Hangouts, and How They Get You Through the Day (New York: Paragon House, 1989).

31 Rabinovitz, Electric, 6; and Miriam Hansen, Babel and Babylon: Spectatorship in American Silent Film (Cambridge, MA: Harvard University Press, 1991), 90- 118.

32 See entries for ecumenism and ecumenical in the Oxford English Dictionary.

33 Gregory Levine, Daitokuji: The Visual Cultures of a Zen Monastery (Seattle: University of Washington Press, 2005). 
34 Witold Rybczyński notes that the notion of the ensemblier as separate from the architect began to emerge at the Exposition Internationale des Arts Décoratifs et Industriels Modernes in Paris in 1925. I thank him for his advice (pers. comm., fall 2012). See also his Home: A Short History of an Idea (New York: Penguin, 1986), 180.

35 Daniel Miller, "Introduction," in Materiality, ed. Daniel Miller (Durham, NC: Duke University Press, 2005). For a powerful mix of autobiography and anthropological study on the capacity to affect and be affected by ordinary objects, see Kathleen Stewart's Ordinary Affect (Durham, NC: Duke University Press, 2007). Farshid Moussavi's recent work at the 2013 Venice Architecture Biennale takes a creative approach to "Architecture and Affects." See http:// www.nytimes.com /2012/12/03/arts/design/defining-the-emotional-cause-of-affect.html? r=1\&.

36 Michael Taussig, "Tactility and Distraction," Cultural Anthropology $\overline{6}$, no. 2 (1991): 147- 153.

37 Ibid., 149. This entire essay is a reflection and response to Walter Benjamin's oftcited 1935 essay "The Work of Art in the Age of Mechanical Reproduction." This essay has appeared in numerous translations and publications. I used the edition in Hannah Arendt, ed., Walter Benjamin: Illuminations (London: Fontana, 1968), 217- 252.

38 E. H. Gombrich, "A Note Further to the Drawing of Bicycles," Perception 28 (1999): 801.

39 J onathan Hay, Sensuous Surfaces: The Decorative Object in Early Modern China (Honolulu: University of Hawai'i Press, 2010), 8, 96.

40 Gregory Seigworth and Melissa Gregg, "An Inventory of Shimmers," in The Affect Theory Reader, ed. Gregory Seigworth and Melissa Gregg, 1- 28 (Durham, NC: Duke University Press, 2010).

41 Hay, Sensuous Surfaces, 81.

42 Eve Kosofsky Sedgwick's Touching Feeling: Affect, Pedagogy, and Performativity (Durham, NC: Duke University Press, 2003), 21.

43 J ohn Miller and Scott Page, Complex Adaptive Systems (Princeton, NJ: Princeton University Press, 2007), 79. See also S. L. Brown and K. M. Eisenhardt, "The Art of Continuous Change: Linking Complexity Theory and Time-Paced Evolution in Relentlessly Shifting Organizations," Administrative Science Quarterly 42 (1997): 1- 34.

44 Miller and Page, Complex, 9.

45 Ibid., 81.

46 Ibid., 82.

47 I had the opportunity to visit a "meditation space" Ando designed at the UNESCO headquarters in Paris in December 2013. I asked one of the employees if it was often used for silent reflection or meditation and she said, "Well, it seems to be more used as a place for employees to take cigarette breaks." I guess this could be a form of meditation?

48 I should note here that nearly every one of these places also has a presence on the World Wide Web. I do not have space to discuss this aspect of their publicness extensively, but this factor should be further examined in the future. While I will mention the Internet/ web presence of many of these sites, I will not address this as a separate category or public space. This is being studied by numerous scholars, and Daniel Veidlinger, in particular, has been conducting promising research of Buddhist websites.

49 Italo Calvino, If on a Winter's Night a Traveler, trans. William Weaver (New York: Alfred Knopf, 1993 [1979]).

50 Jogyō is mentioned in the fifteenth, twenty-first, and twenty-second chapters of the Lotus Sutra, and his images are found at many Nichiren monasteries. Patricia Graham notes that these statues were actually carved by artists specializing 
in secular sculpture and not by traditional Buddhist artists. See her Faith and Power, 242-244. She also notes that the monastery is accessible only by cable car. However, there is a road up to the monastery and I drove there directly from Osaka.

51 I thank Elizabeth R. Kenney for discussing these temples with me and for all of her advice in Kyoto in 2011.

\section{CHAPTER ONE: MONUMENTS AND METABOLISM}

1 Đinh Bộ Lĩnh was given the name Đại Thắng Minh Hoàng Đế. I thank Amy Le for translating this history for me.

2 I want to thank Hanh Ly Nguyen, Van Chat Nguyen, Bang Anh Tuan, Dang Thi Cam Tu, David Biggs, and Edward Miller for their assistance in Vietnam.

3 The introduction to this particular book (locally published at the Huyền Không Huế Temple in 2013) was compiled by Thích Siêu Minh and contains instructions on how to perform Theravada rituals, an explanation of the chanting of the triple gem (Buddha, Dhamma, Sangha), and a statement claiming that these are the oldest liturgical chants in the history of Buddhism. Thích Pháp Trí did the translation based on Thích Hộ Tông and Thích Minh Châu's original work. Thích Viên Minh of the Huyền Không Huế Temple published the guide of chants, which they call dhāraṇi (using the Sanskrit name of protective chants in the Vajrayana and Mahayana traditions instead of paritta). The rise of the study of Theravada Buddhism in Vietnam is beyond the scope of this book. However, Edward Miller and I are undertaking a study of it and of the origins of the Pali library at the Xá Lợi Temple in Saigon and the large number of Thai Buddha images appearing at Vietnamese temples. While there are not many Theravada temples outside the Cambodian border region of South Vietnam, there is a longterm Theravada temple launched by Sri Lankan monks in Hue today.

4 Thích Nhật Từ, ed., Tủ Sách Đạo Phật Ngày Nay (The Buddhist Bookshelf Today, or simply Buddhism Today) (Ho Chi Minh City: Nhà Xuất Bản Tôn Giáo, 2011). This book is part of a series by Thích Nhật Từ, which includes over one hundred works on Vietnamese Buddhism doctrine and guides to Vietnamese ceremonial chanting. He also produces CDs and VCDs of Vietnamese Buddhist music and traditional Vietnamese folk songs.

5 I sincerely thank Amy Le for translating this profile for me and for her help in making sense of several liturgical books from the park. See Lưu Vinh and Huyền Chi, "Kinh Doanh-Nước Mắt-Nụ Cười" (Business-Tears-Laughter), in Saigon’s Kinh Doanh \& Pháp Luật (Business \& Law Newspaper), J anuary 2, 2013.

6 More information can be found by writing to Suối Tiên Incorporated (Suối Tiên Cultural Tourism Company), 149 Nguyễn Duy Dương, Phường 3, Quận 10. TP. HCM.

7 Amy Le translated this passage.

8 There is now another amusement park near Suối Tiên called Dam Sen Water Park. It has larger pools and longer slides, but less particularly Buddhist and Vietnamese historical themed statues, displays, and rides. For an interesting American Christian comparable example, see the Creation Museum in Petersburg, Kentucky. The museum-founded by the Christian evangelical group Answers in Genesis, led by Ken Ham, which promotes what they see as a Biblical explanation for existence and wants to provide an alternative to Darwin's theory of evolution-has Biblical displays, films, games, and rides, and even zip lines. It is a highly politicized site. See http://creationmuseum.org/. See also a critical assessment of the park and its finances by MarkJ oseph Stern, at http:// www.slate.com/articles/health and science/science/2013/11/ark encounter _finances_obamacare_sank_ken_ham_s_creationist_theme_park.htm. See 
also the sprawling Tierra Santa Christian Theme Park in Buenos Aires, Argentina. It has life-size dioramas detailing Biblical stories such as the Last Supper, the Crucifixion, and the like. http://www.atlasobscura.com/places/ tierra-santa.

9 http:// www.pritzkerprize.com/1987/essay.

10 http://www.japanfocus.org/-J onathan-Glancey/ 1828.

11 http://architect.architecture.sk/ kenzo-tange-architect/ kenzo-tange-architect .php.

12 Augusto F. Villalon, "Walking toward Buddhist Stillness," Philippine Daily Inquirer, April 30, 2012, http:// lifestyle.inquirer.net/45723/ walking-toward -buddhist-stillness.

13 Many Internet sources and a few published sources in English state that Tange was actually born in Imabari (Ehime Prefecture). However, his own autobiography in J apanese states that he was born in Osaka and moved to Imabari. Much of his youth before middle school (back in Ehime Prefecture) was spent in Shanghai, where he attended a J apanese school. See Kenzo Tange, Ippon no enpitsu kara (Tokyo: nihon tosho centa, 1997), 12-19, 233- 234.

14 Le Corbusier did not win the design contest sponsored by the Kremlin in 1931; Boris Iofan's more bombastic and neoclassical tower won. Construction started on the foundation of a former cathedral, but steel was needed after the German invasion and the superstructure was taken down and used to build bridges and other structures important for the war effort. See Sona Stephan Hoisington, "Ever Higher: The Evolution of the Project for the Palace of Soviets," Slavic Review 62, no. 1 (2003): 41- 68. See also Frederick Starr, "Le Corbusier and the USSR," Cahiers du Monde russe et soviétique 21, no. 2 (1980): 209- 221.

15 Le Corbusier, Vers unearchitecture (Paris: Editions Flammarion, 2008 [1923]). There is a new English translation by J ohn Goodman, Towards an Architecture (Los Angeles: Getty Research Institute, 2007).

16 For a good history of Conder and other Western architects and artists like Ernest Fenollosa, and their work with J apanese artists and architects like Kuki Ryūchi, Okakura Kakuzō, and Katayama Tōkuma, as well as the early development of the study of modern architecture in J apan (especially Kyoto and Tokyo), see Alice Tseng's The Imperial Museums of Meiji Japan (Seattle: University of Washington Press, 2008). She also provides details about the founding of the Imperial University's Department of Engineering. She shows that it was often Westerners that promoted traditional J apanese architecture while their J apanese colleagues wanted to be creative and work in new designs.

17 David Stewart, The Making of a Modern Japanese Architecture (Tokyo: Kodansha International, 1987), 170.

18 Raymond was interviewed by Tange on a radio program in April 1960. There they voiced their opposing views, and Raymond accused Tange and other young J apanese architects of abandoning the "immortal principles" of "true J apanese tradition." See Stewart, The Making, 168n3.

19 Ken Tadashi Oshima, International Architecture in Interwar Japan: Constructing Kokusai Kenchiku (Seattle: University of Washington Press, 2009), 85, 177, 190, and 277n10.

20 Ibid., 85, 99. Makita's Double-Bell House was so named because it stood in the Bunkyō ward of Tokyo, where both Catholic and Buddhist bells can be heard. For more information on this new class of J apanese international scholars and artists, see also Michael Wachutka, Kokugaku in Meiji-Period Japan: The Modern Transformation of "National Learning" and the Formation of Scholarly Societies (Leiden: Global Oriental, 2012).

21 Quoted in “Architect Who Modernized J apan Dies at 91," Reuters 2005.0322.

22 http://architect.architecture.sk/ kenzo-tange-architect/ kenzo-tange-architect .php. 
23 See this temple building in Patricia Graham's Faith and Power in Japanese Buddhist Art: 1600-2005 (Honolulu: University of Hawai'i Press, 2007), 236.

24 I thank Kenzo Tange's daughter-in-law, Denise Tange, of Tange Associates in Tokyo, and his son, Paul Noritaka Tange, for their help. The former kindly sent me many documents and answered many of my questions. She also sent me a section of Terunobu Fujimori's description of the Bangkok-J apanese Cultural Center (in J apanese) along with the reproductions of Kenzo Tange's original blueprints for the design. I thank Masami Tahara for helping me translate one particularly troublesome section.

25 Many of Gropius's ideas came from the Dutch De Stijl movement, which emphasized primary colors and geometric design. This is barely mentioned in Tange's writings and seems to have had little impact on his work. For more information of Gropius's workflow methods, see his The New Architecture and the Bauhaus, trans. P. Morton Shand (Cambridge, MA: MIT Press, 1965); and Sigfried Giedion's Walter Gropius: Work and Teamwork (New York: Reinhold, 1954). Early on in his career he developed the "socialist" idea of the Arbeitstrat für Kunst, which was a method of having studios that invited painters, architects, sculptors, and writers to work together on ideas for buildings. This evolved into a broader notion of baubrüderschaften, or building brotherhoods. See Wolfgang Pehnt, "Gropius the Romantic," Art Bulletin 53, no. 3 (1971): 379- 392, esp. 379- 380. Pehnt also notes that Gropius, who is most often associated with the Bauhaus, actually had many different phases of his career. Early on he was quite the romantic, who did not eschew all ornament or sentimentality and celebrated art for art's sake and did not believe that all buildings were designed to be practical. Later in his life he returned to this romantic attitude, especially in writing about his short trip to J apan. Gropius wrote rather romantically aboutJ apanese architecture in "Architecture in Japan," Perspecta 3 (1955): 8- 21.

26 For an expanded study of Le Corbusier's experience with J apanese architecture, see William Curtis, Le Corbusier et le Japon (Paris: Picard, 2007), which is based on a colloquium in Tokyo in 1997 on this subject.

27 Nnamdi Elleh, Abuja: The Single Most Ambitious Urban Design Project of the 20th Century, vol. 5, Architektur der Welt (Weimar: VDG, Verlag und Datenbank für Geisteswissenschaften, 2001).

28 Kenzo Tange and Udo Kultermann, Kenzo Tange: Architecktur und Städtebau 1946- 1969 (Zürich: Verlag für Architektur/Artemis, 1970), 240- 241.

29 Stewart, The Making, 170.

30 Tange, Ippon no enpitsu kara.

31 Vinayak Bharne, "Manifesting Democracy: Public Space and the Search for Identity in Post-War Japan," J ournal of Architectural Education 63, no. 2 (2010): 38- 50, esp. 40- 41.

32 There could be one tangential influence of "Oriental" architecture on Tange's work. Zeynep Çelik argues that many of Le Corbusier's ideas for urban planning actually came from Islamic architecture, especially after Le Corbusier's visits to Morocco, Algeria, Turkey, and Tunisia. His references to Islamic architecture appear in his work as early as 1915 and can be seen most distinctly in his urban plan for Algiers. Indeed, Le Corbusier was delighted by the way courtyards and quiet family spaces were hidden from view of the main streets in Algiers. He saw these tranquil spaces on family courtyards where the "street [was] abolished" (64) as reflecting the fact that, in his eyes, "Asia [was] forever religious" (63). Therefore, perhaps one of Tange's inspirations for designing the monastic zones and meditative spaces of Lumbini off of the main thoroughfare was inspired not by Buddhism, but by North African Islamic architecture. See Zeynep Çelik, "Le Corbusier, Orientalism, Colonialism," Assemblage 17 (1992): 58- 77. 
34 Tange also designed the master plan for the Sacred Heart Catholic University in Taipei, Taiwan, and the Sacred Heart of J esus International School in Tokyo. Both included chapels. See H. R. von der Mühl and Udo Kultermann, Kenzo Tange (Munich: Verlag für Architektur, 1978), 32- 33.

35 Ibid., 244.

36 Kenzo Tange and Noboru Kawazoe, Ise: Prototype of J apanese Architecture (Cambridge, MA: MIT Press, 1965). Tange produced an English version of this original study in J apanese on the encouragement of J ohn Burchard at MIT.

37 Kenzo Tange, Katsura: Tradition and Creation in J apanese Architecture (New Haven, CT: Yale University Press, 1972), forward.

38 Ibid., 28.

39 Ibid., 36.

40 Gropius, "Architecture in Japan," 15, 18- 19.

41 Stewart, The Making, 205.

42 Gropius, "Architecture in Japan," 80.

43 Stewart, The Making, 205- 206.

44 I was fortunate to find two of Tange's original letters to Mumford in the University of Pennsylvania's Rare Book and Manuscript Collection, dated J une 18, 1961, and July 5, 1967 (part of the larger collection of Lewis Mumford Papers 19051987). Both letters thank Mumford for sending his books The City in History and the Myth of the Machine (both classics in the field of urban studies). Mumford had sent these to Tange immediately after their respective first printings. Tange thanks Mumford for work on the philosophy of cities and states that he is using those books in teaching his own students.

45 http://www.pritzkerprize.com/1987/ bio.

46 Dozens of descriptions and photographs of the master plan are available online. Reliable and relatively up-to-date ones are found on the UNESCO World Heritage site for Lumbini, at http:// whc.unesco.org/ en/ list/666; and a description by the late well-known Nepali scholar, Min Bahadur Shakya, at http://pnclink.org / pnc2005/chi/ Presentation-PDF/ 052-Min-CA.pdf. I thank Professor Shakya for his kindness and help with my project.

47 Tokushin Kasai founded the hotel, which includes a J apanese restaurant and its own herb and vegetable garden. An award from the Council of Mahavihara Buddhist Monks of Sri Lanka for his philanthropy is displayed in the lobby.

48 These small zones off of a main thoroughfare are certainly influenced by Le Corbusier's unrealized city master plan, Ville Radieuse (presented publicly in 1924 and published in 1933). Le Corbusier's plans for the capital of the Punjab, Chandigarh, and for Algiers also reflect this overall plan.

49 Especially funded by the family of U Ngwe San and Daw San Hwe.

50 I was unable to get much information, except complaints from sources (who would rather not be named) that they were causing too much noise and bothering the other monasteries.

51 Basanta Bidari, Lumbini: A Haven of Sacred Refuge (Kathmandu: Hill Side Press, 2002), 5- 8.

52 Ibid., 73- 84. Seealso Tansen Sen, Buddhism, Diplomacy, and Trade (Honolulu: University of Hawai'i Press, 2003), for a general introduction to the early Chinese pilgrimages to this area.

53 Bidari, Lumbini, 83- 97. See Charles Allen, who has written general books exploring this discovery and the origins of the idea of Buddhist pilgrimage. See particularly, The Buddha and Dr Fuhrer: An Archaeological Scandal (London: Haus Publishing, 2011), and The Search for the Buddha: The Men Who Discovered India's Lost Religion (NewYork: Caroll and Graf, 2002). Seealso Philip Almond, The British Discovery of Buddhism (Cambridge: Cambridge University Press, 2007), 20-22. They show that seeing a visit to the Buddha's birthplace as an important 
activity for devout Buddhists was largely an invention of the late nineteenth and early twentieth centuries, and this, more than the largely unsupported and biased understandings of the deleterious or destructive power of Muslim political and military power in the region, explains why the birthplace of the Buddha was largely forgotten until recent times. There are also a slew of books about travel to Buddhist holy sites by modern pilgrims, including Ajahn Sucitto and Nick Scott, Rude Awakenings: Two Englishmen on Foot in Buddhism's Holy Land (Boston: Wisdom Publications, 2005); and Swati Mitra, Walking with the Buddha: Buddhist Pilgrimages in India (New Delhi: Eicher Goodearth, 1999). Another archaeological controversy recently affected the Lumbini region with the supposed discovery of the Buddha's original home, http://antiquity.ac.uk/ant /087/ant0871104.htm.

54 No author, A Tourist Guide to Nepal (Delhi: Nepal Trading Corporation, 1959). General scholarly books hardly mentioned it at all. For example, Luciano Petech's Materials for the Study of Nepalese History and Culture: Medieval History of $\mathrm{Ne}$ pal (c. 750-1480), vol. 10 of Serie Orientale Roma, Materials for the Study of Nepalese History and Culture, vol. 3 (Rome: Istituto Italiano per il Medio ed Estremo Oriente, 1958) only mentions Lumbini once, on page 81, because of one Aśokan inscription there. The fact that the Buddha was born there is not mentioned. Gitu Giri's new study of Lumbini tourism has a nice summary of the basic history of its development and social activities, which have attempted to bring together the local community and foreign visitors. I thank J ulia Hintlian and Christoph Cueppers for finding this book for me and for Hintlian's extensive comments on her experience living and observing tourists and pilgrims in Lumbini for two months in 2014. See Gitu Giri, Lumbini Tourism (New Delhi: Adroit Publishers, 2014).

55 Kobe passed away in 1971. The other two members were Ejler Alkjaer and Silae Brown. Lumbini Development Project Report (Kathmandu: Lumbini Development Company, 1979), 8.

56 Gitu Giri, Sacred Complex of Lumbini (New Delhi: Adroit Publishers, 2008), 50- 53.

57 These documents were kindly given to me by Christoph Cueppers.

58 United Nations, "Lumbini: The Birthplace of the Buddha," United Nations Archives Series 0200, Box 5, File 3 (1968-1970), n.p.

59 United Nations, F. R. Allchin and K. Matsushita, Report for the Lumbini Development Project, December 1969 (unpublished internal report), 31.

60 Pers. comm., June 2013. I thank Professors Kurose and Nishimura for their kind assistance.

61 See Kobe's Report of the United Nations Mission for the Development of Lumbini, December 18, 1967-J anuary 9, 1968 (unpublished internal report); and F. R. Allchin and K. Matsushita, Report for the Lumbini Development Project, December 1969 (unpublished internal report). The United Nations Archives for this period also include U Thant's letters and correspondence with the fifteenmember United Nations advisory committee.

62 A series of cables confirm support by the king of Thailand in 1971 and invitations to the UN team to Bangkok. I thank Christoph Cueppers for providing me with copies of these cables.

63 United Nations Archives, 15, 74/ 19, Drawer 6, File 56, 1970- 1973. Development of Lumbini in Nepal General Correspondence. Official: Narasimhan.

64 R. K. Basu, Note for Record, October 5, 1971 (internal report after a meeting with the advisory committee for the Lumbini Project). United Nations Archives Series 0200, Box 5, File 3 (1968- 1970), n.p.

65 Ibid. See also http://tribhuvan.academia.edu/ RupeshShrestha/ Papers/519675 /Lumbini_its_challenges_now_and_then; and http://www.buddhistchannel.tv

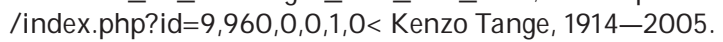


66 http://nepalitimes.com/issue/2010/05/26/ Nation/ 17099.

67 Basu, Note for Record, n.p.

68 United Nations Archives, 15, 74/ 19, Drawer 6, File 56, 1970- 1973. Development of Lumbini in Nepal General Correspondence. Official: Narasimhan.

69 Ibid.

70 Many successful parts of the master plan have been developed since 1980. The Lumbini International Research Institute was built between 1989 and 1995 in different stages following a striking and creative design by Tange. It is funded by the Reiyukai Foundation. The research facility contains a very comprehensive Buddhist research library with over thirty-five thousand volumes in several important Buddhist languages. It hosts visiting scholars and students and holds regular conferences and seminars. It is run by Christoph Cueppers. I thank him for all of his time and assistance in my research. The museum, next door to the research institute, was also designed by Tange, but has suffered terrible mismanagement and theft, and many of its pieces are missing, have mold growing on them, or are mislabeled. The Maya Devi Temple, which is largely a building built around an archaeological pit where the supposed exact site of the Buddha's Birth is located, is visited by many people. It was opened in 2003. A wooden path for people to circumambulate, meditate, or chant surrounds the pit. Other small successes include the dedication of the Eternal Peace Flame, the construction of the central canal and walkways, and the grounds around the Maya Devi Temple. Most of the site, though, is unkempt and in a state of disrepair. Bathrooms, garbage barrels, proper drainage, and guards are few and far between. The auditorium that was supposed to be completed in the space between the research center and museum has never been built. See His Majesty's Government, The Lumbini Development Committee Report (Kathmandu: Babar Mahal, 1980), 13- 22.

71 “Lumbini Master Planner Dies," Nepali Times 241, April 1- 7, 2005.

72 Waldheim visited in February 1981 and de Cuéllar in March 1989. BoutrosBoutros Ghali and Kofi Annan never visited the site, but wrote letters of support for the project. Ban Ki-Moon visited in 2008. Dag Hammarskjöld was actually the first secretary-general of the UN to visit Lumbini in 1959 and wrote a short haiku about his visit: "Like glittering sunbeams / The cute notes reach the gods / In the birth grotto." He never instituted any policy about Lumbini though. See http:// www.unesco.org/new/ en/ kathmandu/culture/ lumbini-past -present-future/ un-secretaries-general-on-lumbini/. See also “UN Support to Peace to Continue: Ban Ki Moon,” The Rising Nepal (November, 2, 2008), as well as Lumbini Development Trust, Message from UNSG (March 8, 1989), www .lumbinitrust.org/articles/view/96; and U Thant, View from the UN (New York: Doubleday, 1978); United Nations, Secretary-General Kofi Annan's message to the World Buddhist Summit, press release SG/SM/6812, November 30, 1998.

73 There are no entrance fees for Nepalis. Indian visitors have to pay only sixteen rupees. Citizens from other South Asian countries like Bangladesh or Pakistan have to pay one hundred rupees. All other nationals have to pay two hundred rupees. There are heavy fees for foreigners who want to use cameras, though. They must pay the equivalent of ten USD if they want to use a camera. There are few guards, and one can walk in and out of the site easily. For example, I walked into the site at 5:15 a.m. with some other pilgrims from Korea; no guards were in evidence, and I had to voluntarily track down a person at the ticket office three hours later to pay my fee. If I had not sought out the ticket office, I would not have had to pay, although many, including me, give donations to the Maya Devi Temple and individual monasteries, nuns, and monks. I interviewed many Thai and Burmese visitors who had come in large tour buses. They gave donations to their own monasteries, but did not pay individual entrance fees, as the buses 
bypassed the ticket office and parked directly at the individual monasteries. It was unclear whether the tour bus companies had to pay fees themselves. One of the Thai bus drivers seemed to be unaware of any fee, and so I imagine no Nepali official had approached him to pay.

74 http://www.ekantipur.com/the-kathmandu-post/2010/08/06/nation/lumbini -master-plan-in-force/211284/.

75 Y. H. Kwaak and Abelardo Brenes, Lumbini: The Fountain of World Peace: Report for the Vision and Scoping Mission (Cambridge, MA: Harvard University Press, 2002); Tara Nanda Mishra, "Evolution of Buddhism and Archaeological Excavations in Lumbini," Ancient Nepal: J ournal of the Department of Archaeology 155 (2004): 10-18; UNESCO, Lumbini, the Birthplace of the Lord Buddha (World Heritage List, UNESCO World Heritage Centre 1992-2012), whc.unesco.org/en/list/666/.

76 From the presentation "Key Concepts of the Kenzo Tange Master Plan," by Yukio Nishimura and Takefumi Kurose, at the second annual meeting of the International Scientific Steering Committee (ISSC) in Lumbini on July 12, 2011. See also http:// www.unesco.org/new/ en/ kathmandu/culture/jfit-lumbini-project/ .

77 Many members of Tange's design team worked on Lumbini, including the architects Sadao Watanabe, Atsushi Arata, Nachio Torisu, and several professors of literature and archaeology, such as Chie Nakane (Tokyo University) and Takayasu Higuchi (Kyoto University). They were also advised by K. Takahashi of the Center of Housing, Building, and Planning in New York City, and Chamnong Phahulrat, the councilor of the Thai embassy in Tokyo.

78 Villalon, "Walking toward Buddhist Stillness."

79 http://www.thehimalayantimes.com/fullNews.php?headline=Superimposed+ master+plans+and+the+sacred+garden\&NewsID=340321.

80 Kenzo Tange and URTEC, Master Plan for the Development of Lumbini: Phase II, Final Report (Tokyo: Kenzo Tange and URTEC, 1978). See also http:// www .academia.edu/523789/_Lumbini_its_challenges_now_and_then.

81 An example of the bureaucracy and controversy over the site can be seen here, http://completenepal.wordpress.com/2012/11/06/greater-lumbini-master -plan-a-herculean-task-ahead/\#more-3197.

82 Kate Molesworth and Ulrike Müller-Böker, "The Local Impact of UnderRealisation of the Lumbini Master Plan: A Field Report," Contributions to Nepalese Studies 32, no. 2 (2005): 183-211, esp. 186. As of 2000, the population of the Terai is 42 percent Muslim, 53 percent Hindu, and 5 percent Buddhist.

83 I also thank Kesab Shakya, former vice-chair of the Lumbini Development Trust from 2007 to 2009, for providing me with candid information about his work with Tange's master plan. Not only was he in charge of the day-to-day operations of the LDT, but he was also responsible for the development of seven sites of Kapilavastu and Ramagrama.

84 D. P. Dhakal, "Status of Tourism and Its Prospects in Buddhist Sites in Nepal, with Reference to Lumbini," paper presented to the UNDP, September 1999, as cited in Molesworth and Müller-Böker, "Local Impact of Under-Realisation," 187.

85 Indian nationals can get three-day visas for Lumbini, but other countries' citizens have more difficult restrictions and large visa fees.

86 Thanks to Victor Mair (pers. comm., July 2011), I learned about a meeting and eyewitness report about the poor state of development in Lumbini in 1986. A well-known scholar who had visited Lumbini in 1986, and who wished to remain anonymous, stated,

[The] project had been going for quite a few years, but there was no visible progress. There was a Tibetan temple and a Theravada temple near 
the site. The Nepalis in charge of the project had built themselves a nice bungalow with offices, but that was about it. There was a rusty old sign touting the project, and some desultory excavation going on around the Mayadevi temple. The sign advertised that the project would be completed under the supervision of a J apanese architect on a date that was long overdue. My feeling at the time was that they should leave the place the way it was, barren and desolate. That would illustrate the Buddhist doctrine of emptiness. A few years later, I happened to be visiting Fo Kuang Shan, near Kaohsiung in southern Taiwan, and attended a banquet that Ven. Hsing Yun, the founder of Foguang Shan, was hosting for Tai Situ Rinpoche, a Tibetan lama who has a monastery in the Kangra Valley in northern India. . . . At the banquet, Hsing Yun justified his reputation as a "power monk" by launching into a tirade directed at the Lumbini project. "We have been donating money for years, and what are the results?" he thundered. "I built the whole complex at Fo Kuang Shan in less time with less money. What is the Nepali government doing with all that money?" Tai Situ smiled sheepishly. "That is the Nepali government," he said. "That's the way they operate." And now the Chinese are getting involved. Just what we need.

I thank Victor Mair and his anonymous source for this information.

87 K. Pudel, "Waiting for Visitors," Spotlight 19, no. 4 (2000): 19- 25; CK Lal, "Illusions of Grandeur: The Story of the Lumbini Master Plan," Contributions to Nepalese Studies 4, no. 2 (1999): 365- 381; A. M. Tripathi, "Lumbini: Progress in Circles?" Good Governance 1, no. 3 (2003): 4- 9.

88 Molesworth and Müller-Böker, "Local Impact of Under-Realisation," 195.

89 See http://nepalitimes.com/news.php?id=6399\#.URlF5_Ke49U and http:// www.himalmag.com/component/content/article/2947-Lumbini-as-disneyland .html. For a more sober reflection on the problems, see http://www.academia .edu/523789/Lumbini_its_challenges_now_and_then.

90 Michael Pahlke kindly informed me that Ferdinand Stange also founded the Lamayuru Meditation Centre, which is located just next to the Great Lotus Stupa and opened its doors not very long after the inauguration of the Tara Foundation complex in 2004. Every spring, just ahead of the Tibetan New Year (lo gsar) a Yamantaka retreat is executed, with thirty to forty yogins coming from Ladakh, Tibet, and Nepal for this event. During the rest of the year, single practitioners stay in approximately eight small guest houses there. The Meditation Centre is under the spiritual leadership of Stange's teacher, Drubpon Sonam Jorphel Rinpoche, as is the Lotus Stupa.

91 http:// whc.unesco.org/archive/2006/mis666-2005.pdf. "While the Mission recognized the strong commitment of the national authorities, and LDT in particular, to manage the site and implement the Master Plan of Kenzo Tange of 1979, it also noted how this Master Plan did not provide an adequate guidance for the conservation of the site, and should betherefore accordingly be reviewed."

92 http:// www.myrepublica.com/portal/index.php?action=news_details\&news id $=44628$.

93 http://www.mikeldunham.blogs.com/mikeldunham/2012/11/ how-to-buy -lumbini-prachanda-inks-deal-with-chinese-without-consulting-nepal -government.html.

94 Congress leader Karan Singh stated that the Indian government "should remain cautious about it as Lumbini, also a UNESCO World Heritage Site, is situated close to the Indian border. . . . Both India and Nepal can benefit from tourism if we could market the entire Buddhist circuit, including Lumbini, together with 
India's Bodh Gaya and Sarnath," http://economictimes.indiatimes.com/india -should-be-cautious-about-chinese-interest-in-lumbini/articleshow/ 10657991 .cms.

95 In July 2011 the Indian Times reported that the Chinese ambassador to Nepal, Li Debiao, was involved with talks with the Nepal government for a project in Lumbini. The new Chinese ambassador to Nepal, Yang Houlan, visited Lumbini and met former Nepal prime minister Madhav Kumar Nepal and discussed Lumbini's development. The Indian Times reporter stated that "the growing Chinese interest comes at a time Beijing is trying to bring religious institutions under its control. After appointing a Panchen Lama of its own, it has since then said that all reincarnations of Tibetan Buddhist leaders would have to be approved by the state, raising fears that the dragon means to choose a successor to the current Dalai Lama as well." See http://articles.timesofindia.indiatimes .com/2011- 07-28/south-asia/29824578_1_lumbini-madhav-kumar-nepal -nepal-government.

96 http:// www.globalpost.com/dispatches/globalpost-blogs/india/nepal -prachanda-lumbini-china.

97 http://www.mikeldunham.blogs.com/mikeldunham/2012/11/ how-to-buy -lumbini-prachanda-inks-deal-with-chinese-without-consulting-nepal -government.html.

98 http://chinadigitaltimes.net/2011/07/ the-lumbini-project-chinas-3bn-for -buddhism/. See also the recent article in $\mathrm{Al} \mathrm{J} \mathrm{azeera,} \mathrm{which} \mathrm{traces} \mathrm{the} \mathrm{various}$ efforts by the Indian and Chinese government to use the "soft power" of Buddhism to attract money, allegiance, tourists, and international goodwill, http:// www.aljazeera.com/indepth/features/2013/01/2013171148400871.html.

99 http://chinadigitaltimes.net/2011/07/ the-lumbini-project-chinas-3bn-for -buddhism/.

100 http://www.dcnepal.me/news_nepali.php?nid=63728.

101 Ibid. For more information, see also http://www.ekantipur.com/the-kathmandu -post/2011/10/21/nation/ broader-lumbini-development-plan-on-horizon /227441.html.

102 http:// www.chinanationalnews.com/index.php/sid/209860424/scat/9366300 fc9319e9b/ ht/China-builds-477-mn-Buddhist-themed-park.

103 David Geary has recently completed a thorough dissertation on the history of Bodh Gaya and its modern development as a pilgrimage and tourist site. I want to thank him for sending mea summary of his book (in progress) on Bodh Gaya, called Destination Enlightenment: From the Hermitage of Shakyamuni Buddha to World Heritage. See also his "Destination Enlightenment: Branding Buddhism and Spiritual Tourism in Bodh Gaya, Bihar," Anthropology Today 24, no. 3 (2008): 11-14. On the competing visions between Western Buddhist enthusiasts and local concerns in Bodh Gaya, see also Kory Goldberg's Buddhists without Borders: Transnational Pilgrimage, Social Engagement, and Universal Education in the Land of Enlightenment (PhD diss., 2011, Université du Québec à Montréal), as cited in Hiroko Kawanami and Geoffrey Samuel's forthcoming edited volume on Buddhism, development, and disaster.

104 See the recent dissertation tracing the history of this project by J essica Falcone, Waiting for Maitreya: Of Gifting Statues, Hopeful Presents, and the Future Tense in FPMT's Transnational Tibetan Buddhism (PhD diss., Cornell University, 2010). For a broad overview of the Tibetan history of pilgrimage to India, especially in the modern period, see Toni Huber's Holy Land Reborn: Pilgrimage and the Tibetan Reinvention of Buddhist India (Chicago: University of Chicago Press, 2008); and for a study on the reification of ideal Buddhist cultures through the work on pilgrimage sites and museums, especially in regard to Tibet, 
see Clare Harris's fascinating Museum on the Roof of the World (Chicago: University of Chicago Press, 2012).

\section{CHAPTER TWO: ECUMENICAL PARKS AND COSMOLOGICAL GARDENS}

1 In 1936, a year before the Tiger Balm cave of hell opened, a hell park was built on the island of Ikuchijima in the Inland Sea of J apan near Hiroshima. It was also built as an underground passage. See Patricia Graham's Faith and Power in Japanese Buddhist Art 1600- 2005 (Honolulu: University of Hawai'i Press, 2007), 230-231.

2 For information on these hell parks, see my Lovelorn Ghost and the Magical Monk: Practicing Buddhism in Modern Thailand (New York: Columbia University Press, 2011), chapter 3. See also information on Wat Muang in this chapter.

3 See the cremation volume from Wat Thepsirindarasat, published by his children, called Rim Khop Fa (Wiriyaphan family, Rim Khop Fa, Bangkok: Wat Thepsirindarasat, 2544 [2001]). This book is extremely hard to find, as it was never meant for sale or wide distribution except to people who attended the funeral. I thank Thongchai Likhitpornsawan for finding me a copy. Some additional information on his early life, especially his affection for a cooperation with Braphai, is found in his autobiography, Lek Wiriyaphan, Chiwit lae phonngan (Bangkok: self-published, 2544 [2011]), especially chapter 1. This book is written in the form of an autobiography; however, since it was published after his death, it contains numerous additions by his friends and family, and many family photographs. There are sections in his own words and the reflections of his admirers. It was not published as a cremation volume like Rim Khop Fa though.

4 For the rest of her life, according to Lek's friend, Sisak Walliphodom, he helped her check her blood and gave her injections.

5 The chapter is titled "Khu chiwit" (Couple or Partners for Life), Wiriyaphan, Chiwit lae phonngan, 37-51. The chapter includes many photographs of her, as well as a large portrait he had commissioned of her.

6 The last chapter of his autobiography includes a series of laudatory essays about Lek and Braphai written by his friends and scholars, including Phichai Wasanasong, Pricha Wilbulsin, Sak Bunbhan, and Charun Mathanom, among others. See Wiriyaphan, Chiwit lae phonngan, 249-272. Suthon Sukphisit also wrote a touching articleabout Lek in the Bangkok Post after he passed away_-Reflections of a Rich Heritage," December 6, 2000 (online at www.bangkokpost.com).

7 Lek and Braphai published dozens of books in the Muang Boran (Ancient City) series, which continue to come out today, as the publishing house still has members of his family in the executive committee. Most of the books focus on monastic architecture, Buddhist murals, history of Thai epigraphy, Khmer architecture, fabrics and other traditional arts, and Thai drama and costumes. As part of the Muang Boran publishing house, a series has been produced with funding from the related but separate Munnithi Lek-Braphai Wiriyaphan (The Lek and Braphai Wiriyaphan Foundation). Most of these books have come out after Lek and Braphai's deaths. Sisak Walliphodom and Walaisak Songsiri have written many of the books in this series, including Phiphithaphan Bhrawatisat Thong Thin (Bangkok: Munnithi Lek-Braphai Wiriyaphan, 2551 [2008]), on museums and traditional folk arts in Thailand; Khu meu chukit (Bangkok: Munnithi Lek-Braphai Wiriyaphan, 2551 [2008]), on Thai folk culture; and Phi kap phut (Bangkok: Munnithi Lek-Braphai Wiriyaphan, 2550 [2007]), on ghost rituals in Thailand, by Sisak Walliphodom; and Phiphithaphan khong khon thammada (Bangkok: Munnithi Lek-Braphai Wiriyaphan, 2551 [2008]), on home and temple museums, by Walaisak Songsiri. Together they wrote a book 
on the far northern province of Phrae in 2008, Nakhon Phrae (Bangkok: Munnithi Lek-Braphai Wiriyaphan, 2551 [2008]). The foundation also published two sets of studies on Thai museums, art, and culture, Bhrasopkan phiphithaphan thong thin (Bangkok: Munnithi Lek-Braphai Wiriyaphan, 2552 [2009]), and Bantheuk chak thong thin (Munnithi Lek-Braphai Wiriyaphan, 2552 [2009]), which include contributions from some of the best scholars in traditional culture and art in the country. Braphai herself published a study of the murals at Wat Ko Kaeo Suttaram and maintained an interest in Buddhist murals throughout her life, see Braphai Wiriyaphan, Wat Ko Kaeo Suttaram (Bangkok: Muang Boran, 1977).

8 See http://en.wikipedia.org/wiki/Taman_Mini_Indonesia_Indah. See also Bianca Blosker's fascinating study of "simulacrascapes" in China in her Original Copies: Architectural Mimicry in Contemporary China (Honolulu: University of Hawai'i Press, 2013). She looks at the recent phenomena in Chinese suburbs of recreating to scale neighborhoods and monuments from Paris, Vienna, and various other European cities and using them, not as amusement parks, but as residential housing blocks. Of course, J apan and the United States both have "Dutch" and "French" and other European theme parks. In fact, when I was a child, my parents took me to Dutch Wonderland in Lancaster, Pennsylvania, and I have taken my own children to a Netherlands-themed amusement park in Japan; to the Venetian, Paris, and Caesar's Palace casinos in Las Vegas; and to smaller sites, like Crystal Grotto in the Memorial Park Cemetery in Memphis, Tennessee, created in 1938 by Mexican artist Dioñicio Rodriguez. My family and I had trouble finding it, and it is not well advertised, but this whimsical cave is filled with handmade statues within a large cave underneath the cemetery. The cave walls are covered in large crystals, and the entrance and surrounding pond look like a mythological hobbit's home. It is both a playground for children and a pedagogical tool teaching the life of Christ.

9 The first Thai guidebook to the Ancient City was published in 1977 (Braphai Wiriyaphan, Muang Boran, Bangkok: Rongphim Phikanet, 2520 [1977]). At that time the park contained only seventy-five buildings and monuments. Between that first edition and the edition produced around the time of Lek's passing (Braphai Wiriyaphan, Guide to Muang Boran, Bangkok: Viriya Business Co., n.d.), the descriptions in Thai became a bit longer, with slightly more historical detail, but largely remained the same. From the photographs, the other major change seems to be that in the 1970s there were far more wild animals like baboons and elephants roaming around the park.

10 Wiriyaphan, Rim Khop Fa, 39.

11 Ibid., 49.

12 Ibid., 39.

13 Ibid., 62.

14 Braphai Wiriyaphan, Muang Boran, and her Guide to Muang Boran, 4.

15 Braphai Wiriyaphan, Muang Boran, 42. For example, one of my students at the University of Pennsylvania, Sirintra Pattaramalai, told me that when she was going to high school in Bangkok, her class participated in a "fun run" race at Muang Boran.

16 Ibid., 70.

17 Braphai Wiriyaphan, Guide to Muang Boran, 5.

18 Wiriyaphan, Rim Khop Fa, 62.

19 Lek Wiriyaphan, Bantheuk Khwam Khit (Bangkok: n.p., 2544 [2001]). It was published in honor of both Lek and Braphai's cremations.

20 Wiriyaphan, Chiwit lae phonngan, 211.

21 A series of thirty documentary films on Thai culture and the importance of preserving traditional Thai folk arts called Pheua pho phiang phaen din goet (produced by the Lek-Braphai Wiriyaphan Foundation) came out after Lek's death 
and was part of his larger project to foster an appreciation of these practices in the next generation. These well-produced documentaries, with interviews with local artists and everyday citizens, with occasional commentaries by Thai scholars, were divided into five or six chapters, each about five to eleven minutes in length. These short episodes were played on Asia Satellite TV from approximately 2009 to 2011.

22 See Wanchai Tantiwittayapitak, Sran Thongpan, and Wiyada Thongmit, trans. Charun Gaini, The Erawan Museum: Convergence of Dreams, Faith, and Gratitude (Bangkok: Viriya Business Co., 2006), 56- 59.

23 See the Sanctuary of Truth's own website and Wiriyaphan, Rim Khop Fa, 59.

24 http://www.sanctuaryoftruth.com/.

25 Note: These are transliterations of their Chinese names from Thai script taken from the literature available on-site at the Wihan Sien. Most Sino-Thai were originally Hakka, Hokkien, or Teo Chiu (or Teochew) speakers, and the writing of their own names or the names of Chinese deities, literary characters, and the like often are influenced not only by these Chinese dialects, but also by Central Siamese tones.

26 While it is beyond the scope of this book to trace the history of monasteries that have been sites of intense tourist activity and the repositories of giant sculptures, it should be noted that this is not a new phenomenon at all in Thailand. Large Buddha images have been found at major Thai monasteries for several centuries. For example, one of the oldest monasteries in Bangkok, Wat Chetuphon (popularly known as Wat Pho), was the site for one of the largest Buddha images in the city. See "Copy of the King's Initiative to Construct the Reclining Buddha in Wat Phra Chetuphon," in Brachum chareuk wat phra chetuphon (Bangkok: Wat Phra Chetuphon Clergy, 2554 [2011]), 72.

27 The Thai name is Uthayan Sasana Phra Photisat Guan Im. It should be noted that "inter-religious" is not in the Thai title, but only on the English brochure (it is "The Park for the Religion of the Bodhisattva Guanyin" in Thai). In small print in Thai there is another, rather strange, name, Uthayan haeng khwam garunabhrani jak fakfa sukhawadi su daen thai, or "The Park [that projects] Love and Mercy from the [edge of] Heaven to [the border of] Thailand" (undated brochure printed at the park). A short biography of Dr. Suchat is posted online in English. Here he claims that his first park was a failure, despite the support of "many country leaders, religious leaders, and leaders of religious and peace organization[s]" because the "international Communist Party and ill-wishers to Thailand paid 400 million baht to overthrow the project. . . . The World Peace Envoy conceded to be collapsed for Thailand not to be Communists and the world war likely to happen to postpone to nowadays to more than 20 years."

28 http:// www.worldpeaceenvoy.org/.

29 Large Guanyin statues are increasingly commonplace in Thailand. Besides the places mentioned in the text, a few other places to see good examples of large and actively patronized images of Guanyin are Wat Muang in Angthong, Koh Loi in Sri Ratcha (Chonburi), and a large image on the popular tourist island of Koh Samui. At all these places, these Guanyin images are part of larger Thai monasteries complete with festival grounds, flea markets, fountains, and food courts. The Koh Loi (Floating Island) image in Sri Ratcha is connected to the mainland by a long causeway with a huge weekend market, an outside movie theatre, amusement park, astrologer's booths, boating club, and aquarium. Alongside Guanyin's pavilion are several shrines to local famous Thai monks and Thai Buddha images. It is the central entertainment district of Sri Ratcha. I thank the many people at Koh Loi who guided me around the various shrines and swapped stories about the various activities there throughout theyear. Separate Chinese-Thai monasteries are also centered around images of Guanyin, 
like the beautiful Sala Mae Guan Im built in the 1830s along the Chao Phraya River in Bangkok and the more modern and much larger Guanyin Shrine in the Lad Phrao section of Bangkok. I thank Susanne Kerekes for providing me with information about the latter.

30 The exact time of his death, the room number of the hospital in which he died, and his exact age are dutifully marked at the monastery because they are all connected to special calculations for making amulets and batches of tattoo ink for use in protective magical ceremonies. For example, public documents posted at the monastery state that he died of liver cancer at fifty-four years, six days, and seven hours old, on the seventh of March in the year 2544 of the Thai calendar. He died at the oldest hospital in Thailand (Sirirat Hospital), in building number 84, in room 925, on the ninth floor. He died at 16:54 (4:54 p.m.). To see more about the ritual technology behind these ceremonies in Thailand generally, see my Lovelorn Ghost, chapter 2. For more information about tattooing in Laos and Thailand see Catherine Becchetti, Le mystere dans les lettres (Bangkok: Éditions des cahiers de France, 1991).

31 The uniforms of premodern Thai kings are often similar to the imagined uniforms worn by Indian god-kings, and the names of different parts of the uniforms (belts, armor, etc.) have Thai-Sanskrit names taken from Indic epics.

32 I thank Arthid Sheravanichkul for his help in identifying some of these images and helping me with the Mandarin names.

33 For a study of the role of the "Hindu" hermit in Thai religion, see my "This Hindu Holy Man is a Thai Buddhist," Southeast Asia Research 21, no. 2 (2013): 191209. Here I provide detailed information about the history of various phra reusi in Thailand and the ways in which figures traditionally associated with Hindu traditions are venerated and depicted in Thailand.

34 Benedict Anderson recently published a short monograph about Wat Phai Rong Wua; it is a provocative study. Anderson concentrates on the founder's politics and personal life as much as the aesthetics and religious practices at the park. See Benedict Anderson, The Fate of Rural Hell: Asceticism and Desire in Buddhist Thailand (Calcutta: Seagull Books, 2012). See also Erick White's thorough review of the book at http://asiapacific.anu.edu.au/newmandala/2012/09/ 12 / review-of-fate-of-rural-hell-tlcnmrev-xlii/.

35 http://www.lifeinkorea.com/Travel2/55.

36 http:// www.asiarooms.com/en/travel-guide/south-korea/seoul/museums-in -seoul/moga-buddhist-museum.html.

37 http:// londonkoreanlinks.net/2010/05/26/park-chan-soo-review/.

38 Ibid. In a book edited by J effrey Samuels, Mark Rowe, and me, called Figures of Buddhist Modernity in Asia (Honolulu: University of Hawai'i Press, 2016), Hwansoo Ilmee Kim describes the work of the Korean Buddhist nun, Hŭisang, who, unlike Chan-soo Park, brings her Buddhist art to urban areas and conducts drawing and meditation courses for busy, upwardly mobile people living in various cities in Korea.

39 For a longer description and bibliographic references for the study of Thai murals, seemy Lovelorn Ghost, chapter 4. Seealso Uab Sanasen's Ten Contemporary Thai Artists (Bangkok: Graphis, 1984), 144- 161.

40 See Chalermchai Kositpipat, Wat Rongkhun (n.d.); Chalermchai Kositpipat, Roi ruang rao khong Wat Rongkhun (DVD) (Chiang Rai: Wat Rongkhun, no date).

41 http://www.bangkokpost.com/ business/tourism/485541/temple-plans-non -chinese-loos.

42 Dozens of available sites are easily found online in Thai and English. See, for example, http:// www.youtube.com/watch?v=y456xcuXDUU, http:// www.thawan -duchanee.com/index-eng.htm, http:// www.photodharma.net/ Thailand/ Black -House/ Black-House.htm, http:// www.neverendingvoyage.com/ black-house 
-chiang-rai-thailand/, http://www.nationmultimedia.com/top40/detail/ 7058, http://www.sombatpermpoongallery.com/thawan-duchanee/, http://www .rama9art.org/artisan/2004/october/trinity/index.html. Dozens of individual exhibition catalogs, in Thai and English, are also easily found, for more information about specific shows over his career. See Sanasen's Contemporary Thai Artists, 58- 79, for some of his early work.

43 http:// www.thawanduchanee.com/. See also the recent book on Thawan by Russell Marcus, Thawan Duchanee: Modern Buddhist Artist (Chiang Mai: Silkworm Books, 2013).

44 Thawan has become so famous among international modern art circles that his works are selling for several thousands of US dollars at international auctions. For example, at a recent Sloane and Kenyon auction, one of his paintings sold for over seven thousand US dollars.

45 http:// www.antiquealive.com/masters/ buddha/sculpture.html.

46 There is no shortage of information on Tadao Ando's life. He grants numerous interviews (although rarely allows people to visit his studio), and has lectured at Harvard, Yale, and other universities. He often writes prefaces or short essays in books in J apanese and English, and he has been the subject of a film by Michael Apted, narrated by David Bowie, called Inspirations (Image Entertainment, 2003). See numerous biographies, including Masao Furuyama's Ando (New York: Taschen, 2006); Philip J odidio, Ando (New York: Taschen, 2004); and Francesco Dal Co, Tadao Ando: Complete Works (1975- 1995) (New York: Phaidon, 1997). Interviews can be found online in many places. A good source for a detailed print interview and examples of his design can be seen in Yukio Futagawa, ed., Tadao Ando: Recent Project (Tokyo: A.D.A. Edita, 2009).

47 Philip J odidio, Tadao Ando at Naoshima (New York: Rizzoli, 2006). Foreword is by Ando.

48 See Philip Drew, Church on the Water, Church of the Light: Tadao Ando (Singapore: Phaidon, 1996). See also Furuyama, Ando, 34- 39, 46- 50, 54- 57.

49 Jodidio, Tadao Ando at Naoshima, 13.

50 Its design is similar in some ways to the chapel at the Class of 1959 Chapel on the grounds of the Harvard University Business School (designed by Moshe Safdie and built three years after Ando's church, in 1992). It is also, of course, similar to the Catholic Chapel of the Holy Cross near Sedona, Arizona, in his use of an extremely large unornamented concrete crucifix over a window to cast a shadow over the main congregation space. The Chapel of the Holy Cross was built in 1956, based on Marguerite Brunswig Staude's design. See Kate Ruland-Thorne's Upon this Rock (Sedona: Church of the Holy Cross, 2011). As far as I determined, Ando does not cite this chapel as an inspiration.

51 A short description of this temple is found in Graham's Faith and Power, 242- 245. I thank Yoko Hayami and John Holt for accompanying me to the temple.

52 For photographs, see http://www.architizer.com/en_us/blog/dyn/21616/a-neces sary-courtesy-the-glass-temple/\#.UT5BRjeukS4.

53 Some graves can cost more than the equivalent of 250,000 USD, and these costs, in addition to annual fees, pay for the upkeep and staff.

54 I thank Yoko Hayami for all her help finding the monastery and for translating in my interview with the caretaker. She was of great assistance while I was in Kyoto. I also thank her and J ohn Holt for helpful advice with my research while in J apan.

55 A much broader study of the various ways to interpret the importance of the grotesque in Buddhist cultures is Michelle Osterfeld Li's very helpful Ambiguous Bodies: Reading the Grotesque in Japanese Setsuwa Tales (Stanford, CA: Stanford University Press, 2009). See especially pages 38-48, where she discusses the importance of comedy, leisure, and horror in religious aesthetics. 
56 For comparative examples from Japanese history and literature, see Michael Dylan Foster's Pandemonium and Parade: Japanese Monsters and the Culture of Yokai (Berkeley: University of California Press, 2008).

57 See Li, Ambiguous Bodies, 38. See also Charlotte Eubanks, Miracles of Book and Body: Buddhist Textual Culture and Medieval J apan (Berkeley: University of California Press, 2011); Foster, Pandemonium and Parade; J ohn Ruskin, "Grotesque Renaissance," in The Stones of Venice, vol. 3 (Sunnyside: George Allen, 1886 [Dover, 2005]), 126; Wolfgang J . Kayser, The Grotesque in Art and Literature, trans. Ulrich Weisstein (Bloomington: Indiana University Press, 1963); Charles Baudelaire, "On the Essence of Laughter," in Charles Baudelaire: The Painter of Modern Life and Other Essays, trans. and ed. J onathan Mayne, 147- 165 (London: Phaidon, 1964); Victor Hugo, "Preface to Cromwell," in Prefaces and Prologues to Famous Books, ed. Charles Eliot, 354- 408 (New York: Collier and Sons, 1910). I also want to thank my colleague, Peter Stallybrass, for conversations on this issue. See his (with Allon White) The Politics and Poetics of Transgression (Ithaca, NY: Cornell University Press, 1986). He and Michelle Osterfeld Li note that, unlike the approach of Bakhtin, the grotesque in literature, architecture, and art is not necessarily a way of challenging the sanctity and order of the elite classes, but is actually a type of "displaced abjection" that made ugliness and buffoonery-often associated with not only immorality but also the lower classes-a openly ridiculed aspect of daily life.

\section{CHAPTER THREE: BUDDHIST MUSEUMS AND CURIO CABINETS}

1 http:// www.pagrandlodge.org/ freemason/0504/tot.html. I thank the archivists at the Grand Lodge of Philadelphia for their assistance in locating information about Sommervilleand for showing me some of the objects he donated to thelodge.

2 Maxwell Sommerville also wroteromantically about his travels. See especially his Siam on the Meinam from the Gulf to Ayuthia together with Three Romances Illustrative of Siamese Life and Customs (London: Sampson Low, Marston and Company, 1897).

3 Curators at the University of Pennsylvania have told me that most of these gems have been recently discovered to be fake. Pers. comm., 2013.

4 The department was housed in the museum, and Sommerville turned a section of it into a space for his large collection of Asian antiquities (most of which are still there today, although largely in storage).

5 My former student, J oel Dietz, worked hard documenting and tracking down items in this collection for a research project he took on in my graduate course on Buddhist Art and Material Culture. He and Stephen Lang (the "keeper" of the Asian collection at the museum) worked together to research Sommerville's Buddhist temple. In an unpublished research paper, Dietz found Culin's note. See also the newspaper North American, J anuary 30 (year unknown) (University of Pennsylvania Archives [UPA]); see also Ira Jacknis, "The Stewart Culin Papers, the Brooklyn Museum," 1985 (Brooklyn Museum archive); and Stewart Culin, "Professor of Glyptology" (Brooklyn Museum archive). I thank J oel Dietz for finding these documents. Culin also described various details regarding the setup of the Buddhist temple. Culin calls Sommervillea "charlatan" and states that at the opening of the temple the professor insisted that people take off their shoes before entering. He is also said to have originally desired to locate the temple inside an abandoned church in the center of the city.

6 The University of Pennsylvania Museum Archives (UPMA) has one copy of the original, as well as one copy of the latter.

7 Maxwell Sommerville, Monograph of the Buddhist Temple of the Free Museum of Science and Art of the University of Pennsylvania (Philadelphia: University of Pennsylvania Museum, 1904), 3. 
8 Old Penn Weekly Review, February 20, 1904, 151 (UPMA).

9 North American, May 7, 1904 (UPMA).

10 North American, J anuary 30 (year unknown) (UPMA).

11 While I certainly offered my limited advice, I am not an expert in assessing the value of individual Buddhist pieces of art and have no training in museum studies or art appraisal, and I let them know that directly. They merely asked me (and continue to ask me) my opinion on the rarity and style of certain pieces.

12 I met with a representative of the Singapore Tourism Board in J uly 2012. They are a large, well-funded, and politically connected organization that, unlike in other Buddhist countries, has a considerable role in promoting the growth of religious organizations as places open to visitors of all faith traditions.

13 Many have questioned the authenticity of the tooth relic, often stating that it is actually a water buffalo's tooth. Its authenticity is not my concern here, as I am focused on the temple as a public and leisure space and on Shi Fa Zhao's role in its design and marketing. For critical comments on the authenticity of the tooth relic, see, for example, Jack Meng-Tat Chia, "Buddhism in Singapore: A State of the Field Review," Asian Culture 33 (J une 2009): 90. See also http:// www.buddhistchannel.tv/index.php?id=57,4529,0,0,1,0\#.Unnm_5TwK-c, http:// news.asiaone.com/ News/ The\%2BStraits\%2BTimes/Story/ Is\%2BBuddha \%2Btooth\%2Bhere\%2Bthe\%2Breal\%2BMcCoy\%253F.html, http://www.channel newsasia.com/stories/singaporelocalnews/view/289746/1/.html, http:// www .dhammaweb.net/dhamma_news/view.php?id=331, and http:// www.buddhist channel.tv/index.php?id=57,4484,0,0,1,0.

14 For further reading on Buddhism in Singapore, see Jack Meng-Tat Chia's "Teaching Dharma, Grooming Sangha: The Buddhist College of Singapore," Sojourn: J ournal of Social Issues in Southeast Asia 24, no. 1(April 2009): 122-138; Khun Eng Kuah-Pearce, State, Society and Religious Engineering: Towards a Reformist Buddhism in Singapore, 2nd ed. (Singapore: Institute of Southeast Asian Studies, 2009); Y. D. Ong, Buddhism in Singapore: A Short Narrative History (Singapore: Skylark Publications, 2005). See also Xianjue 刘先觉 and Lee Coo 李谷, Singapore Xinjiapo Fojiao jianzhu yishu 新加坡佛教建筑艺术 [Buddhist Architecture in Singapore] (Singapore: Kepmedia International Pte Ltd., 2007); and Shiling Cheryl Tan's master's thesis, Religious Alternation, Spiritual Humanism: Tzu Chi Foundation in Singapore (master's thesis, National University of Singapore, 2008). A more specialist museum on Chinese Buddhist art in Singapore is the Kong Hiap Memorial Museum, located in Chiam Pok Eee Temple (8 Geylang East Avenue 1). See http:// www.sbl.org.sg/ en/index .php?option=com_content\&view=article\&id=65:kong-hiap-memorial -museum\&catid=37:sbl\&Itemid=77. I thank Jack Meng-Tat Chia for his help with this research and for his advice in general. His comments greatly improved this chapter.

15 Longhua can also be a name for China. I thank Victor Mair for help with this translation. The English name does not emphasize the "localness" of the temple as either Singaporean or Chinese. See information on the temple's website, www .btrts.org.sg, as well as in Shi Fa Zhao, From Dawn to Dusk, trans. Tan Yen Kee (Singapore: Buddha Tooth Relic Temple, 2010), 214-223; and Shi Fa Zhao, Buddha Tooth Relic Temple and Museum (Singapore: Buddha Tooth Relic Temple, 2006), 14-15. This was the temple's first publication showing the stages of construction in detail and making note of the origins of the materials and the artisans who were commissioned. I thank Ee Tiang Hwee for providing me with a copy. From Dawn to Dusk is a coffee-table book that describes the embroidery, sculpture, woodwork, architecture, and different sections of the temple and museum. The attention is clearly placed on the material of the temple, its rarity and craftsmanship. Shi Fa Zhao also founded the Metta Welfare Association in 1992. See http:// www.metta.org.sg/main/. 
16 I thank Michael Feener for taking me to the templeand museum for the first time after it opened in 2007.

17 For more information see Shi Fa Zhao's (in cooperation with David Tay and others) two-volume Perspective: Buddha Tooth Relic Temple and Museum through the Eyes of the People: Architecture and Artefacts (vol. 1), and Pulse: Buddha Tooth Relic and Museum: Peopleand Prayer (Singapore: Buddha Tooth Relic Temple, 2008).

18 Although much of Singapore's Chinese population is originally from this region, they largely speak Mandarin now. The Singapore government started a Mandarin education campaign in 1979, and today regionally Chinese language differences are less pronounced. See Wendy Bokhorst-Heng, "Singapore's Speak Mandarin Campaign: Language Ideological Debates and the Imagining of the Nation," in Language Ideological Debates, ed. J an Blommaert (Berlin: Walter de Gruyter, 1999), 235- 265; and Saravanan Gopinathan, ed., Language Society and Education in Singapore (Singapore: Marshall Cavendish Academic, 1998). Jack Meng-Tat Chia shared these references with me.

19 This is also one of the reasons, Ee Tiang Hwee stated, that the female Kuan Yin is not displayed at the temple and that only the Tang-era male Avalokiteśvara is featured. Shi Fa Zhao believes that the female "incarnation" of Avalokiteśvara only appeared after the Tang dynasty. For a more detailed history of this development, see Chün-fang Yü's Kuan-yin: The Chinese Transformation of Avalokiteśvara (New York: Columbia University Press, 2000).

20 Many of the architectural elements in Nara and Heian J apanese architecture have influence not only from indigenous sources, but also from Baekje architecture of Korea. This is not mentioned in Shi Fa Zhao's comments on the design, though, and only Tang is emphasized. The exterior of the temple was designed by Shi Fa Zhao in consultation with the Beijing architectural firm Landscape Architecture Corporation of China, in consultation with the Singapore architectural firm Yi Architects. The exterior woodwork was done by Yue Feng Construction Company, which used Balao trees from Borneo. The entire design is based on an amalgamation of features from various Tang-period temples in Nara and Kyoto. For more information, see also http:// www.btrts.org.sg/ history -of-temple-design.

21 They were excited that I knew an artist in Thailand who made wax and resin images of monks and asked for my help contacting him. Since that time, new resin images have been installed in the mezzanine section of the museum, including ones of Jing Xin, Yuan Zong, and Shi Fa Zhao himself, which I saw in March 2015. There is also a more prominent display in the "dharma hall" of the "Compassionate South Seas Freedom Bodhisattva Avalokitesvara."

22 This is an old practice found in many Buddhist cultures. For an interesting textual source in Pali, see the story of Viriyapaṇitita, in which, because his family does not have any more jewelry to donate in order to create a golden Buddha image, the protagonist, Viriyapaṇitita, slices off his own skin and donates it for covering the image. Padmanabh Jaini, ed. Paññāsa-Jātaka (in the Burmese Recension), vol. 1 (Jātakas 1- 25) (London: Pali Text Society, Text Series No. 172-173, 1981): Viriyapanditita is story no. 25.

23 A good source for Shi Fa Zhao's writings and the types of daily health, social, and spiritual advice promoted by the Buddha Tooth Relic Temple and Museum is the Nagapuspa Magazine (subtitled An Abundance of Contented Lifestyle), published about five times a year in both English and Chinese. Possessing the same name as the museum, the glossy magazine offers stories like "Wellness from Listening," about the healing benefits of music, the spirituality of tea drinking, and the true meaning of Chinese New Year. Many of these articles are written by Shi Fa Zhao and others are by psychologists, physicians, monks, and social 
commentators in Singapore. The magazine also contains advertisements for art exhibitions, jewelry stores, and other cultural events and commercial venues in Singapore.

24 Thanks to a little more research and help from J ack Meng-tat Chia, I discovered that Shi Fa Zhao received his ordination from Venerable Miao Hua (http:// www .btrts.org.sg/venerable-miao-hua), who was the supervisor of Leong San monastery in Singapore from 1979 to 1992. Subsequently, Shi Fa Zhao received his higher ordination at Cuibiyan (literally Green Cliff and Rock) monastery in Taiwan, http:// www.goldenpagoda.org.sg/ -goldenpa/goldenpagoda/index.php ?page $=26$.

25 Shi Fa Zhao, The Pursuit of True Happiness and Other Life Observations (Singapore: International Press Softcom, 2007), 15, 138.

26 Ibid., 20.

27 Ibid., 148, 164.

28 Ibid., 92, 82, 190, 108.

29 Shi Fa Zhao et al., Perspective, 6.

30 Perspective: Buddha Tooth Relic Temple and Museum through the Eyes of the People: Architecture and Artefacts (vol. 1), and Pulse: Buddha Tooth Relic and Museum: People and Prayer (Singapore: Buddha Tooth Relic Temple, 2008).

31 The monks that assist Shi Fa Zhao and perform rituals at the Buddha Tooth Relic Temple and Museum were mostly trained in Taiwan at various institutions including Yuan Kuang Buddhist College, Fo Guang University College of Buddhist Studies, Fu Yan Buddhist Institute, Luminary Buddhist Institute, Dharma Drum Sangha University, Hsuan Chuang University, and Ching Chueh Buddhist Shanga University.

32 The virtual 3-D online tour of the temple and museum is still under construction and can be seen, partly, online now at http:// www.btrts.org.sg/ virtualtemple /index.html.

33 A clear exception to this is the Jacques Marchais Museum of Tibetan Art on Staten Island in New York City. It claims to be the first example of Himalayan architecture in North America and the first museum in North America dedicated to Tibetan Buddhist art. See http:// www.tibetanmuseum.org/. I thank Celeste Gagnon for recommending my visit to the Marchais Museum.

34 Louis Gabaude, "A New Phenomenon in Thai Monasteries: The Stūpa Museum," in The Buddhist Monastery: A Cross-Cultural Survey, ed. Pierre Pichard and François Lagirarde (Paris: École Française d’Extrême-Orient, 2003), 169.

35 Paritta Chalermpow Koanantakool, "Contextualizing Objects in Monastery Museums in Thailand," in Buddhist Legacies in Mainland Southeast Asia, ed. François Lagirarde and Paritta Chalermpow Koanantakool (Bangkok: Princess Maha Chakri Sirindhorn Anthropology Centre/ École Française d'ExtrêmeOrient, 2006), 149- 167.

36 Anake Nawigamune, Nana phiphithaphan (Bangkok: Saeng Daet Phuan Dek, 2549 [2006]); and Anake Nawigamune, Sombat Muang Songkhla (Bangkok: Filasatai, 2550 [2007]).

37 I thank Christine McDaniel for conversations and advice about this issue.

38 I thank Toshiya Unebe for guiding me to see work by Chūta Itō in Nagoya (especially in the cemetery of the Thai-J apanese Buddhist Temple [Nittaiji] and for recommending others. See also Richard J affe's study of Itō and other J apanese Buddhist artistic connections between South and Southeast Asia in Richard M. J affe, 'Buddhist Material Culture, Indianism,' and the Construction of Pan-Asian Buddhism in Pre-War Japan," Material Religion 21, no. 3 (2006): 266-292; and Richard M. Jaffe, "Seeking Shakyamuni: Travel and the Reconstruction of J apanese Buddhism," J ournal of Japanese Studies 30, no. 1(2004): 65- 96.

http:// www.sanae-quilt.com. 
40 Takamatsu also designed a third building on the grounds of a monastery in 1982. However, unlike the museum and reception hall at the Higashi Hongan-ji and the Star Peak assembly and activity center, Takamatsu's first monastic project actually involved rebuilding the central worship hall of a monastery, not a public building. Located in Gihu (Central Japan), the Saifuku-ji monastery's main worship hall was dilapidated, and the abbot requested Takamatsu's assistance in rebuilding it. He wanted a fireproof structure that would accommodate a number of worshippers. Takamatsu's radical solution involved building a large concrete bunker with a stark interior with little ornamentation besides the Buddha image. See his work at http:// www.takamatsu.co.jp/jp/index.html.

41 I thank several tour guides for assisting me and especially Ray Yamamoto, a J apanese Shin priest from Honolulu, for his excellent descriptions of the monastery. I also thank Shigeki Saito for his very kind help when I visited. His stories, guidance, and recommendations were all very helpful. I thank Miki Morita for introducing us.

42 http://nspacedesign.co.jp/project_en?item=1492. Although I won't go into detail, in my interviews I learned that the curators, the directors of the museum, and the architect did not always see eye to eye in the design phase. The architect also had to deal with very strict Kyoto building codes that are further complicated by the fact that the museum is directly across from a UNESCO World Heritage site. I thank Takashi Irisawa for explaining these issues to me. See also http:// www.nikken.co.jp/en/projects/cultural/museum-auarium/ryukoku-museum -at-ryukoku-univerisity.html.

43 Although the collection is relatively weak when it comes to Southeast Asian art, it is impressive, and I am confident that that region will be better represented soon.

44 http://japanvisitor.blogspot.com/2012/09/ryukoku-museum-kyoto.html, and http:// museum.ryukoku.ac.jp/en/message/index.html. This exhibition has now been replaced with a smaller show on the history of a small Shingon temple near Osaka and its private collection (ed. Dezain Ohmukai Tsutomu, Sakamoto Yoshiko, Ichikawa Mariko) called Treasures of Tada-ji Temple in Wakasa (Japanese: Wakasa Tadaji no Meihou) (Kyoto: Ryukoku Daigaku, 2013). A larger catalog of the museum's collections, while not comprehensive, is a good introduction-Bukkyo no Kita Michi: Silku Road Tannken no Tabi (Kyoto: Ryukoku Daigaku, 2012). The museum is placing images of much of their collection online. The exhibition in 2013 was a retrospective of the painter Ikuo Hiyayama and a display of his personal collection of Silk Road art. Shunpei Iwai, an expert in Silk Road art history, curated this show. The director of the entire museum, Akira Miyaji, is also an expert on this region and specifically the art of Gandharan Buddhism. Herecently published Collected Essays on theArt of Gandhar $\bar{a}$ and Bāmiyān (Kyoto: Ryukoku University Press, 2012). Some pieces from the Kōzui Ōtani collection are also on display. Ōtani was a leader of Shin Buddhism and dispatched three expeditions across Asia between 1902 and 1914.

45 The Higashi Hongan-ji is not mentioned, just the Nishi.

46 Richard Jaffe, Fabio Rambelli, and many others have been conducting research on the J apanese fascination with and imaginary construction of the Indic origins and history of Buddhism. See Richard M. J affe, "Seeking Shakyamuni." I thank Fabio Rambelli for conversations about this at the University of Heidelberg in the summer of 2012.

47 This is from a letter in J apanese and English in the museum's brochure See this also online at http:// museum.ryukoku.ac.jp/en/message/index.html.

48 Ibid. See also http:// museum.ryukoku.ac.jp/en/exhibition/concept.html.

49 I thank Masami Tahara for helping me translate photograph captions that hang on the wall in the monastery and trace its recent history. 
50 Toshiya Unebe assisted me at Tōgan-ji and helped me in interviewing the abbot. Dr. Unebe noted that the abbot was very reluctant to answer direct questions about the origins of the South Asian pieces of art and the relic.

51 I thank Lori Meeks, Hank Glassman, and Miki Morita especially for their assistance understanding this inscription. For more information on the way certain phallic, boundary, and "safe birth" stones, perhaps connected to the following of Jizō, were used in Japan, see Glassman's The Face of Jizō: Image and Cult in Medieval J apanese Buddhism (University of Hawai'i Press, 2012), chapter 4.

52 I thank Miki Morita for helping me find these sites, which I found, because of their colloquial language, very difficult to translate. For some of the tamer examples, see http://ja.wikipedia.org/ wiki/\%E6\%A1\%83\%E5\%B7\%8C\%E5\%AF\%BA, http:// b-spot.seesaa.net/article/98095190.html, http://ameblo.jp/okimuk3 /entry-11253888906.html, and http://4travel.jp/domestic/area/toukai/aichi / nagoya/imaike/ travelogue/ 10389983/.

53 See Michel Foucault's The Order of Things, trans. Anon. (London: Routledge, 1970), and "Different Spaces," in Aesthetics, Method, and Epistemology: Essential Works, vol. 2, ed. J. Faubion (London: Allen Lane, 1998), 175- 185.

54 Douglas Crimp, "On the Museum's Ruins," in The Anti-Aesthetic, ed. H. Foster (Port Townsend, WA: Bay Press, 1983), 43- 56; Eilean Hooper-Greenhill, Museums and the Shaping of Knowledge (London: Routledge, 1992); Craig Cunlas, "Oriental Antiquities/ Far Eastern Art," in Formations of Colonial Modernity in East Asia, ed. Tani Barlow (Durham, NC: Duke University Press, 1997), 413446; Ruth Phillips, Trading Identities: The Souvenir in Native North American Art from the Northeast (Seattle: University of Washington Press, 1998), 49- 71. More broadly, see the work of Crispin Paine on the rise of museums and how they have changed the way religious art is seen, especially Religious Objects in Museums: Private Lives and Public Duties (London: Bloomsbury, 2013), and Godly Things: Museums, Objects \& Religion (London: Leicester University Press, 2000). The journal Material Religion had a special issue dedicated to religion and museums (8.1 [March 2012]).

55 Svetlana Alpers, "The Museum as a Way of Seeing," in Exhibiting Cultures: The Poetics and Politics of Museum Display, ed. Steven Lavine (Washington, DC: Smithsonian, 1991), 25- 32.

56 Diana Eck, "Excerpts from Darshan," in Religion, Art, and Visual Culture, ed. S. Brent Plate (New York: Palgrave, 2002), 167; Richard Davis, "From the Lives of Indian Images," in Religion, Art, and Visual Culture, ed. S. Brent Plate (New York: Palgrave, 2002), 180.

57 Stanley Abe, "Inside the Wonder House: Buddhist Art and the West," in Curators of the Buddha, ed. Donald LopezJr. (Chicago: University of Chicago Press, 1995), 63-106; Maurizio Peleggi, Thailand: The Worldly Kingdom (London: Reaktion Books, 2007), 154- 161.

58 Peleggi, Thailand, 156.

\section{CONCLUSIONS AND COMPARISONS}

1 The private family company now earns over 250 million US dollars per year. See J effrey Rothfeder, McIlhenny's Gold (NewYork: HarperCollins, 2007), 6. I thank Cliff Cosgrove for first informing me about this image.

2 Ibid., 5.

3 This company "village" was started in the 1880s by Edmund McIlhenny and his wife Mary Eliza Avery. It came to be a model for other company towns throughout the United States. 
4 Shane Bernard was extremely helpful in my research. I was surprised when I learned from him that there have been no protests by local Christian communities about the presence of the Buddha image in the center of the island. He said there has been only one complaint by one Christian worker about the statue. It was not a strong complaint, and the worker did not quit or attempt to damage the image.

5 Bernard also sent me a photograph of the warehouse packing label that was included with the statue when it arrived from New York. It simply states, "The Manhattan Storage and Warehouse Company, 52nd and Seventh Streets, New York, NY." No date or other documentation is available. He has had three different art historians examine the statue. One stated that it could be over nine hundred years old, and two others (anonymous) stated that it was most likely two hundred to three hundred years old. The family used to keep the statue's glass shrine doors unlocked, but a piece of the statue's ear was stolen once, and so now it is locked and opened upon request. Bernard sent me many photographs of the statue in the 1940s, and the gardens have changed very little since then. Ned enjoyed having his photograph taken in front of the image.

6 See Rothfeder, McIlhenny's Gold, 7, 141-143. Ned McIlhenny was not the first in his family to collect Asian antiquities and plants. J ohn Avery McIlhenny, Ned's father, collected J apanese netsuke figurines in the late nineteenth century.

7 This was confirmed to me when I visited the local Lao Buddhist temple (Wat Thammarattaram) about a twenty-minute drive from the island. I interviewed the abbot and several devotees (Opma Kamini, Laem Chantawongsi, Son Payara, Sangwan Sayasing, and Buapan Homluangpaxan) in Lao. The abbot, Bolian Sanatnigon (monk's name: Phra Suwanno), was excited to tell me about the Lao community's respect for the Avery Island image. However, since their own temple was finished in 2008, they have their own Lao Buddha images to honor now and do not visit Avery Island as frequently.

8 His views on comparison have been a subject of inspiration and debate for over thirty years and are discussed in numerous publications. Two places that provide an accessible overview are in J onathan Z. Smith, "A Matter of Class: Taxonomies of Religion," in his Relating Religion (Chicago: University of Chicago Press, 2004), 160-178, and his "In Comparison a Magic Dwells," in Imagining Religion (Chicago: University of Chicago Press, 1982), 19- 35. Kimberley Patton and Benjamin Ray (eds.) provide an overview of the impact of Smith's work on comparison and new approaches to comparative religion in A Magic Still Dwells (Berkeley: University of California Press, 2000).

9 Ulrich Timme Kragh, "Of Similes and Metaphors in Buddhist Philosophical Literature: Poetic Semblance through Mythic Allusion," Bulletin of the School of Oriental and African Studies 73, no. 3 (2010): 479- 502, esp. 481.

10 Ibid., 481.

11 Ibid., 482.

12 See, for example, Alfred Gell, Art and Agency: An Anthropological Theory (Oxford: Clarendon, 1998), 1- 27; J eremy Tanner, "Portraits and Agency: A Comparative View," in Art's Agency and Art History, ed. Robin Osbourne and J eremy Tanner (Oxford: Blackwell Press, 2007), 70- 94.

13 J ohn Bowen and Roger Petersen, "Introduction: Critical Comparisons," in their Critical Comparisons in Politics and Culture (Cambridge: Cambridge University Press, 1999), 3-4.

14 Alicia Turner, Saving Buddhism: The Impermanence of Religion in Colonial Burma (Honolulu: University of Hawai'i Press, 2014); Anne Hansen, How to Behave: Buddhism and Modernity in Colonial Cambodia, 1860- 1930 (Honolulu: University of Hawai'i Press, 2007); Erik Braun, The Birth of Insight (Chicago: University of Chicago Press, 2013); Craig Reynolds, The Buddhist Monkhood in 
Nineteenth Century Thailand (PhD diss., Ann Arbor, University Microforms International, 1973).

15 Sharon Zukin, Landscapes of Power: From Detroit to Disney World (Berkeley: University of California Press, 1991), 27-31.

16 For more information see Koji Yukiyama, Secrets of Creation: The Prints of Kiyoshi Hasegawa (Yokohama: Yokohama Museum of Art, 2006), 86. 



\section{Bibliography}

Note: As thereare different conventions in Burmese, Chinese, English, French, German, Italian, Japanese, Lao, Nepali, Portuguese, Thai, and Vietnamese for how to list publications according to the first and family names, I have decided to consistently list the authors in the English alphabetical order of their family names.

Abe, Stanley. "Inside the Wonder House: Buddhist Art and the West." In Curators of the Buddha: The Study of Buddhism under Colonialism, edited by Donald S. Lopez Jr., 63- 106. Chicago: University of Chicago Press, 1995.

Adams, Parveen. "Out of Sight, Out of Body: The Sugimoto/ Demand Effect." Grey Room 22 (Winter 2006): 86- 103.

Ajahn Sucitto and Nick Scott. Rude Awakenings: Two Englishmen on Foot in Buddhism's Holy Land. Boston: Wisdom Publications, 2005.

Allen, Charles. The Search for the Buddha: The Men Who Discovered India's Lost Religion. New York: Carroll \& Graf, 2002.

—. The Buddha and Dr Fuhrer: An Archaeological Scandal. London: Haus Publishing, 2011.

Almond, Philip. The British Discovery of Buddhism. Cambridge: Cambridge University Press, 2007.

Alpers, Svetlana. "The Museum as a Way of Seeing." In Exhibiting Cultures: The Poetics and Politics of Museum Display, edited by Steven D. Lavine, 25- 32. Washington, DC: Smithsonian Institution, 1991.

Amrit Chusuwan. Khwam tuk (Suffering). Bangkok: DOB Hualamphong Gallery, 2553 [2010].

Anake Nawigamune. Nana phiphithaphan. Bangkok: Saeng Daet Phuan Dek, 2549 [2006].

—. Sombat Muang Songkhla. Bangkok: Filasatai, 2550 [2007].

Anderson, Benedict. The Fate of Rural Hell: Asceticism and Desire in Buddhist Thailand. Calcutta: Seagull Books, 2012.

Anupong Chantorn. Hope in the Dark. Bangkok: Amarin Printing, 2010.

Apinan Poshyananda. Montien Boonma: Temple of the Mind. New York: The Asia Society, 2003.

—. Modern Art in Thailand: Nineteenth and Twentieth Centuries. Oxford: Oxford University Press, 1992.

Arendt, Hannah, ed. "The Work of Art in the Age of Mechanical Reproduction." In Walter Benjamin: Illuminations. London: Fontana, 1968 [1935]: 217- 252.

Baan Lae Suan. Young Female Artists of the Year. Curated by Thavorn Ko-udomvit. Bangkok: Amarin Printing, 2009.

Bakhtin, Mikhail. Rabelais and His World. Translated by Hélène Iswolsky. Cambridge, MA: MIT Press, 1968; reprint, Bloomington: Indiana University Press, 1984. 
Baudelaire, Charles. "On the Essence of Laughter." In Charles Baudelaire: The Painter of Modern Life and Other Essays, translated and edited by J onathan Mayne, 147- 165. London: Phaidon, 1964.

Becchetti, Catherine. Le mystere dans les lettres. Bangkok: Éditions des Cahiers de France, 1991.

Bharne, Vinayak. "Manifesting Democracy: Public Space and the Search for Identity in Post-War J apan." J ournal of Architectural Education 63, no. 2 (2010): 38- 50.

Bidari, Basanta. Lumbini: A Haven of Sacred Refuge. Kathmandu: Hill Side Press 2002. Blosker, Bianca. Original Copies: Architectural Mimicry in Contemporary China. Honolulu: University of Hawai'i Press, 2013.

Bokhorst-Heng, Wendy. “Singapore's Speak Mandarin Campaign: Language Ideological Debates and the Imagining of the Nation." In Language Ideological Debates, edited by Jan Blommaert, 235- 265. Berlin: Walter de Gruyter, 1999.

Bowen, J ohn, and Roger Petersen, eds. Critical Comparisons in Politics and Culture. Cambridge: Cambridge University Press, 1999.

Braun, Erik. The Birth of Insight. Chicago: University of Chicago Press, 2013.

Brouwer, Daniel, and Robert Asen, eds. Public Modalities: Rhetoric, Culture, Media, and the Shape of Public Life. Tuscaloosa: University of Alabama Press, 2010.

Brown, S. L., and K. M. Eisenhardt. "TheArt of Continuous Change: Linking Complexity Theory and Time-Paced Evolution in Relentlessly Shifting Organizations." Administrative Science Quarterly 42 (1997): 1- 34.

Bukkyo no Kita Michi: Silku Road Tannken no Tabi. Kyoto: Ryukoku Daigaku, 2012.

Bunchai Bencharongkul. Phipihithaphan Silapa Thai Ruam Samai. Bangkok: Borisat Phipihithaphan Silapa Thai Chamgat, 2555 [2012].

Calvino, Italo. If on a Winter's Night a Traveler. Translated by William Weaver. New York: Alfred Knopf, 1993 [1979].

Cate, Sandra. Making Merit, Making Art: A Thai Temple in Wimbledon. Honolulu: University of Hawai'i Press, 2003.

Çelik, Zeynep. "Le Corbusier, Orientalism, Colonialism." Assemblage 17 (1992): 58- 77.

Chia, Jack Meng-Tat. "Buddhism in Singapore: A State of the Field Review." Asian Culture 33 (June 2009): 81- 93.

—. "Teaching Dharma, Grooming Sangha: The Buddhist College of Singapore." Sojourn: J ournal of Social Issues in Southeast Asia 24, no. 1 (April 2009): 122- 138.

Chua, Lawrence. Building Siam: Leisure, Race, and Nationalism in Modern Thai Architecture, 1910-1973. PhD diss., Cornell University, 2012.

Clark, John. Asian Modernities: Chinese and Thai Art Compared, 1980 to 1999. Sydney: Power Publications, 2010.

"Copy of the King's Initiative to Construct the Reclining Buddha in Wat Phra Chetuphon." In Brachum chareuk wat phra chetuphon. Bangkok: Wat Phra Chetuphon Clergy, 2554 [2011].

Covell, Stephen G. Japanese Temple Buddhism: Worldliness in a Religion of Renunciation. Honolulu: University of Hawai'i Press, 2005.

Crimp, Douglas. "On the Museum's Ruins.” In TheAnti-Aesthetic: Essays on Postmodern Culture, edited by Hal Foster, 43- 64. Port Townsend, WA: Bay Press, 1983.

Crossley, Nick, and J ohn Michael Roberts, eds. After Habermas: New Perspectives on the Public Sphere. Oxford: Blackwell, 2004.

Csordas, Thomas J., ed. Transnational Transcendence: Essays on Religion and Globalization. Berkeley: University of California Press, 2009.

Cunlas, Craig. "Oriental Antiquities/Far Eastern Art." In Formations of Colonial Modernity in East Asia, edited by Tani E. Barlow, 413-446. Durham, NC: Duke University Press, 1997.

Curtis, William. Le Corbusier et leJ apon. Paris: Picard, 2007.

Dal Co, Francesco. Tadao Ando: Complete Works (1975- 1995). NewYork: Phaidon, 1997. 
Davis, Erik. "Review of J ustin McDaniel's The Lovelorn Ghost and the Magical Monk." J ournal of Asian Studies 71, no. 2 (2012): 585- 588.

Davis, Richard. "From the Lives of Indian Images." In Religion, Art, and Visual Culture, edited by S. Brent Plate, 176- 181. New York: Palgrave, 2002.

Debord, Guy. The Society of the Spectacle. Translated by Fredy Perlman and friends. Detroit: Black and Red, 1971.

De Certeau, Michel. The Practice of Everyday Life. Translated by Steven Rendall. Berkeley: University of California Press, 1984.

Dezain Ohmukai Tsutomu, Sakamoto Yoshiko, Ichikawa Mariko, eds. Treasures of Tada-ji Temple in Wakasa (Japanese: Wakasa Tadaji no Meihou). Kyoto: Ryukoku Daigaku, 2013.

Drew, Philip. Church on the Water, Church of the Light: Tadao Ando. Singapore: Phaidon, 1996.

Eck, Diana. "Excerpts from Darshan." In Religion, Art, and Visual Culture, edited by S. Brent Plate, 171- 175. New York: Palgrave, 2002.

Elleh, Nnamdi. Abuja: The Single Most Ambitious Urban Design Project of the 20th Century. Vol. 5, Architektur der Welt. Weimar: VDG, Verlag und Datenbank für Geisteswissenschaften, 2001.

Emirbayer, Mustafa, and Mimi Sheller. "Publics in History." Theory and Society 27, no. 6 (1998): 727- 779.

Eubanks, Charlotte. Miracles of Book and Body: Buddhist Textual Culture and Medieval J apan. Berkeley: University of California Press, 2011.

Falcone, J essica. Waiting for Maitreya: Of Gifting Statues, Hopeful Presents, and the Future Tense in FPMT's Transnational Tibetan Buddhism. PhD diss., Cornell University, 2010.

Fernandez, James W., ed. Beyond Metaphor: The Theory of Tropes in Anthropology. Stanford, CA: Stanford University Press, 1991.

Foster, Michael Dylan. Pandemonium and Parade: Japanese Monsters and the Culture of Yokai. Berkeley: University of California Press, 2008.

Foucault, Michel. The Order of Things. Translated by Anonymous. London: Routledge, 1970.

—_. "Different Spaces." In Aesthetics, Method, and Epistemology, Essential Works of Foucault, 1954- 1984. Vol. 2, edited by James Faubion, 175- 186. London: Allen Lane, 1998.

Fraser, Nancy. "Politics, Culture, and the Public Sphere: Toward a Postmodern Conception." In Social Postmodernism: Beyond Identity Politics, edited by Linda Nicholson and Steven Seidman, 287-314. Cambridge: Cambridge University Press, 1995.

Furuyama, Masao. Ando. New York: Taschen, 2006.

Futagawa, Yukio, ed. Tadao Ando: Recent Project. Tokyo: A.D.A. Edita, 2009.

Gabaude, Louis. "A New Phenomenon in Thai Monasteries: The Stūpa Museum." In The Buddhist Monastery: A Cross-Cultural Survey, edited by Pierre Pichard and François Lagirarde, 169- 186. Paris: École Française d’Extrême-Orient, 2003.

Geary, David. Destination Enlightenment: Branding Buddhism and Spiritual Tourism in Bodh Gaya, Bihar. Anthropology Today 24, no. 3 (2008): 11- 14.

"Destination Enlightenment: Buddhism and the Global Bazaar in Bodh Gaya, Bihar." PhD diss., University of British Columbia, 2009.

Gell, Alfred. Art and Agency: An Anthropological Theory. Oxford: Clarendon, 1998.

Giedion, Sigfried. Walter Gropius: Work and Teamwork. New York: Reinhold Publishers, 1954.

Giri, Gitu. Sacred Complex of Lumbini. New Delhi: Adroit Publishers, 2008.

—. Lumbini Tourism. New Delhi: Adroit Publishers, 2014.

Glassman, Hank. The Face of Jizō: Image and Cult in Medieval J apanese Buddhism. Honolulu: University of Hawai'i Press, 2012. 
Goldberg, Kory. Buddhists without Borders: Transnational Pilgrimage, Social Engagement, and Universal Education in the Land of Enlightenment. $\mathrm{PhD}$ diss. (forthcoming), Université du Québec à Montréal.

Gombrich, E. H. “A Note Further to the Drawing of Bicycles.” Perception 28 (1999): 801. Gopinathan, Saravanan, ed. Language Society and Education in Singapore. Singapore: Marshall Cavendish Academic, 1998.

Graham, Patricia Jane. Faith and Power in Japanese Buddhist Art, 1600-2005. Honolulu: University of Hawai'i Press, 2007.

Gropius, Walter. “Architecture in J apan." Perspecta 3 (1955): 8- 21.

- The New Architecture and the Bauhaus. Translated by P. Morton Shand. Cambridge, MA: MIT Press, 1965.

Habermas, J ürgen. The Structural Transformation of the Public Sphere: An Inquiry into a Category of Bourgeois Society. Translated by Thomas Burger, with the assistance of Frederick Lawrence. Cambridge, MA: MIT Press, 1991 [1962].

Halley, J ean. The Affective Turn: Theorizing the Social. Durham, NC: Duke University Press, 2007.

Hansen, Anne. How to Behave: Buddhism and Modernity in Colonial Cambodia, 1860 - 1930. Honolulu: University of Hawai'i Press, 2007.

Hansen, Miriam. Babel and Babylon: Spectatorship in American Silent Film. Cambridge, MA: Harvard University Press, 1991.

Harris, Clare E. The Museum on the Roof of the World: Art, Politics, and the Representation of Tibet. Chicago: University of Chicago Press, 2012.

Harris, Ian, ed. Buddhism, Power, and Political Order. London: Routledge, 2007.

Hay, J onathan. Sensuous Surfaces: The Decorative Object in Early Modern China. Honolulu: University of Hawai'i Press, 2010.

Henley, Simon. The Architecture of Parking. London: Thames and Hudson, 2009.

Henricks, Thomas S. Play Reconsidered: Sociological Perspectives on Human Expression. Urbana: University of Illinois Press, 2006.

Higashiyama, Kaii. Kaii Higashiyama [autobiography and major works in J apanese]. Tokyo: Nikkei, 1991.

Hirschkind, Charles. The Ethical Soundscape: Cassette Sermons and Islamic Counterpublics. New York: Columbia University Press, 2009.

His Majesty's Government. The Lumbini Development Committee Report. Kathmandu: Babar Mahal, 1980.

Hoisington, Sona Stephan. "Ever Higher: The Evolution of the Project for the Palace of Soviets." Slavic Review 62, no. 1(2003): 41- 68.

Hooper-Greenhill, Eilean. Museums and the Shaping of Knowledge. London: Routledge, 1992.

Hoskin, John, and Saroj Kuphachaka. Ten Contemporary Thai Artists. Bangkok: Graphis, 1984.

Hubbard, Jamie. The Yamaguchi Story: Buddhism and the Family in Contemporary Japan. DVD. BBC/ Education Communication International, 2009 [1988].

Huber, Toni. Holy Land Reborn: Pilgrimage and the Tibetan Reinvention of Buddhist India. Chicago: Chicago University Press, 2008.

Hugo, Victor. "Preface to Cromwell." In Prefaces and Prologues to Famous Books, edited by Charles W. Eliot, 354- 408. New York: P. F. Collier \& Sons Co., 1910.

Huizinga, Johan. Homo Ludens: A Study of the Play-Element in Culture. Boston: Beacon Press, 1955.

Jacknis, Ira. The Stewart Culin Papers, the Brooklyn Museum. Archives, Brooklyn Museum of Art, Brooklyn, NY, 1985.

Jaffe, Richard M. Neither Monk Nor Layman: Clerical Marriage in Modern Japanese Buddhism. Princeton, NJ : Princeton University Press, 2002. "Seeking Shakyamuni: Travel and the Reconstruction of J apanese Buddhism." J ournal of J apanese Studies 30, no. 1 (2004): 65- 96. 
—_. 'Buddhist Material Culture, 'Indianism,' and the Construction of Pan-Asian Buddhism in Pre-War Japan." Material Religion 21, no. 3 (2006): 266- 292.

Jaini, Padmanabh S., ed. Paññāsa-Jātaka: or Zimme paṇnāsa (in the Burmese Recension). Vol. 1 (Jātakas 1-25). London: Pali Text Society, Text Series No. 172-173, 1981.

J ay, Martin. “That Visual Turn.” J ournal of Visual Culture 1, no. 1(2002): 87- 92.

J odidio, Philip. Ando. New York: Taschen, 2004.

- Tadao Ando at Naoshima: Art, Architecture, Nature. New York: Rizzoli, 2006.

. Public Architecture Now! New York: Taschen, 2010.

J ordt, Ingrid. Burma's Mass Lay Meditation Movement: Buddhism and the Cultural Construction of Power. Athens: Ohio University Press, 2007.

Kansadaeng silpakam haeng chat krang thi 53. Bangkok: Silapakorn University Art Centre, 2550 [2007].

Karlsson, Klemens. "Material Religion and Ethnic Identity: Buddhist Visual Culture and the Burmanization of the Eastern Shan State." In The Spirit of Things: Materiality and Religious Diversity in Southeast Asia, edited by Julius Bautista, 61- 78. Ithaca, NY: Cornell Southeast Asia Program Publications, 2012.

Kawanami, Hiroko, and Geoffrey Samuel, eds. Buddhism, International Relief Work, and Civil Society. London: Palgrave Macmillan, 2013.

Kayser, Wolfgang J. The Grotesque in Art and Literature. Translated by Ulrich Weisstein. Bloomington: Indiana University Press, 1963.

Kim, Sooja, Tae Hyunsun, and Ra Hee Hong Lee. Kim Sooja: A Needle Woman. Seoul: Rodin Gallery, 2000.

Khanakammakan fai bhrachasamphan lae phoipae khrong kan jat sang phra phutthamettabhrachathaitrailokanatha khanthanratha-anuson nai phra baromrachinubhatham [Committee for the Construction of the Promotion of the Monument of Buddha of Compassion... ] Phra phutthamettabhrachathaitrailokanatha phutthamettabhrachathaitrailokanatha khanthanratha-anuson. Bangkok: Amarin Printing and Publishing, 2558 [2015].

Kositpipat, Chalermchai. Wat Rongkhun (n.d.).

—. Roi ruang rao khong Wat Rongkhun (DVD). Chiang Rai: Wat Rongkhun, no date.

Kragh, Ulrich Timme. "Of Similes and Metaphors in Buddhist Philosophical Literature: Poetic Semblance through Mythic Allusion." Bulletin of the School of Oriental and African Studies 73, no. 3 (2010): 479- 502.

Kuah-Pearce, Khun Eng. State, Society and Religious Engineering: Towards a Reformist Buddhism in Singapore, 2nd ed. Singapore: Institute of Southeast Asian Studies, 2009.

Kwaak, Y. H., and Abelardo Brenes. The Fountain of World Peace-Report for theVision and Scoping Mission, Lumbini. Cambridge, MA: Harvard University, 2002.

Lal, CK. "Illusions of Grandeur: The Story of the Lumbini Master Plan." Contributions to Nepalese Studies 4, no. 2 (1999): 365- 381.

. "The Prince of Peace." Nepali Times 95, May 24, 2002.

Le Corbusier. Vers une architecture. Paris: Editions Flammarion, 2008 [1923]. English translation by J ohn Goodman. Towards an Architecture. Los Angeles: Getty Research Institute, 2007.

Leheny, David. The Rules of Play. Ithaca, NY: Cornell University Press, 2003.

Levine, Gregory. Daitokuji: The Visual Cultures of a Zen Monastery. Seattle: University of Washington Press, 2005.

Li, Michelle Osterfeld. Ambiguous Bodies: Reading the Grotesque in J apanese Setsuwa Tales. Stanford, CA: Stanford University Press, 2009.

Lumbini Development Project Report. Kathmandu: Lumbini Development Company, 1979.

Lumbini Development Trust. Message from UNSG. March 8, 1989.

Ly, Boreth. "Of Trans(national) Subjects and Translation: The Art and the Body Language of Sopheap Pich." In Modern and Contemporary Southeast Asian 
Art: An Anthology, edited by Nora A. Taylor, and Boreth Ly, 117-130. Ithaca, NY: Cornell University Press, 2012.

Mackenzie, Rory. New Buddhist Movements in Thailand: Towards an Understanding of Wat Phra Dhammākaya and Santi Asoke. London: Routledge, 2007.

Maffesoli, Michel. “Post-Modern Sociality.” Telos 85 (1990): 89- 92.

Mair, Heather, Susan M. Arai, and Donald G. Reid, eds. Decentering Work: Critical Perspectives on Leisure, Social Policy, and Human Development. Calgary: University of Calgary Press, 2010.

Maki, Fumihiko, Alexandra Munroe, and Arata Isozaki. New Public Architecture. Ann Arbor: University of Michigan Press, 1985.

Mannell, Roger C., and Douglas A. Kleiber. A Social Psychology of Leisure. State College, PA: Venture, 1997.

Marcus, Russell. Thawan Duchanee: Modern Buddhist Artist. Chiang Mai: Silkworm Books, 2013.

McDaniel, J ustin Thomas. The Lovelorn Ghost and the Magical Monk: Practicing Buddhism in Modern Thailand. New York: Columbia University Press, 2011.

__. "This Hindu Holy Man is a Thai Buddhist." Southeast Asia Research 21, no. 2 (2013): 191- 209.

Miller, Daniel, ed. Materiality. Durham, NC: Duke University Press, 2005.

Miller, Ian Jared. Foreword by Harriet Ritvo. The Nature of the Beasts: Empire and Exhibition at the Tokyo Imperial Zoo. Berkeley: University of California Press, 2013.

Miller, John H., and Scott E. Page. Complex Adaptive Systems: An Introduction to Computational Models of Social Life. Princeton, NJ: Princeton University Press, 2007.

Mishra, Tara Nanda. "Evolution of Buddhism and Archaeological Excavations in Lumbini." Ancient Nepal: Journal of the Department of Archaeology 155 (2004): 10- 18.

Mitra, Swati. Walking with the Buddha: Buddhist Pilgrimages in India. New Delhi: Eicher Goodearth, 1999.

Miyaji, Akira. Collected Essays on the Art of Gandharā and Bāmiyān. Kyoto: Ryukoku University Press, 2012.

Molesworth, Kate, and Ulrike Müller-Böker. "The Local Impact of Under-Realisation of the Lumbini Master Plan: A Field Report." Contributions to Nepalese Studies 32, no. 2 (2005): 183- 211.

Moore, Jerry, ed. Visions of Culture: An Annotated Reader. Lanham, MD: AltaMira Press, 2009.

Newell, Catherine. Monks, Meditation and Missing Links: Continuity, 'Orthodoxy' and the Vijjā Dhammakāya in Thai Buddhism. PhD diss., School of Oriental and African Studies, London, 2008.

No author. A Tourist Guide to Nepal. Delhi: Nepal Trading Corporation, 1959.

Ogawa, Morihiro, and Kaii Higashiyama. The Complete Prints of Higashiyama Kaii: A Catalogue Raisonne. Sydney: Radio House Art, 2000.

Oldenburg, Ray. The Great Good Place: Cafes, Coffee Shops, Community Centers, Beauty Parlors, General Stores, Bars, Hangouts, and How They Get You Through the Day. New York: Paragon House, 1989.

Ong, Y. D. Buddhism in Singapore: A Short Narrative History. Singapore: Skylark Publications, 2005.

Oshima, Ken Tadashi. International Architecture in Interwar Japan: Constructing Kokusai Kenchiku. Seattle: University of Washington Press, 2009.

Paine, Crispin. Godly Things: Museums, Objects \& Religion. London: Leicester University Press, 2000.

Religious Objects in Museums: Private Lives and Public Duties. London: Bloomsbury, 2013. 
Panya Vijinthanasarn and Andrew Stahl. Anywhere Anytime Anyhow. Bangkok: Amarin Printing, 2009.

Panya Vijinthanasarn, Thongchai Srisukprasert, and Anupong Chantorn. Buddha, Dharma, Ecclesiastic. Bangkok: Amarin Printing, 2012.

Paritta Chalermpow Koanantakool, "Contextualizing Objects in Monastery Museums in Thailand." In Buddhist Legacies in Mainland Southeast Asia, edited by François Lagirarde and Paritta Chalermpow Koanantakool, 149- 167. Bangkok: Princess Maha Chakri Sirindhorn Anthropology Centre/École Française d'Extrême-Orient, 2006.

Patton, Kimberley C., and Benjamin C. Ray, eds. A Magic Still Dwells: Comparative Religion in the Postmodern Age. Berkeley: University of California Press, 2000.

Pehnt, Wolfgang. “Gropius the Romantic.” Art Bulletin 53, no. 3 (1971): 379- 392.

Peleggi, Maurizio. Thailand: The Worldly Kingdom. London: Reaktion, 2007.

Per, Aurora Fernández, and J avier Arpa. The Public Chance: New Urban Landscapes. Madrid: a+t architecture publishers, 2008.

Petech, Luciano. Materials for the Study of Nepalese History and Culture: Medieval History of Nepal (c. 750-1480). Vol. 10 of Serie Orientale Roma, Materials for the Study of Nepalese History and Culture, Vol. 3. Rome: Istituto Italiano per il Medio ed Estremo Oriente, 1958.

Phatyos Buddhacharoen. Namo Buddhaya: A Path toward Divine Light. Bangkok: Amarin Printing, 2010.

Phatyot Phutthachaloen. Mindfulness. Bangkok: Amarin, 2003.

Phillips, Ruth. Trading Identities: The Souvenir in Native North American Art from the Northeast. Seattle: University of Washington Press, 1998.

Pike, Sarah. "Why Prince Charles Instead of 'Princess Mononoke'? The Absence of Children and Popular Culture in "The Encyclopedia of Religion and Nature.'” J ournal of the American Academy of Religion 77, no. 1(2009): 66- 72.

Plate, S. Brent, ed. Religion, Art, and Visual Culture: A Cross-Cultural Reader. New York: Palgrave, 2002.

Pudel, K. “Waiting for Visitors." Spotlight 19, no. 4 (2000): 19- 25.

Punyawi Iamsakun. Sati: Mahakamsilpakam wan silpa bhirasri. Bangkok: Silapakorn University Art Centre, 2552 [2009].

Rabinovitz, Lauren. Electric Dreamland: Amusement Parks, Movies, and American Modernity. New York: Columbia University Press, 2012.

Rea, Christopher, and Nicolai Volland, eds. The Business of Culture: Cultural Entrepreneurs in China and Southeast Asia, 1900- 60. Hong Kong: Hong Kong University Press, 2015.

Reader, Ian, and George J. Tanabe Jr. Practically Religious: Worldly Benefits and the Common Religion of Japan. Honolulu: University of Hawai'i Press, 1998.

Reynolds, Craig. The Buddhist Monkhood in Nineteenth Century Thailand. PhD diss., Ann Arbor, University Microforms International, 1973.

Rimer, J. Thomas. Since Meiji: Perspectives on theJ apanese Visual Arts, 1868- 2000. Honolulu: University of Hawai'i Press, 2012.

Rojek, Chris. Ways of Escape: Modern Transformations in Leisureand Travel. Boston: Rowman and Littlefield, 1993.

—. Decentering Leisure: Rethinking Leisure Theory. London: Sage, 1995.

—. Leisure and Culture. London: Macmillan Press, 2000.

Rojek, Chris, Susan M. Shaw, and Anthony J. Veal, eds. A Handbook of Leisure Studies. New York: Palgrave, 2006.

Rothfeder, J effrey. McIlhenny's Gold. New York: HarperCollins, 2007.

Rowe, Mark Michael. Bonds of the Dead: Temples, Burial, and the Transformation of Contemporary J apanese Buddhism. Chicago: University of Chicago Press, 2011.

Ruland-Thorne, Kate. Upon this Rock: Marguerite Brunswig Staude and Her Sedona Chapel. Sedona: Church of the Holy Cross, 2011. 
Ruskin, J ohn. "Grotesque Renaissance.” In The Stones of Venice, vol. 3 of The Fall. Sunnyside: George Allen, 1886; New York: Dover, 2005.

Rybczyński, Witold. Home: A Short History of an Idea. New York: Penguin, 1986.

Salzman, Michele Renee. On Roman Time: The Codex Calendar of 354 and the Rhythms of Urban Life in Late Antiquity. Berkeley: University of California Press, 1990.

Samuels, J effrey, Justin Thomas McDaniel, and Mark Rowe, eds. Figures of Buddhist Modernity in Asia. Honolulu: University of Hawai'i Press, 2016.

Sanasen, Uab. Ten Contemporary Thai Artists. Bangkok: Graphis, 1984.

Sand, J ordan. Tokyo Vernacular: Common Spaces, Local Histories, Found Objects. Berkeley: University of California Press, 2013.

Sasson, Vanessa R., ed. LittleBuddhas: Children and Childhoods in Buddhist Texts and Traditions. New York: Oxford University Press, 2012.

Schearer, Susan S., ed. and trans. Petrarch: On Religious Leisure. New York: Italica Press, 2002.

Sedgwick, Eve Kosofsky. Touching Feeling: Affect, Pedagogy, and Performativity. Durham, NC: Duke University Press, 2003.

Seigworth, Gregory J., and Melissa Gregg. "An Inventory of Shimmers." In The Affect Theory Reader, edited by Gregory J. Seigworth and Melissa Gregg, 1- 28. Durham, NC: Duke University Press, 2010.

Sen, Tansen. Buddhism, Diplomacy, and Trade: The Realignment of Sino-Indian Relations, 600-1400. Honolulu: University of Hawai'i Press, 2003.

Shi Fa Zhao. Buddha Tooth Relic Templeand Museum. Singapore: Buddha Tooth Relic Temple, 2006.

- The Pursuit of True Happiness and Other Life Observations. Singapore: International Press Softcom, 2007.

—. From Dawn to Dusk. Translated by Tan Yen Kee. Singapore: Buddha Tooth Relic Temple and Museum, 2010.

Shi Fa Zhao, David Tay, et al. Perspective: Buddha Tooth Relic Temple and Museum through the Eyes of the People: Architecture and Artefacts (vol. 1) and Pulse: Buddha Tooth Relic and Museum: People and Prayer (vol. 2). Singapore: Buddha Tooth Relic Temple, 2008.

Sisak Walliphodom. Phi kap phut. Bangkok: Munnithi Lek-Braphai Wiriyaphan, 2550 [2007].

—. Bantheuk chak thong thin. Bangkok: Munnithi Lek-Braphai Wiriyaphan, 2552 [2009].

—. Bhrasopkan phiphithaphan thong thin. Bangkok: Munnithi Lek-Braphai Wiriyaphan, 2552 [2009].

Sisak Walliphodom and Walaisak Songsiri. Khu meu chukit. Bangkok: Munnithi LekBraphai Wiriyaphan, 2551 [2008].

Nakhon Phrae. Bangkok: Munnithi Lek-Braphai Wiriyaphan, 2551 [2008].

_. Phiphithaphan Bhrawatisat Thong Thin. Bangkok: Munnithi Lek-Braphai Wiriyaphan, 2551 [2008].

Smith, J onathan Z. “In Comparison a Magic Dwells.” In his Imagining Religion, 19- 35. Chicago: University of Chicago Press, 1982.

—_. "A Matter of Class: Taxonomies of Religion." In his Relating Religion, 160-178. Chicago: University of Chicago Press, 2004.

Sommerville, Maxwell. Siam on the Meinam from the Gulf to Ayuthia together with Three Romances Illustrative of Siamese Life and Customs. London: Sampson Low, Marston and Company, 1897.

—. Monograph of the Buddhist Temple of the Free Museum of Science and Art of the University of Pennsylvania. Philadelphia: University of Pennsylvania Museum, 1904.

Spracklen, Karl. The Meaning and Purpose of Leisure. New York: Palgrave, 2009. Constructing Leisure: Historical and Philosophical Debates. New York: Palgrave, 2011. 
Stallybrass, Peter, and Allon White. The Politics and Poetics of Transgression. Ithaca, NY: Cornell University Press, 1986.

Starr, Frederick. "Le Corbusier and the USSR." Cahiers du Monde russe et soviétique 21, no. 2 (1980): 209- 221.

Stewart, David B. The Making of a Modern Japanese Architecture: 1868 to the Present. Tokyo: Kodansha International, 1987.

Stewart, Kathleen. Ordinary Affect. Durham, NC: Duke University Press, 2007.

Surasit Saokong. Khwam sangob nai lanna lae rajasthan. Bangkok: Surapon Gallery, 2553 [2010].

Tan, Shiling Cheryl. Religious Alternation, Spiritual Humanism: Tzu Chi Foundation in Singapore. Master's thesis, National University of Singapore, 2008.

Tanabe, George, and Ian Reader. Practically Religious: Worldly Benefits and the Common Religion of Japan. Honolulu: University of Hawai'i Press, 1998.

Tange, Kenzo. Katsura: Tradition and Creation in J apanese Architecture. New Haven, CT: Yale University Press, 1972.

—. Ippon no enpitsu kara. Tokyo: nihon tosho centa, 1997.

Tange, Kenzo, and Noboru Kawazoe. Ise: Prototype of Japanese Architecture. Cambridge, MA: MIT Press, 1965.

Tange, Kenzo, and Udo Kultermann. Kenzo Tange: Architecktur und Städtebau, 19461969. Zürich: Verlag für Architektur/Artemis, 1970.

Tange, Kenzo, and URTEC. Master Plan for the Development of Lumbini: Phase II, Final Report. Tokyo: Kenzo Tange and URTEC, 1978.

Tanner, J eremy. "Portraits and Agency: A Comparative View." In Art's Agency and Art History, edited by Robin Osbourne and J eremy Tanner, 70-94. Oxford: Blackwell Press, 2007.

Taussig, Michael. "Tactility and Distraction.” Cultural Anthropology 6, no. 2 (1991): 147- 153.

Thant, U. View from the UN. New York: Doubleday, 1978.

Thongchai Srisukprasert. Logiyadharma. Bangkok: Amarin Printing, 2012.

Tripathi, A. M. “Lumbini: Progress in Circles?” Good Governance 1, no. 3 (2003): 4- 9.

Tseng, Alice Y. The Imperial Museums of Meiji Japan: Architecture and the Art of the Nation. Seattle: University of Washington Press, 2008.

Tsutomu, Dezain Ohmukai, Sakamoto Yoshiko, and Ichikawa Mariko, eds. Wakasa Tadaji no Meihou. Kyoto: Ryukoku Daigaku, 2013.

Từ, Thích Nhật, ed. Tủ Sách Đạo Phật Ngày Nay (The Buddhist Bookshelf Today, or simply Buddhism Today). Ho Chi Minh City: Nhà Xuất Bản Tôn Giáo, 2011.

Turner, Alicia. Saving Buddhism: The Impermanence of Religion in Colonial Burma. Honolulu: University of Hawai'i Press, 2014.

Turner, Victor. Dramas, Fields, Metaphors. Ithaca, NY: Cornell University Press, 1974.

—. Image and Pilgrimage in Christian Culture: Anthropological Perspectives. New York: Columbia University Press, 1978.

—. Process, Performance, and Pilgrimage: A Study in Comparative Symbology. New Delhi: Concept Publishing, 1979.

United Nations. Report of the United Nations Mission for the Development of Lumbini, December 18, 1967-January 9, 1968. Kobe. Internal Report.

—. "Lumbini: The Birthplace of the Buddha." Archives, Series 0200, Box 5, File 3 (1968-1970).

—. Report for the Lumbini Development Project, December 1969. F. R. Allchin and K. Matsushita. Internal Report. New York: UN.

—. Development of Lumbini in Nepal General Correspondence. Official: Narasimhan. Archives, 15, 74/ 19, Drawer 6, File 56, 1970- 1973.

—. Note for Record, October 5, 1971. R. K. Basu. Internal report after a meeting with the advisory committee for the Lumbini Project.

—. Secretary-General Kofi Annan's message to the World Buddhist Summit. Press release SG/ SM/6812, November 30, 1998. 
Status of Tourism and Its Prospects in Buddhist Sites in Nepal, with Reference to Lumbini. D. P. Dhakal. Paper presented to the UNDP, September 1999.

“UN Support to Peace to Continue: Ban Ki Moon." The Rising Nepal. November 2, 2008.

Van der Veer, Peter, ed. Handbook of Religion and the Asian City: Aspiration and Urbanization in the Twenty-first Century. Berkeley: University of California Press, 2015.

Vichoke Mukdamanee et al. Chintaphap chak phra phutthasasana. Bangkok: Mahawithayalai Silapakorn, 2545 [2002].

Vichoke Mukdamanee et al. Withi Thai nai Phap Phra Bot. Bangkok: Mahawithayalai Silapakorn, 2546 [2003].

Villalon, Augusto F. "Walking toward Buddhist Stillness." Philippine Daily Inquirer, April 30, 2012.

Vinh, Lưu, and Huyền Chi. "Kinh Doanh- Nước Mắt- Nụ Cười" (Business-TearsLaughter), in Saigon's Kinh Doanh \& Pháp Luật (Business \& Law Newspaper), January 2, 2013.

Veblen, Thorstein. The Theory of the Leisure Class. New York: Modern Library, 2001 [1899].

von der Mühl, H. R., and Udo Kultermann. Kenzo Tange. Munich: Verlagfür Architektur, 1978.

Wachutka, Michael. Kokugaku in Meiji-Period Japan: The Modern Transformation of "National Learning" and the Formation of Scholarly Societies. Leiden: Global Oriental, 2012.

Walaisak Songsiri. Phiphithaphan khong khon thammada. Bangkok: Munnithi LekBraphai Wiriyaphan, 2551 [2008].

Wanchai Tantiwittayapitak, Sran Thongpan, and Wiyada Thongmit. The Erawan Museum: Convergence of Dreams, Faith, and Gratitude. Translated from the Thai by Charun Gaini. Bangkok: Viriya Business Co., 2006.

Warner, Michael. Publics and Counterpublics. New York: Zone Books, 2002.

Wichok Mukdamani. Jintakab jak phraphutthasasana. Bangkok: Silapakorn University Art Centre, 2545 [2002].

Wichok Mukdamani and Nirmalendu Das. Thai-India Art and Cultural Exchange 2003- 2004. Bangkok: Silapakorn University Art Centre, 2005.

Winnifrith, Tom, and Cyril Barrett. The Philosophy of Leisure. New York: St. Martin's Press, 1989.

Wiriyaphan, Braphai. Guide to Muang Boran. Bangkok: Viriya Business Co., n.d.

—. Muang Boran. Bangkok: Rongphim Phikanet, 2520 [1977].

Wiriyaphan, Lek. Bantheuk Khwam Khit. Bangkok: n.p., 2544 [2001].

—. Chiwit lae phonngan. Bangkok: self-published and printed, 2544 [2001].

Wiriyaphan family. Rim Khop Fa. Bangkok: Wat Thepsirindarasat, 2544 [2001].

Xianjue, and Lee Coo. Singapore Xinjiapo Fojiaojianzhu yishu. [Buddhist Architecture in Singapore]. Singapore: Kepmedia International Pte Ltd., 2007.

Yamaguchi, Yumi. Warriors of Art: A Guide to Contemporary Japanese Artists. Translated by Arthur Tanaka. Tokyo: Kodansha International, 2007.

Yü, Chün-fang. Kuan-yin: The Chinese Transformation of Avalokiteśvara. New York: Columbia University Press, 2000.

Yukiyama, Koji. Secrets of Creation: The Prints of Kiyoshi Hasegawa. Yokohama: Yokohama Museum of Art, 2006.

Zugazagoitia, Julian, Nicolas Bourriaud, and Thierry Raspail. Kim Sooja: Conditions of Humanity. Milan: 5Continents Books, 2004.

Zugazagoitia, Julian, Kim Sooja, and Oliva Maria Rubio Sooja. Kim Sooja: To Breathe. Madrid: Museo Nacional Centro de Arte Reina Sofia, 2006.

Zukin, Sharon. Landscapes of Power: From Detroit to Disney World. Berkeley: University of California Press, 1991. 


\section{Index}

Page numbers in bold indicate illustrations.

Abe, Stanley, 160

Abuja (Nigeria) city plan, Tange

design of, 66

accumulation, acts of, 16

affect, study of, 23- 24

Afghanistan, giant Buddhas of Bamiyan in, 7, 100

Ali, Maksood, 69, 73- 74

Allchin, F. R., 57- 58

Amida Buddha, Yobiko Daibutsu of, 7

Amnuai Kantian, 142

amusement parks, 7, 8, 11, 20, 171; Fairy Stream Amusement Park, 4, 23,

30- 35, 31, 34; motives for

visits to, 16; Tiger Balm

Gardens, 82; Wiriyaphan family projects as, 95, 100

Ancient City, 84, 87- 91, 92, 95, 99-100, 191- 192n.7; family visit to, 89; guidebooks to, 90 , 192n.9; lack of authenticity, 89- 90,99

Ando, Tadao, 26, 41, 122-126, 129, 181n.47, 195n.46

Anek Kusala Sala (Wihan Sien), 101, 102- 103, 193n.25

Ang Thong, Thailand, Wat Muang in, 107-112

architects, 25-26. See also specific architects

architecture: distractions in, 22; experience and memory of, 23; ongoing changes in biography of, 27-28; Tange philosophy of metabolism in, 36, 40, 67, 72, 74,77

Arnold, Edwin, 77
Asian Civilizations Museum (Singapore), 148, 152

Asia Pacific Exchange Cooperation Foundation (APECF), 75- 77

Avalokiteśvara statues and images, 1, 107, 198n.19. See also Guanyin statues and images; at Buddhist Tooth Relic Temple, 141, 143, 144, 145, 147; at Haw Par Villa, 83; at University of Pennsylvania museum, 132

Avery Island Buddha image, 162- 165, 163, 202nn.4- 5

Awaji Shima, Japan, 14; Kannon statue on, 4; Water Temple on, 123- 124,126

Aw Boon Haw, 82

Aw Boon Par, 82

Baker, Chris, 177n.4

Bali, Garuda Wisnu Kencana Cultural Park in, 17- 18, 18

Bamiyan Buddhas, 7, 100

Bangkok-J apanese Cultural Center, $38,184 n .24$

Bangladeshi monks at Lumbini Park, 47, 47- 48, 49

Basu, R. K., 57, 61, 62

Beach of the Gods water park, 32, 33, 34,34

Beautiful Indonesia in Miniature Park, 87- 88

Beppu Daibutsu, 7

Bernard, Shane, 164, 202nn.4- 5

Bezeklik Cave Temples Restoration, 155

Bharne, Vinayak, 41- 42

Bhiam Bunyachot, 87 
Biển Tiên Đồng (Beach of the Gods), $32,33,34,34$

birthplace of Buddha, 45; discovery of, 56; Tange design of park and memorial for, 27, 36, 38, 40, 48-49, 55- 57 (See also Lumbini)

Black House, 120- 121

Bodh Gaya: as awakening site, 56, 78; as pilgrimage and tourist site, 4, 68, 78, 190n.103

Bodiford, William, 3

Bowen, J ohn, 169

Buddha Tooth Relic Temple and Museum, 135-148; authenticity of tooth relic at, 197n.13; construction of, 137, 138, 138; costs and income of, 139-140, 141; display of tooth relic at, 142-143; exterior of, 139, 139, 198n.20; Nagapuspa Buddhist Culture Museum at, 20, 143-144, 154, 156, 161; Naga trees planted at, 139; source of tooth relic at, 136-137; wax and resin images at, 141, 198n.21

Buddhist Culture Museum, 20, 143- 144, 154, 156, 161

Bunleua Sulilat, 121- 122

Burma: Khemarattha Standing Buddha in, 177n.4; Laykyun Setkyar Buddha in, 4; stone canon at Kuthodaw monastery in, 79

Calvino, Italo, 27

Cambodian monastery at Lumbini, 50, 51

cave of Buddhist hells at Haw Par Villa, 83- 84

Centro Ecuménico Khun Iam, 115, 116

Chan, Melissa, 77

Chan Buddhism, 144-145

Chapel of Rokkozan, 124-125, 125

Chiang Mai, Thailand, 12, 88, 142

Chiang Rai, Thailand, 14, 88, 140;

Wat Rong Khun monastery in, 118-120, 119

children: anime/manga characters popular with, 7; learning about Buddhism, 180n.25; as visitors to Buddhist leisure places, 16, 147

China: Dunhuang Buddhist theme park in, 77; interest in development and management of Lumbini, 75- 77, 190n.95; Leshan Buddha in, 1, 78, 100; Shi Fa Zhao influenced by, 138-139, 140, 141, 144-145, 147; and Wihan

Sien Chinese museum, 102- 103; Wiriyaphan family influenced by, 91, 92; Zen sect in, 43

Church of the Light, 124, 125- 126 Church on the Water, 124 comparative projects and gestures, 166- 169

complex adaptive systems, 6, 25, 36 complicated systems, compared to complex systems, 25

Conder, J osiah, 37, 183n.16

conversation places in Tange designs, 40,42

Le Corbusier (Charles-Édouard J eanneret), 183n.14, 184n.32, 185n.48; Ando influenced by, 123; Tange influenced by, 36- 37, $38,39,41,42,43$

Cowell, David, 63

Crystal Grotto (Tennessee), 192n.8

Cueppers, Christoph, 51, 72, 187n.70

Culin, Stewart, 132, 196n.5

Dahal, Puspa Kamal (Prachanda), 75, 76

daibutsu, 7, 8; Kamakura Daibutsu, 4, 7; Nagoya Daibutsu, 158, 159; Ushiku Daibutsu, 1- 2

Daikannon of Sendai, 1-4, 2, 22, 28, 29, 78, 101, 173

Dech Sanitwong, M. L., 92

Dhakal, D. P., 67- 68

Dharma Drum Mountain monastery, 13

Dharmapala, Angrika, 56, 77- 78

Dietz, J oel, 196n.5

Đinh Văn Vui, 33

distractions, 22, 129

Double-Bell House of Makita, 37, 183n. 20

Dunham, Mikel, 76

Dunhuang Buddhist theme park, 77

East Monastic Zone of Lumbini Park, 46, 49-51, 66

ecumenical parks and sites, 5- 6, 17-24, 81, 82-130, 135, 161; of Ando, 122-126; of Bunleua Sulilat, 121- 122; Guanyin Ecumenical Center, 115; Haw Paw Villa, 
82- 84; hell parks, 113-114;

Khao Chi Chan, 101- 102, 102;

Moga Buddhist Museum,

115- 118, 116; of Shi Fa Zhao,

$6,27,136,140,143,144,145$,

147; similarities of, 169-172;

Somdet To statues, 104- 105;

of Sommerville, 134; of Suchat, 105- 107; Suối Tiên (Fairy

Stream) Amusement Park as, 32- 33, 35; of Tange, 6, 36, 54; of Thawan Duchanee, 120-121; Wat Muang, 107-112; Wat Yansangwararam, 101; Wihan Sien, 102-103; of Wiriyaphan family, 6, 84-100; of Woon Wee Teng, 151

Ee Tiang Hwee, at Buddha Tooth Relic Temple, 135- 148, 198n.19

Ehime, Japan, 14, 124

elephant statue, Erawan, 84- 85, 92- 94, 93, 100, 129

empire-making, 18- 19

ensembliers, 22, 169, 181n.34

Erawan Elephant, 84- 85, 92- 94, 93, 100, 129

Eternal Peace Flame at Lumbini Park, 46

Facebook, 9, 13, 21

failure of Buddhist leisure and tourist sites, 4- 5, 25; at Lumbini, $54,67,75$

Fairy Stream Amusement Park, 4, 23, 30-35, 31, 34

Feener, Michael, 28

Feroci, Corrado, 80, 120

Floating Island, 193n.29

Fo Guang Shan, 81, 179n.20, 189n.86

Foundation for the Preservation of the Mahayana Tradition (FPMT), 78

From Dawn to Dusk: The Buddha Tooth Relic Temple and Museum (Shi Fa Zhao), 146

Führer, Anton, 56

Fukushima, Japan, 1

Gabaude, Louis, 148-149

Garuda Wisnu Kencana Cultural Park, 17- 18, 18

Gell, Alfred, 169

German Tara Foundation, Lotus Stupa at Lumbini sponsored by, 52- 53, 70- 71, 71, 72
Glancey, J onathan, 35

Glass Temple, 127- 129, 128, 195n.53

Goenka Meditation Center at Lumbini Park, 51

Goh Aik Sai, 135, 144, 148

Goh Ee Choo, 141

Golden Pagoda Temple, 136, 137

golden toilet facilities at Wat Rong Khun, 120

Gombrich, E. H., 22- 23

Great Drigung Kagyud Lotus Stupa at Lumbini Park, 52- 53, 70- 71, 72

"great men" of history, 24, 26

Gregg, Melissa, 23

Gropius, Walter, 39, 43, 184n.25

Guanyin Ecumenical Center, 115, 116

Guanyin Inter-Religious Park, 105- 107, 193n.27

Guanyin statues and images, 22, 107, 193- 194n.29; Awaji Kannon, 4; in Guanyin Ecumenical Center, 115; in Guanyin Inter-Religious Park, 107; in Haw Par Villa, 83; near Wat Muang entrance, 112; Sendai Daikannon, 1-4, 2, 22, 28, 29, 78, 101, 173; in Suối Tiên (Fairy Stream) Amusement Park, 30, 32; in University of Pennsylvania museum, 132

Habermas, Jürgen, 10-11

"Haiku Effect" in designs of Ando, 123

Hamaguchi, Ryuichi, 38

Hansen, Miriam, 16

Harmsworth Park (London), 81

Hasegawa, Kiyoshi, 173- 175

Haw Par Villa, 82- 84, 83

Hay, J onathan, 23

Hayami, Yoko, 128, 129, 195n.54

hell parks, 11, 27, 113-114, 129-130, 191nn.1- 2; at Haw Par Villa, 83- 84; at Wat Muang, 107, 109, 111, 112, 113; at Wat Sang Saen Suk, 113

Hewitt, George, 27

Higashi Hongan-ji monastery, 154, 155; Reception Office museum in, 152- 153

Hiroshima Peace Memorial, 38, 39, 74

Ho Chi Minh City, Vietnam, 7, 40; Fairy Stream (Suối Tiên) Amusement Park in, 4, 23, 30- 35, 31, 34; J ade Emperor Pagoda in, 113, 114 
Holt, J ohn, 128, 129, 195n.54

Horiguchi, Sutemi, 37

Huizinga, J ohan, 15

Huỳnh Đồng Tuấn, 33, 34

Hwang, Soonil, 115

If on a Winter's Night a Traveler (Calvino), 27

in-between agents, architects as, 25- 26

India: Bodh Gaya as pilgrimage and tourist site in, 4, 68, 78, 190n.103; origin and history of Buddhism in, 156, 200n.46

interdependence and interconnections, 24- 25

International Buddhist College, 21

International Gotami Nun's Temple in Lumbini Park, 50, 51

International Scientific Steering Committee, 64

Internet/web presence, 7, 9, 13, 172, 179n.19, 181n.48, 191n.48; of Buddha Tooth Relic Temple and Museum, 199n.32; of ecumenical sites, 21; of monasteries, 13, 21, 179n.19; of Thawan Duchanee, 120, 194- 195n.42

Ireland, Asian gardens and Buddha images in, 165, 165

Irisawa, Takashi, 154, 200n.42

Ise Shrine, 42, 43

Iwai, Shunpei, 154

J ade Emperor Pagoda, 113, 114

J apan, 7- 8; Ando designs of buildings in, 122-126; Awaji Kannon in, 4; daibutsu in, 4, 7, 158, 159; Glass Temple in, 127-129, 128; Higashi Hongan-ji monastery and Reception Office museum in, 152-153, 154, 155; Hiroshima Peace Memorial in, 38, 39, 74; meisho in, 9, 10; misemono in, 7- 8, 9, 10; Ōkura Shukokan museum in, 150; Reiyukai Buddhist sect in, 63; Ryukoku Museum in, 20, 152, 153- 157, 154, 200nn.42-44; Sarasvatī Museum and Daibutsu garden in, 157-160; Sendai Daikannon in, 1-4, 2, 22, 28, 29, 78, 101, 173; Soto Zen temples of, 21; Star Peak of
Seirei in, 28- 29, 29, 152; Tange life and projects in, 35- 44, 45, $60,66,74$; tsunami in (2011), 1-2, 3; Water Temple in, 123-124, 126; White Temple in, 126- 127

Japanese Funds-in-Trust, 64 J eanneret, Charles-Édouard (Le Corbusier), 183n.14, 184n.32, 185n.48; Ando influenced by, 123; Tange influenced by, 36- 37, 38, $39,41,42,43$

J inapañjara (Verses on the Victor's Armor), 104

Jōgyō Bosatsu, 29, 181n.50

Kaeo Khamwibun, 108

Kamakura Daibutsu, 4, 7

Kannon statues and images, 107, 127, 132. See also Guanyin statues and images; Awaji Kannon, 4; Ōfuna Kannon, 7; Sendai Daikannon, 1-4, 2, 22, 28, 29, 78, 101, 173

Karma Sangbo Sherpa, 72- 73, 74

Katsura Palace, 42- 43

Kedge, Peter, 78

Keller, Helen, 153

Khao Chi Chan, 101- 102, 102

Khemarattha Standing Buddha, 177n.4

Khun Paen, 91

Klautau, Orion, 3

Kobe, Susumu, 57

Koh Loi, 193n.29

Komyo-ji Temple, 124

Kositpipat, Chalermchai, 119-120

Kōsō, Wajo, 9

Kragh, Ulrich Timme, 168

Kuan Yin, 141, 157, 198n.19

Kurose, Takefumi, 59- 60

Kushinagar site, 78

Kuthodaw monastery, 79

Kyoto, J apan: Glass Temple in, 127-129, 128; Higashi Hongan-ji monastery and Reception Office museum in, 152- 153, 154, 155; Municipal Museum in, 155; Ryukoku Museum in, 20, 152, 153- 157, 154, 200nn.42-44; Zen monasteries of, 43

Lal, C. K., 68

Lang, Stephen, 196n.5 
language: in Buddhist universities, 21; and lack of classical Buddhist language, 19

Laos, 113; sculpture gardens of Bunleua Sulilat in, 121-122; tattooing in, 108, 194n.30; War Memorial in, 81

Laykyun Setkyar Buddha (Burma), 4

Lee, J oon-Youb, 117- 118

leisure, 15-16, 180n.26

Leshan Giant Buddha, 1, 78, 100

Levine, Gregory, 21

local optima, 6, 24-27, 169

Lotus Stupa of German Tara Foundation at Lumbini Park, 52- 53, 70-71, 71, 72

Luang Pho Ariyawanso (Suchat Kosonkitiwong), 26, 105- 107, 111, 112, 193n.27

Luang Pho Kasem Achansupho (Phra Khru Wibun Achankhun), 108

Luang Phrabang (Laos), 113

Lumbini, Nepal, 35, 39, 40, 45- 77, 79; abandoned and nevercompleted monasteries in, 50, 50- 54, 52, 68, 71; APECF interest in, 75- 77; Bangladeshi monks in, 47, 47-48, 49; as birthplace of Buddha, 27, 36, 38, 40, 48-49, 55- 57; central walkway or link in, 46, 47; Chinese interest in, 75- 77, 190n.95; construction costs in, 60, 61, 62- 63; construction delays in, 64, 67, 188-189n.86; conversation spaces in, 40, 42, 74; deliberate lack of decorative elements in, 23; East Monastic Zone in, 46, 49- 51, 66; entrance fees in, 48, 187- 188n.73; Eternal Peace Flame in, 46; as failure or success, 54, 67, 69, 75; fund raising for projects in, 61, 62- 63, 64, 73; future of, 75- 78; impact of development in, 67- 69, 70, 74; International Gotami Nun's Temple in, 50, 51; lack of return visits to, 69; local tourists visiting, 70- 72, 73; Lotus Stupa of German Tara Foundation in, 52- 53, 70- 71, 71, 72; Mahabodhi Society of India in, 50, 51; master plan for, $45,49,54,60,63-68,73,74$,
79, 185n.46, 187n.70, 189n.91; Maya Devi Temple in, 46, 48-49, 66, 73, 187n.70; Nepali monasteries and centers in, 53; regional development plans in, 61- 62; sacred garden area in, 35, 48-49, 60, 65; Sokyo monastery of J apan in, 52, 52; souvenirs sold at, 69, 69; Tange visit to (1972), 53, 54- 55; Thai monastery in, 50- 51; Thant in development of, 55- 60; United Nations in development of, 57- 63; West Monastic Zone in, 46, 51- 54, 66

Lumbini Development National Directive Committee of Nepal, 75, 76, 77

Lumbini Development Steering Committee, 75

Lumbini Development Trust, 46, 47, 54, $64,68,72-73$

Lumbini International Research Institute, 51, 187n.70

Macao, Guanyin Ecumenical Center in, 115, 116

Maekawa, Kunio, 37

Mahabodhi Society of India at Lumbini Park, 50, 51

Mahanak elixir, 86

Maitreya statues and images: in Buddha Tooth Relic Temple and Museum, 140-141, 143, 145, 147; in Guanyin Inter-Religious Park, 107; in Haw Par Villa, 83; proposed in Kushinagar, 78; in Suối Tiên (Fairy Stream) Amusement Park, 30; in Wihan Sien, 103

Maki, Fumihiko, 35

Makita, Seinosuke, Double-Bell House of, 37, 183n.20

Manit Walliphodom, 87

Manohra, Ancient City monument to, 91

Matsushita, K., 57- 58, 64

Maya Devi Temple in Lumbini Park, 46, 48-49, 66, 73, 187n.70

McIlhenny, Edward "Ned" Avery, 162-165, 167

meisho, 9, 10

metabolism, architectural, Tange on, $36,40,67,72,74,77$

Mies van der Rohe, Ludwig, 43 
Miller, Daniel, 22

Miller, J ohn, 25

misemono, 7- 8, 9, 10, 79, 129, 178n.9

Miyaji, Akira, 156-157

Moga Buddhist Museum, 115- 118, 116

monasteries, 8-9; Ancient City replicas of, 87, 88, 89, 99; daibutsu and misemono built at, 9; festival and leisure activities in, 10; Glass Temple, 127-129, 128; Higashi Hongan-ji, 152- 153, 154, 155; Internet presence of, 13, 21, 179n.19; in Lumbini, 48- 54, 62, 65, 66, 68, 70, 71, 72, 74, 75; museums in, 148-149, 152-153, 157; Nichiren monastery of Myōken, 28- 29; Nishi Hongan-ji, 153, 154, 155- 156; social and familial activities in, 12-13; Thai style of design, 38, 123; Tōgan-ji, 157-160; as tourist sites, 9, 12-13, 56, 72, 78; Water Temple, 123-124, 126; Wat Muang, 107-112; Wat Rong Khun, 118-120, 119; Wat Sang Saen Suk, 113; Wat Yansangwararam, 101; White Temple, 126- 127;

Zen, 43

Mount Myōken, Star Peak on, 28-29, 29, 152

Mount Rokko, Chapel of Rokkozan at, 124- 125, 125

Muang Boran, 87- 88, 191- 192n.7. See also Ancient City

Mumford, Lewis, 44, 185n.44

"museum effect," 160

museums, 6, 7, 9, 27, 131-161; Asian Civilizations Museum, 148, 152; in Awaji Kannon, 4; criticisms of, 160; as ecumenical sites, 19, 27; in Erawan Elephant, 85, 92, 93; in Lumbini Park, 46, 60, 63, 69, 77; Moga Buddhist Museum, 115-118, 116; in monasteries, 148-149, 152-153, 157; motives for visits to, 15, 16; Nagapuspa Buddhist Culture Museum, 20, 143-144, 154, 156, 161; Nei Xue Tang, 150-152; Ōkura Shukokan, 150; as personal creation of local historians and collectors, 149-150; Reception Office museum at Higashi
Hongan-ji monastery, 152- 153;

Ryukoku Museum, 20, 152, 153- 157, 154, 200nn.42-44; Sarasvatī Museum, 157- 160; in Sendai Daikannon, 3, 4; at University of Pennsylvania, 132-135; Wihan Sien, 101, 102- 103, 193n.25

Myōken, 28

Nabesawa, Kakui, 127- 129

Nagapuspa Buddhist Culture Museum, 20, 143-144, 154, 156, 161

Nagoya, J apan, Sarasvatī Museum and Daibutsu garden in, 157- 160

Nakamura, Hajime, 59

Nakamura, Hisako, 153

Nakayama, Zenjyō, 127

Narasimhan, G. V., 63

Naritasan Shinjōji Peace Pagoda, 9

Nei Xue Tang museum, 150-152

Nepal, Lumbini sites in. See Lumbini

Nichiren monastery of Myōken, 28- 29

Nishi Hongan-ji monastery, 153, 154, 155- 156

Nishimura, Yukio, 59- 60, 64

Niwa (Hasegawa), 173, 174

Nōfuku Daibutsu, 7

"A Note Further to the Drawing of Bicycles" (Gombrich), 22- 23

Nuarta, I Nyoman, 17

Oda Baisen, 157- 158

Oda Nobunaga, 157

Oda Nobuyuki, 157

Ōfuna Kannon, 7

Okamoto, Eizzaburō, 7

Ōkura, Kihachiro, 150

Ōkura Shukokan museum, 150

Olcott, Henry Steel, 56

ordination hall in Ang Thong, Thailand, 112

Overdorf, J ason, 76

Page, Scott, 25

Pahlke, Michael, 51

Palace of the Soviets, 36- 37

Paritta Chalermpow Koanantakool, 148- 149

Park, Chan-soo, 115- 118, 116, 118, 121

Pathak, Rachana, 69

Pattaya, Thailand, Sanctuary of Truth in, 4, 23, 84, 94- 99, 96, 100,129 
Peace Memorial at Hiroshima, 38, 39, 74

Peleggi, Maurizio, 160

Pepper, William, 132

Pérez de Cuéllar, J avier, 63

Perspective: Buddha Tooth Relic Temple and Museum through the Eyes of the People (Shi Fa Zhao), 146

Petersen, Roger, 169

phallic and sexual images at Sarasvatī Museum, 157- 160

Phannipha Kulabut, 109, 112-113

Phibulsongkhram, Pleak, 79

Phra Putthamingmongkol Akenakkiri, 4

Phra Reusi in Thailand, 112, 194n.33

Phutthamonthon Buddhist park, 79- 80

Powerscourt (Ireland) Asian gardens and Buddha images, 165, 165

Pritzker Prize, 35, 122

public culture, Buddhist, 5, 6-17; spectacle attractions in, 7-8, 9, 10

The Pursuit of True Happiness and Other Life Observations (Shi Fa Zhao), 145

Rabinovitz, Lauren, 16

Ranade, J ayaveda, 76

Raymond, Antonín, 37, 43, 44, 183n.18

Reception Office museum, 152- 153

Reiyukai Buddhist sect funding Lumbini projects, 63, 187n.70

Rényi, Erdős, 25

Rijal, Minendra, 76, 77

Rinzai Zen, 127, 145, 167

Rocha, Cristina, 115

Ruskin, J ohn, 130

Ryukoku Museum, 20, 152, 153-157, 154, 200nn.42- 44

Ryukoku University, 153-157

Saigon, Vietnam, 7, 40; Fairy Stream (Suối Tiên) Amusement Park in, 4, 23, 30-35, 31, 34; Jade Emperor Pagoda in, 113, 114

Saint Mary's Roman Catholic Cathedral (Tokyo, Japan), 40-41, 41, 42

Sakapala (Venerable), 137

Sala Keaoku, 122

Salzman, Michele, 10

Samarasekara, J ustin, 61

Sanae, Hattori, 150
Sanctuary of Truth, 4, 23, 84, 94- 99, 100, 129; photographs of, 96, 98, 99

Sa-nga Kulkopkiat, 102- 103

Sarasvatī Museum and Daibutsu garden, 157- 160

Sarnath site, 78

sculpture gardens, 11, 26, 27; of Bunleua Sulilat, 121- 122; at Haw Par Villa, 82, 83; at Lumbini Park, 70; at Moga Buddhist Museum of Park, 115-118, 118; of Thawan Duchanee, 121; at Wat Muang, 108, 109, 112; at Wat Rong Khun, 118-119; at Wihan Sien, 102

Sedgwick, Eve, 24

Seigworth, Gregory, 23

Sendai Daikannon, 1-4, 2, 22, 28, 29, 78, 101, 173

Sendai tsunami (2011), 1-2, 3

sexual and phallic images at Sarasvatī Museum, 157- 160

Shan Buddha images, 177n.4

Sherman, Anna Julia, 131

Shi Fa Zhao, 6, 20, 23, 25, 27, 170, 173; Buddha Tooth Relic Temple and Museum of, 135-148; at Golden Pagoda Temple, 136, 137; motivation and focus of, 171- 172; photograph of, 138; training and lineage of, 144-145; writings of, 145-146, 198-199n.23

Shin Buddhism, Ryukoku Museum material on, 153-154, 155, 156

Silk Road, 19, 154, 200n.44

Simmons, Tony, 78

Singapore, 9, 14, 165; Asian Civilizations Museum in, 148, 152; Buddha Tooth Relic Temple and Museum in, 135- 148 (See also Buddha Tooth Relic Temple and Museum); Haw Par Villa in, 82- 84, 83; Nei Xue Tang museum in, 150-152; Tange designing buildings in, 39

Singh, Jaskaram, 56

Sisak Walliphodom, 87, 88, 90, 100, $191 n .7$

Smith, J. Z., 166, 202n.8

Sokyo monastery of J apan at Lumbini Park, 52, 52 
Somdet To statues, 104- 105

Sommerville, Maxwell, 131- 135, 136, 196nn.1- 7; appearance of, 133; gem collection of, 132, 196n.3

Sonehara, Satoshi, 3

Sorapong Chartree, 104

Soto Zen, 21, 157, 158

South Korea, sculpture garden of Park in, 115-118, 118

spectacle attractions, 7- 8, 9, 10, 79, 129, 178n.9

Spring Temple Vairocana Buddha statue, 1

Sri Lanka, Temple of the Tooth Relic in, 135- 136

Stange, Ferdinand, 70, 72, 189n.90

Star Peak of Seirei, 28- 29, 29, 152

Statue of Liberty, 1; replicas of, 4, 83

The Structural Transformation of the Public Sphere (Habermas), 10

Suan Narok (Hell Garden at Wat Muang), 107, 109, 111, 112

success of Buddhist leisure and tourist sites, 4- 5, 6; at Lumbini, 54, 69,75

Suchat Kosonkitiwong (Luang Pho Ariyawanso), 26, 105- 107, 111, 112, 193n.27

Sugawara, Yorozu, 3

Suối Tiên Amusement Park, 4, 23, 30-35, 31, 34

Taiwan: Dharma Drum Mountain monastery in, 13; Fo Guang Shan in, 81, 179n.20, 189n.86

Takamatsu, Shin, 29, 41, 152, 199-200n.40

Takamura, Kōun, 7, 8

tallest Buddha image (Khao Chi Chan), 101- 102, 102

Taman Mini Indonesia, 87- 88

Tang dynasty architecture, as influence on Buddha Tooth Relic Museum, 138-139, 140, 147

Tange, Denise, $184 \mathrm{n} .24$

Tange, Kenzo, 6, 25, 35-44, 130, 170; Ando influenced by, 123; architectural influences on, 37- 38, 39, 43-44, 173; architectural philosophy of, 40, 44; Bangkok-J apanese Cultural Center design of, 38, 184n.24; Buddhist influence on, 40-43, 58-60, 64, 66; chosen for
Lumbini project, 58- 59; early life of, 36- 37, 183n.13;

Hiroshima Peace Memorial, 38, 39, 74; Lumbini Park design of, $23,27,35,36,45-77,79$; on metabolism in architecture, 36 , $40,67,72,74$, 77; personality of, 171; religious life of, 60; as reluctant Buddhist, 35; Saint Mary's Roman Catholic Cathedral designed by, 40-41, 41, 42; urban design projects of, 39-40, 58, 59, 66; URTEC firm of, 39, 60; visit to Lumbini (1972), 53, 54- 55; Yokohama Museum of Art designed by, 39, 173

Tange, Paul Noritaka, 184n.24

Tara Foundation of Germany, Lotus Stupa at Lumbini sponsored by, 52- 53, 70- 71, 71, 72

tattoos, 108, 194n.30

Taussig, Michael, 22

Temple of the Heart Nagapuspa Photography Competition, 146

Temple of the Tooth Relic (Sri Lanka), 135- 136

Thailand, 8, 9, 12, 13, 14; Ancient City in (See Ancient City); ecumenical architecture of Wiriyaphan family in, 84- 100; Erawan Elephant in, 84- 85, 92- 94, 93, 100, 129; Guanyin Inter-Religious Park in, 105-107, 193n.27; International Buddhist College in, 21; Khao Chi Chan in, 101-102, 102; Lumbini monastery built by group from, 50 - 51; monastery museums in, 148-149; mural characters in, 119, 119-120; Phra Putthamingmongkol Akenakkiri in, 4; Phra Reusi in, 112, 194n.33; Phutthamonthon Buddhist park in, 79- 80;

Sanctuary of Truth in, 4, 23, 84, 94- 99, 96, 100, 129; Somdet To statues in, 104- 105; tattooing in, 108, 194n.30; visitors to Lumbini Park from, 68; walking Buddha statue in, 7, 80; Wat Dhammakaya in, 13; Wat Muang in, 107-112; Wat Rong Khun in, 118-120, 119; Wat Sang Saen 
Suk in, 113; Wat

Yansangwararam in, 101; Wihan

Sien in, 101, 102- 103, 193n.25

Thant, U, in Lumbini Park development, 55- 60, 66

Thawan Duchanee, 120-121, 194- 195nn.42- 44

Theravada Buddhism: in Lumbini, 47-48, 49, 53, 54, 66; in Vietnam, 32, 182n.3

Thianchai Rungruaiyat, 108

Thích He Tông, 32

Thích Nhật Tứ, 32, 182n.4

Thích Quảng Tâm, 32

Tian Tan Buddha, 4

Tiger Balm, 82

Tiger Balm Gardens, 82- 84, 83

Tōgan-ji monastery, Sarasvatī Museum on grounds of, 157- 160

Tokyo, Japan: misemono in, 7; Saint Mary's Roman Catholic Cathedral in, 40-41, 41, 42; Tange projects in, 39-41, 42, 44, 60, 66, 74; Ueno Daibutsu in, 7

Tooth Relic Temple (Singapore), 135-148. See also Buddha Tooth Relic Temple and Museum

Tooth Relic Temple (Sri Lanka), 135- 136

tsunami of 2011 in Japan, 1-2, 3

Turner, Victor, 10

ubosot (ordination hall) in Ang Thong, 112

Ueno Daibutsu, 7

UNESCO, 64, 67, 77, 185n.46

United Nations, in development of Lumbini Park, 57- 63, 64, 70, 77, 187n.72

United Nations Committee for the Development of Lumbini, 59- 60, 63

United Nations Development Programme, 59, 60, 63

United Nations Industrial Development Organization, 76

United States: Ando projects in, 123; Asian gardens in, 165; Avery Island Buddha image in, 162- 165, 163, 202nn.4- 5; Crystal Grotto in, 192n.8; Tange projects in, 39; University of Pennsylvania museum in, 132-134
University of Pennsylvania, Sommerville at, 132-134, 133

URTEC firm of Tange, 39, 60

Ushiku Daibutsu, 1-2

Vairocana Buddha, 141, 143; Leshan statue, 1, 78

Vietnam: Fairy Stream (Suối Tiên) Amusement Park in, 4, 23, 30- 35, 31, 34; J ade Emperor Pagoda in, 113, 114; Theravada Buddhism in, 32, 182n.3

Villalon, Augusto F., 35, 64- 65

Villa Savoye, 36- 37

Visit Lumbini Year 2012 campaign, 48, 69, 73- 74

Waldhiem, Kurt, 63

War Memorial (Laos), 81

Warner, Michael, 14

Watanabe, Sadao, 59

Wat Chetuphon (Wat Pho), 193n.26

Wat Dhammakaya, 13

Water Temple, 123-124, 126

Wat Muang, 107-112; giant seated Buddha at, 107, 109, 110; hell park at, 107, 109, 111, 112, 113; mirrored hall at, 108, 109

Wat Rong Khun, 118-120, 119

Wat Sang Saen Suk, 113

Wat Thipsukhanaram, 177n.3

Wat Yansangwararam, 101

web presence. See Internet/ web presence

West Monastic Zone of Lumbini Park, 46, 51- 54, 66

White Temple, 126- 127

Wibun Achankhun (Luang Pho Kasem Achansupho), 108

Wihan Sien, 101, 102-103, 193n.25

Wilailak Songsiri, 87, 191n.7

wine produced at Fairy Stream Amusement Park, 33- 34

Wiriyaphan, Braphai, 27, 84, 85- 88, 100, 129, 170; Ancient City of, 88, 91, 121 (See also Ancient City); businesses and financial success of, 86, 87; Chinese influence on, 91, 92; early life of, 85- 86; Erawan Elephant of, 25; illness and death of, 86, 92; land purchased by, 86, 87, 94, 95; marriage to Lek, 86, 87; materials collected 
by, 89; motivation of, 90 , 98, 171; as part of complex system, 25

Wiriyaphan, Lek, 6, 27, 84- 100, 129, 170, 173; Ancient City of, 87- 91 (See also Ancient City); autobiography of, 85, 86, 191n.3, 191nn.5- 6; books published by, 87, 191n.7; businesses and financial success of, 86, 87;

Chinese influence on, 91, 92; early life of, 85; Erawan Elephant of, 84- 85, 92- 94, 93, 100,129 ; intent of projects, 99- 100; marriage to Braphai, 86, 87; motivation of, 90, 98, 171; as part of complex system, 25; poetry of, 91- 92; Sanctuary of Truth of, 4, 23, 84, 94- 99, 96, 100, 129; success of projects, 99- 100

Wiriyaphan, Pakpian, 92 Wiriyaphan, Pichan, 95, 99
Wiriyaphan Insurance Company, 98

Woon Wee Teng, 150-152

World Buddhist University, 21

World Peace Envoy, 105- 107, 193nn.27- 28

Wright, Frank Lloyd, 37

Xiao Wunan, 75, 77

Yamada, Mamoru, 37

Yamaguchi, Takashi, 41, 126-129; Glass Temple of, 127-129, 128; White Temple of, 126-127

Yobiko Daibutsu, 7

Yokohama Museum of Art, 173, 174

Yoshida, Isoya, 38

Zen Buddhism, 144-145; influence on Tange, 42, 43, 44; Rinzai Zen, 127, 145, 167; Soto Zen, 21, 157, 158 


\section{About the Author}

J ustin Thomas McDaniel (PhD, Harvard University, 2003) is professor of Buddhist studies and chair of the Department of Religious Studies at the University of Pennsylvania. His research foci include Lao, Thai, Pali, and Sanskrit literature, Buddhist art and architecture, and ritual studies. His first book, Gathering Leaves and Lifting Words, won the Harry Benda Prize for best first book in Southeast Asian studies. His second book, The Lovelorn Ghost and the Magic Monk, won the Kahin Prize for best book in Southeast Asian studies.

McDaniel is coeditor of the journals Buddhism Compass and Journal of Lao Studies, and an associate editor of the J ournal of Asian Studies. He has won teaching and advising awards at Harvard University, Ohio University, and the University of California, and the Ludwig Prize for Teaching at the University of Pennsylvania. In 2012 he was named a Guggenheim Fellow, and in 2014 a fellow of Kyoto University's Center for Southeast Asian Studies. His forthcoming work includes edited books on Thai manuscripts, Buddhist biographies, Portuguese art in Asia, and Buddhist cosmology. 
